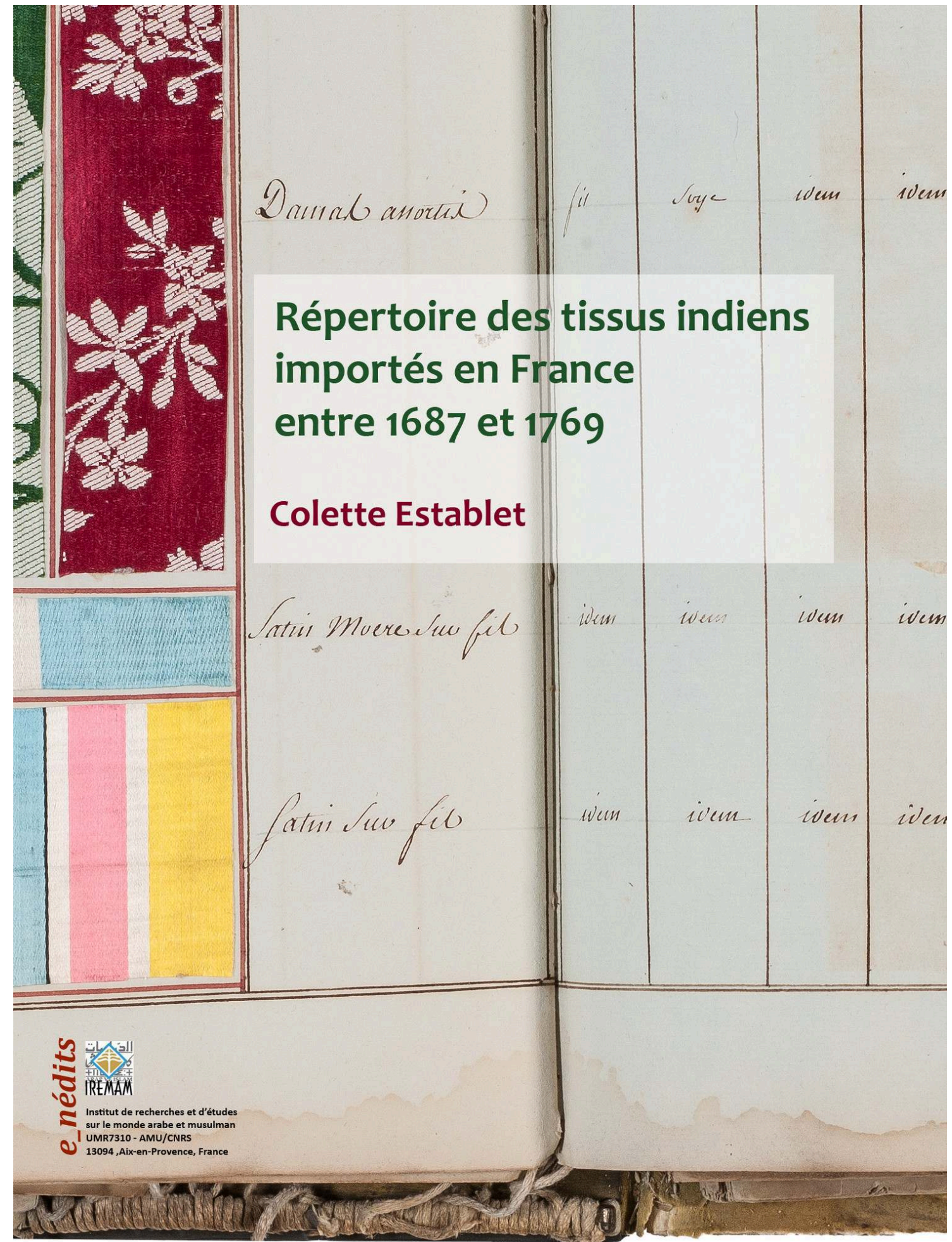




\section{Répertoire des tissus indiens importés en France entre 1687 et 1769}

Colette Establet

DOI : 10.4000/books.iremam.3841

Éditeur : Institut de recherches et d'études sur les mondes arabes et musulmans, IREMAM

Lieu d'édition : Aix-en-Provence

Année d'édition : 2017

Date de mise en ligne : 12 mai 2017

Collection : Livres de l'IREMAM

ISBN électronique : 9782821881549

\section{openatition ebooks}

http://books.openedition.org

Référence électronique

ESTABLET, Colette. Répertoire des tissus indiens importés en France entre 1687 et 7769 . Nouvelle édition [en ligne]. Aix-en-Provence : Institut de recherches et d'études sur les mondes arabes et musulmans, 2017 (généré le 12 janvier 2021). Disponible sur Internet : <http://books.openedition.org/iremam/ 3841 >. ISBN : 9782821881549. DOI : https://doi.org/10.4000/books.iremam.3841.

Ce document a été généré automatiquement le 12 janvier 2021.

(C) Institut de recherches et d'études sur les mondes arabes et musulmans, 2017

Conditions d'utilisation :

http://www.openedition.org/6540 
Les textiles ont constitué l'essentiel du commerce des Compagnies des Indes au XVIII ${ }^{\mathrm{e}}$ siècle.

Différents types de sources autorisent une observation précise des cargaisons indiennes acheminées dans les ports du royaume de France pendant plus d'un siècle, et permettent d'énumérer des centaines de noms de textiles, parfois même d'en décrire pour chacun l'apparence, la taille, le prix. Souvent chiffrées, ces sources établissent des quantités et suggèrent des proportions. Arrivent certes en France des toiles peintes, des soieries chatoyantes et multicolores, de fines mousselines souvent brodées; mais ce sont les banales toiles de coton, blanches ou de couleurs, unies, à raies ou à carreaux, licites ou prohibées, les humbles mouchoirs et de valeur souvent moyenne, qui constituent la part de loin la plus importante des cargaisons de textiles provenant des Indes et de Chine.

Les descriptions des affiches de vente, les récits des voyageurs, et quelques échantillons de textiles trouvés au Victoria and Albert Museum à Londres et au Musée des Arts décoratifs à Paris, ont souvent autorisé à définir de façon concrète, à illustrer même certains de ces quelques centaines de tissus. Sur de simples noms, on a tenté de reproduire une texture, de mettre une image.

Le voyage de certains de ces textiles ne s'arrête pas aux ports du royaume : d'autres vaisseaux se chargent d'exporter vers l'Afrique une partie de ces étoffes dont le lot le plus important est constitué d'étoffes " prohibées». Là-bas, elles seront échangées contre des noirs qui continueront de force le circuit vers des contrées occidentales encore plus lointaines, les Antilles, l'Amérique. Ce commerce de traite se poursuit avec la traversée du retour : les navires chargés de denrées « exotiques » reviennent à leur lieu de départ. La boucle s'est fermée. 
SOMMAIRE

Remerciements

Colette Establet

Introduction et sources

Sources

\section{Les textiles dans les importations des Compagnies des Indes}

Valeur des textiles dans l'ensemble des importations indiennes

La nature des cargaisons textiles

Les difficultés de l'identification et de la classification

La classification proposée

Proportion en nombre et en valeur des différents tissus importés

Le devenir des tissus prohibés

Les pièces prohibées et la traite

L'échange, l'amorce d'un commerce quadrangulaire

\section{Les différents tissus : approche descriptive}

Les chittes

Les chittes

Les tissus mêlés coton soie

Les soieries

Les mousselines

Mouchoirs et stinkerques

Les mouchoirs

Les mouchoirs du Bengale

Les mouchoirs du Mazulipatnam

Les mouchoirs de Pondichery

Les mouchoirs de Paliacate

Les mouchoirs de Trinquebar

Chandernagor, Karikal, Madrapac

Les stinquerques

Les toiles de coton

Conclusion

Bibliographie

Liste des tableaux 


\title{
Remerciements
}

\author{
Colette Establet
}

1 Nous remercions chaudement tous ceux et celles qui nous ont aidée : l'ensemble du personnel des Archives nationales d'outre-mer à Aix-en-Provence, du Service historique de la Défense, à Lorient, des Archives municipales et départementales de Loire Atlantique, à Nantes ; l'IREMAM, à Aix-en-Provence, Sabine Partouche, qui a mis en ligne cet ouvrage ; la MMSH, à Aix-en-Provence et Olivier Dubois pour ses précieuses indications bibliographiques.

2 C'est avec Jean-Paul Pascual, aujourd'hui disparu, que nous nous sommes penchés en premier lieu sur les noms des tissus indiens présents à Damas au XVIII ${ }^{\mathrm{e}}$ siècle. La suite de ce travail, portant sur le répertoire des tissus indiens importés en France au XVIII ${ }^{\mathrm{e}}$ siècle, doit beaucoup à des conversations avec Brigitte Nicolas, conservatrice du Musée de la Compagnie des Indes de Lorient. Rosemary Crill, Senior Curator South \& South East Asian textiles and dress, alors en poste au Victoria and Albert Museum, à Londres, nous a grandement aidée à identifier et illustrer les textiles indiens. Hélène Renaudin, Assistante de conservation dans les Collections Mode et Textile, aux Arts Décoratifs à Paris nous a facilité le travail de recherche d'échantillons de textiles indiens.

3 C'est René Estienne, ancien Directeur du Service historique de la Défense, à Lorient, qui nous a fait connaître (et étudier), la Disposition de la vente des marchandises apportées des Indes, de 1741, catalogue dont la précision et l'intérêt nous a poussé à continuer notre recherche.

4 Enfin, rappelons la qualité des données présentées par Donald Wellington dans French East India Companies : elles ont servi de base à notre ouvrage. 


\section{AUTEUR}

\section{COLETTE ESTABLET}

Aix Marseille Univ, CNRS, IREMAM, Aix-en-Provence, France 


\section{Introduction et sources}

1 Un catalogue, conservé au Service historique de la Défense à Lorient, présente la «Disposition de la vente des marchandises» apportées des Indes, puis de Saint Domingue, puis de Chine. Dans ce catalogue, épais de 351 pages, prévu pour être porté à la connaissance de marchands acheteurs, les marchandises sont énumérées dans le détail : numéros et marques des balles, nombre de lots, nombre de pièces; et, pour les tissus, aunage des pièces nommées, quantités, parfois description et état des tissus à l'arrivée.

2 Ces marchandises sont arrivées le 20 et 29 avril, le 5 et 24 mai, le 18 juin, le 7 et le 8 août 1741 au port de «l'Orient», apportées par plusieurs vaisseaux armés par la Compagnie des Indes : l'Apollon, l'Hercule, le Lys, le Maurepas, le Saint Geran, le Fulvy et le Phoenix ; ils viennent de l'Ile de Bourbon, de Pondichery, du Bengale et de Moka. Le 16 juillet et le 8 août de la même année, le Neptune et le Jason, provenant de Chine, pénètrent le port. La Vestale, l'Aurore et la Flore, dont la date d'arrivée n'est pas indiquée, ramènent de Saint Domingue quelques maigres lots de sucre, d'indigo, de café et de coton.

3 Le 25 septembre 1741, et les jours suivants, dans la salle de la Compagnie, les marchandises importées sont proposées à la vente.

4 Comme la tombe de Toutankhamon permettait d'approcher les éléments d'une civilisation matérielle égyptienne disparue, ce document exceptionnel témoigne de tout ce que la France attendait de l'Orient, du moins de la Côte de Coromandel, du Bengale et de Chine, en cette moitié du XVIIIe siècle, bois rouge et de sapan, thés divers, poivre, café de Moka et de Bourbon, tissus, cauris, encre, indigo, rotins, paravents, sucre, laque, porcelaines de Chine diverses.

5 En 1741, les 4177 lots de tissus présentés dans le catalogue constituent l'essentiel de la cargaison : sur eux seuls se portera donc notre attention.

6 Les résultats d'une première exploration ont été brièvement présentés dans l'ouvrage Les compagnies de Indes ${ }^{1}$ : part des textiles dans la vente de 1741 par rapport aux autres importations, énumération des tissus, "rangés » dans les tiroirs d'une classification proposée, toiles, mousselines, tissus coton soie, indiennes, soieries, mouchoirs, etc.

7 Les tiroirs sont remplis de cent huit noms de tissus différents, des noms qui laissent perplexe et insatisfait : à quoi ressemblait la pièce ? Quelle en est la texture, quelle en 
est la couleur, quelle est sa finesse ? À ces objets du quotidien, il manque la matérialité, l'aspect sensuel. On aimerait voir, regarder, toucher. De ces tissus fragiles, que reste-til ? Certains musées, parfois, possèdent bien dans leurs collections de ces tissus « en chair et en os ", sur lesquels, la plupart du temps, aucun des noms que l'on trouve dans les affiches des ventes n'a été posé.

8 L'étude du catalogue de 1741, une année parmi tant d'autres, est si riche en enseignements sur les tissus qui ont le plus intéressé les marchands qu'elle a suscité un projet plus large : tenter une exploration plus systématique des cargaisons de textiles débarquées et vendues dans nos ports, pendant une longue période de près d'un siècle (1687-1769).

La qualité des sources autorise le défi.

\section{Sources}

10 Si Le Catalogue de 1741 présente, avec une extrême précision, les noms, les quantités, les lots de toutes les marchandises arrivées à Lorient à la fin du printemps et au début de l'été 1741 , d'autres types de documents permettent d'aborder la question essentielle des ventes, à Nantes, à Lorient, à Saint Malo.

La « publicité des ventes, [qui] se fait en deux temps. Immédiatement après l'arrivée d'un vaisseau, de longues et étroites bandes de papier portant l'indication des quantités et une description succincte de la cargaison sont adressées aux principaux négociants; puis deux mois avant la vente, une seconde liste est envoyée. Elle précise la date de la vente ; puis elle donne la liste et la quantité des produits mis en vente... Quelques jours avant le début de la vente, des affiches apposées à proximité de la salle rappellent les conditions de paiement... Des échantillons des marchandises sont exposés, et on distribue aux présents des listes détaillées avec la composition de chaque lot. $»^{2}$ Telle est la "disposition des marchandises » de 1741. «À l'issue de chaque vente, l'imprimeur de la Compagnie publiait une liste avec le prix atteint par chaque lot $»^{3}$, un compte rendu des ventes où figure également, parfois, le nom de l'acquéreur.

11 Ces documents, affichettes, billets d'adjudication et comptes rendus des ventes, inégalement répartis dans le temps autorisent une connaissance large et quantifiée de l'ensemble des importations. Si les diverses affichettes apportent de nombreuses données sur les quantités de biens, vendus la plupart du temps à Lorient, rares, malheureusement, sont les documents qui permettent l'évaluation des biens. Enfin, les échantillons manquent complètement, évidemment disparus, une absence qui nuit gravement à la connaissance matérielle des tissus.

12 Donald Wellington, de l'Université de Cincinnati a publié un ouvrage French East Indian Companies, sur l'histoire des Compagnies et de leur organisation, et il consacre une partie entière à l'étude du commerce réalisé entre 1687 et $1768^{4}$. Il a accumulé des trésors de données puisées dans les différents centres d'archives de Lorient, Nantes, Aix en Provence et Paris, qu'il présente en annexe dans une série de tableaux. Nous avons vérifié les données de Wellington, justes, à quelques minimes erreurs près qui ont été corrigées. Les comptes de Wellington sont d'autant plus remarquables qu'il lui a parfois fallu repérer et trouver les affichettes de vente correspondant à plusieurs arrivées de bateaux. Ainsi, en 1726, Le Saint Louis est arrivé le 10 septembre à St Malo, la Syrenne venant de Pondichery et du Bengale sont arrivés tardivement le 20 septembre à l'Orient; à leur suite, le Duc de Chartres, le Neptune et l'Apollon, puis le Vierge de 
Grace venus du Bengale ; puis le Mercure et le Danaé venant de Canton, enfin le Jason et l'Argonaute venant du Bengale. Wellington a rassemblé les données des différentes affichettes de vente dans un seul document pour l'année 1726. La même remarque s'applique à l'année 1731. À Aix, et Nantes deux documents concernent l'année $1731^{5}$. Le document aixois, placé dans un registre plutôt consacré aux cargaisons de départ, est précieux, car il relève la valeur totale des biens vendus et la valeur à la pièce de chaque tissu. Mais les deux documents ne coïncident pas exactement. Certains textiles n'apparaissent pas dans le document aixois, en particulier toutes les soieries. Une explication : le document nantais, qui n'expose pas les prix de vente, prend en compte toutes les marchandises amenées par les vaisseaux le Duc de Chartres, la Diane, la Méduse, le Lys, le Mars, Athalante et Neptune, tandis que le document aixois concerne les cargaisons des seuls Duc de Chartres, du Neptune et du Lys. Wellington a rassemblé l'ensemble des marchandises vendues dans son tableau $4^{6}$.

Une exception cependant dans ses comptes, l'année 1716. Dans le dossier de Nantes ${ }^{7}$ est inscrit en tête :

«La compagnie des Indes orientales établie à St Malo, vendra dans la ville de Nantes le 20 août prochain...les marchandises ci-après apportées des Indes par les navires La paix, les Deux Couronnes, le Lys arrivés en l'année 1716. »

Or, ce dossier indique que la vente s'est faite en 1718. Wellington n'a tenu compte que de la vente, effectuée en 1716, des marchandises apportées par les bateaux Mercure, Venus et Jason. D'autres bateaux sont arrivés plus tard, la même année, dont les cargaisons semblent n'avoir été vendues qu'en 1718. On n'aura jamais aucune preuve de la justesse de mon interprétation: j'ai donc ajouté aux quantités recueillies par Wellington pour 1716 les données de 1718, comme s'il n'y avait eu qu'une seule vente... en deux temps. Par ailleurs, deux documents de 1760 et 1768, non utilisés par Wellington, ont permis d'élargir un peu la connaissance du nombre de pièces proposées à la vente.

Peut être alors construit un large tableau de 39 colonnes correspondant à 39 ventes, à l'intérieur de la période 1687-1769, trente-neuf années sur les quatre-vingt-deux ans de la période concernée, près de la moitié8.

Ce premier tableau ne concerne donc que les quantités de pièces arrivées et vendues.

On ne pourra approcher la valeur de ces textiles qu'avec des données plus partielles fournies par des sources plus rares, concernant les années 1687, 1691,1721, 1725, 1758, 1760,1767 et 1768 .

Par ailleurs, la fréquentation des documents a montré que l'on pouvait être plus précis dans les désignations des tissus que Wellington ne l'avait été.

Nous avons donc modifié les tableaux de Wellington, en rajoutant quelques années, et surtout en détaillant les textiles : Wellington a réuni sous un même nom, des pièces que les scripteurs des affichettes, du catalogue de 1741, ou des bulletins de vente, ont détaillées, indiquant le lieu de fabrication, ou y ajoutant des adjectifs qui en précisent la variété. Les guingans de Wellington peuvent être des guingans de Pondichery, ou de Madras, ou du Bengale, ou du Masulipatam, de Paliacate, du Bengale ou de Patna ou des guingans balassor, ce qui éclaire le sens de l'obscur balacor; les tangebs, des mousselines, sont « à fleurs », ou " brodées ", ou « de Patna. »

Après les transformations personnelles apportées aux tableaux 3, 4, 10 de Wellington, la base de cette étude reposera sur un tableau de 39 colonnes indiquant les années et 
285 lignes, indiquant les différents types de tissus. Au centre des cellules, des chiffres. Nous ne nous priverons pas, non plus, chemin faisant, d'ajouter d'autres sources que nous citerons.

21 La comptabilité des marchandises est faite en pièces pour les tissus, quelques rares fois en aunes; en poids (livres) pour la plupart des autres biens. Malheureusement, quelques mesures non destinées à la comptabilité des textiles, apparaissent, rarement, dans les catalogues de vente des compagnies, les jarres, les ballots, les paquets, dont on peut parfois évaluer l'équivalent de poids en livres ou en pièces. L'uniformisation nécessaire de ces mesures anciennes en livres et en pièces, laisse donc place à quelques imprécisions. Parfois même, toute conversion est impossible, lorsque le scripteur a décrit- pour des biens autres que les tissus- le nombre de "jarres" pour la gomme gutte ou a seulement inscrit «partie» ou «divers» pour la porcelaine. Ces imprécisions et variantes dans l'utilisation des mesures s'estompent au fil des années: fréquentes dans les affichettes de la Compagnie des Indes Orientales, elles deviennent rares, voire inexistantes pour celles de la Compagnie des Indes. En 1764, cependant, un scripteur a enregistré en aunes les quantités de pièces : nous avons transformé ces aunes en pièces, connaissant par d'autres documents, et pour certains de ces textiles, leurs aunages moyens.

22 L'histoire a fait ce qu'elle voulait des traces du passé. Les importations ne sont pas connues sur une période continue. Certaines années sont particulièrement bien représentées. Pour l'année 1758, une fois n'est pas coutume, la valeur totale de chaque type de produit d'importation est indiquée, tandis que les quantités de biens n'apparaissent pas. Bref, des manques, des incertitudes, des imprécisions...qui n'interdisent pas la mesure. Comme l'affirmait physicien et mathématicien écossais William Thomson (1824-1907), Lord Kelvin. «Quand vous pouvez mesurer ce dont vous parlez et l'exprimer par des nombres, vous connaissez quelque chose à son sujet ; mais quand vous ne pouvez ni le mesurer ni l'exprimer par des nombres, votre connaissance $\mathrm{du}$ sujet est vraiment faible et insatisfaisante. $»^{9}$ Manipulant des chiffres, nous ne pouvons faire autrement qu'additionner, multiplier, calculer des pourcentages. Ces données sont soumises à des incertitudes, à des carences, à des imprécisions infligées par le passage du temps; elles autorisent seulement l'approche d'une réalité qu'il serait imprudent de juger définitive et absolue.

Dans une première partie, grâce à ces sources qui combinent noms et nombres et autorisent l'analyse de quantités et de proportions, nous estimerons la valeur des textiles introduits par les Compagnies par rapport à l'ensemble des importations au cours du XVIIIe siècle. Nous nous efforcerons de répondre ensuite à deux questions posées par Brigitte Nicolas, conservateur du Musée de la Compagnie des Indes à Lorient. La première concerne la nature des cargaisons textiles : « quelle était la nature de ces cargaisons de textiles? " ${ }^{10}$ Quelles sont les catégories de tissus les plus, les moins demandés? Quelles en sont les proportions? La seconde concerne la proportion des tissus qui ne sont pas destinés à rester dans le royaume, mais ceux qui sont dits "prohibés", devant être expédiés à l'étranger, en Afrique essentiellement: "Il conviendrait de chiffrer la part des recettes dégagées par la vente des textiles indiens destinées à la traite ou à l'habillement des esclaves. ${ }^{11}$ Nous essaierons d'en approcher la proportion.

24 En deuxième partie sera présenté l'essentiel de ce travail: rassembler le plus d'informations possibles sur l'identification de ces textiles, tenter d'établir un 
dictionnaire raisonné des textiles importés, un catalogue, un répertoire, en utilisant plusieurs sources : les dictionnaires et index déjà existants, souvent incomplets, voire contradictoires, rarement illustrés; les descriptions des voyageurs, des commerçants au contact de ces pièces dans un large XVIII ${ }^{\mathrm{e}}$ siècle ; tous les renseignements quelque peu concrets recelés dans les archives des ventes des cargaisons indiennes participeront également à l'identification des textiles ramenés dans les vaisseaux.

Ces descriptions sont longues et fastidieuses: composition du textile, aunages, couleurs, prix, détails variés, carreaux, lisières, raies, origines géographiques, aideront peut-être tous ceux qui possèdent des tissus dans les musées ou les collections, les observent, les mesurent, à mettre un nom précis sur telle pièce conservée dans un tiroir, une armoire, un carton. Enfin, quand faire se peut, on mettra un peu de chair sur ces immatériels vocables, en visitant les collections de musées, en faisant appel aux illustrations présentées dans quelques ouvrages.

\section{NOTES}

1. Colette Establet, «Le raz de marée des tissus de la vente de 1741 », in Les Compagnies des Indes, sous la direction de René Estienne, Coédition Gallimard / Ministère de la Défense - DMPA, Albums Beaux Livres, 2013, p. 232.

2. Haudrère Philippe, La Compagnie française des indes au XVIII ${ }^{\mathrm{e}}$ siècle, Paris, ed. Les Indes savantes, 2 tomes, 2005, p. 307.

3. Haudrère Philippe, op. cit., p. 315.

4. Wellington D.C. French East Indian Companies, a historical account and record of trade, Oxford, Hamilton Books, 2006.

5. ANOM C2/272, f 31 à $34, \mathrm{HH} 226 / 40$.

6. Wellington D.C., op. cit., p. 144.

7. $\mathrm{HH} 202 / 74$.

8. $1687,1691,1699,1704,1710,1712,1714,1715,1716,1717,1719,1720,1721,1722,1723,1724$, $1725,1726,1728,1729,1731,1732,1733,1734,1737,1738,1739,1740,1741,1749,1750,1756,1760$, $1761,1764,1766,1767,1768,1769$.

9. Lolanda Guevara et Carles Puig, Les mesures du monde Calendriers, longueurs et mathématiques, dans Le monde est mathématique coll. dirigée par Cédric Villani, 2010. RBA France 2013.

10. Nicolas Brigitte, «La compagnie française des indes et le textile indien » in Le goût de l'Inde, Rennes, Presses universitaires de Rennes, 2008, p. 20 à 31.

11. Nicolas B., Lorient, la Bretagne, et la traite, 2006, p. 101. 
I. Les textiles dans les importations des Compagnies des Indes 


\section{Valeur des textiles dans l'ensemble des importations indiennes}

1 Dans cette étude générale sur la part de la valeur des textiles dans l'ensemble des les importations indiennes, entre 1687 et 1769 , nous utiliserons le seul tableau $10^{1}$, présenté en annexe dans l'ouvrage de Wellington.

2 Une première constatation : la croissance de la valeur de l'ensemble des ventes des cargaisons indiennes et secondairement chinoises, est multipliée par dix environ durant la période.

Tableau 1. Évolution générale des importations des Compagnies des Indes (en valeur)

\begin{tabular}{|l|l|}
\hline Années & Valeur en livres \\
\hline 1687 & 2073714 \\
\hline 1691 & 2040905 \\
\hline 1721 & 1867468 \\
\hline 1725 & 4265043 \\
\hline 1758 & 10613120 \\
\hline 1760 & 4848213 \\
\hline 1767 & 19030840 \\
\hline 1768 & 22914060 \\
\hline Total & 67653363 \\
\hline
\end{tabular}

3 Les chiffres absolus sont un peu différents de ceux présentés par Ph. Haudrère qui a utilisé d'autres données. En revanche, la courbe d'évolution est semblable. 
«Le produit de la vente des marchandises provenant du commerce au-delà du Cap augmente rapidement à partir de 1730 ; le chiffre d'affaires annuel double alors en dix ans, de sept millions de livres à quatorze millions par an. " ${ }^{2}$

4 Dans un document, mal placé en fin du carton ${ }^{3}$, non daté, intitulé Du commerce de la France avec les Indes Orientales depuis 1716 jusqu'à 1788, un scripteur, anonyme, a récapitulé les valeurs des importations des Indes vers la France, les exportations de la France vers les Indes, les excédents des importations sur les exportations, la part des Antilles dans les exportations, et la part des importations des Indes employées à la traite des nègres. Limitons nous à la colonne des importations des Indes : les chiffres sont différents, toujours inférieurs à ceux que présente Wellington, sauf pour $1760 .{ }^{4}$

5 La tendance à l'accroissement est identique. Nous reviendrons sur ce document mystérieux.

Une deuxième conclusion : dans les cargaisons, pendant l'ensemble de la période, les textiles dominent ; cependant la part des tissus tend à diminuer avec les années.

7 Sur cette période de près de cent ans, les tissus ont représenté près de $60 \%$ de la valeur de toutes les importations.

Tableau 2. Valeur et proportion des différents produits importés

\begin{tabular}{|c|c|c|}
\hline Produits & Valeur totale en livres & Proportion \\
\hline Teintures & 5067 & 0,0 \\
\hline Laques & 9834 & 0,0 \\
\hline Vernis & 9943 & 0,0 \\
\hline Papier & 23671 & 0,0 \\
\hline Gommes & 80692 & 0,1 \\
\hline Rotin & 87182 & 0,1 \\
\hline Porcelaine & 217285 & 0,3 \\
\hline Autres textiles, chanvre, lin, etc. & 345100 & 0,5 \\
\hline Drogues & 353487 & 0,5 \\
\hline Salpêtre & 524000 & 0,8 \\
\hline Bois & 538621 & 0,8 \\
\hline Cauries & 1647170 & 2,4 \\
\hline Poivre & 2475975 & 3,7 \\
\hline Matières premières textiles & 3365395 & 5,0 \\
\hline Café & 8781573 & 13,0 \\
\hline
\end{tabular}




\begin{tabular}{|l|l|l|}
\hline Thé & 8953339 & 13,2 \\
\hline Textiles & 40235029 & 59,5 \\
\hline Ensemble & 67653363 & 100 \\
\hline
\end{tabular}

8 Cependant, pour ne citer que les plus importantes des cargaisons (celles dont la proportion dépasse les $3 \%$ ), la part des textiles, la part du poivre, en valeur, a tendance à diminuer avec les années par rapport au café, au thé, et aux matériaux bruts textiles (soie brute, soie tany, fils de coton, soie nankin). Entre 1687 et 1768, le café passe 0,3 à $8,1 \% \mathrm{du}$ produit des ventes; le thé de 0,3 à 16,2 . Les matières premières textiles, passent de 5,2 à $10 \%$. Sur l'ensemble de la période, les importations de soie dominent nettement par rapport aux importations de fils de coton. La laine ne compte pas. Avec les années, les importations de fils de coton diminuent nettement alors que les importations de soie augmentent. La valeur des fils de coton augmente à peine entre 1687 et 1768, passant de 27300 livres à 32387 livres ; l'ascension des importations de soie brute est fulgurante entre ces deux dates, de 80053 livres à 2259393.

9 En revanche, le poivre passe de 4,2 à 2,4 \%, et les tissus de 81,7 à $59,5 \%$ de la valeur des importations.

10 Cependant, même si leur part diminue, les textiles, pendant toute la période, forment l'essentiel des cargaisons: en 39 années, sont entrées en France 6491875 pièces de tissus, une moyenne de 166458 pièces par année. Haudrère constatait : « de 100000 pièces à la fin du XVII e siècle et au début du XVIII ${ }^{\mathrm{e}}$, à 200 000, puis 300000 pièces. $\|^{5}$

11 Cette moyenne masque d'importantes variations, exprimées par le graphe suivant. Ces variations peuvent être liées à l'irrégularité ou à l'absence de sources pour certaines années. Elles sont également imputables à des évènements extérieurs :

«La guerre de succession d'Autriche, écrit Ph. Haudrère, est une parenthèse qui est suivie d'une vive reprise ; par contre les années qui suivent la guerre de Sept-Ans ne connaissent pas un mouvement analogue. $»^{6}$ 
Graphe 1. Nombre de textiles importés suivant les années

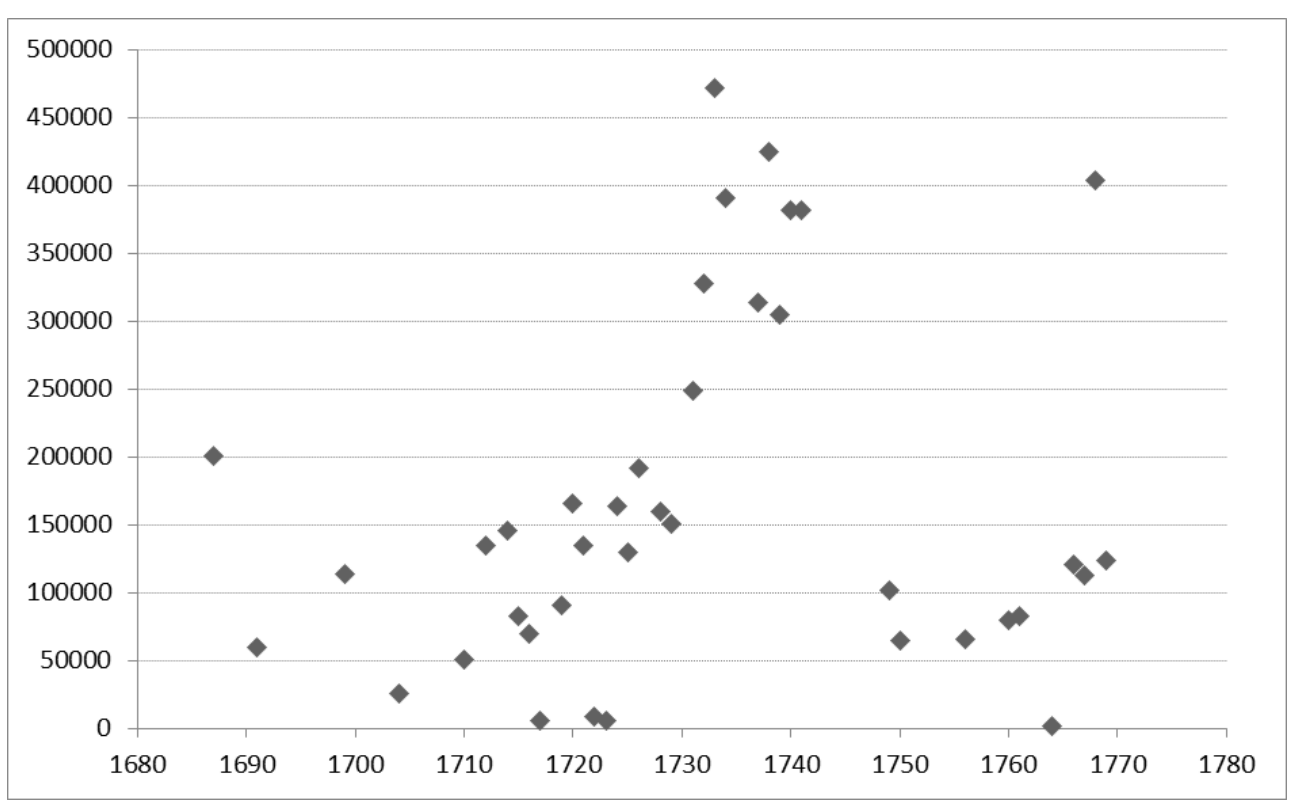

Graphe 2. Valeur des textiles importés suivant les années

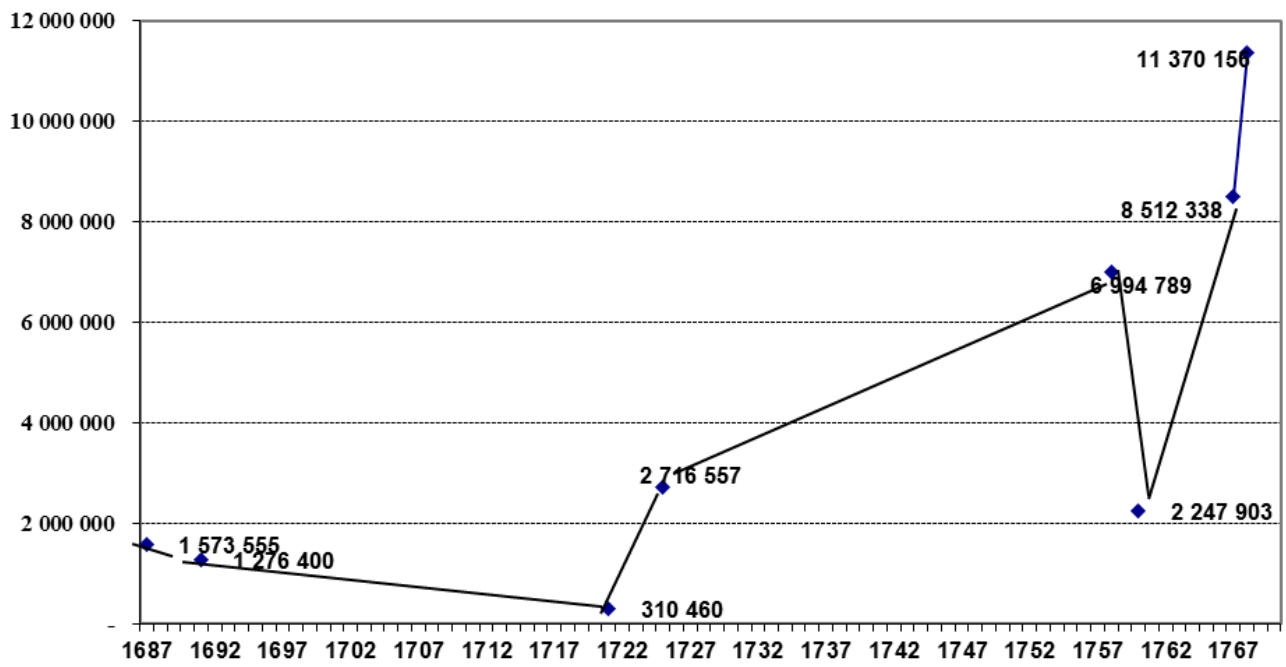

\section{NOTES}

1. Wellington D.C., op. cit., p. 194.

2. Haudrère Ph. 2005, La Compagnie française des indes, tome1, p. 313.

3. AOM C $/ 56$.

4. 1725 : 6700130 livres ; $1758: 5998750 ; 1760: 543178$; $1767: 14817159$; 1768 : 16473817.

5. Haudrère Philippe. Le Bouëdec Gérard, Les compagnies des Indes, Rennes, ed. Ouest France, 1999, p. 81. 
6. Haudrère Ph, La Compagnie française des Indes, p. 313. 


\section{La nature des cargaisons textiles}

1 Brigitte Nicolas, après avoir insisté sur l'importance des textiles dans les cargaisons remarquait: "Cela établi, il reste bien des interrogations, dont les deux suivantes: quelle était la nature de ces cargaisons de textiles? Quels étaient leurs usages en France? $»^{1}$ Nous n'aborderons ici que la première de ces deux questions; la seconde exigeant des sources complètement différentes de celles que nous utilisons.

\section{Les difficultés de l'identification et de la classification}

2 Allons à l'essentiel, simplifions, oublions tous les noms de couleurs, oublions les fleurs, les rayures, les motifs, oublions les aunages, l'origine du tissu lorsqu'elle est indiquée : cantonnons nous à identifier et classer les noms des différents textiles répertoriés, près de 150, auxquels s'ajoutent des objets faits de tissus divers, qui sont des biens fabriqués et dont le nom est donné en français : mouchoirs, couvertures, tours de lit, cravates, jarretières et bas, broderies sans plus de précision, et autres.

Identifier ces tissus, c'est se heurter à de nombreuses difficultés.

\section{Problèmes de transcription phonétique tout d'abord}

$4 \quad$ L'identification de ces tissus n'est pas allée sans mal : les noms de ces produits sont en effet écrits par des scripteurs qui se fient à ce qu'ils entendent d'une langue qui ne possède pas les mêmes systèmes phonatoires, et transcrivent dans un alphabet latin des sons étrangers à cette langue. Le glossaire qui termine l'ouvrage de $\mathrm{D}$. Wellington, The French East India Company, ${ }^{2}$ donne un excellent exemple de ces multiples variantes: ainsi, le textile bafta apparaît sous plusieurs formes : «bafta, baffetas, baffoted, baft, baftah, bufta, baff ». Les deribands sont aussi « des deriabads, deribadis, detehtdis ou derebands ». Les exemples sont nombreux.

Le sens de tous ces noms, souvent d'origine arabe, persane, hindi et tamoul, nous échappe, ainsi qu'aux contemporains européens aux prises avec des langages inconnus d'eux. C'est J. Irwin, dont la formation linguistique est solide, qui essaie au mieux d'approcher le sens et l'étymologie de certains termes. 


\section{Les divergences des spécialistes}

6 Les définitions données par les spécialistes sont parfois contradictoires. Ainsi, le tissu Doreas-doria est défini dans Hobson-Johnson ${ }^{3}$ : «à l'origine, le doriya était fait de coton blanc; mais maintenant, il est fait de soie, de soie et coton.» Dans le glossaire de Wellington, le même dorea se présente sous plusieurs formes: 1/ «mousseline ou cotonnade blanche, provenant du Bengale suivant Savary. » 2/ mélange de coton et de soie, à raies ou carreaux, 3 / "mélange de coton et de soie, belle à très belle qualité, venant du Bengale » d'après Chaudhuri. 4/ Doriah : « simple cotonnade blanchie.» Et pour J. Irwin : «tissu de soie et coton à rayures ou à carreaux tissé dans la région de Malda Kasimbazar. » Il faudra se résigner à ce que la classification proposée, après maintes hésitations et remaniements, soit cependant imparfaite.

7 Il a donc fallu «butiner» dans tous les nombreux ouvrages et dictionnaires qui rappellent les noms des tissus, dont nous donnons ci-dessous une liste non exhaustive. ${ }^{4}$

8 Il faudrait également essayer de reconstituer l'apparence de ces pièces. Les textiles, fragiles, n'ont laissé que de rares témoignages matériels de leur existence. L'édition de 1867 des 18 volumes de Forbes Watson conservée à Londres au Victoria and Albert Museum illustre cependant, à l'aide de nombreux échantillons, certains de ces tissus importés par les Compagnies. B. Nicolas, conservatrice du Musée de la Compagnie des Indes à Lorient, s'attache à présenter des images de ce monde disparu; elle nous a signalé l'existence d'un catalogue du Musée des arts décoratifs, à Paris, le Recueil des échantillons des toiles et des toileries fabriquées en France et en Angleterre, daté de 1789, collection des Arts décoratifs ${ }^{5}$. Dans ce catalogue sont présentés des échantillons de textiles qui imitent les tissus indiens. Les photos que nous représentons sont issues de ces deux sources ${ }^{6}$.

\section{La classification proposée}

9 La classification des textiles adoptée comporte, comme toute classification, une part d'arbitraire. Classer, c'est ranger ; on hésite, on déplace, on perd, on replace... et on recompte!

10 La base de ce classement difficile repose sur les données mêmes des scripteurs d'affiches et du catalogue de 1741 qui, tout en énumérant les tissus proposés à la vente, propose parfois des définitions générales. Les remarques des voyageurs commerçants, Legoux de Flaix en particulier, permettent également l'identification de ces tissus maintenant disparus, dont ils notent, pour chacun d'entre eux, les différentes variétés et qualités.

\section{Les classifications d'époque permettent un premier « rangement »}

11 Dans certains des catalogues qui présentent aux acheteurs potentiels les cargaisons des vaisseaux, les scripteurs proposent d'abord une première classification de l'ensemble des marchandises importées, tissus et autres :

"Chapitre premier: «des marchandises sujettes à la marque comme mousselines, toiles de coton blanches, et mouchoirs de cotton de Bengalle et de Masulipatam.

Chapitre second : des drogueries et épiceries, soyes ecrüe, tany et de Pékin et cotton filé sauf les déchets...et porcelaines. 
Chapitre troisième : contenant les toiles teintes et rayées de couleurs dont l'usage et le débit sont prohibés dans le royaume. $»^{7}$

12 En ce qui concerne les seuls textiles, quelques rédacteurs d'affiches, catalogues, listes de vente, et autres ont établi, eux-mêmes, quelques descriptions. C'est sur elles que nous établirons une première classification. Ainsi, en $1691^{8}$, le scripteur énumère le contenu de la cargaison du vaisseau le Lonray: sous un titre «Etoffes de soye », il a inscrit, taffetas, armoisins, étoffes écorce d'arbre, satins, mouchoirs de soye; sous l'étiquette mousselines et toiles de coton : doréas, casses, sanas ou amans, mallemolles, tangebs, bétilles, salampouris blancs, garas, adatays, basins, mêlant alors dans une même catégorie, mousselines et toiles; ou encore « 265 balles de toiles de coton fines, la plupart mousselines claires et rayées. »

13 En $1714^{9}$, un scripteur a écrit, à la main, "mousselines », en face de mallemolles, casses, tanjebs, terindins, tocques, doreas, mallemolles brodées, tangebs brodés, jamdanis, sacerbatis. Il a aussi inscrit les indications «prohibées » en face d'autres marchandises : boulboule chamay ou bazins à carreaux, salempouris bleus, guinées bleues, fottes, bolsas ou couris, guingans, nilae, pinasse, alibanis, calladaris, ballasor, mouchoirs de Pondichery, mouchoirs du Bengale. »

14 En $1716^{10}$, sur une affichette concernant la vente des marchandises apportées des Indes Orientales par les navires le Mercure et la Vénus, arrivés à Brest et à Nantes le 25 février et celles du navire le Jason, un autre scripteur anonyme, et bien intentionné, a noté, de façon manuscrite et pour une raison inconnue, le type des tissus présentés à la vente. Il a inscrit « toilles grosses de coton » devant les salempores blancs, les garas, les baffetas blancs, les guingans blancs; "toiles grosses et fines " devant les guinées blanches, les percalles, les socretons; «toiles fines de coton» devant les sanas et les sologasis, "espèce de sanas "; "mousselines très claires " devant les chavonis, les bétilles, les toques tarnatane et diverses ; "mousselines " devant les "organdins " divers, les casses et même des pièces cravates; "fines mousselines" devant les mallemolles, "mousselines très fines" devant les térindannes, les sarabartis, les terindins ; «mousselines doubles » devant les tangebs; «mousselines rayées » devant les doréas.

Ces quelques précieuses indications fournies par les scripteurs « d'époque » s'adressant à des acheteurs potentiels permettent un premier rangement de nombre de tissus en toiles de coton grosses et fines, en mousselines.

La même affichette de 1716 présente les noms et quantités des "marchandises qui doivent être vendues pour être envoyées à l'étranger ", c'est à dire des marchandises prohibées. Devant les alibanis, «toilles bleues rayées»; «toiles peintes» devant les chittes; «toiles rayées » devant les chilas; " mousselines rayées à fleurs » devant les skinkerques; les mamobobanis, "mousselines rayées de fil écru»; "mousselines rayées de soie » devant les soucis; " taffetas» devant les arains, «taffetas à fleurs de soie» devant les jamavars; "mousselines rayées d'écorce» devant les nelis, les guingans, les armoisins ; "prohibées", les soieries, quelques toiles de coton peintes, rayées ou de couleurs et des mousselines dans lesquelles apparaissent la soie.

\section{Les classements des voyageurs commerçants}

17 Enfin, certains voyageurs ont parfois aussi laissé des témoignages vivants de leurs trouvailles. Ils font étalage de leurs difficultés, dont témoigne la constatation de P. 
Blancard : «La connaissance des toiles et des mousselines dépend de l'habitude de les considérer. $»^{11}$

Nous utiliserons "La manière de négocier aux Indes de Roques ${ }^{12}$, si vivant et riche d'enseignements, ouvrage qui correspond à des voyages effectués avant tout dans le Gujarat plus d'un demi-siècle avant la moitié du XVIIIème. Par la suite, les textiles du Gujarat ont perdu leur place majeure dans les exportations. ${ }^{13}$ Cependant, se déplaçant vers Sironj, Roques décrit les pièces réalisées à la fin du XVIIème siècle provenant de régions extérieures au Gujarat.

Les descriptions de Legoux de Flaix ${ }^{14}$ seront maintes fois citées. L'« Essai historique, géographique et politique sur l'Indoustan avec le tableau de son commerce, ce dernier pris dans une année moyenne depuis 1702 jusqu'en 1770 »; bien qu'édité en 1807, il est presque contemporain des affichettes et catalogues traités.

20 Signalons également Le manuel du commerce des Indes orientales et de la Chine de Pierre Blancard, édité en 1806. ${ }^{15}$ Blancard avait été chargé, en 1770, de la gestion des opérations commerciales de la frégate la Thétis et avait fait six voyages en Inde dans les années suivantes.

21 Legoux de Flaix (p.4) expose d'abord un premier moyen de classification adopté, dit-il, par les marchands de son temps, une classification par matériau, et par couleur : soie, toiles, fines, communes, blanches, de couleurs. De cette description, le mélange soiecoton est exclu.

22 À plusieurs reprises, Legoux ${ }^{16}$, comme Blancard ${ }^{17}$ distingue «toiles et mousselines ». Legoux donne même l'étymologie du terme mousseline : «masséli, mot indou que nous ne pourrions traduire exactement... et dont a vraisemblablement fait le mot mousseline. $»^{18}$

Mais, dès que l'on aborde la description des toiles blanches, la situation se complique.

Legoux ${ }^{19}$ se hasarde à présenter et classer les tissus de coton de façon plus précise, à propose des méthodes de blanchissage, en toiles fortes, fines et mousselines: « les toiles fortes ou communes: par exemple, les baffetas, les amames, les guinées ou les garas »; puis « les toiles superfines, les mousselines, les organdis, les doréas et toutes les espèces de bétilles"; et enfin les toiles comprises de nouveau sous le nom de toiles fortes, qui ne sont pas des toiles « communes", les percales, les amames et les casses, telles que seraient en Europe les courtrai, les toiles de Hollande, et même nos belles batistes » Constatons donc que les amames sont classées à la fois dans les toiles fortes communes et les toiles fortes de bonne qualité. Même contradiction à propose des baffetas : « le baffetas quoique porté dans la classe des toiles fines et rangé dans celle des toiles fortes...». ${ }^{20}$

Ces confusions, voire divergences, se comprennent : en réalité, la qualité des textiles est diverse. Legoux explique d'ailleurs à propos des baffetas: «Les qualités varient infiniment car on en fait de très fins et d'autres sont aussi grossiers que les garats. $»^{21}$ Blancard ${ }^{22}$ insiste aussi sur l'importance des variétés dans chacun des textiles : "Les toiles telles que les tarnatanes, les organdis, les bétilles, les mouchoirs organdis et stinkerques, ainsi que les percales... se désignent par la première, seconde troisième qualité, ainsi que par leur longueur et leur largeur. » Le Catalogue de 1741 (et la plupart des autres catalogues étudiés) présente ainsi les variétés de chacun des textiles : cinq types de "guinées blanches sorte hollandaise " distinguées par différents aunages de longueur et de largeur, deux variétés de " guinées de Masulipatam », quatre d'organdis, 
huit de casses, six de tanjebs, etc. Legoux ${ }^{23}$ insiste sur ce qui donne au textile sa qualité : «On connaît six espèces de guinées du nord. Elles reçoivent toutes leurs dénominations du nombre de conjons dont elles se composent. Le mot conjon, de l'idiome Télinga, signifie 120 fils... De quelque nombre de conjons que soit une pièce de guinée, la largeur de la pièce n'en augmente pas pour cela, elle n'est seulement que plus fine. Les différentes espèces de cette toile sont celles de 19 conjons, 23, 26, 3236 et de 50.» B. Nicolas explique : «La qualité du tissage se mesure en conjons, c'est à dire au nombre de fois où 120 fils de chaîne se présentent dans la largeur...Plus le nombre de conjons est important, plus la toile est fine. » Elle propose, dans la foulée, une classification des cotonnades blanches : les grossières, les ordinaires, les fines et les très fines. Il s'agit... par ordre croissant de finesse, des garas, des baffetas, des guinées et des percales. » ${ }^{24}$

La recherche a été longue, lassante, hasardeuse, parsemée d'embuches, elle n'a pas cependant été vaine. La plupart de ces variétés de tissus ont été reconnues et rangées dans des tiroirs un peu branlants, un peu désordonnés, dont il faudra les sortir pour les identifier avec plus de finesse, les décrire, et, si possible, pour en donner une image concrète. On se limitera, la plupart du temps, dans cette longue énumération, aux textiles rencontrés dans nos archives. D'autres tissus existent qui ont échappé aux ventes dont les catalogues, pendant ces 39 années, nous sont parvenus.

Quelques rectifications ont été apportées dans les listes de Wellington. Le terme "pacotille » ne désigne pas un tissu, mais un certain type de marchandise. L'analyse des données permet de conclure que certains textiles apparaissent plusieurs fois dans les listes de Wellington, avec des orthographes différentes. Lorsque les halibannies figurent dans les importations de telle ou telle année, les alabannies n'y figurent pas et inversement: les habanis recensés, en fin de période, apparaissent lorsque ni halibannies ni alabannies ne sont évoqués, et seraient encore une variante de ces alabannies, qui a donné du fil à retordre (c'est le cas de dire) aux scripteurs; le même terme apparaît aussi en 1737 sous le nom haby bani. De même pour les amans et hamans : en 1699 et 1710, le terme aman est utilisé, les autres années, c'est haman. (La même méthode d'analyse révèle que, dans les tableaux, lorsque il y a du aman, il n'y a pas de haman et vice versa). Enfin, pour les mêmes raisons, challis, chalia, et chila désignent un seul et même tissu. De même, les canadaris et les caladaris.

Différences de qualité, différences d'aunage, peut-être également variations dans le temps des qualités des tissus présentés, ces imprécisions n'interdisent cependant pas un classement peut-être grossier des 6491205 pièces, réalisé avant tout grâce aux indications de tous les scripteurs et auteurs cités ci-dessus ${ }^{25}$ : toiles de coton, grosses et fines, blanches, et de couleurs, mousselines, mouchoirs, stinkerques, cravates, soieries, tissus coton-soie, toiles peintes.

Inclassables ont été 832 pièces de "pacotille"; deux exceptionnels lots de velours; quelques 100 « camelots de laine ». Et quelques tissus dont nulle trace n'a été retrouvée dans nos archives, ni dans les récits, ni dans les dictionnaires et glossaires divers; à l'exception de 2892 pièces de fottamura, ces derniers sont peu représentés : « 20 pièces d'annabas dont on sait, par Savary, qu'elles étaient des « pagnes qui se font à Rouen et en Hollande, qui sont rayés de bleu, ou de blanc par rayes égales, d'environ un pouce de large...une des meilleures marchandises pour le commerce de Guinée et particulièrement la côte d'Angola. »Certes, ces annabas sont des pièces présentes dans les cargaisons négrières, mais elles ne proviennent pas des Indes..et l'on se demande pourquoi 20 pièces font partie des ventes de cargaisons indiennes. 
Échappent également à la classification quelques jarretières, manchettes, ceintures, et autres pièces toutes faites et rares, sur lesquelles on reviendra. Et d'obscures "marchandises de Dacca, ou de Patna ", plus de 23000 pièces dont scripteur a omis de donner le détail. On ne saura non plus pas grand-chose sur les textiles uniquement qualifiés de "broderies "; cependant, leur quantité n'est pas à négliger, 15922 pièces qui s'ajoutent sans doute au groupe des mousselines brodées sur lesquelles le scribe donne plus de détails.

\section{Proportion en nombre et en valeur des différents tissus importés}

\section{En nombre}

Le tableau suivant expose le nombre de pièces importées classées suivant la nature du tissu, et la part de chaque étoffe dans l'ensemble des importations.

Tableau 3 : Part de chaque groupe d'étoffes (en nombre et en proportion) dans l'ensemble des importations

\begin{tabular}{|l|l|l|}
\hline Toiles diverses de coton & 3393849 & 52,3 \\
\hline Mousselines & 1907396 & 29,4 \\
\hline Mouchoirs et stinquerques & 677742 & 10,4 \\
\hline Toiles peintes & 151032 & 2,3 \\
\hline Tissus coton soie & 146684 & 2,3 \\
\hline Tissus de soie & 99687 & 1,5 \\
\hline Cravates & 74587 & 1,1 \\
\hline Inclassables & 40228 & 0,6 \\
\hline Total (en nombre de pièces) & 6491205 & 100,0 \\
\hline
\end{tabular}

De loin en tête, les toiles de coton variées, fines et grosses, blanches, rayées, de couleur, auxquelles on peut ajouter la plupart des mouchoirs et certaines des cravates, à eux seuls, près des $2 / 3$ des ventes ; puis les mousselines, souvent de coton ; les « indiennes » ou chittes ou toiles peintes et les tissus coton-soie n'arrivent qu'en lointaine troisième position, loin derrière les cotonnades ; les soieries sont peu représentées.

B. Nicolas avait souligné l'importance des toiles de coton parmi les textiles importés qui met en cause une opinion dominante : « cette part du commerce est assez éloignée du commerce de luxe souvent associé à l'image de la Compagnie. $»^{26}$

\section{Évolution}

Il n'y a pas beaucoup de changement, pendant cette période, dans les types de textiles importés. A une exception près : les toiles peintes et imprimées, les «indiennes ». Plus 
de 78000 pièces d'indiennes en 1687, 32000 en 1699, moins de 800 dans les années suivantes, une remontée en fin de période, en particulier en 1761. C'est évidemment la prohibition qui a limité les importations de toiles peintes et imprimées: "La prohibition sur les toiles imprimées imposée de 1689 à 1759 est dure...Elle frappe d'interdiction leur vente, leur port et leur fabrication. $»^{27}$ La mise en suspens de l'interdiction, en 1759, explique sans doute la remontée des importations d 'indiennes en 1761, plus de 10000 pièces. Les indiennes ont pourtant frappé d'admiration les contemporains...et les historiens, éblouis : dans l'ouvrage, Le goût des Indes, toute la partie concernant le transfert des technologies est consacré aux indiennes; et, dans l'ensemble de la bibliographie consacrée aux importations textiles indiennes, la proportion d'ouvrages traitant des « indiennes » est considérable. Le bel arbre cache la forêt.

\section{En valeur}

Les sources sont moins nombreuses, et moins détaillées. Wellington, dans son tableau 10 , a pu retrouver le montant des biens vendus pour seulement huit années dont les comptes rendus de vente ont été conservés. Et le tableau ignore la valeur de bien des tissus, les moins fréquemment cités. Nous fonderons notre analyse sur ses données, vérifiées.

Certaines sources, partielles, concernant d'autres années, existent qui permettent de trouver une estimation précise du prix de chaque tissu, suivant sa qualité, son aunage : ces éléments seront utilisés dans la partie suivante consacrée à l'examen de chaque textile. Un document ${ }^{28}$, particulièrement utile et cité par E. Margoline-Plot ${ }^{29}$ donne le détail des prix, en pagodes, en roupies, à la pièce, à la courge, de marchandises de la côte de Coromandel et du Bengale.

On ne peut évoquer la valeur particulière des textiles sans vérifier le mouvement général des prix pendant cette période. H. Hauser ${ }^{30}$ constate : «On distinguera, de 1500 à 1800 , trois périodes...à savoir : A/ Période d'un grand mouvement de hausse, XVIème et première partie du XVIIème siècle; puis $B / . .$. palier ou baisse, jusqu'au troisième et quatrième quart du XVIIIème siècle ; et ensuite $\mathrm{C} /$ nouvelle période hausse allant de la fin du XVIIIème siècle au début du XIXème. » Ces variations n'empêchent donc pas une réflexion sur la valeur de ces biens de 1687 à1768.

Les prix varient en fonction de la qualité des pièces (nombre de conjons), qui, ellemême, est liée à l'époque à laquelle les achats sont faits, comme Dermigny ${ }^{31}$ le souligne: "Trois causes principales qui font hausser ou baisser la marchandise... la cherté du riz et quelquefois le manque de la récolte de coton... Il faut saisir le moment pour acheter...Toutes les toiles qui se fabriquent chez les tisserands depuis janvier jusqu'en février sont faites avec du coton de l'année précédente et il est démontré que plus il est vieux, plus le fil qu'il produit est fin et moins il grossit au lavage. Les toiles fabriquées dans les mois ci-dessus sont mieux soignées par les raffougois ${ }^{32}$ qui n'étant pas très occupés dans ces temps-là, portent plus d'attention à leur travail, ce qui contribue... à la perfection plus ou moins grande des toiles... tandis que le raffouga, depuis juin jusqu'en octobre... où les tisserands suspendent leurs travaux des manufactures pour se livrer à la récolte du riz, pressé dans son travail, n’y porte plus la même attention. "

39 En huit années, le commerce des seuls tissus atteint la somme de 35002158 livres, en moyenne 4375270 livres par an. Cette moyenne ne signifie pas grand-chose, car la valeur des importations varie beaucoup d'une année sur l'autre. 
40 Les textiles ont été classés comme dans le paragraphe précédent: toiles de coton variées, mousselines, indiennes, cravates, mouchoirs et stinkerques, tissus mélangés de coton et soie, soieries. Certaines des données sont imprécises : en 1758, un scripteur pressé a seulement indiqué le montant des ventes sans en préciser la nature, 6994789 livres; en 1767, il est fait allusion à des «marchandises de Dakka » (700 443 livres), à des «marchandises de Patna " (157 891 livres), sans plus de détails, ainsi qu'à des «broderies du Bengale" (192 176 livres) ; en 1768, à 414419 livres de «broderies »s sans précision. Il faut abandonner tout espoir de définition précise de ces textiles, que l'on considérera comme « inclassables ».

41 Dans un premier temps, cependant, nous essaierons d'estimer la part prise par chacun de ce groupe de tissus :

Tableau 4 : Valeur en chiffres absolus et en proportion de tous les groupes de tissus

\begin{tabular}{|l|l|l|}
\hline & Valeur en livres & Pourcentages \\
\hline Inclassables & 8460718 & 24,2 \\
\hline Toiles coton & 15530494 & 44,4 \\
\hline Mousselines & 7884322 & 22,5 \\
\hline Mouchoirs & 2043588 & 5,8 \\
\hline Soieries & 393145 & 1,1 \\
\hline Coton soie & 301973 & 0,9 \\
\hline Indiennes & 239560 & 0,7 \\
\hline Cravates & 84817 & 0,2 \\
\hline Stinquerque & 63541 & 0,2 \\
\hline Total valeurs & 35002158 & 100,0 \\
\hline
\end{tabular}

Dans un deuxième temps, éliminons des comptes ces « inclassables » :

Tableau 5 : Valeur en chiffres absolus et en proportion de tous les groupes de tissus, sans les inclassables

\begin{tabular}{|l|l|l|}
\hline & Valeur en livres & Pourcentages \\
\hline Toiles coton & 15530494 & 58,5 \\
\hline Mousselines & 7884322 & 29,7 \\
\hline Mouchoirs & 2043588 & 7,7 \\
\hline Soieries & 393145 & 1,5 \\
\hline
\end{tabular}




\begin{tabular}{|l|l|l|}
\hline Coton soie & 301973 & 1,1 \\
\hline Indiennes & 239560 & 0,9 \\
\hline Cravates & 84817 & 0,3 \\
\hline Stinquerque & 63541 & 0,2 \\
\hline Total valeurs & 26541440 & 100,0 \\
\hline
\end{tabular}

43 La part de toutes toiles de coton, blanches, de couleur, teintes, est prédominante, responsables de plus de $58 \%$ du produit des ventes, que renforce encore la valeur des mouchoirs, la plupart du temps faits de coton, et l'on arrive alors aux deux tiers des ventes.

La part des mousselines atteint presque le tiers.

Les soieries comptent pour moins de $2 \%$ des tissus importés. Les tissus mélangés coton et soie, les indiennes n'arrivent pas au $1 \%$.

On peut cependant nuancer le tableau, estimant que les mousselines occupent une place plus importante. En effet, les marchandises de Dakka» (700 443 livres), et les marchandises de Patna (157 891 livres) font peut-être partie des célèbres mousselines du Bengale ; ainsi que les broderies du Bengale (192 176 livres) et les « broderies », sans précision, (414 419 livres) : on verra par la suite que les broderies étaient souvent effectuées sur mousselines. Si l'on ajoute la valeur de ces incertaines mousselines à la valeur de l'ensemble des tissus (diminués des simples « tissus » non définis), la part des mousselines augmente de plus de $5 \%$, atteignant plus du tiers, près de $35 \%$ de l'ensemble de la valeur des textiles importés. En nombre de pièces, les mousselines représentaient moins de $30 \%$ des textiles; en valeur près de $35 \%$. L'attention portée en deuxième partie à la description et au prix de chaque pièce indique que cette hypothèse est plausible : les mousselines sont chères.

\section{NOTES}

1. Nicolas Brigitte, «La compagnie française des indes et le textile indien " in Le goût de l'Inde, 2008, Gérard Le Bouëdec et Brigitte Nicolas (dir.), Rennes, Presses universitaires de Rennes, 2008, p.20 à 31 .

2. Wellington D. C., French East India Companies, a historical account and record of trade, Oxford, Hamilton Books, 2006, p.214.

3. Hobson-Jobson, A glossary of colloquial anglo-indian words and phrases, New Delhi Munshiran Manoharlal Publishers Pvt Ltd, 1994.

4. Nous avons particulièrement utilisé : Hobson-Jobson, A glossary of colloquial anglo-indian words and phrases, New Delhi, Munshiran Manoharlal Publishers Pvt Ltd, 1994 ; l'ensemble des articles de John Irwin ("Indian textile trade in the seventeenth century, Journal of Indian textile History, Calico Museum of Textiles, Ahmedabad, India, 2ème édition, 1996), spécialiste des tissus et qui est 
au contact proche des nombreuses langues indiennes parlées dans les différentes régions du subcontinent; l'ouvrage de Chaudhuri K.N. The trading world of India and the English East India Company, 1660-1760, Cambridge University Press, Londres, version digitalisée de 2006 de l'ouvrage imprimé en 1978. ; l'ouvrage, et en particulier le Glossaire de D. Wellington, The French East Indian Companies, Oxford, Hamilton Books, 2006; Le goût de l'Inde 2008, Gérard Le Bouëdec et Brigitte Nicolas (dir.) Rennes, PUR, 2008 ; les documents d'archives présentés par Dermigny Louis dans Cargaisons indiennes, Solier et Cie, Paris, SEVPEN, 1959-1960. Son glossaire des marchandises, des mesures et des monnaies, quoique un peu plus tardif (1781-1793), ses notes sur les toiles de l'Inde vendues à la Martinique (prix de vente et même affichage du bénéfice réalisé), ont été infiniment précieux.

Ajoutons que de nombreux dictionnaires: Savary des Brulons Jacques, Dictionnaire universel de commerce: contenant tout ce qui concerne le commerce qui se fait dans les quatre parties du monde, 2 vol., Paris, Jacques Estienne, 1723 ; Flachat, Jean-Claude, Observations sur le Commerce et sur les Arts d'une partie de l'Europe, de l'Asie, de l'Afrique et même des Indes Orientales, Lyon, Jacquenot, 1766. ; Birdwood George C. M., The industrial Arts of India with map and woodcuts, 2 vol, 1880., South Kensington Museum Art Handbooks, Londres, Chapman and Hall. Forbes Watson, The textile manufactures and the costumes of the people of India, 1867, Londres; Hardouin-Fugier Elizabeth. Berthod Bernard, Les Etoffes, Chavent-Fusaro, Paris, Les éditions de l'armateur, 1994.

5. Numéro d'inventaire G.G.4. in BAD G752 (CG4), album d'échantillon Le tissu, XVIII ${ }^{\mathrm{e}}$ siècle.

6. Nous n'avons pas pu accéder à la Collection Krishna Ribout, conservée au Musée Guimet.

7. $\mathrm{HH} 225 / 541729$.

8. CAOM, C2/16/182.

9. $\mathrm{HH} 201 / 3$.

10. HH202.

11. Blancard, Pierre, Manuel du Commerce des Indes orientales et de la Chine, Paris, Bordeaux, 1806, dans sa version reprint, Nabu Public Domain Reprints, 4 novembre 2011, p. 231.

12. Roques, Georges, La manière de négocier aux Indes 1676-1691, texte présenté et annoté par Valérie Bérinstain, Ecole Française d'Extrême-Orient, 1996, Paris, Maisonneuve et Larose, 1996.

13. Legoux, p. 270. Les exportations ...de cette partie de l'Hindoustan sont considérablement diminuées depuis plus d'un demi-siècle.

14. Legoux de Flaix, Alexandre, 1807, Essai historique, géographique et politique sur Indoustan : avec le tableau de son commerce: ce dernier pris dans une année moyenne, depuis 1702 jusqu'en 1770, époque de la suppression du privilège de l'ancienne Compagnie des Indes Orientales, Paris, Pougin.

15. Blancard P. Manuel du commerce des Indes orientales et de la Chine, 1806, Bernard, Quai des Augustins, dans sa version Reprint, Nabu Public Domain Reprints, 4 novembre 2011.

16. Legoux, op. cit., p.17.

17. Blancard P. op. cit., p.230.

18. Legoux, op. cit., p. 345.

19. Legoux, op. cit., p.17.

20. Legoux, op. cit., p. 357.

21. Legoux, op. cit., p. 357.

22. Blancard p., op. cit., p. 221.

23. Legoux, op. cit., p.3.

24. Nicolas Brigitte. «La compagnie française des indes et le textile indien », in le goût de l'Inde, op. cit., p.22.

25. Legoux classe les textiles par par origine géographique. Marchandises de la côte de Coromandel: guinées, percales, salampouris, mouchoirs divers, chites, dorés ou bétilles, organdis, jamdanis, basins, guingans, pinasses, demi guinées bleues; marchandises du Bengale : nensouques, mallemolles, casses, amames, baffetas, garats, doréas du Gange, sirsakas, sistresays 
et canadaris, mouchoirs, steinkerques, soies. Il évoque également les marchandises de Surate dont nous ne trouvons évidemment nulle trace dans ce catalogue. (op. cit., p. 435-437)

26. Nicolas Brigitte, op. cit., Le goût de l'Inde, p.23.

27. Nicolas B. Le goût de l'Inde, op. cit., p. 28.

28. AOM, 25 DFC-96-145.

29. Margoline-Plot E. Les Pacotilles d'indiennes, la Boutique et la mer, thèse soutenue à l'université de Bretagne-Sud, 2014.

30. Hauser Henri., Recherche et documents sur l'histoire des prix en France de 1500 à 1800, Paris, Les Presses modernes, 1936, p.70.

31. Dermigny, op. cit., p. 423.

32. Le mot est traduit « apprêteurs » par Dermigny, op. cit., p. 420. 


\section{Le devenir des tissus prohibés}

1 La décision, l'installation, le déroulement de la prohibition, ont fait l'objet de nombreuses études. ${ }^{1}$ On se contentera ici de cerner les noms des tissus prohibés, d'estimer la part de ces textiles dans les cargaisons de textiles indiens ou chinois qui arrivent dans les ports français, et d'évaluer dans la mesure du possible la proportion de ces pièces prohibées qui vont prendre le chemin de l'Afrique ou des Antilles dans le commerce de traite.

\section{Quels sont les tissus prohibés?}

2 Dans les affichettes de ventes, les tissus sont énumérés et la mention " tissus prohibé » n'existe pas. En général cependant, ces tissus prohibés sont regroupés en fin d'affichette $(1704,1712,1716,1728,1741)$. En revanche, dans la plupart des catalogues de vente et des bulletins d'adjudication, le nom des «tissus prohibés» figure clairement.

3 Le catalogue de 1741, après avoir établi le nombre et le contenu des lots de textiles, annonce ${ }^{2}$ : «marchandises prohibées qui ne seront vendues qu'à condition d'être envoyées à l'étranger. » Sont déclarées prohibées :

- les toiles de coton de couleur ou rayées, les salempores et guinées bleues, les neganepaux rouges et bleus, les bajupataux, bleus et blancs, les chazelas, bleus ou rouges et blancs, les guingans de Pondichery, de Karikal, de Madras et du Masulipatam et les mouchoirs de Pondichery.

- les textiles coton-soie mêlés : les tapchilas, les coupis, limaces ou limancais, tepays, alajas, chuquelas, nelis, sirsacas, pinasses, alibanees, caladaris, chalbafs, soucis, dissouchae.

- les soieries : les taffetas, darins, lampas, damas, pékins, gourgourans, patisoyes, satins, damas, lampas, jamawars, armoisins, mandarines, soieries de toutes sortes, unies, rayées à bouquets.

- les toiles peintes, chittes et autres ${ }^{3}$.

4 Cette liste est confirmée par les indications des commerçants voyageurs comme Legoux de Flaix, ou les ouvrages, les dictionnaires cités qui énumèrent et décrivent les tissus. 
5 Par ailleurs, une enquête a été effectuée sur les bulletins de vente de 12 années, qui entourent ou prolongent les données de $1741: 1716,1718,1723,1726,1728,1731,1741$, 1750, 1767 et 1768. Ces années-là, la mention « prohibé » a été notée, en marge du nom de l'étoffe. Comme les importations diffèrent d'une année sur l'autre, certes, tous les tissus prohibés n'apparaissent pas en même temps sur ces listes, de même que les étoffes rarement importées, non présentes ces années-là. Mais les données de ces bulletins de vente et d'adjudication confirment et complètent celles du catalogue de 1741.

6 Sont " marchandises prohibées ", ont écrit les scripteurs devant chacun des noms, et à chacune de ces dates:

- toutes les toiles peintes, chittes, couvertures de toiles peintes, tours de lit et chaperconnes, mouchoirs peints ; toutes les toiles de coton bleues, salempores, guinées, sanas, baffetas, garas et même "basins de couleur »; toutes les toiles de coton rayées ou à carreaux, bajupataux, nekanias, néganepaux, nankins, limaces, korottes, katequis, chazelas guingans, de Madras, de Pondichery, du Bengale, du Masulipatam, de Paliacate, parfois qualifiés de «balacor », parfois qualifiés " guingans d'herbe. »

- tous les tissus mêlés coton soie : alibannes, alajas, cotonis, fatoyes, nilae, sirsacas, sistrissoye, tepay, pinasses, dissouchae, chalbaf, caladaris, challies, coupis, ou coutis, tapchilas, kichorchay, chuquelas, fottes.

- toutes les soieries: damas, pékin, armoisin, gourgourans, satins, longuis, lampas, patissoye, taffetas, jamawars, étoffes dits "écorce d'arbre", darins, serge de soie, chaparoumas ou mouchoirs de taffetas de soie, les soucis (mousselines dans lesquelles la soie est mêlée au coton), les grisettes.

- le cas des mouchoirs est particulier. Les mouchoirs de Pondichery sont prohibés à chacune des dates; mais les mouchoirs d'autres provenances connaissent un statut différent qui reste sans explication : les mouchoirs du Bengale sont prohibés en 1716, 1718, 1723 ; du Masulipatam, en 1723; de Paliacate, rouge et blanc, en 1716. A la lecture de ces données, il semblerait que les mouchoirs, d'où qu'ils proviennent, ont été prohibés jusqu'en 1725 ; après cette date, seuls les mouchoirs de Pondichery restent interdits à la vente en France.

- certaines des étoffes, licites, deviennent même prohibées lorsque la soie y fait son apparition : quelques stinquerques brodés de soie, ou rayés de bleu et de rouge (rayures sans doute de fils de soie), une partie des broderies, (celles qui sont « brodées de soie ou à fleurs d'argent et d'or); des sanas (licites lorsqu'ils sont blancs) "brodés de soie mogue», des mallemolles (licites) mais brodées de soie, ont pu être importées à condition d'être vendues hors du royaume.

7 Certains tissus ont certainement échappé à ces documents. La prohibition a touché beaucoup de pièces dont il faut essayer d'établir le nombre et la valeur.

8 Le tri serait facile, si l'on n'avait pas quelques doutes sur le respect des textes installant et adoucissant la prohibition. L'interdiction concerne une période incluant l'année 1689, date de la mise en place de la prohibition, jusqu'à 1759 où elle s'adoucit.

9 En 1687 déjà, deux ans avant la décision de prohibition, une croix signalait, dans les documents de vente, les toiles bleues et les toiles peintes, mais pas les soieries ni les tissus coton soie. On suppose, sans en être certain, que cette croix, placée par le scripteur, était appliquée sur certaines étoffes qui étaient sur le point d'être prohibées.

10 En revanche, après l'adoucissement de la prohibition en 1759, dans les ventes de 1767 et 1768, les toiles blanches comme les salempores et autres sont suivies d'un f, France; 
tandis que sont déclarées "prohibées ", (le mot est inscrit en toutes lettres ou abrégé par un p.), les étoffes de soie, les nankins, les toiles de couleur et rayées, les chittes, ainsi que les soieries, les coton-soie et les toiles bleues rayées, etc., comme si l'adoucissement de la prohibition n'avait pas été totalement efficace. Les mouchoirs de Pondichery portent l'indication « prohibé » jusqu'en 1750.

\section{Quelle est la part, en nombre et en valeur, de ces tissus prohibés dans les cargaisons arrivées des Indes?}

11 On connaît l'identité des textiles prohibés et non prohibés, même si la mention "prohibé » a été omise dans beaucoup des affichettes et des catalogues de vente; on connaît les quantités et la valeur de tous les tissus : la richesse des documents permet donc d'estimer la part occupée par ces tissus dans l'ensemble des cargaisons de textiles venues d'Asie.

\section{En nombre}

Comptons donc comme prohibées toutes ou presque toutes les soieries, les toiles peintes, ou imprimées, les textiles coton-soie. Il est plus difficile d'estimer le caractère licite ou interdit des cotonnades. Parmi les toiles de coton, sont interdites à la vente dans le royaume les toiles de coton teintes ou à rayures, à carreaux, 757868 pièces sur les 3393753 de toiles de coton dénombrées plus haut, soit 22,3\% des cotonnades. Le cas des mouchoirs est plus compliqué. Souvent, les mouchoirs vendus sont simplement qualifiés de «mouchoirs" sans que le scripteur en ait indiqué l'origine. Nous avons détaillé par nous-mêmes l'origine de ces mouchoirs, et n'avons obtenu des renseignements sûrs qu'à partir de 1716. Aussi faut-il renoncer, jusqu'à 1716, à connaître l'origine géographique des mouchoirs et leur caractère licite ou prohibé. Or, dans les bulletins de vente ou d'adjudication, du moins jusqu'en 1723, figurent comme prohibés non seulement les mouchoirs de Pondichery mais également tous les autres, ceux du Bengale, Masulipatam, et de Paliacate. Legoux, à une date postérieure, considère encore les mouchoirs du Bengale et ceux de Paliacate comme des mouchoirs colorés à carreaux de diverses couleurs, "marchandises de traite ", destinées à l'Asie ou aux côtes de l'Afrique. Mais restons aux données sûres: près de 40000 mouchoirs prohibés de Pondichery. Auxquels il faut donc rajouter un «plus » non quantifiable de mouchoirs qui ne sont pas de Pondichery, et sembleraient bien avoir été, jusqu'à cette date de 1723, marchandises illicites, un peu moins de 50000 pièces.

Il est alors possible de présenter dans le tableau suivant une estimation établie sur des bases chiffrées du nombre des marchandises prohibées. La rigueur des chiffres gomme un peu le caractère estimatif du document. Espérons que d'autres données confirmeront plus tard ces hypothèses.

Tableau 6 : nombre des tissus prohibés dans les cargaisons

\begin{tabular}{|l|l|}
\hline Nature du textile & Nombre de pièces \\
\hline Toiles peintes & 151032 \\
\hline Tissus coton soie & 146684 \\
\hline
\end{tabular}




\begin{tabular}{|l|l|}
\hline Soieries & 99687 \\
\hline Mouchoirs & de 40000 à 90000 \\
\hline Toiles de coton teintes, à rayures etc. & 757868 \\
\hline Total des tissus prohibés & 1245271 \\
\hline
\end{tabular}

14 En nombre, ces tissus prohibés représentent de 1195271 à 1245271 de pièces (si l'on y englobe ces mouchoirs dont le caractère prohibé semble exister du moins jusqu'en 1723), sur les 6491205 pièces vendues, soit plus de $19 \%$ des cargaisons textiles, le cinquième, une proportion considérable.

\section{En valeur}

La valeur comparée des tissus importés, licites et prohibés, repose sur les données du tableau 10 de Wellington, enrichi par nos propres recherches.

De nouveau, Il faut noter qu'il est aisé d'observer la valeur des textiles prohibés qui ne sont pas des cotonnades. Il est plus difficile d'estimer le prix des toiles de coton prohibées et celle des toiles de coton autorisées à la vente dans le royaume.

17 La valeur totale des toiles de coton a été estimée à 15530494 livres. Mais les données sont parfois floues sur la qualité de toutes ces toiles, regroupées dans une même catégorie peu précise: "toiles diverses" ou "autres “ sur lesquelles on n'a pas de précision de nom; ou seulement qualifiées de "toiles abîmées", sans plus. Ces imprécisions concernent une somme de près de 2 millions de livres (1 959 683). C'est donc sur une valeur totale moindre (13 570811 livres) que l'on peut estimer la part des toiles de coton prohibées dans l'ensemble des importations de cotonnades: en valeur les toiles non prohibées représentent $86 \%$ de la valeur totale des cotonnades (11 675173 livres), les toiles de coton prohibées, 14 \% (1 895638 livres).

18 Les difficultés d'estimation ne peuvent être niées : ces calculs, qui s'étalent sur une longue période de plus de 80 ans, si précis soient-ils, sont établis sur des données qui ne recouvrent que huit années. De plus, les scripteurs ont parfois omis d'inscrire la valeur de certains de ces textiles prohibés. Enfin, une partie des basins ou percales sont soit blancs, licites, soit bleus, donc prohibés ; les scripteurs ne leur ayant attribué aucune valeur, ils seront donc ignorés des comptes, mais cette valeur existe, faible sans doute, qui devrait se rajouter à cette estimation.

19 Ces comptes débouchent cependant sur une estimation qu'il faudrait étayer par d'autres enquêtes : ces 3258968 livres de tissus prohibés représentent 13,5\% de la valeur totale des étoffes importées, 24581757 livres, (diminuée du prix des “cotonnades" diverses dont le nom n'a pas été précisé).

Tableau 7 : valeur des tissus prohibés dans les cargaisons.

\begin{tabular}{|l|l|}
\hline & Valeur en livres \\
\hline Tissus coton soie & 301973 \\
\hline
\end{tabular}




\begin{tabular}{|l|l|}
\hline Mouchoirs de Pondichery & 24627 \\
\hline "Mouchoirs" sans qualiicatif (jusqu'en 1725) & 355691 \\
\hline Soucis & 22751 \\
\hline Mousselines de soie & 25583 \\
\hline Soieries & 393145 \\
\hline Indiennes & 239560 \\
\hline Toiles de coton prohibées & 1895638 \\
\hline Valeur totale des tissus prohibés & 3258968 \\
\hline
\end{tabular}

La proportion en valeur des tissus prohibés dans la masse de tous les tissus importés ne semble donc pas égaler la proportion en nombre, d'après ces tableaux : elle est plus faible, $13,5 \%$ environ.

D'autres documents que les données du tableau 10 de Wellington permettent l'étude de la valeur proportionnelle des tissus prohibés dans les cargaisons. Etablis pour l'année $1758^{4}$, deux sources permettent d'estimer, sur cette année précise, la valeur comparée des prohibées (ici seulement marchandises de soie et cotonnades prohibées) et la part des marchandises "blanches" et des mouchoirs, tachés ou non tachés. Dans le premier de ces documents, la valeur des prohibées représente $17,2 \%$ de l'ensemble; dans le deuxième, $22 \%$; donc des chiffres un peu supérieurs à ceux que l'on a exposés cidessus, mais cohérents par rapport à eux.

Les étoffes prohibées représenteraient donc, en nombre, moins de $20 \%$ d'une cargaison et un peu moins en valeur. Ce «moins » ne peut dépendre qu'une différence de valeur entre les cotonnades licites et les cotonnades prohibées.

Quelques documents autorisent la comparaison de valeur des cotonnades licites ou destinées à être exportées.

\section{Valeur comparée des cotonnades licites et des cotonnades prohibées, réalisée à partir de deux petites enquêtes}

Une première enquête a été menée à partir des documents d'archives qui présentent à la fois le type du tissu, sa couleur, et son prix de vente.

En 1725 , le salempore blanc a été vendu entre 14 à 44 livres suivant sa qualité et sa taille; le salempore bleu: 18,5 .

En 1729, la guinée blanche, entre 28 et 77 livres; la bleue, de 16 à 17 livres. Le salempore blanc de 14 à 46, le salampore bleu de 14 à 16 .

En 1738, les baffetas blancs, de 10 à 25 livres, les baffetas bleus de 10 à 10,6; les garas blancs de 9 à 26, les garas bleus, 14,5; les guinées blanches de 27 à 129, les guinées bleues de 20 à 21 livres; les mouchoirs de Pondichery de 20 à 21 livres; les mouchoirs d'autres regions, non prohibés à cette date, de 20 à 60 ; les salempores blancs de 15 à 60 ; les salempores bleus, de 17 à 19 .

En 1739 , le salempore blanc de 15 à 60 , bleu de 17 à 19 ; le gara blanc de 9 à 26 , le bleu de 
14 à 15 ; la guinée blanche de 28 à 109 , la guinée bleue de 20 à 21 ; les mouchoirs de Pondichery de 20 à 22, ceux du Masulipatam de 25 à 31 .

En 1767, la guinée blanche valait 41,9 livres, la guinée bleue, 24,6; les mouchoirs de Pondichery, 14,5 livres; les autres mouchoirs de 25 à 86 ; mais une exception dans cette liste : les salempores blancs se sont vendus à 18 livres, les salempores bleus à 27 .

En 1768 , les guinées blanches sont à 26,7 livres; les guinées bleues, à 16 ; les mouchoirs de Pondichery à 9,5 ; les mouchoirs non prohibés de 17 à 75 ; nouvelle exception pour les salempores: les blancs à 18,3 , les bleus à 28 (on ignore la taille des pièces de salempores vendues ici; or l'aunage des salempores est très variable, de 12 à 30 aunes : ces salempores bleus peuvent être de grand aunage, 30 aunes).

Ces exceptions n'empêchent pas de constater que les mêmes toiles, suivant qu'elles sont blanches et non prohibées, ou bleues et prohibées n'ont pas été vendues au même prix ; et ne sont pas de la même qualité.

Une deuxième petite enquête a été réalisée sur la valeur moyenne des toiles de coton prohibées et non prohibées.

En 1725, la toile prohibée vaut à peu près 24 livres, la toile licite, 29 .

En 1739, le document très précis, donne des valeurs extrêmes de vente pour un certain nombre d'étoffes. On a réduit les écarts et calculé une moyenne, un "à peu près", "entre les deux". Les toiles prohibées (doutis, garas, guinées bleues, mouchoirs de Pondichery, salempores bleus, et divers guingans) valent en moyenne, 17 livres. Les toiles non prohibées, baftas, garas, sanas, salempores, mouchoirs divers, guinées blanches, socreton et percales) 32 livres et demie.

En 1767, la valeur moyenne d'une pièce prohibée est de 15,8 et de 37 livres pour les autres.

En 1768, la valeur moyenne de la pièce des cotonnades prohibées (bajupataux, fottes, guinées bleues, guingans de madras et de Pondichéry, korottes, limancas, mouchoirs de Pondichery, salamporis bleues et nankins verts) a atteint 13 livres; la valeur moyenne des toiles blanches licites, 34,5 livres (baffetas, basins, garas, guinées, hamans, mouchoirs divers, percales, salampouris blancs et sanas). On peut conclure que les toiles de coton prohibées ne sont certes pas sans valeur mais d'une valeur inférieure aux toiles de coton licites.

\section{Les pièces prohibées et la traite}

Une partie seulement de ces toiles prohibées est destinée au commerce de traite. La proportion en est difficile à évaluer.

\section{La traite et les marchandises dites de traite}

Le sujet de la traite a été maintes fois abordé. Bornons nous à citer les premières dispositions concernant «le commerce de Guinée ». Les Lettres patentes et arrêts du Conseil portant règlement pour la libre pratique du commerce de Guinée, janvier 1716 disent : " Article Premier : Nous avons permis \& permettons à tous les négociants de notre Royaume, de faire librement à l'avenir, le Commerce des Nègres, de la poudre d'or \& de toutes les autres marchandises qu'ils pourront tirer des côtes d'Afrique, depuis la rivière de Serre Lionne inclusivement, jusqu'au cap de Bonne Espérance. $»^{5}$ 

ainsi, en 1757, a été dressé l'état général de ce qui a été sauvé du vaisseau le Philippeaux et remis à terre à Sainte Marie : parmi les marchandises de traite : 1163 pièces de toile bleue, 29 de mouchoirs de compagnie des 16 à la pièce, une pièce de 15 en mouchoirs, 31 mouchoirs rouges dont deux percés, 10 pièces de latchasse (alaja ?), 16 de chittes de Goa, 39 de bafetas, 21 de fottes, quatre tapis de chitte et autres, miroirs, fusils de traite et fusils de soldat.... une partie de ces toiles : les salempouris bleus sont « prohibés et vendus aux négociants français et étrangers pour l'Afrique. »

goux de Flaix, grand observateur du commerce de la côte de Coromandel, a compris ces liens lorsqu'il écrit : "c'est l'établissement des colonies et la traite des nègres qui ont fait naître cette branche de commerce avec l'Indoustan » [... $]^{6}$

Margoline ${ }^{7}$ étend même, et sans doute de façon partiellement erronée, cette destination " coloniale » (Afrique et colonies) à l'ensemble des toiles : « Les cotonnades blanches de l'Inde et du Bengale sont certainement les textiles les plus importants dans les cargaisons. Leur commerce ne s'arrête pas à la consommation sur le vieux continent. Il est indéfectiblement lié au trafic de la traite négrière. »

B. Nicolas rappelle que «La compagnie perpétuelle des Indes établie en 1719 a reçu...le monopole de la traite des noirs...De 1719 à 1770 , elle arma...près de 160 expéditions de traite. Elle assuma la quasi-totalité de traite au Sénégal...Parallèlement, elle perçut des taxes pour chaque esclave introduit en Amérique. ${ }^{8}$ Elle décrit la mise en place de la prohibition et souligne à propos des textiles prohibés ${ }^{9}:$ «Ce sont ces mêmes étoffes que les armateurs négriers vinrent acheter à Lorient et cela jusqu'à la disparition de la Compagnie des Indes. Cela pouvait peut-être aller au-delà du simple achat. Il n'est pas impossible que certains armateurs passèrent directement commande de leur marchandise de traite à la Compagnie des Indes...L'analyse de plusieurs documents ne laisse aucun doute à ce sujet. Les inventaires des vaisseaux au départ de l'Inde mentionnent régulièrement la prise en charge de cauris ou de textiles prohibés " pour le compte et risque » d'armateurs privés. » Elle conclut son article en posant ainsi le problème : «Il conviendrait de chiffrer la part des recettes dégagées par la vente des textiles indiens destinées à la traite ou à l'habillement des esclaves. »

Le problème est difficile à résoudre: on a estimé, dans la partie précédente, la proportion d'étoffes prohibées d'une cargaison qui échapperont, en principe, au marché français: elle atteindrait, en valeur et en nombre, un pourcentage non négligeable (15... $20 \%$ ?). Une partie s'en ira alimenter le commerce de traite : combien ? Pour une fois, la tentative de réponse ne pourra qu'échapper à la précision extrême des chiffres, tableaux, courbes et statistiques. Mais quelques conclusions sont sûres.

La part des textiles dans les cargaisons négrières est prédominante, et plus particulièrement des textiles indiens, affirment les historiens.

Mehdi $Z_{\text {muda }}{ }^{10}$ estime à $41 \%$ la proportion des tissus et à $23 \%$ celle des cauris dans marchandises embarquées sur le baron de Binder, en 1789. Liliane Crété ${ }^{11}$ estime que la part des tissus se situe entre 50 et $70 \%$ d'une cargaison. Pour P. Villiers et J.P. Duteil ${ }^{12}$ : «Les textiles comportent jusqu'à $50 \%$ de la cargaison. Les pièces de laine et de soie ne sont jamais absentes mais les indiennes sont les plus appréciées. Les compagnies indiennes vont trouver un grand débouché dans le commerce négrier, puis, à partir du 
milieu du siècle, les Européens surpassent à prix égal les produits indiens. » Fascinés par les « indiennes ", les auteurs ont oublié ou sous-estimé la part des tissus coton soie et des cotonnades peintes. Faut-il prendre «indiennes" dans son sens large, étoffes indiennes, et non pas chittes? Jean Tarrade ${ }^{13}$ souligne la diversité des cargaisons négrières, suivant qu'elles sont destinées directement aux Antilles ou à la côte africaine. "Dans les expéditions de traite à la côte de Guinée, les exportations sont naturellement d'un type différent: l'armateur doit assurer le ravitaillement de l'équipage... prévoir la nourriture des esclaves pendant la traversée d'Afrique en Amérique et surtout charger les marchandises de troc avec les courtiers indigènes et les roitelets noirs de côtes africaines. » En 1775, la cargaison se compose ainsi : «11,5\% pour le ravitaillement, $88,9 \%$ pour les articles de traite, dont $47,6 \%$ pour les toiles, et $8,85 \%$ pour les cauris...En $1788,12,4 \%$ pour le ravitaillement, $87,6 \%$ pour les articles de traite (dont 50,23\% pour les toiles, 2,47 pour les mouchoirs, 3,38 pour les cauris).» L'auteur insiste sur la première place occupée par les articles textiles, dont la variété est moins grande que pour les voyages en droiture (dirigés vers les colonies des Antilles) car « les exigences africaines quoique très précises sont moins diversifiées que celles des colons...»

Prédominance de textiles donc, en particulier de textiles indiens. J. Tarrade conclut à la "prédominance écrasante des toiles principalement les toiles des Indes... Les exportations pour le commerce de la traite...Les principaux articles de traite ont une origine extramétropolitaine. Les uns proviennent de l'océan indien comme les cauris ou la majeure partie des textiles... En note «les états de 1775 distinguent les toiles des Indes pour $68,99 \%$ des toiles exportées, tandis que ceux de 1788 regroupent les toiles étrangères et des Indes..pour 79,8\%. ». B. Nicolas ${ }^{14}$ évoque un document concernant Nicolas Lambert, commis de traite principal sur le fleuve Sénégal pour le compte de la Compagnie des Indes en $1721-23^{15}$ :

«En quantité, les toiles indiennes dépassent de loin les textiles français ... et, citant le commis Nicolas Lambert : « Sur 1507 aunes de tissu nécessaires pour le paiement de la coutume, (1790 mètres) : 1078 (1280 m) sont des «toiles bleues », 400 aunes (475 m) sont des toiles de Rouen...Ces toiles... étant envoyées comme toiles de l'Inde, elles coûtent plus cher. Les armateurs n'en prennent même dans leurs cargaisons qu'autant qu'ils n'en trouvent point assez de l'Inde pour compléter leur assortiment... »

Enfin, A. Kouame ${ }^{16}$, dans sa thèse sur les cargaisons négrières estime à 70 à 78 \% la part des textiles dans les cargaisons de traite dont les trois quarts des Indes Orientales.

Les proportions varient, en fonction des années sans doute et d'autres facteurs ignorés : elles sont toujours fortes cependant, plus de $50 \%$ dans la plupart des cas.

\section{Quels textiles ramenés des Indes dans les vaisseaux de la Compagnie sont-ils susceptibles de remplir en partie les cargaisons négrières?}

Les textiles prohibés certes. Tous? Certainement pas. Il sera toujours difficile d'estimer avec précision la part de la cargaison indienne qui va prendre le chemin de l'Afrique. On voit les tissus partir, mais, à l'arrivée, en Afrique, dans les Antilles, où sont-ils ? Des représentations de costumes portés en Afrique pourraient aider, mais elles sont rares, éparpillées dans une bibliographie dispersée. 
41 Nous avons essayé de retrouver, à travers les costumes présentés dans le deuxième volume des Esquisses sénégalaises de l'Abbé P.-D.Boilat, des traces de ces tissus peut-être d'origine indienne dans les costumes portés par plusieurs ethnies. ${ }^{17}$

Les toiles de coton "prohibées » figurent toutes dans les cargaisons négrières décrites. Il est inutile d'énumérer chaque nom de ces "toiles de coton des Indes de toute couleurs. $\rrbracket^{18}$ Ces toiles ont été nommées et décrites plus haut. Les "guinées bleues forment dans la longue durée une des bases de la cargaison » affirme Daget cité par Kouamé $^{19}$. Daget poursuit : les guingans le sont moins. »Cependant, dans le repertoire des tissus de 1788 conservé aux Arts Décoratifs, un scripteur a écrit, sous un échantillon de guingan : « les guingans s'envoient aux Isles pour faire des chemises aux nègres. Les armateurs en envoient même souvent des chemises toutes faites.» Et, sous le nom guinée, il a été décrit :

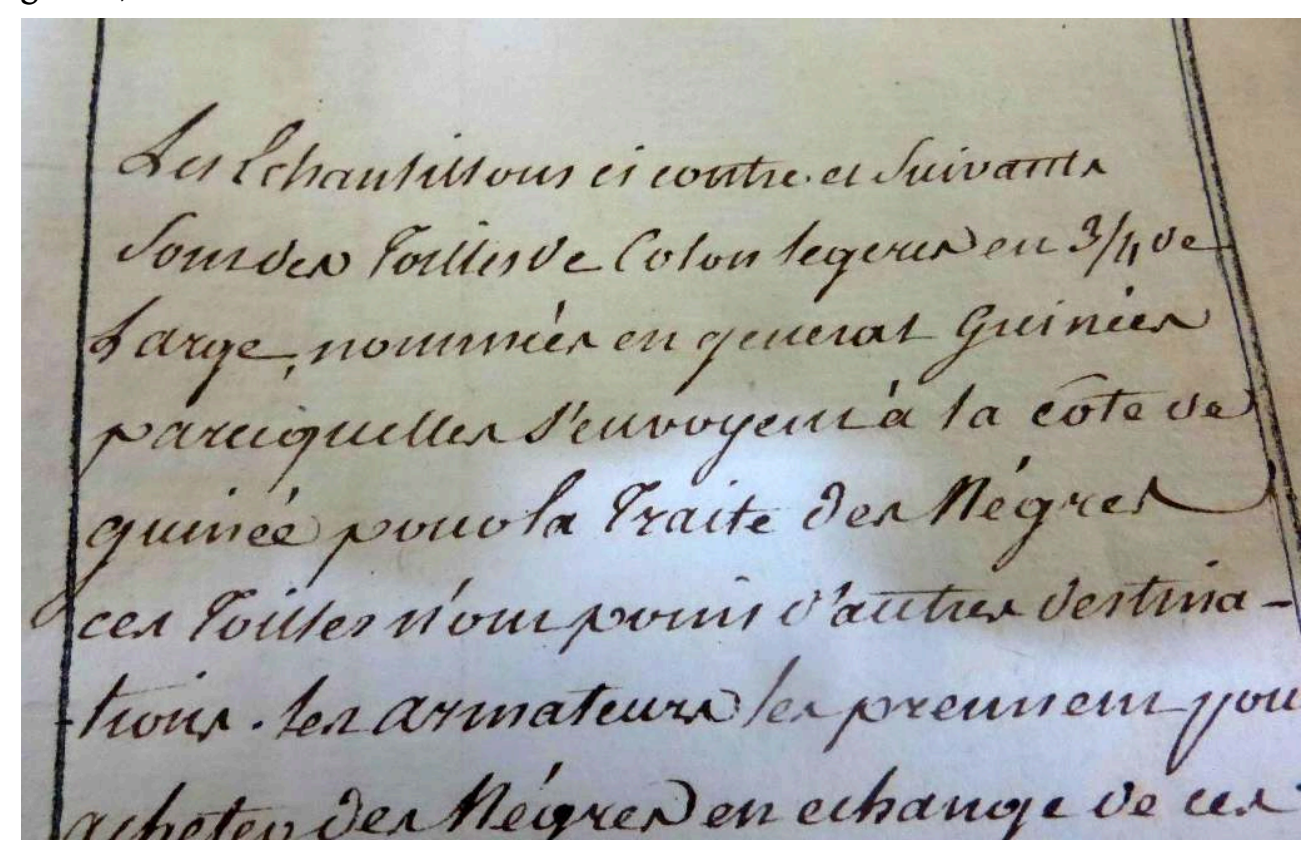

Nos données sur les textiles prohibés en général, sur la longue durée aussi, placent en tête les 180000 guingans, les 112384 guinées, les 101085 salempores.

L'Abbé Boilat écrit:

«tous les personnages maures que j'ai représentés à l'exception du prince Baba (planche 11), sont habillés de bleu; les Maures ne connaissent pas d'autres vêtements que la guinée bleue de l'Inde qu'ils achètent à nos escales pour de la gomme du désert. Cette étoffe est très légère et convient parfaitement pour voyager dans ces climats. $\|^{20}$

En effet, le bleu est plus ou moins présent sur les 24 planches représentant les costumes. Notons également que les rayures apparaissent souvent sur les vêtements, sans que l'on puisse savoir s'il s'agit de toiles rayées de coton ou de toiles rayées cotonsoie. 
Une photo Planche 2, p. 7 homme sérère de Mbissel au royaume de Sine, un tisserand

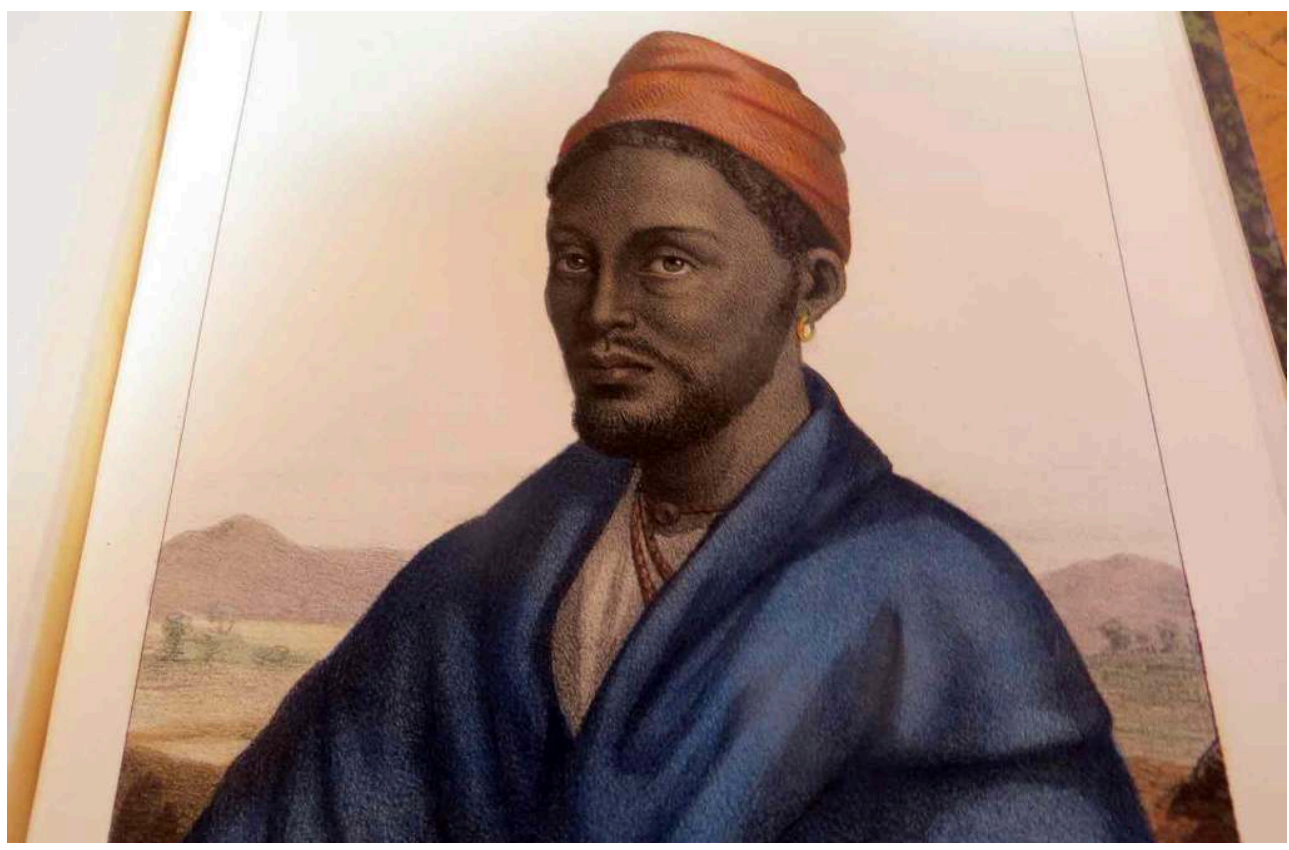

Une photo Planche 9, p. 16, femme wolofe portant son enfant sur le dos

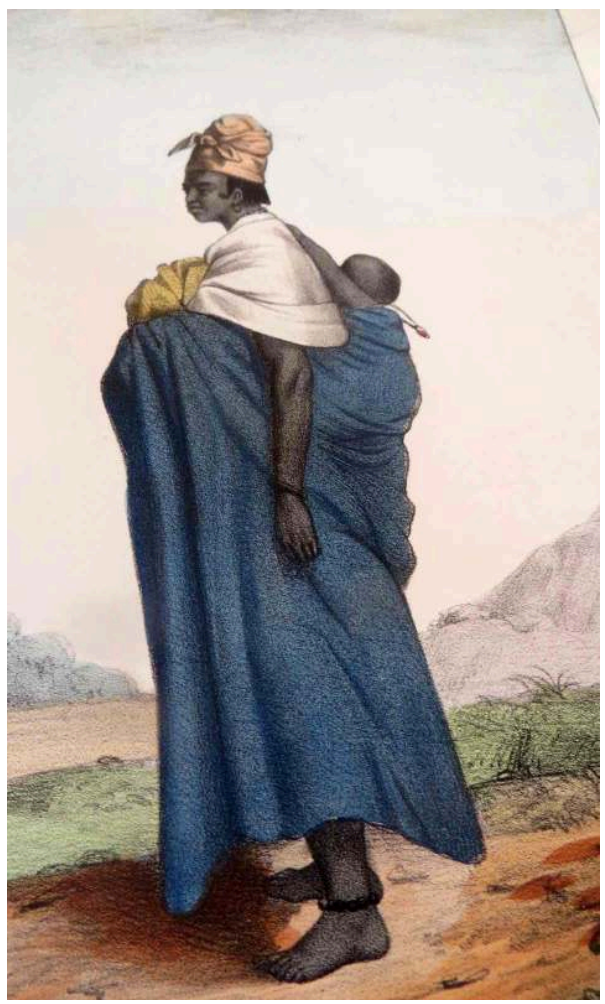

- Les soieries ? On imagine mal la totalité des onéreuses soieries partir vers l'Afrique. Cependant, A. Kouamé, dans sa thèse ${ }^{21}$ cite Nicolas Lodjou Gaybor ${ }^{22}$ : «les soieries, les velours, les damas et les satins rayés à grandes fleurs et aux couleurs vives sont des articles préférés et destinés aux nobles, aux hauts dignitaires et aux rois. " Il cite également Römer $^{23}$ : «Le roi des Ashanti «Opccu» ...encourage le tissage dans son royaume, fait acheter du taffetas de soie, des tissus rouges, bleus et verts, plusieurs 
milliers d'aunes de fils de laine et de soie. Les tisserands les effilent et les retissent avec le coton local et écharpes très colorées, blanc, bleu et rouge...; de la soie est commandée à Tours dans des couleurs éclatantes...la soie est utilisée par les noirs pour faire des pagnes.»

47 Dans plusieurs cargaisons de traite a été relevée la présence de soieries: A. Kouamé y trouve des «taffetas rayés ${ }^{24}$; des "soieries » sans plus en 1782,1783 et $1784^{25}$; des " photes de soie ${ }^{26}$ des « étoffes de soie », en valeur 97156 livres, entre 1728 et $1753^{27}$; des « damas cramoisis à fleurs. $»^{28}$

Dans les Esquisses sénégalaises ${ }^{29}$ sur la planche 24 est représentée une femme Bambara, en « tenue de fête » qui porte un « mboube en soie » à rayures bleu et marron.

Une Photo Planche 24 et p. 31 femme Bambara «tenue de fête » (Abbé Boillat, op. cit., p. 28.)

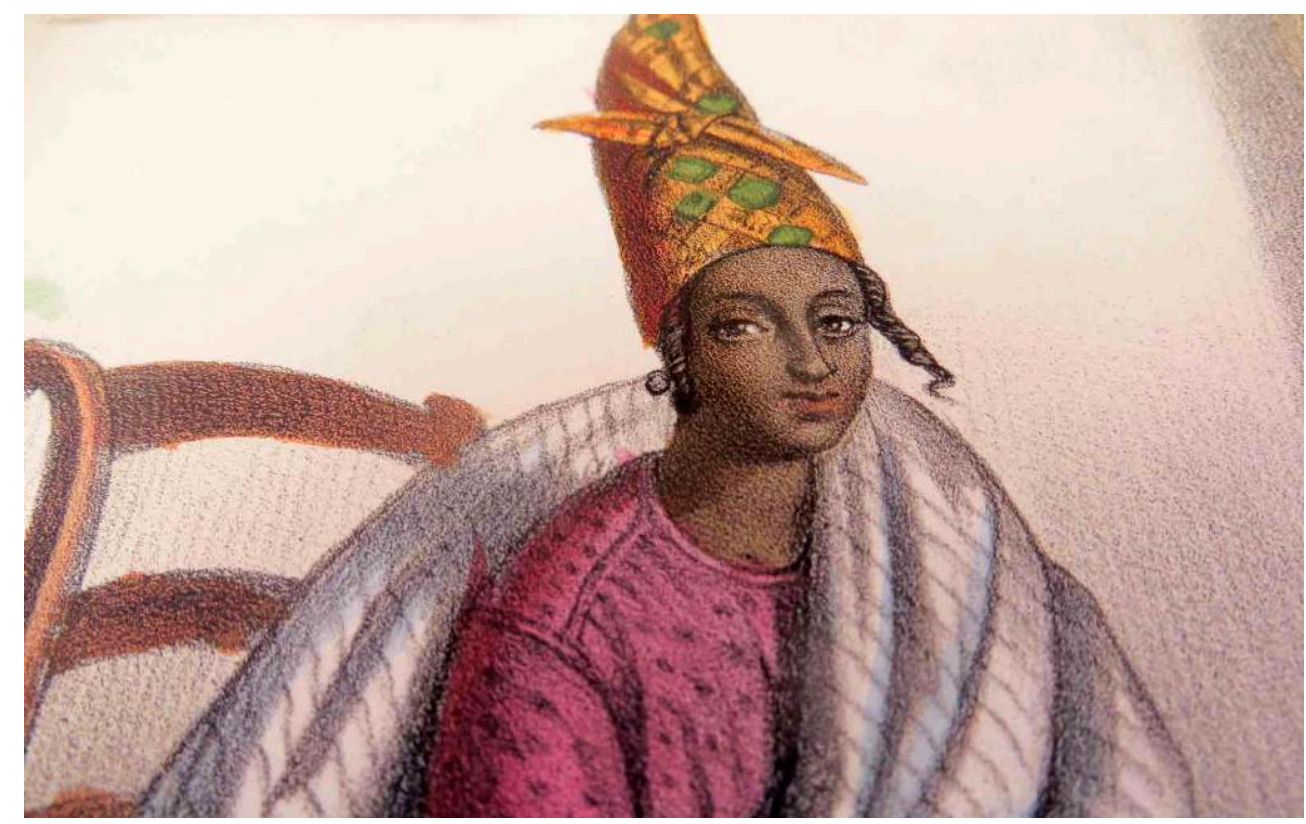


Un homme (planche 21) de type sarackoullé, porte une choussabe à grandes manches teint en indigo du Ngalam, dont le « devant de la poitrine et dos sont brodés en soie de couleur

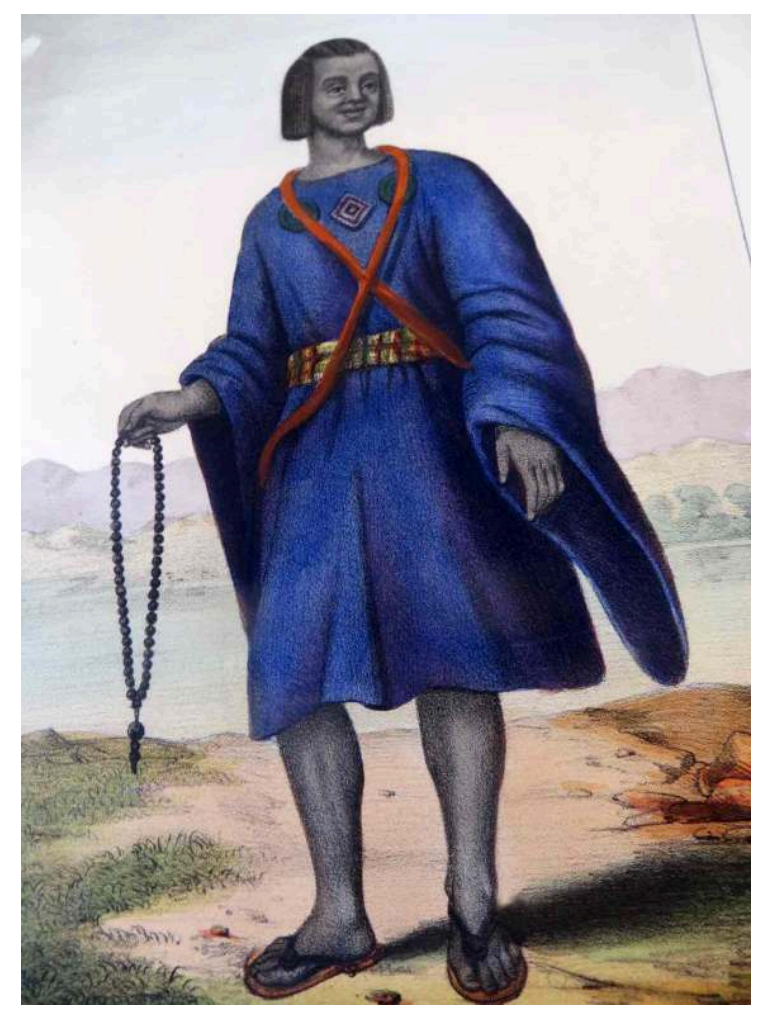

La planche 4 reproduit le « Marosso ou mari de la reine du Walo, premier général, en tenue de réception, type wolof, jupe bleue avec rayures en bas, le haut rose semble soyeux »

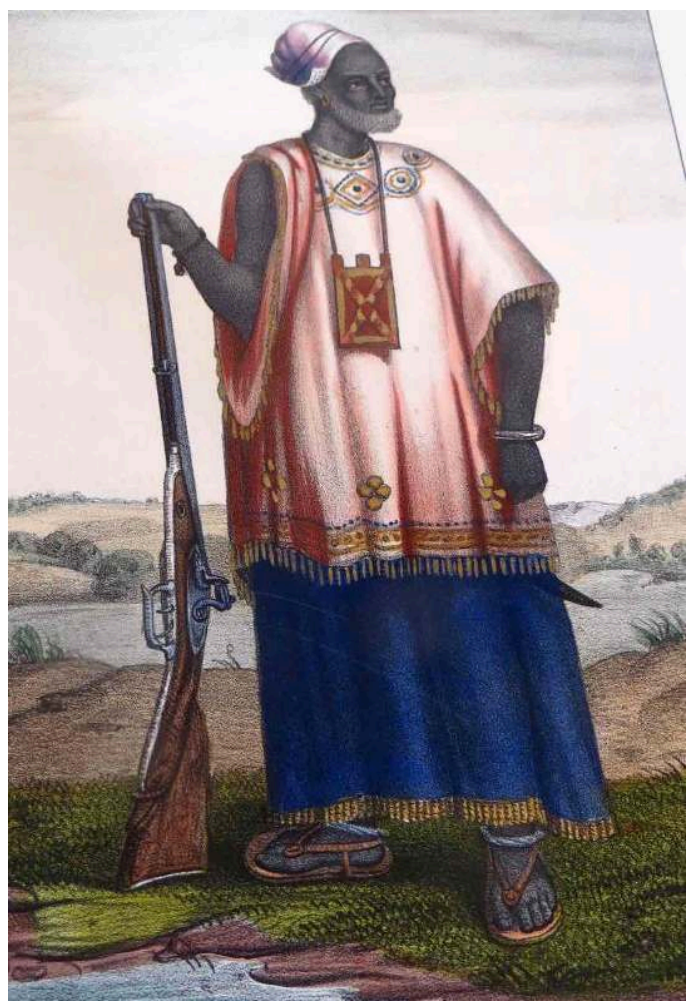


On peut donc estimer qu'une au moins, des étoffes de soie chargées en Inde, a pu être exportée en Afrique ou dans les colonies d'Amérique. Bien d'autres soieries pouvaient provenir de pays européens ; mais là n'est pas notre sujet.

- Les indiennes? B. Nicolas, évoque la question. Elle constate ${ }^{30}$, dans un document consacré à Nicolas Lambert, un commis de traite principal sur le fleuve Sénégal pour le compte de la Compagnie des Indes en $172123^{31}$ que «les indiennes faisaient figure d'exception... marchandises écoulées avec parcimonie aux plus hauts dignitaires africains. » Rares peut-être, mais présentes. B. Nicolas observe une gravure, qui montre "les populations vêtues d'étoffes généralement unies ou à carreaux", mais aussi (exceptionnellement) à motifs floraux suggérant un chitte. ${ }^{32}$ Plusieurs éléments laisseraient penser que les indiennes parvenaient cependant sur le marché africain. Les "indiennes", très peu nombreuses dans les cargaisons arrivant dans le royaume, semblent cependant présentes dans les cargaisons négrières, sans que l'on puisse en établir nombre, ni proportion, ni parfois l'origine (française ou indienne). Daget ${ }^{33}$ signale l'existence d'indiennes, de provenance indienne mais également de production française. Kouamés ${ }^{34}$, évoque des «toiles peintes » en 1716 ; des «indiennes » qui font partie de la cargaison de 0 . Luzitano, en 1782; ou d'indiennes, de calancas ou demi calancas (qalamkar, toiles peintes), mais de fabrication française pour les années 1721, 1730. Les indiennes qui apparaissent dans les cargaisons ne sont donc pas toutes d'origine indienne, mais leur présence atteste d'une demande qui existe en Afrique et dans les colonies. Pour Eugénie Margoline ${ }^{35}$,

"Le commerce négrier est d'ailleurs un débouché inespéré pour les toiles peintes des Indes que les Nantais achètent en grande quantité (nous n'en sommes pas sûrs, quant à nous) et dont la prohibition interdit la consommation sur le territoire... «Les marchands français utilisent les importations étrangères pour s'approvisionner en indiennes, nécessaires au commerce de la traite des Noirs. Les précautions prises pour contrôler les entrées ne sont pas toujours suffisantes et il se commet de nombreux abus sous prétexte de ce commerce. La contrebande qui en découle est d'ailleurs rapidement identifiée. Le roi interdit alors : [...] de faire venir de Hollande ou autre pays du Nord dans le royaume, [...] même sous prétexte d'entrepôt, aucune toiles blanches des Indes, caladaris, toiles peintes aux Indes appelées chites, ou étoffes de pure soie et mêlées de soie, à peine de confiscation desdites marchandises et de trois mille livres d'amende. Or, la règlementation a de nombreuses fois été bafouée.»

51 La demande des marchands français, l'obstination des fabricants d' "indiennage " bravant les interdictions, prouveraient qu'en Afrique et dans les colonies, la demande d'indiennes existait bel et bien. Et que les rares indiennes qui parviennent des Indes dans les ports français sont peut-être en partie embarquées dans les cargaisons de traite.

Les textiles coton soie, introduits, en petite quantité, depuis la prohibition, font également partie des tissus qui trouvent un marché en Afrique ou aux Antilles. Daget cite les caladaris, les boclans ; Kouamés ${ }^{36}$, les caladaris (p. 36 et 451), et évoque des tissus de couleur que les tisserands effilent et retissent avec le coton local en écharpes très colorées, les alajas (p. 396), les coupis (et coutis p. 418, 452, de « couleur vive » p. 477), les alibanis (p. 450 et 460), les chilas (p.452), chalbafs, tepoys, dissouchae, soucis (p.533). Concluons: une grande partie des textiles prohibés d'origine indienne (les toiles de coton peintes, les indiennes, peut-être, les toiles de coton teintes, les toiles de coton rayées ou à carreaux, les toiles de coton soie mélangés, et même quelques soieries) part vers l'Afrique ou les Antilles. La proportion de ces réexpéditions dépend certainement 
de la date des envois, du lieu auquel ils sont destinés et même des variations de la demande africaine. Le "profil type " des cargaisons pouvait en effet légèrement se modifier.

Il faut y ajouter quelques pièces non prohibées. Dans plusieurs cargaisons parties de Lorient pour le commerce de Guinée de 1783 à 1787, constate Kouamé, ${ }^{37}$ se trouvent également des toiles non prohibées qui trouvent preneur sur le marché africain: quelques mousselines, des bétilles, des «toiles blanches » pour Jules Sottas ${ }^{38}$, des garas blancs, des guinées blanches pour Daget ${ }^{39}$. E. Margoline ${ }^{40}$ expose que, "d'après le registre de Nantes, les négociants expédient $11 \%$ de leurs toiles blanches vers les îles d'Amérique, la Martinique, Saint-Domingue, ou bien ils les réemploient dans le commerce de la traite des Noirs. » Enfin, Catherine Coquery-Vidrovitch ${ }^{41}$ cite les guinées blanches, et les salampouris blancs, parmi les marchandises que l'on échange par tête de captifs.

Ajoutons à ces toiles blanches des mouchoirs Burgos, cités par Daget ${ }^{42}$ et Kouamét3 (qui paraissent n'être prohibés que dans le premier quart du XVIIIème siècle). Legoux les identifie aux mouchoirs du Bengale ${ }^{44}$ : "Cet article, dit-il, ne parait dans nos exportations que depuis environ 70 à 80 années...des mouchoirs bleus à l'imitation des mouchoirs rouges qui se font à Paliacate... Les mouchoirs de Burgos sont un article important de nos exportations, soit pour l'Europe, soit pour les différentes régions d'Asie, soit enfin pour les diverses échelles des côtes d'Afrique.» Il cite aussi les mouchoirs de Paliacate, particulièrement exportés dans les colonies du Nouveau Monde : « depuis la créole européenne jusqu'à la plus chétive esclave négresse,...toutes aiment à se parer la tête d'un mouchoir de Paliacate " et: " les nègres de ce pays s'attachent plus à l'éclat et au brillant de la couleur qu'à la grande finesse du tissu...Les mouchoirs de Paliacate...se payent, dans les Antilles et les autres colonies, des prix exorbitants, jusqu'à deux louis le mouchoir...Les bénéfices sont près de $300 \%$. $»^{45} \mathrm{Il}$ est donc bien possible que d'autres mouchoirs embarqués dans les cargaisons de la traite soient également non pas des mouchoirs de Pondichéry, prohibés, mais des mouchoirs du Bengale, de Paliacate, non prohibés au moins à partir des années 1725.

On peut tenter alors de répondre à la question posée par B. Nicolas ${ }^{46}:$ «Il conviendrait de chiffrer la part des recettes dégagées par la vente des textiles indiens destinées à la traite ou à l'habillement des esclaves. » Nous ne proposerons que des estimations. De 1687 à 1769, la part en nombre et la valeur des tissus prohibés arrivés d'Inde dans des ports français aurait atteint une proportion variant entre 15 et $20 \%$ de toutes les étoffes importées d'Inde. ${ }^{47}$ Certes, quelques une de ces toiles ne partiront pas en Afrique. Il est difficile d'en estimer la proportion. Gageons cependant que la part essentielle fait partie du commerce de traite. Il faut par ailleurs rajouter à ces textiles prohibés certaines toiles de coton blanches non prohibées et les mouchoirs de Burgos: on peut estimer que le sixième, le cinquième, des tissus chargés dans les cargaisons indiennes part en Afrique.

57 (À ces cargaisons de textiles s'ajoutent d'ailleurs d'autres biens asiatiques, les cauris, apportés en Afrique, $2,4 \%$ de la valeur des cargaisons ${ }^{48}$ entre 1687 et 1768 : et la proportion de biens d'origine asiatique qui prennent le chemin de l'Afrique s'en trouve encore augmentée). 


\section{L'échange, l'amorce d'un commerce quadrangulaire}

58 Ces biens seront échangés contre des hommes noirs ou femmes et enfants; qui de là, gagneront les Antilles et l'Amérique, dont les vaisseaux ramèneront sucre, coton, etc. Mais ceci est une autre histoire, que nous ne traiterons pas, sauf à donner quelques exemples des modalités de l'échange.

«On étale l'essentiel de l'assortiment sur le gaillard d'arrière. Les courtiers, intermédiaires ou acheteurs l'examinent. On reçoit des chefs locaux, invités à dîner, et parfois à des beuveries. On établit les conditions de la troque, et d'abord les coutumes ou taxes d'ancrage et de commerce, puis la valeur de base d'un captif en monnaie de compte locale, la barre, le paquet; l'once de traite, la pièce, parfois le pagne. Ce n'est que par conversion et référence à la facture de l'armateur que le négrier blanc peut estimer la valeur en monnaie des captifs qu'il troquera contre ses marchandises: pour les négriers noirs, se faire payer un individu mâle ou femelle 4 livres sterling, 20 dollars, 20 piastres, ou 100 livres tournois, ce qui est à peu près la même somme, cela n'a aucun sens... À terre, les préliminaires sont les mêmes sauf que la marchandises inerte, conduite en pirogue à la plage, étalée aux regards de l'éventuel acquéreur, sera rangée le soir, ou conservée sous garde armée. Les pirogues livreront la marchandise humaine... (S. Daget ${ }^{49}$ )

Il s'agit bien d'un échange, et non d'une vente : les termes en varient selon les années, et selon les lieux, tous les spécialistes de la traite le signalent, dont E. Margoline ${ }^{50}$.

Ne donnons qu'un seul exemple, exposé par Catherine Coquery-Vidrovitch ${ }^{51}$, qui cite W. Boman $^{52}$ :

«Les gens de Juda (au Dahomey) s'attachent si fort au négoce d'esclaves qu'ils peuvent en fournir mille tous les mois...Quand les esclaves sont arrivés à Fida (Juda), on les met tous ensemble dans une prison et, lorsque nous voulons les acheter, on nous les amène dans une grande place où, après qu'ils ont été mis tout nus sans distinction de sexe, ils sont visités jusqu'au moindre de leur membre par nos chirurgiens. On met à part tous ceux qui ont été trouvés en bon état, et, pour ceux à qui il manque quelque chose, ils sont mis parmi les impotents... ceux qui ont plus de 35 ans, ceux qui sont estropiés aux bras ou aux jambes, ceux qui ont perdu une dent, ou qui ont des taies sur les yeux ou qui ont une maladie honteuse.

Cependant, il y a au feu un fer avec les armes ou le nom de la Compagnie, et on applique ce fer chaud sur la poitrine de ceux que l'on a choisis. Nous ne sommes pas longtemps à faire le marché de ces esclaves, le prix en est réglé, et les femmes valent le quart ou le cinquième moins que les hommes.

On remet ensuite les esclaves dans la prison où ils vivent à nus à nos dépens; du pain et de l'eau...Pour éviter la dépense, nous les envoyons à la première occasion à bord de nos vaisseaux...Ils entrent dans les vaisseaux tout nus...il y en a quelquefois six à sept cents dans un navire... »

61 Le même auteur, après s'être penchée sur les conditions de l'échange, en détaille les termes, s'appuyant sur un récit de voyage. ${ }^{53}$ Nous ne reprendrons de ses citations que la valeur de l'échange en tissus, dans les années 1725-27.

«Prix des captifs

Quantité de marchandises que l'on donne par tête de captif

Pour un homme : chittes de Pondichery, 10 à 12 pièces, ou 12 pièces de guinées bleues pour un homme, 10 pour une femme; ou 16 pièces de tapsels, pour un homme, 10 pour une femme "...Sont aussi cités les salempores blancs et bleus, les guinées blanches, les nicanées, les bastas, les limineas, les mouchoirs de Pondichery, mais sans référence au nombre de pièces pour un homme ou pour une femme». 
En 1726, les guinées bleues s'étaient vendues de 35 à 36 livres; l'esclave aurait alors « valu » de 350 à 420 livres. En 1721 les chittes de Pondichery, ont été vendues 60 livres, et la valeur de l'esclave pourrait être estimée de 600 à 720 livres.

Les valeurs présentées ici sont cohérentes par rapport à d'autres données. Nous n'en donnerons que quelques exemples. Pour Serge Daget ${ }^{54}$ : pour des " pièces d'Inde, audessus de 14 ans (ou de 18 à 30 ans), mesurant 1,80 mètres, sans aucune tare physique apparente ou décelable des dents au rectum, des testicules à la salive, du vagin aux seins ", à Whydah, un noir de sexe masculin a été échangé contre une valeur de 264 livres tournois, une captive, 192, en 1724 ; en1712 sur la cote de l'or, de 384 à 410 livres.

Eugénie Margoline ${ }^{55}$ met en rapport directement le nombre de pièces vendues et le nombre de noirs espérés. Elle cite Armel de Wismes ${ }^{56}$ qui parle de 800 pièces d'étoffes pour traiter environ 300 Noirs ; soit moins de trois pièces pour un noir. Elle ajoute : « il en faut certainement un peu plus »; et se réfère à la cargaison du navire la Musette, en 1786, pour la Côte de l'Or en Guinée qui comprend plus de 1800 pièces d'étoffes et de toiles pour traiter 350 à 400 Noirs, plus de quatre pièces. ${ }^{57}$ Henry-René d'Allemagne ${ }^{58}$ précise qu'il faut environ 9.400 pièces pour acquérir 600 Noirs de la côte d'Angole, ce qui représente $63 \%$ de la valeur de la cargaison ; 16 pièces pour un noir.

Mehdi Zmuda ${ }^{59}$, en 1775, à Juda : un homme 440 livres, une femme 320 ; en Guinée, 1777, un homme 278 livres ; citant le baron de Binder, en 1789: 707 livres ; ou encore 440 livres, pour une femme, de 32 à 360 ; sur la côte d'Angole, 387 livres.

Selon Pierre Pluchon ${ }^{60}$, les prix ont augmenté de la première moitié XVIIIème, 100 livres ; à la fin de l'Ancien Régime, 600. De 1738 à 1789, sur 29 navires, la valeur d'un esclave a oscillé de 251 à 707 livres.

7 Ces échanges ont concerné beaucoup de monde : les négriers français ont déporté en Amérique, au sens large, plus d'un million d'Africains constate S. Daget. Et B. Nicolas ${ }^{61}$ : «La compagnie perpétuelle des Indes établie... arma...près de 160 expéditions de traite...La compagnie trouva dans le commerce avec l'Afrique...celui de la traite humaine avec son extension en Amérique l'extraordinaire opportunité de résoudre les contradictions de la politique mercantiliste. En absorbant les textiles prohibés indiens... la traite africaine permit l'improbable équation qui consistait...à maintenir l'équilibre financier de la Compagnie en lui permettant de continuer à importer les textiles indiens et à protéger d'autre part l'industrie textile française. »

Inde asiatique, Europe, Afrique, Amérique, ce commerce, exercé pendant plus de deux siècles, a été nommé «commerce triangulaire». En réalité, "c'est bien quatre continents qui furent impliqués dans la traite de l'esclave africain. » ${ }^{62} \mathrm{Ce}$ commerce « quadrangulaire » relie quatre continents, intégrés dans des échanges mondiaux.

\section{Le profit de l'opération}

Il doit être possible, mais ceci est aussi une autre et longue histoire, d'évaluer le profit de l'opération.

Deux documents, en 1767 et 1768, signalent, pour chaque tissu importé, le prix d'achat et le prix de vente. En 1767, le bénéfice aurait été de $77 \%$, différence entre le prix de vente et le prix d'achat pour une cinquantaine de tissus autorisés et prohibés. Les étoffes autorisées rapportent plus que les tissus prohibés ( $80 \%$ en moyenne... $90 \%$ pour les seules mousselines). Pour les tissus prohibés, le bénéfice est plus mince, $50 \%$. En 
1768 , le bénéfice réalisé sur l'ensemble des textiles a légèrement baissé, 69,6\%. Comme l'année précédente, les tissus autorisés ont plus rapporté $(77,5 \%)$ que les tissus prohibés $(28 \%)$. Les mousselines arrivent encore en tête du profit, $90 \%$.

71 Mais l'histoire de ces tissus prohibés, (de moindre profit au moment de leur vente en France ?) va très loin au-delà des frontières du royaume: les tissus sont échangés contre des esclaves, qui seront échangés, eux et leur travail, contre le sucre, le café et autres denrées coloniales. Histoire économique difficile à quantifier, mais dont le déroulement, dans une grande partie de l'Europe et de l'Amérique, a abouti à asseoir la prédominance durable de nos contrées de l'ouest.

\section{NOTES}

1. E. Margoline-Plot, dans sa thèse, page 56 et suivantes, résument les décisions de prohibition, les explique, et en suit le déroulement.

2. Vente des marchandises des Indes, p. 174.

3. Une description de ces tissus prohibés, et parfois une illustration seront données dans la partie suivante.

4. IP262/45/9 et IP 262/45/10.

5. Cité par Margoline-Plot E., thèse, p. 98.

6. Legoux. op. cit., p. 134-135.

7. Margoline-Plot E., thèse, p. 45.

8. Nicolas B. Lorient, la Bretagne, et la traite, 2006, p.97.

9. Nicolas B. Lorient, la Bretagne, et la traite, 2006, p.101.

10. Mehdi Zmuda, Saint Malo port négrier? XVIIème-XVIIIème siècle, Phenix editions, 2004, p. 115.

11. Crété $\mathrm{L}$. La traite des nègres sous l'ancien régime, Perrin, Paris, 1989.

12. Villiers P. Duteil J.P : l'Europe, la mer et les colonies XVIIème XVIIIéme Hachette, 1997, p. 168.

13. Tarrade J. Le commerce colonial de la France à la fin de l'ancien régime, PUF, t. 1, 1972 p. 122-126.

14. Nicolas B. Lorient, la Bretagne ..., p. 102 sq.

15. SHD Lorient 1P274 liasse 1.

16. Aka Kouamé, 2005, Les cargaisons de traite nantaise, p. 393sq.

17. Abbé P.-D.Boilat, Bertrand Paris, 1853 Esquisses sénégalaises.

18. Kouamé, op. cit., p. 361.

19. Kouamé, op. cit., p. 36.

20. Abbé Boilat, op. cit., Observations sur les planches de XI à XVI, p. 24.

21. Kouamé, op. cit., p. 386..

22. Nicolas Lodjou Gaybor, Africains et Européens dans le golfe de Guinée, p. 85.

23. Römer L.F, Le Golfe de guinée, 1700-1750, Traduction, introduction et notes par Mette Dige, Hess, Paris, l'Harmattan, 1989, p.145.

24. Kouamé, op. cit. é, 361.

25. Kouamé, op. cit., 364.

26. Kouamé, op. cit. p.436.

27. Kouamé, op. cit. p.452.

28. Kouamé, op. cit. p. 297.

29. Abbé Boilat, op. cit., p. 31. 
30. Nicolas B. Lorient, la Bretagne, op. cit., p. 107 sq.

31. SHD Lorient 1P274 liasse 1.

32. Nicolas B. Lorient, la Bretagne, op. cit., p.108.

33. Daget, la traite des noirs, Ouest France, 1990, op. cit., p.89.

34. Kouamé, thèse, op. cit., p. 361-364.

35. Margoline-Plot E., Les pacotilles d'indiennes, la boutique et la mer, 2014, p. 91, 123.

36. Kouamé, op. cit., p. 36, p. 396, 418, 451, 452, 477, 450, 460, 452, 533.

37. Kouamé, op. cit., p. 422.

38. Sottas, op. cit., p. 91

39. Daget, op. cit., p. 36.

40. Margoline-Plot E., thèse citée, p. 97.

41. Coquery-Vidrovitch Catherine, La découverte de l'Afrique, l'Harmattan, 2003, p. 178.

42. Daget, op. cit., p. 36.

43. Kouamé, op. cit., p. 422.

44. Legoux, op. cit., p. 370-372.

45. Legoux, op. cit., p. 62-77.

46. Nicolas B., Lorient op cité p. 110

47. Un seul document, conservé dans le carton C2/56 aux Archives d'Aix en Provence, permettrait à première vue, d'avoir une vision globale de la valeur totale de toutes les importations indiennes (tissus et autres), de 1716 à 1788. Il s'intitule : "Du commerce de la France avec les Indes Orientales depuis 1716 jusqu'à 1788." Le document ne porte pas de date d'élaboration. Ce document incertain a été placé en fin de carton C2/56 dans les archives d'Aix (AOM). Il comprend plusieurs colonnes, dont une est réservée à la valeur des exportations de l'Inde vers la France, année par année ; l'autre "la part des Indes employée à la traite des nègres à raison de 11/20", c'est à dire, on le verra, concerne les tissus prohibés.

Le document est curieux: il y a des erreurs pour un certain nombre d'années consécutives, pendant lesquelles la part réservée à la traite dépasse de beaucoup le montant total des importations de l'Inde vers la France. Si l'on fait abstraction de ces erreurs, curieusement, chaque année, la part du commerce réservé à la traite égale $55 \%$, à quelques exceptions près, du montant total des importations indiennes. Ce document est non fiable, et doit être rejeté ici. Le titre même "à raison de 11/20", soit 55\%, laisse à penser que le travail du scripteur qui a confectionné cet immense tableau, était destiné sans doute à prouver l'importance de la traite dans les importations indiennes, et semble aussi majorer l'importance, en valeur, des importations indiennes.

48. Calculé d'après le tableau 10 de Wellington, p.194 sq.

49. Daget S. La traite négrière, 1987, Rennes Ouest France, p. 139.

50. Margoline-Plot E., thèse citée, p. 97.

51. Coquery-Vidrovitch C., La découverte de l'Afrique, l'Harmattan, 2003, p. 176 sq.

52. Boman W, Voyage de Guinée, Urtecht, 1705, p.96, 97.

53. Labat P., « Le voyage du chevalier des Marchais en Guinée en 1725-1727, Paris 1730, Tome 2, p. 114.

54. Daget S. op. cit., p. 139-143.

55. Margoline-Plot E., thèse citée, p. 99 sq.

56. De Wismes A., Nantes et le temps des négriers, Paris, France-Empire, 1992, p. 60.

57. Koumé, op. cit.., p. 293-295.

58. D’Allemagne, H.-R., La toile imprimée et les indiennes de traite, Paris, Librairie Gründ, 1942, t. 1, p. 161 cité par KOUAME A., op. cit., p. 295-299.

59. Mehdi Zmuda Saint Malo port négrier XVIIème-XVIIIème siècle Phenix Editions, 2004, p. 132.

60. Pluchon P. La route des esclaves, négriers et bois d'ébène au XVII e siècle, Hachette, Paris, 1980, p. 132-133. 
61. Nicolas B. Lorient, «De la côte de Coromandel aux côtes du Sénégal, les tribulations des indiennes de traite» dans Lorient, la Bretagne et la traite. (p. 97-111).

62. Nicolas B. « De la côte de Coromandel aux côtes du Sénégal, les tribulations des indiennes de traite » dans Lorient, la Bretagne et la traite, p. (p. 97-111). 
II. Les différents tissus : approche descriptive 


\section{Les chittes}

1 Comment mettre un peu d'image sur ces avalanches de noms? Les affichettes de vente sont avares de descriptions. En revanche, dans les annonces détaillées des lots, soit avant soit après la vente, quelques détails éclairent la spécificité des textiles importés et vendus : les aunages en largeurs et longueurs, les couleurs et les dessins, s'ils sont mentionnés. Quelques voyageurs contemporains des ventes ont apporté leur propre éclairage sur des textiles dont on recherche si vainement les traces. Enfin, on n'oubliera pas la précieuse bibliographie générale citée page? Existera peut-être alors la possibilité de proposer une image qualifiant des noms de tissus dont on a souvent perdu les caractéristiques : la matière? La couleur? Des rayures, des broderies, des liserés? La taille de la pièce?

Enfin, tout espoir n'est pas perdu de retrouver, dans les collections et les musées, quelques échantillons, quelques images perdues, quelques pièces mêmes: un rêve si souvent formulé.

\section{Les chittes}

3 Victimes de la prohibition, les chittes ou «perses » ou «indiennes", toiles de coton peintes, ne comptent que pour un peu plus de $2 \%$ des tissus importés, en nombre et moins de $1 \%$ en valeur. La prohibition ne les a cependant pas complètement exclues des cargaisons. Elles apparaissent avant tout en 1687, avant la prohibition ou certaines des années postérieures à 1759 , lorsque s'adoucit la prohibition. Malgré la faible part des chittes dans les importations textiles indiennes, la bibliographie éblouie qui leur est consacrée est plus qu'importante : limitons nous, dans nos descriptions aux données des archives citées.

4 C'est en 1687 que ces toiles sont, dans les documents, les mieux détaillées. "Toiles peintes » a précisé le scripteur bien intentionné. 16840 pièces de chittes de Seronge, ont été vendues 68635 livres. "Le principal centre de toiles peintes écrit J. Irwin ${ }^{1}$ était Sironj, dans le Rajputana... mentionné pour la première fois en 1611. » La ville a été décrite par le voyageur français Thevenot. ${ }^{2}$ Dans la même vente, 1180 chittes " peintes des deux côtés, » ont été estimées 11761 livres. Les 41433 chittes d'Ahmedabad ont été moins prisées : s'agirait-il de cotons imprimés? « les cotons imprimés et non pas peints 
provenaient surtout d'Ahmedabad", souligne Irwin ${ }^{3}$, sans être certain que tous les chittes d'Ahmedabad étaient imprimés et non peints. D'autres noms d'origine apparaissent dans les années suivantes: 1712, chittes d'Ahmedabad encore; de Pondichery en 1721,1741 et 1768 , de Madras et de Patna ; en 1761 « chittes «chapés " du bengale, chittes de la côte. L'affichette de vente de 1777 donne aux chittes plusieurs origines: Gujarat, Surate, Madras, Patna et Marchaye.

5 Les aunages varient: soit 7 aunes sur près d'une aune, soit $3 \frac{112}{2}$ à 4 aunes; la pièce la moins longue doit être tout simplement une « demi pièce » dont l'existence est attestée en 1716 par le scripteur, qui précise même le tissu sur lequel a été réalisée l'indienne, du basin.

6 Le prix varie également. Quatre livres en 1687, pour les chittes de Séronje; même valeur pour les chittes rouges de Séronje, mais plus du double, près de 10 livres pour les " toiles peintes des deux côtés "; les chittes d'Ahmedabad, moins onéreuses, à 3,4 livres la pièce. En 1716-18 : entre 16,5 et 42 livres; en 1768, de 13,5 à 15 livres pour les chittes de Pondichery ; les chittes de Madras, entre 30 et 39 livres. Dermigny ${ }^{4}$ évoque le cas de chittes de Madras, achetés 17 livres la pièce.

7 Ces variations de valeur recouvrent certainement des variations de qualité, d'origine, voire même de technique : peinture? Impression? En l'absence d'images appliquées à ces tissus vendus, c'est le Catalogue de 1741 qui détaille le mieux ces pièces importées et vendues malgré la prohibition : 3 aunes $3 / 4$ et plus, sur 11/12: «de différentes couleurs et desseins, à fond blanc surtout, mais aussi à fonds jaune, vert, bleu et rouge »; quelques pièces à " petits bouquets ", d'autres « rayées comme ci-dessus . »

8 En 1687, d'autres cotonnades peintes entourent les simples chittes: 1330 couvertures de toiles peintes piquées, onéreuses, 261 l'une, onze «tours de lit » de chitte, à 52 livres la pièce en moyenne, dont on ne sait si ces couvertures et tours de lit sont ceux que Legoux décrit comme "tapis de lit ", "espèce de courte pointe dont on couvre les couchettes...d'un seul lè et d'un dessin baroque pour la plupart...qu'il estime entre 80 et 160 livres la pièce, longue, dit-il de quatre aunes sur trois et demi, en une seule pièce» ; et des mouchoirs peints (à 21 livres la pièce à cette date), qui se retrouvent dans les ventes en 1729 et 39 . Sont-ce les «mouchoirs à vignettes » décrits par Legoux, « autre espèce de toile peinte ", sur percale, ou sur salampouris ${ }^{5}$ et estimés entre 1584 et 1848 francs la courge (ensemble de vingt pièces), soit entre 79 et 92 livres la pièce.

9 Nous renvoyons le lecteur sur le site The Textile Manufactures of India http:// www.tmoi.org.uk/ qui présente de nombreux échantillons de chintz (toiles peintes) et ne présenterons ici que les échantillons qui figurent dans le catalogue des Arts décoratifs cité p. 97 et p. 11. 
Toiles peintes, inv. BAD 6752 (GG4), album d'échantillons, 1789, p. 111. Les Arts Décoratifs, Paris

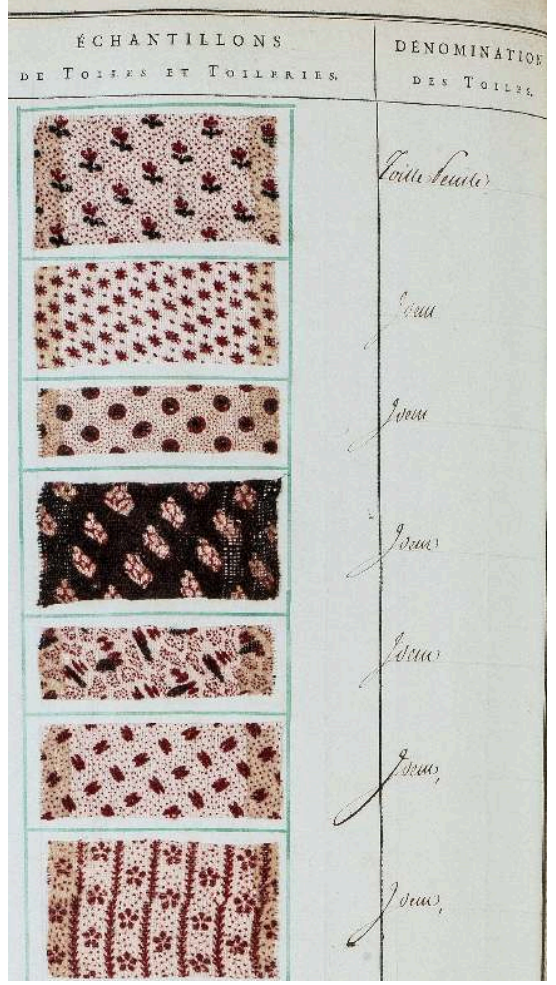

Photo Les Arts Décoratifs, Paris/Jean Tholance (photo soumise à accord préalable, rétrocession photo interdite) 
Toiles peintes, inv. BAD 6752 (GG4), album d'échantillons, 1789, p. 97. Les Arts Décoratifs, Paris

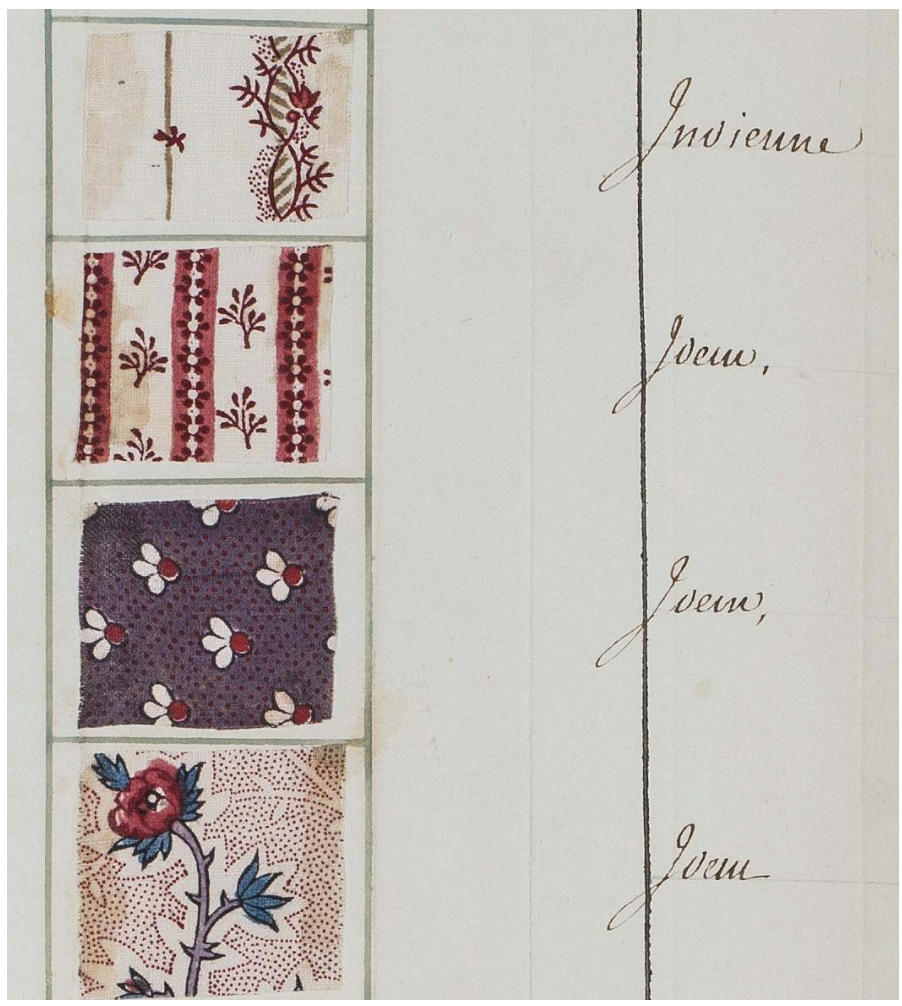

Photo Les Arts Décoratifs, Paris/Jean Tholance (photo soumise à accord préalable, rétrocession photo interdite)

\section{NOTES}

1. Irwin John, Journal of Indian Textile History, Ahmedabad, Calico Museum of Textiles, 1996, I, p. 13.

2. Thévenot Jean, Relation d'un voyage fait au Levant, Paris, L. Billaine, 1664, III, p. 21.

3. Irwin John, op. cit., p. 13.

4. Dermigny Louis, op. cit., p. 53.

5. Legoux, op. cit., p. 94. 


\section{Les tissus mêlés coton soie}

Les tissus mêlés coton soie, tous prohibés, occupent une petite place. Ces tissus étaient très présents dans les pays d'Islam, dont le monde ottoman, et particulièrement à Damas : ce sont des tissus « licites » car leur composition évite à la peau d'entrer en contact avec la soie, ce que l'Islam n'autorise pas, en principe. Ainsi R. Grill écrit à propos d'un tissu indien appelé mashru, qui n'est sans doute autre que le cotoni ou même une variété d'alaja, dans son article "Textiles in Kutch $»^{1}$ :

« ... mashru qui signifie permis, c'est à dire permis aux hommes musulmans à qui la tradition interdit de porter de la soie pure au contact de la peau. Il s'agit d'un tissage de satin : les fils de chaîne se trouvent sur la surface du textile pour créer un effet lisse, et les fils de trame de coton se trouvent sur l'envers de tissu, au contact de la peau de qui le porte. » 
Mushroo. Sur le site tmoi.org.uk du Victoria and Albert Museum, photo numéro $\mathrm{n}^{\circ} 486$. Il existe plusieurs autres photos de mushroo, numérotées 396, puis de 486 à 515 .

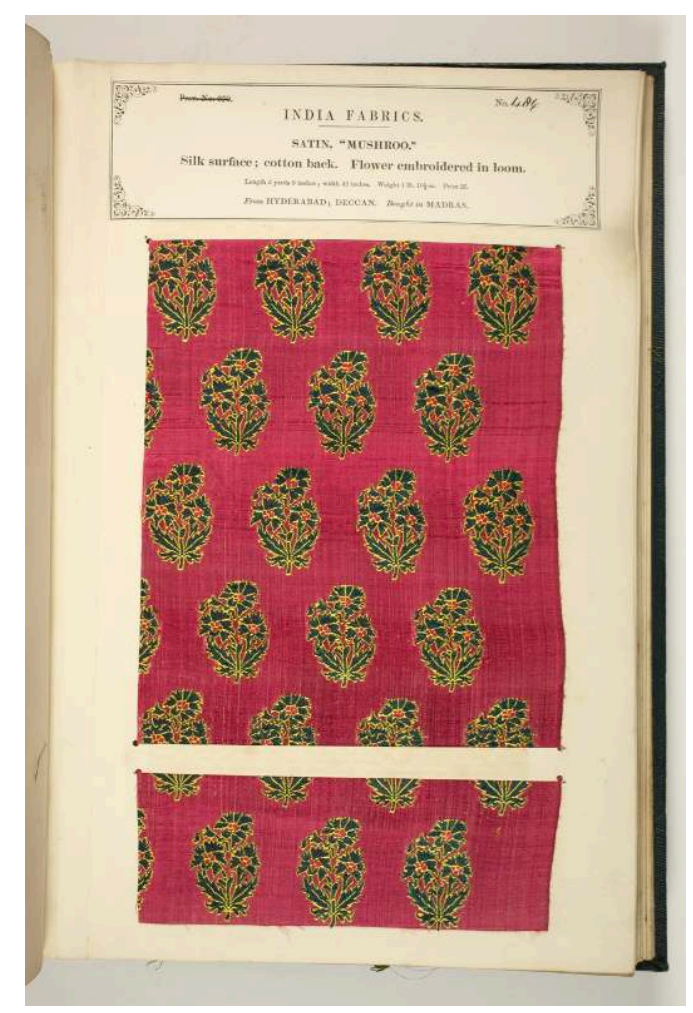

2 Présentons les noms des textiles composés de soie et de coton offerts aux acheteurs, par ordre alphabétique : alajas, allibannee, caladaris, chalbat, chaperconne, chuquelas, cotonis, fatouya, grana, grisette, kichorchay, montichour, nila, pinasse, sirsaca, sistresoye, tapchila et tepay. Ces tissus ont été importés en France dans des proportions tout à fait différentes.

3 Les préférences sont allées aux caladaris et alibannee, aux soucis, plus de 21000 pièces, de loin les plus nombreux; aux tapchila et aux nila, plus de 13000 pièces ; aux alaja et chuquelas, près de de 8000 pièces. Plus de 7000 pièces de pinasses, près de 5000 pièces de sirsaca, plus de 3000 de tepay, les cotonis, plus de 2000, les kichorchay, moins de 1000, les montichour moins de 500. Encore plus rares, les fatouyes, une centaine de pièces, et encore moins présents, moins d'une centaine de pièces, les grisettes, les grana.

\section{Les canadaris ou caladaris}

Legoux décrit ${ }^{2}$ :

«Les meilleures manufactures de canadaris ainsi que les appellent les Européens, et canadarins dans l'idiome du pays, se trouvent dans le petit royaume de Balaçor... dans le haut de la côte d'Orissa...limitrophe du Bengale...La partie des canadaris qui n'est pas en coton est faite avec de la soie même...de la soie mogue...Elles sont fabriquées en soie teinte en rouge, en jaune...Les rayures des canadaris, toujours très peu larges (elles n'ont jamais plus d'un quart de ligne)... sont en blanc et rouge, blanc et bleu, blanc et violet ou en rayures tricolores. » 
Quant au prix des canadaris, dont les pièces sont de dix aunes et sept/huitième de largeur : « on paye celles de la première sorte à raison de 15 roupies sicca et celles de la seconde, treize roupies et demi. » (36 à 40 livres)

6 Sous le nom charadaries ou carridaries, John Irwin évoque « des tissus sans doute de coton et de soie, rayés ou à carreaux, provenant du Bengale qui n'apparaissent qu'à la fin du XVIIème siècle et qui présentent autant de variétés de rayures que les doreas. » ${ }^{3}$

7 Pour Dermigny, les caladaris sont des « toiles de coton à petites raies de couleurs vives, rouges et noires principalement, fabriqués au Coromandel et surtout au Bengale, en pièces de huit aunes sur sept huitième. $»^{4}$

Dans le Catalogue de 1741, 1270 pièces de canadaris, sont évoquées : bleus et blancs, de 7 aunes $3 / 4$ à 8 sur près de $7 / 8$ tandis que 1737 pièces, sur $7 / 8$ à $11 / 12^{\text {ème }}$ qualifiés de « herbe et coton", à « raye » bleues, rouges, ou rouges et bleues. Le terme « herbe" mérite une précision qu'apporte J. Irwin :

«Ce mot est un synonyme de soie sauvage comme tussur ou tasar. Les premiers voyageurs européens ont formulé l'idée fausse que ce tusur n'était pas une soie, mais un tissage venant d'une herbe...Le mot herbe a été utilisé longtemps après que l'on en ait découvert sa réelle nature. $»^{5}$

Photo de Canadaris, inv. BAD 6752 (GG4), album d'échantillons, 1789, p. 71. Les Arts Décoratifs, Paris

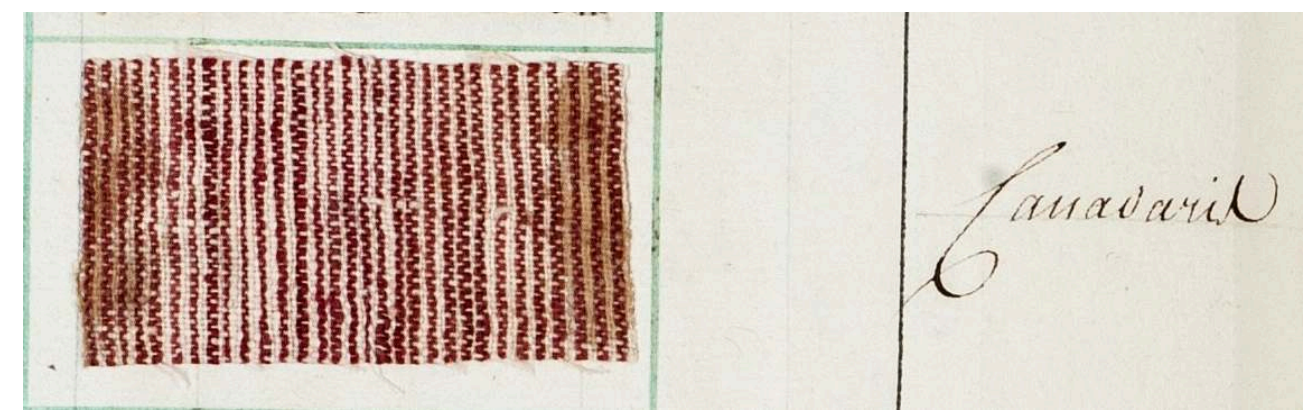

Photo Les Arts Décoratifs, Paris/Jean Tholance (photo soumise à accord préalable, rétrocession photo interdite)

Nos données d'archives, en 1767 et1768, confirment l'origine du textile, le Bengale, ${ }^{6}$ et à peu près la taille des pièces évoquée par Legoux et Dermigny : 1718, huit aunes sur sept huitième ; en $1725,26,39$ et 41 , sept aunes $3 / 4$ à huit sur $5 / 6,7 / 8$, ou 11/12.

Leur prix à la vente a été de 26 à 27 livres en 1716/18; en 1725 et 1726, de 18,8 à 22 ; en 1738 et 1739 , de 21 à $36 ; 12$ livres en 1768 .

\section{Les alibanis ou halibanis... ou habanis ou haby bany}

Seul Savary qualifie l'alibani de toile de coton. John Irwin évoque une composition soie coton, probablement à rayures, provenant de la région de Malda Kasimbazar, dans le Bengale ${ }^{7}$. Chaudhuri fait des alibannies, un textile coton et soie, probablement rayé, d'une qualité moyenne à supérieure, faisant partie du commerce de réexportation ${ }^{8}$. Pour Hobson-Johnson, c'est un «tissu soie-coton, également prohibé, sans doute à rayures ", de 9 aunes à 9 aunes $3 / 4$ sur une aune et plus. »" 
12 Nos données confirment cet aunage : en 1718, 9 et plus sur $1 \frac{1}{2}$ à $11 / 6$; en 17259 à $9 \frac{1 / 4}{4}$ sur 1 aune $1 / 8$; en 1741,9 à $9 \frac{1}{2}$ et plus sur $11 / 8$ à $1 / 6$. Un supplément d'information est donné en 1716 : les alibanies y apparaissent comme des "toiles bleues rayées. » Donc tissu soie coton, à rayures, bleu en fond de toile?

13 Quant à la valeur, de 15,1 à 16,6 livres en 1725, elle oscille dans les années suivantes (1738 et 39) de 11 livres à 13,7 livres.

14 On a suggéré que les habanis ou habassis, dont on n'a trouvé aucune mention dans les dictionnaires, ne seraient qu'une variante linguistique des alibanis; dans la liste des ventes de 1768 , d'origine bengalaise, ils suivent les elatchas, textile coton soie très prisé dans le Moyen-Orient ; ils sont à cette date beaucoup plus onéreux que les précédents, de 57 à 71 livres. Leur prix, et leur place dans les listes de ventes feraient cependant parier sur des mélanges soie coton.

\section{Les soucis}

Les soucis, également très exportés vers les pays de Moyen-Orient, vers les " Mores ", sont des fabriques de soie ou de soie et coton mêlés. Savary décrit ces soucis comme des

«mousselines de soie rayée de différentes couleurs qui viennent des Indes...Il n'y entre aucun coton dans leur fabrique, comme dans les véritables mousselines. Ce qui leur fait donner son nom, c'est une espèce de bourre légère qui paraît sur la superficie de la toile comme sur les mousselines...Les soucis sont de différentes longueurs et largeurs, $y$ ayant des pièces qui n'ont que huit aunes de long sur trois quart de large et d'autres vingt aunes sur deux tiers. $»^{10}$

Soucis divers, numéros $448,449,131,137,134,133$, sous le nom soosee, du site http:// tmoi.org.uk. Ci-dessous $n^{\circ} 448$ 


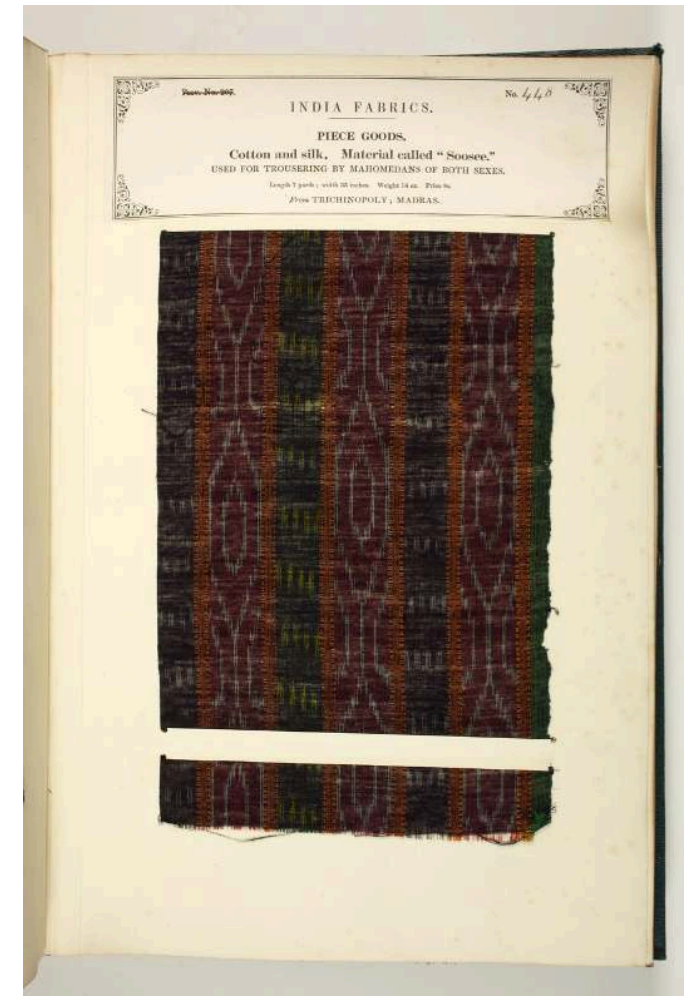

Soucis $n^{\circ} \mathbf{4} 49$ sur le site du Victoria and Albert Museum, http://tmoi.org.uk

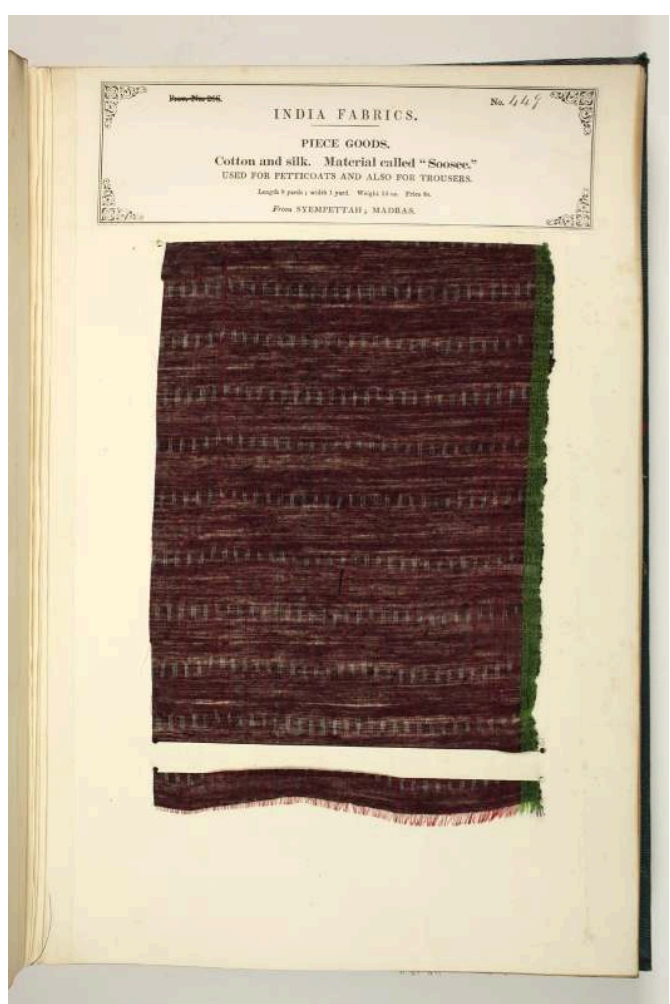


Différentes pièces de soucis (de coton, coton soie et soie) sont présentées sur le site du Victoria and Albert Museum, http://tmoi.org.uk, numéros 131 à 141 ; et numéros 448 à 452 . Ci-dessous $n^{\circ} 131$

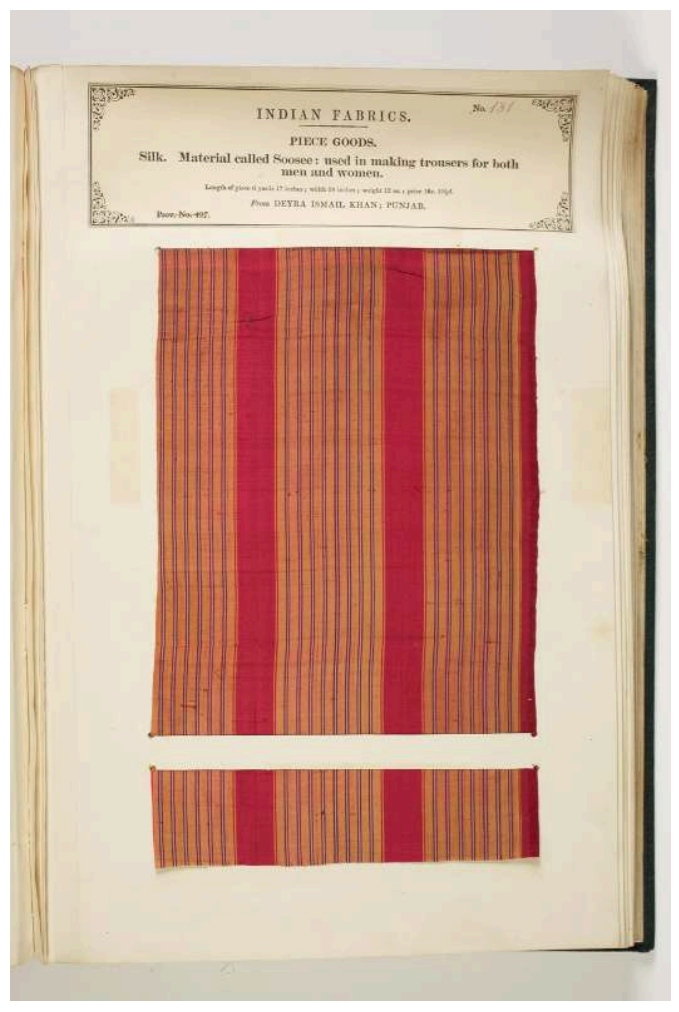

Soucis $\mathrm{n}^{\circ} 135$ sur le site du Victoria and Albert Museum, http://tmoi.org.uk

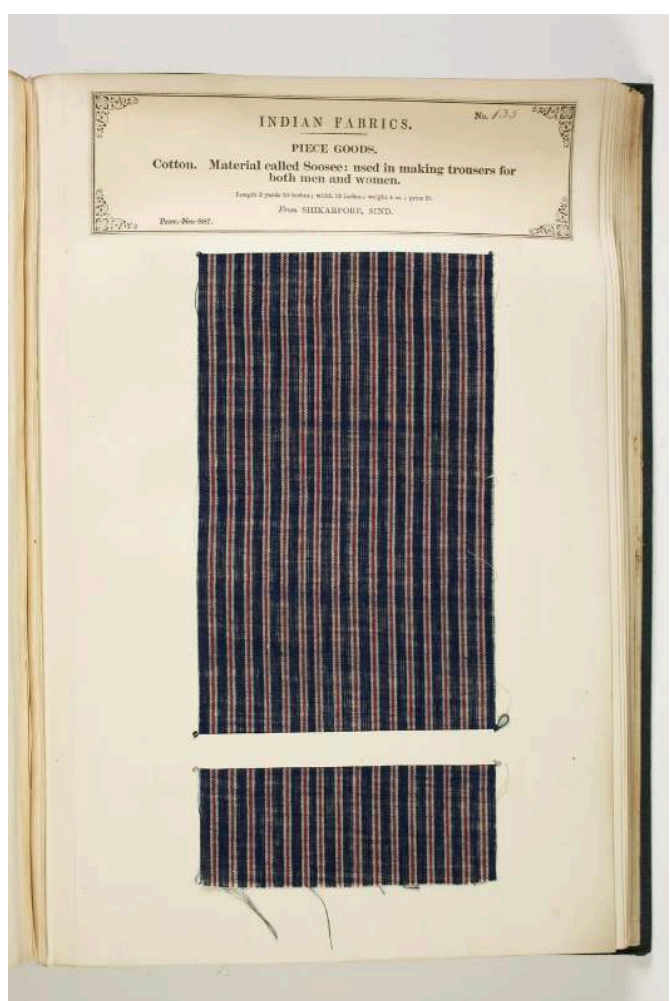


Irwin ${ }^{11}$ hésite sur la composition du tissu provenant du Bengale : «fabrique de soie, écrit-il, ou mélange coton soie, rayée ou à carreaux.» Toutes les autres définitions suggèrent le mélange coton et soie. Roques, à la fin du XVIIème siècle, les décrivait ainsi :

« cette sorte de marchandise est de deux espèces, moitié en bétille et moitié taffetas (de soie)...On les appelle soucis pour les distinguer des bétilles par leur raies qui sont tissées et serrées... Ces raies de taffetas de diverses couleurs les rendent fort prisées...Les dames, en été, ne seront point mal parées de ceux que j'ai achetés. Ils peuvent servir aux femmes en cymarres et jupes, ils sont aussi fort propres à faire des tours de lit pour respirer l'air en été à travers des rideaux sans l'inconvénient des mouches. ${ }^{12}$

\section{Soucis $\mathrm{n}^{\circ} 134$ sur le site du Victoria and Albert Museum, http://tmoi.org.uk}

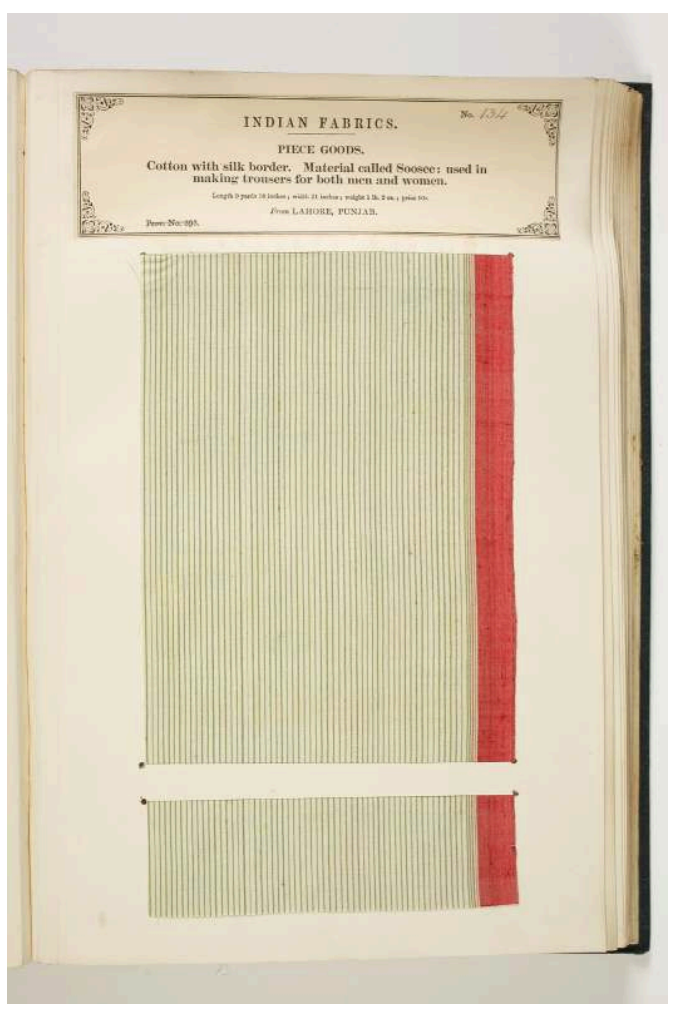

Pour Chaudhuri ${ }^{13}$, les sooseys sont des «mélange de coton et de soie, à raies, de belle qualité, du XVIIème au XVIIIème siècle, pour l'habillement et le commerce de réexportation.»

Ces pièces de soucis sont ignorées par Legoux, par Blancard, par Dermigny.

Les tailles des pièces sont effectivement variées. En 1726, les soucis «assortis » de 18 aunes et plus sur $5 / 6$ à $7 / 8$; en 1739 , de 15 1/2 à 16 aunes sur trois quart à cinq/sixième, ou de 18 aunes sur $9 / 15$ à 7/12.

C'est dans le Catalogue de 1741 que l'on trouve encore la plus minutieuse des descriptions: environ 1500 pièces de soucis occupant une vingtaine de lots. A l'intérieur des lots, une centaine, ou moins, de pièces, de 15 aunes $3 / 4$ à 16 aunes sur $3 / 4$ à $5 / 6$ ou de 18 , et plus à 19 aunes sur 7/12): soit à carreaux, soit à différents types de rayures, petites ou larges, de couleur blanche, ou rouge ou bleue, ou mélangées rouge et bleue. Beaucoup de ces soucis sont blancs à rayes bleues ou rouges. 

l'origine de la pièce est signalée, le Bengale, et le prix est de 27,2 livres; en 1768, 34 livres.

Dans l'ouvrage How india clothed the world, Om Prakash estime les pièces à 8 à 10 roupies sicca, soit de 21,6 à 27 livres. ${ }^{14}$

\section{Les tapchilas, ou tapsels}

«Grande toile de coton rayée, ordinairement de couleur bleue, qui vient ... principalement du Bengale. Cette sorte de toile a 10 aunes de long sur $3 / 4$ à $5 / 6$ de large. C'est une des meilleures marchandises que les Européens portent sur les côtes de Guinée pour la traite des nègres ».15

Sous le nom de tapseels, topseille, tafficilas, nom qui aurait peut-être une origine persane, tafcilab, Irwin décrit une "toile rayée de soie et coton bon marché, très demandée par les vendeurs d'esclaves, aire de Cambay-Ahmedabad. ${ }^{16}$ Irwin localise donc la fabrication de cette toile en Inde de l'ouest, et non pas au Bengale.

En 1741 , l'aunage est de 11 aunes $1 / 4$ à 11 aunes 7/8, sur près de 5/6. En 1760, au nombre des marchandises prohibées, se trouvent quelques peu nombreux tapsilas appelés tapsilas du bengale du Bengale, sans valeur indiquée.

Tapsels, inv. BAD 6752 (GG4), album d'échantillons, 1789, p. 305. Les Arts Décoratifs, Paris

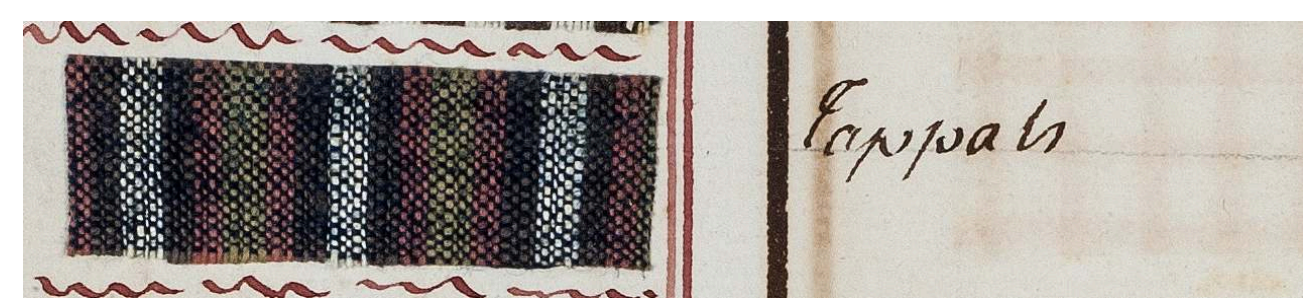

Photo Les Arts Décoratifs, Paris/Jean Tholance (photo soumise à accord préalable, rétrocession photo interdite)

Tapsels, inv. BAD 6752 (GG4), album d'échantillons, 1789, p. 306. Les Arts Décoratifs, Paris

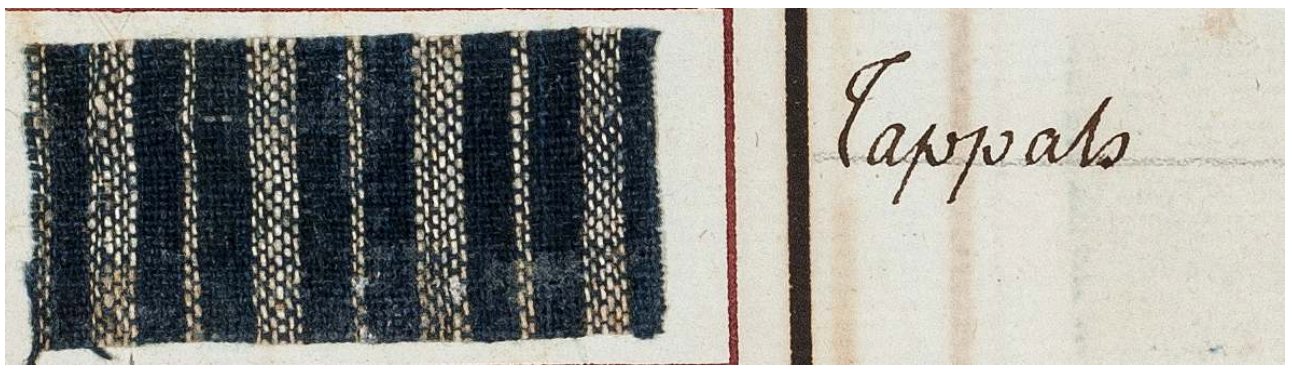

Photo Les Arts Décoratifs, Paris/Jean Tholance (photo soumise à accord préalable, rétrocession photo interdite)

\section{Les nelis ou nillaae}

«Étoffe d'écorce mêlée de soie qui vient des Indes » pour Savary répétant d'ailleurs deux fois le mot soie puisqu'on sait que ce qui était nommé « écorce d'arbre » était de la 
soie. Fions nous plutôt aux autres descriptions. Pour Irwin, « du nom de l'hindi, nila, bleu, ce sont des tissus à raies de mélange coton soie Tussur, quelquefois à fleurs. Elles sont exportées en grandes quantités en Europe dans le dernier quart du siècle »; il complète sa définition en faisant référence à une lettre de 1679 : «brillantes, rayées des plus légères des couleurs, couleur de cheveu, couleur du ciel; il en existe en rouge, rayées de noir, mais elles ne sont pas vendables à Londres. ${ }^{17}$

De petites pièces : en 1725 et 1741, elles sont de 7 aunes et demi à trois sur trois quart à cinq sixième.

Les prix : en 1687, les « nilae » sont à 12, 4 livres; en 1725, de 16 à 19 ; en 1738, de 20,4 à 20,$7 ;$ de 24,3 à 25,2 en $1739 ; 24,2$ livres en 1767 . La valeur s'en abaisse en 1768 à 14,12 livres.

Ni Legoux, ni Blancard, ni Dermigny, qui semblent n'accorder aucun intérêt à ces tissus coton soie, ne font allusion à ces nilae.

\section{Les elatchas}

Les elatchas (alâja) sont également des pièces à rayures coton soie, très utilisées dans le Proche-Orient. «Allegeas, étoffe fabriquée aux Indes orientales. Il y en a de deux sortes. Les uns sont de coton et les autres de plusieurs espèces d'herbes qui se filent comme le chanvre et le lin. ${ }^{18}$ Pour Roques, « cette étoffe est un espèce de taby sur chaîne de soie et trame de coton ${ }^{19}$, évocation confirmée par le dictionnaire de A. Barthélémy à l'article alaja : «étoffe rayée, dont la chaîne est de soie et la trame de coton. ${ }^{20} \mathrm{~J}$. Irwin en fait « un tissu important du Gujarat, mélange de coton et de soie, en général rayé rouge et blanc, ou bleu et blanc, quelquefois avec des fleurs, et embelli de fils d'or et d'argent. Le même tissu était aussi tissé dans le Bengale, mais les alajas du Gujarat contiennent une plus grande proportion de coton, et ont pour cette raison ont été quelquefois qualifiés de calicot. $»^{21}$ Existent aussi les alajas du Bengale : "le mot alaja provient du turc, alcha, rayure; ce sont des tissus mélangés coton-soie, tissés dans le district de Malda-Kasimbazar. $»^{22}$ Le même sens est donné dans le Glossaire de HobsonJobson; mais les couleurs diffèrent : « en général rouge ou bluish red, avec des rayures blanches. $»^{23}$

En 1687, le document de vente évoque une origine autre (et sans doute fausse), les alajas de la Chine. En 1741, 1767 et 1768, la zone de production est indiquée : alaja de Malde $^{24}$, dans le nord du Bengale, au nord-ouest de Murshidabad, d'après L. Dermigny.

En 1716 ou 1718, la pièce est de six aunes sur trois quart et cinq sixième ; en 1726, les alajas "assortis de différentes couleurs" sont de 6 aunes à six et demi sur neuf seizième; en 1739, de sept aunes sur près de cinq huitième; en 1741 , de sept aunes à sept et demi, sur près de 7/8. En 1777, une affichette de vente décrit les alajas : « alajas ou taffetas de Surate, soie et or ; ou rayés ; ou à fleurs d'or. » 
Alaja, sous le nom elacha, Victoria and Albert Museum, $n^{\circ} 568$. D'autres photos existent, sur le site : numéros 563,564 , et 538 sous le nom de elaiche.

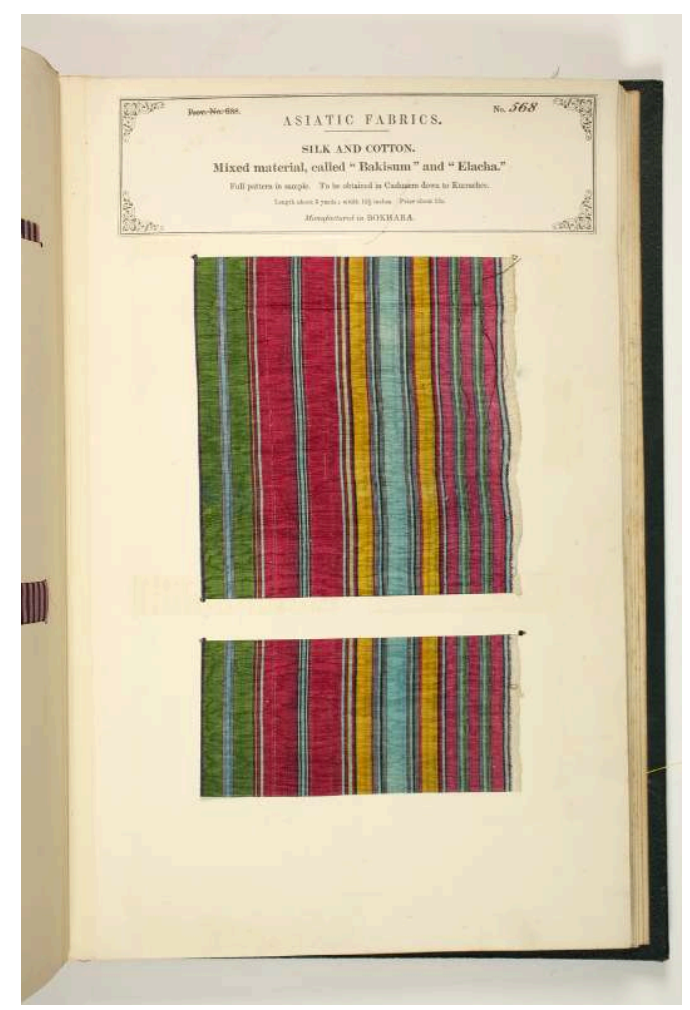

Uddrussa, connu aussi sous le nom d'elacha, $n^{\circ} 561$ sur le site du Victoria and Albert Museum, http://tmoi.org.uk

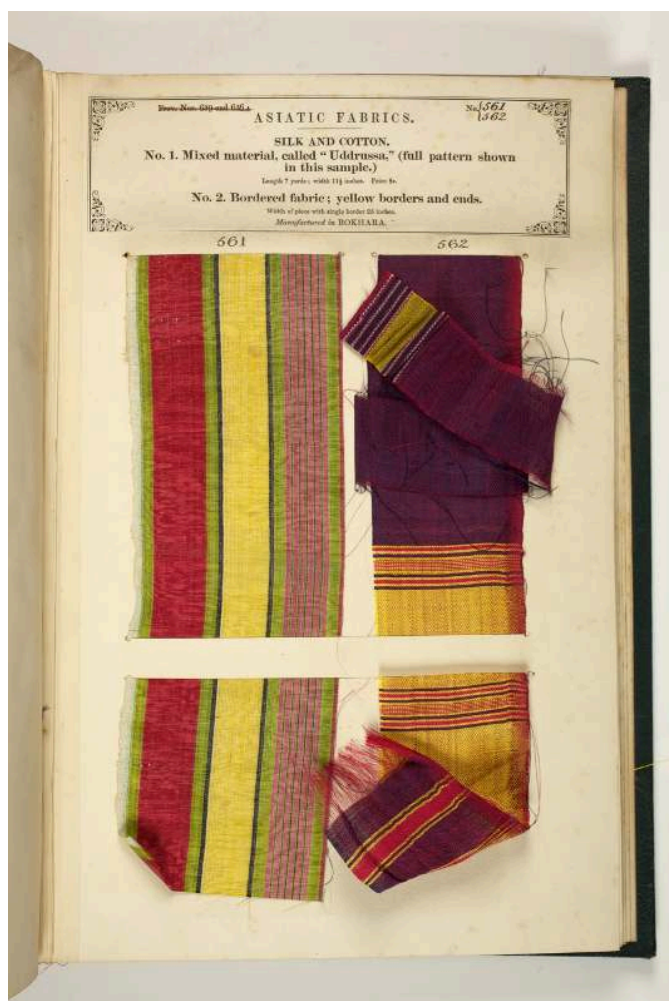



1726, de 24 à 27 en 1738, à 20,9 en 1739 ; entre 16 et 18 seulement en 1767, et 20 en 1768 .

\section{Les chuquelas}

Pour Savary, ce sont des «étoffes soye et coton fabriqués aux Indes orientales, toutes rayées, qui ne diffèrent entre elles que parce qu'il y en a à grandes et à petites raies. Elles ont depuis sept aunes de longueur sur cinq huit de largeur, jusqu'à 16 aunes de long sur cinq six. On les appelle aussi chercolées et cherconnées; " ${ }^{25}$ à l'article cherconnee, « espèce de chuquelas soye et coton. La seule différence qu'il y a, c'est que les vrais chuquelas sont tous rayés, et qu'il y a des cherconnae à carreaux. ${ }^{26} \mathrm{~J}$. Irwin en donne la même définition: "étoffe rayée de mélange soie et coton...et évoque un document de 1688: "chuklaes à petites rayures et de couleurs vives. ${ }^{27}$ Même définition chez Chaudhuri, qui rajoute : « de belle qualité. $»^{28}$

Dans le glossaire Hobson-Johnson, le terme chuquela est rapproché de l'hindi « chaklâ chakrî. » Dans le même glossaire, au terme charconnae, une étymologie est proposée donne au mot charconnae ", de l'hindi " châr-khâna " "à carreaux » et qualifie le tissu de "mousseline à carreaux. $»^{29} \mathrm{Il}$ rapproche le charconnae des doreas, avec une seule différence consistant dans la largeur et le rapprochement des rayures. Rajoutons à ce groupe, avec prudence, les quelques chaperconnes vendus en 1761 .

Les documents d'archives ne permettent pas une vision plus approfondie. En 1687, ces chuquelas sont dits «rayés de couleurs. » Les aunages ne sont jamais de sept aunes, mais, en 1726 , de 14 à 14 aunes et demi sur près de trois quart, en 1739 , de 14 sur près de trois quart; en 1741 , de 13 aunes $2 / 3$ à 14 aunes sur près de trois quart. Les pièces proviendraient $\mathrm{du}$ Bengale, suivant $\mathrm{J}$. Irwin et d'après les indications d'origine présentes dans le document sur les ventes de 1767 et 1768 .

36 Leur prix : sept, six livres la pièce en 1687, 29,1 en 1726, 28 à 33 en 1738, de 23,6 à 25,1 en 1739 , de 33,6 en 1768.

\section{Les pinasses}

37 Les pinasses, "étoffes des Indes orientales, qui sont faites d'écorce d'arbre " décrit Savary30; lequel renvoie à l'article "écorce d'arbres", présenté ci-dessous. Effectivement, les pinasses sont situées dans le Catalogue de 1741 dans une page intitulée « Ecorces d'arbre. »

Legoux de Flaix décrit : « étoffe de coton dont le réseau est croisé, et se fait avec du fil bleu à la chaîne de la pièce, et en coton blanc dans la trame...le mot signifie couleur mêlée...Destiné aux îles de France et de Bourbon. Cet article est compris dans la dénomination générale de marchandise bleue..., toile médiocre n'étant destinée qu'à l'usage de la traite ou à faire les vêtements des nègres des colonies. $»^{31}$

39 E. Hardouin-Fugier rapproche les pinasses des biambonnées, dont elle donne la définition de Savary, «étoffe fabriquée aux Indes avec l'écorce d'un arbre qui se file comme le chanvre, parfois mêlée de soie...En pure écorce on la nomme pinasse. »

De petite taille : 7 aunes $1 / 2$ à 8 sur $5 / 6$ à $7 / 8$ en 1726 ; de 7 aunes $1 / 2$ à 7 3/4 sur 3/4 à $5 / 6$ en 1741. (Legoux en fait des pièces de 11 aunes.) 

livres.

\section{Écorce d'arbre ou étoffe d'arbre}

Écorce d'arbre ou étoffe d'arbre : à l'article écorce d'arbre, Savary précise :

"C'est une étoffe fabriquée aux Indes, de l'écorce d'un arbre, qui se file comme le chanvre. Les longs filaments qu'on en tire après avoir été battue puis rouïe dans l'eau, compose un fil qui tient en quelque sorte le milieu entre la soye et le fil ordinaire, n'étant ni si doux ni si lustré que la soie, ni si dur ni si mat que le chanvre... L'on mêle de la soie dans quelques-unes de ces étoffes. Et celles-là sont les guingans, les nilae, et les cherquemolles...Les fotalongées sont aussi partie écorce et partie soie et ne diffèrent des autres que parce qu'elles sont rayées...Les pinasses et biambonnées sont pure écorce. Toutes ces étoffes sont de 7 à 8 aunes de longueur et de $3 / 4$ ou $5 / 6$ de large, à la réserve des cherquemolles qui n'ont que 4 aunes de long sur $3 / 4$ de large. $»^{32}$

Legoux avait suggéré que ces "écorces d'arbre étaient un type de soie. Or, en 1691, le même document signale la présence d'étoffe "écorce d'arbres ", bien distinguée des étoffes de soie présentes dans une caisse d'échantillon et suggère l'idée que l'écorce d'arbre n'est pas exactement de la soie. Nous n'en savons pas plus. En 1741, ce type d'étoffes précède les pinasses et les nelis dans la liste des biens vendus. En 1767, l'origine en est donnée, le Bengale.

Dans les listes de vente figurent deux fois l'aunage qui est effectivement de 7 aunes $1 / 2$ sur 3/4, et plus ; la valeur : 4 livres en 1691, de 13 à 18 livres plus tard.

\section{Les Sirsakas, les sistresoyes}

Legoux décrit un ensemble de textiles, les canadaris, sirsakas et sistresayes " partie en soie, partie en coton » et reprend plus loin : «Tous les trois tissés avec du coton et de la soie, fabriqués de la même manière...et dans les mêmes ateliers...Nous connaissons ces étoffes sous le nom de bourre du Levant...On fabrique les sirsakas et les sistresoyes avec la meilleure qualité de la bourre de soie »...Les rayures des sirsacas...sont en jaune, en blanc ou en violet. ${ }^{33}$

Hobson-Johnson propose, avec prudence, une étymologie pour ces seersuckers: sir, tête, sukh, plaisir. ${ }^{34} \mathrm{~J}$. Irwin rapprocherait le mot du persan shir o shakkar, lait et sucre et décrit les seersucker: "Une étoffe de soie et coton et faisant référence à une lettre de 1709, présentant des rayures roses, bleues, or, et autres couleurs claires. $»^{35}$

Les sirsaca, ou sirsaka, les sitresoyes ont été plus onéreux que les caladaris, de 52 à 53,7 livres.

Les pièces semblent être de plus grande taille : en 1741 et 1739, de 11 aunes trois quart à 12 saunes sur trois quart à cinq sixième ; et leur prix plus élevé, sans doute pour cette raison, que celui des caladaris : de 52 à 55 livres, de seulement 41 en 1768; 47 livres pour les sistresoyes en 1767 , dont un seul catalogue de ventes affiche la valeur. Legoux écrit qu'on les achète de 14 à 16 roupies sicca la pièce, soit, 37,8 à 43,2 francs. 
D'après J. Irwin, ces pièces proviendraient de la région de Malda-Kasimbazar; du Bengale, note le document de vente de 1767.

\section{Les Tepay}

50 Savary (II, p.1745), sous le nom de tepis remarque: " étoffe de soye et coton qui se fabrique aux indes orientale; il y entre fort peu de soie...Les tepis ont depuis cinq aunes jusqu'à sept aunes de longueur sur deux tiers environ de largeur. » Pour Chaudhuri, ce textile est un «coton et soie» (p. 505) ; Wingate cité par Wellington. «Le tepis est un tissu simple, peu onéreux, de coton mêlé à peu de soie. »

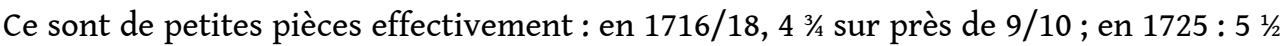
à 6 sur $5 / 8$ à $2 / 3 ;$ en $1741: 7 \frac{11 / 2}{\text { à }} 8$ sur près de $3 / 4$.

La valeur n'est pas aussi misérable que le suggèrent les auteurs précédents : en 1725, de 16 à 16,10 livres ; en 1767, 45 livres la pièce

\section{Les Chalbats ou chalbafs}

53 Ces tissus ne sont évoqués nulle part, dans notre littérature. On avait d'abord estimé que ces chalbat étaient des soieries. Mais à l'étude des données d'archives, on s'aperçoit que, dans la description des lots de vente, ils se situent plutôt au milieu des tissus coton soie, les alajas, les chuquelas, les pinasses, les tepays. De plus, par leur aunage, leur valeur, ils se rapprocheraient des pièces coton soie. En 1768, l'origine des chalbaf a été précisée : Malde, au Bengale, ville productrice aussi d'alajas.

Pièces de long aunage, de 14 sur $3 / 4$ en 1725 et en 1726 , de 13 33/4 à 14 sur près de $3 / 4$ en 1741 , leur prix tourne autour des 30 livres : de 26,5 à 31 en 1725, de 30 en 1726, de 26,1 à 28 en 1738, de 35 en 1767 et de 37,8 en 1768 , les chalbafs de Malde ayant été vendus cette même année seulement 20 livres la pièce.

\section{Les Cotonis}

Comme les alajas, les qutnî, ou cotonis, ont particulièrement intéressé le Proche orient ottoman, comme, dans l'ensemble, tous les textiles coton soie.

Roques, qui voyage et commerce entre 1676 et 1691, à une époque où le Gujarat est la plus importante région de fabrication et d'exportation de tissus, décrit le tissu : «Le cotoni a la trame de coton; les pièces en sont variées, des blancs, des en couleurs, des rayés, des façonnés et mélangés de fleurs et de dessins, des cotonis à fleurs d'or et d'argent; le mot vient du turc: "cotoni, du turc kutnu. Il s'agit d'un satin avec une chaîne soie et une trame coton. Cette étoffe est proche des allegas. Elle peut être façonnée avec des fleurs ou à rayures. ${ }^{36}$ Le textile ayant avant tout été introduit dans les régions arabes et turques, ce sont les Dictionnaires turcs ou arabes qui en donnent les définitions les plus précises. «Etoffe dont le dessus ou la chaîne est le satinet, dont la trame ou l'envers est de coton $»^{37}$, ou $"$ étoffe de soie et de coton. $»^{38}$ Savary en fait une variété d'atlas: "Les atlas cotonis sont ainsi nommés, parce que le fond est de coton et le reste de soie...." ${ }^{39} \mathrm{~J}$. Irwin constate : «importante exportation du Gujarat, tissu soie coton avec chaine de satin souvent à rayures, quelquefois parsemé de fleurs ; 


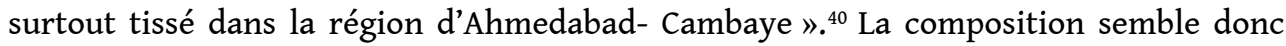
certaine. Mais, à la différence des autres coton-soie déjà mentionnés, le tissu ne semble pas toujours rayures, mais aussi à fleurs : «L'atlas cotonis orné de fleurs de soie, parfois d'or et d'argent est mentionné dans l'inventaire de Mazarin, $1653 »^{41}$; ou « à trame soie et chaîne coton, généralement semé de fleurettes d'or ou d'argent sur un fond rayé de toutes nuances » selon G. Ducousso. ${ }^{42}$

Les documents d'archives ne proposent que peu de descriptions. En 1712, les cotonis sont «rayés à fleurs", ou "rayés "ou "humorés». En 1716 ou 18, l'origine «de Surate » est précisée, donc du Gujarat, région qui alimentait l'Empire ottoman. En 1737, le scripteur évoque des atlas cotonis, atlas rayés à cancanias, à œil de perdrix, des atlas cotonis à fleurs d'or, insistant sur la soie de l'atlas ou satin qui compose en partie le tissu.

\section{Sous le nom Kootnee, $n^{\circ}$ 569/570 sur le site du Victoria and Albert Museum, http://tmoi.org.uk}

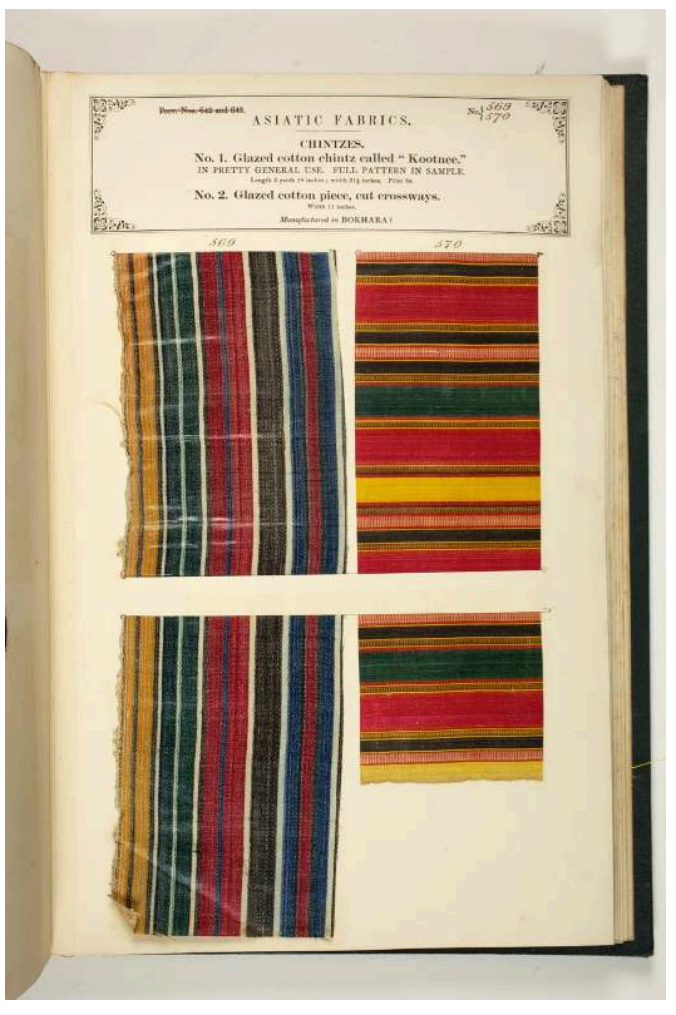

Les pièces sont petites : en 1725 , cinq aunes sur $9 / 16$ à $7 / 12$; en 1716 de cinq à $51 / 3$ sur $7 / 16$, pour les cotonis de Bernagor, ou de 6 à $6 \frac{11 / 2}{2}$ sur $9 / 16$ pour ceux de Sourate.

La valeur : 13,1 à 20 livres en 1725, 12 en 1760.

\section{Les kichorchaye}

Les kichorchaye ont été définis de façon rapide : « east indian cotton cloth » sans plus de précision pour Wingate cité par Wellington ${ }^{43}$, et «toile du Coromandel» pour Dermigny $^{44}$. Ils n'apparaissent dans les listes qu'en toute fin de période, 1767 et 68. Coincés entre les habassis et les chalbafs en 1767 et 1768 , les kichorchayes se sont vendus plus de 88 livres la pièce en 1767 , seulement 39 en 1768 . Nos sources ne font pas allusion à cet onéreux textile. 
61 Entre 1686 et 1717, des pièces d'akranshahi faisaient partie des bagages de quelques pèlerins morts à Damas en revenant de la Mekke ${ }^{45}$, qui avaient fait, en même temps que le pèlerinage, le commerce de tissus indiens. Dans leurs cargaisons retour, ces pièces d'akranshahi étaient parmi les plus onéreuses, estimées, dans un inventaire après décès à plus de 15 piastres (45 livres) ${ }^{46}$ On n'a jamais su identifier ce tissu. Comme les tissus mélangés soie coton sont fréquemment importés des Indes dans l'empire ottoman, cet akranshahi a toutes les chances d'être un tissu coton soie... et ressembler comme deux gouttes d'eau à notre kichorchaye, deux gouttes d'eau qui n'ont laissé aucune trace dans la littérature des textiles.

\section{Les montichours, les grana, les grisettes}

Les montichours, les grana, les grisettes ont été importées en tout petit nombre. Les montichours, ont été décrits par Savary: «Etoffe soie et coton, Indes orientales, cinq aunes par $2 / 3$ et huit aunes sur $2 / 3,3 / 4$ ou $5 / 6 . »^{47}$ L'emplacement de ces trois étoffes, au milieu des caladaris, alibanee, etc, suggère qu'il s'agit de tissus coton-soie. Mais aucune description d'aunage de valeur ni d'aspect n'existe dans les données d'archives.

\section{NOTES}

1. Crill Rosemary, «Textiles in Kutch », dans Chistopher W. London ed. The arts of Kutch, Bombay, Marg Publications, 2000, p. 118-126.

2. Legoux, op.cité, p. 368 sq.

3. Irwin John, op. cit., III, p.67.

4. Dermigny Louis, op.cité, p. 438.

5. Irwin John, op.cité, III, p. 69.

6. $1767,1768, \mathrm{CD} / 50 / 198$ et $\mathrm{CD} / 56$.

7. Irwin John, op. cit., III, p. 67.

8. Chaudhuri K.N. op. cit., p. 503.

9. Hobson-Jobson, op. cit., p. 706.

10. Savary Jacques, op. cit., p. 1588.

11. Irwin John, op. cit., III, p. 71.

12. Roques, p.95 et 96.

13. Chaudhuri, K.N., op. cit., p. 505.

14. Om. Prahash, How India clothed the world, the World of South Asian Textiles1500-1850, ed. by G. Riello, Titrhankar Roy, Brill, Leiden, Boston Brill, 2009, p. 242.

15. Savary, op. cit., p. 1704.

16. Irwin John, op.cité, I, p. 30.

17. Irwin John, op. cit., III, p.71.

18. Savary des Bruslons J., op. cit., I, p. 67.

19. Roques, Georges, op. cit., p.87.

20. Barthélémy, Adrien, Dictionnaire Arabe-Français, Dialectes de Syrie : Alep, Damas, Liban, Jérusalem, 2 vol., Paris, Librairie orientaliste Paul Geuthner, 1969. 
21. Irwin, John, I, p. 25.

22. Irwin, John, 1996/III, p. 66.

23. Hobson-Jobson, op. cit., p. 13.

24. Dermigny Louis, op.cit., p. 420.

25. Savary, op. cit., I, p. 759.

26. Savary, op. cit., I, p. 702.

27. Irwin John, op.cité, II, p. 67 et 68.

28. Chaudhuri, op. cit., glossaire.

29. Hobson-Jobson, op. cit., p. 705 et 706.

30. Savary, op. cit., I, p. 1100.

31. Legoux, op. cit., p. 132133.

32. Savary, op. cit., I, p. 1838.

33. Legoux, op. cit., p. 21 et 367-369.

34. Hobson-Jobson, op. cit., p. 708.

35. Irwin John, op. cit., III, p. 71.

36. Roques Georges op. cit., p. 89-93 et 207.

37. Barthélémy Adrien, op. cit., 1969.

38. Dozy, R., [1845], Dictionnaire détaillé des noms de vêtements chez les Arabes, réédition offset de l'édition d'Amsterdam, Beyrouth, Librairie de Liban, 1845.

39. Savary, op. cit., I, p. 1531.

40. Irwin john, p. 27.

41. Hardouin-Fugier, Elizabeth, op. cit.

42. Ducousso, Gaston, 1913, L'industrie de la soie en Syrie et au Liban, Beyrouth-Paris, A. Challemel

43. Wellington Donald, op. cit., p. 330.

44. Dermigny, Louis, op. cit., p. 440.

45. Establet Colette. Pascual Jean-Paul. Ultime voyage pour la Mecque, Damas, Institut français de Damas, 1998, p. 97.

46. La piastre est évaluée par Valérie Bérinstain, dans " La manière de négocier aux Indes, 1569-1691, de Georges Roques, à 3 livres à la fin du XVIIème siècle en France; et une piastre vaudrait deux roupies 6 pesas. (p. 209).

47. Savary, op. cit., II, p. 787. 


\section{Les soieries}

1 En nombre comme en valeur, les soieries ne représentent que moins de $2 \%$ des textiles vendus. Les plus fréquemment évoqués sont les satins (25\%), les damas (16\%), les gourgourans (15\%), les pékins (14\%), les armoisins (7\%), les taffetas (4\%).

\section{Les satins}

2 Le mot « satin » est l'équivalent européen du mot persan " atlas ». Dans les inventaires après décès ottomans damascènes qui renferment les noms des textiles trouvés dans les maisons et les boutiques, l'atlas est très souvent cité, le mot «satin" n'existe pas. $\mathrm{E}$. Hardouin-Fugier traduit atlas par « satin de soie, fabriqué aux Indes. $»^{1}$

3 «Étoffe de soye polie et luisante, dont la chaîne est fort fine, et sort en dehors; et la tremme (sic) qui est plus grosse est cachée toute en dedans. C'est cette manière de fabriquer le satin qui lui donne ce lustre et ce brillant "... note Savary qui traite dans un paragraphe spécial les satins des Indes... " étoffe assez semblable aux satins qui se fabriquent en Europe. Il y en a de plains soit blancs, soit d'autres couleurs. Il y en a aussi à fleurs d'or ou de soye, à carreaux, de damassés, de rayés et de brochés...Les pièces sont de quatre aunes et demi, de huit et de douze de longueur, sur $3 / 8,5 / 6$ et $5 / 8$ de largeur. $»^{2}$

Dans la vente de 1687, apparaît un satin « Kalquevir » à 40,5 livres la pièce ; s'agit-il du satin «calquier», que E. Hardouin qualifie de «sorte de taffetas (et non pas de satin) orné de dessins en forme de flamme?

5 C'est dans le catalogue de 1741 que l'on trouve la meilleure description des différentes variétés de satins : 185 rayés, 71 unis de $13 \frac{1}{2}$ à 14 aunes sur 7/8, et 150 dits «satin pour broder ", 13 1/2 à 14 aunes ou plus grands, 15 1⁄2 à 16 ; enfin, 84 satins rayés (de ces deux aunages) sur fond blanc, la plupart du temps, rayures vert, jonquille, bleu, rose ou autre fond, variété de couleurs des rayures, jonquille et gris de lin; ou encore satins à bouquets détachés brochés de 15 aunes à 15 1/2 sur 7/8, souvent brochés couleur sur couleur blanc sur blanc, citron sur citron, noisette sur noisette, paille sur paille, bleu sur bleu. 
Satins, inv. BAD 6752 (GG4), album d'échantillons, 1789, p. 243. Les Arts Décoratifs, Paris

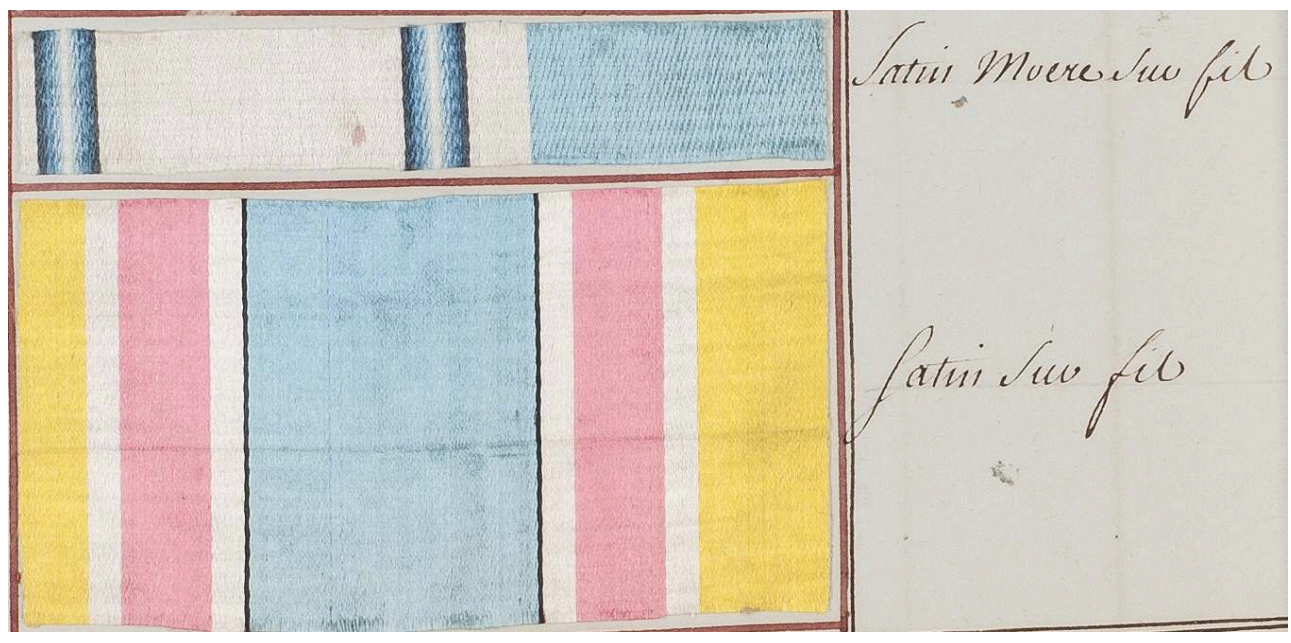

Photo Les Arts Décoratifs, Paris/Jean Tholance (photo soumise à accord préalable, rétrocession photo interdite)

6 Ces tailles sont confirmées en 1726 (13 1/2 à 14 aunes sur 7/12 à 5/8) et 1739, 14 aunes.

7 Les prix sont variables et s'envolent au cours des ans : un « satin façon de Séronge » n'a été estimé, en 1687, qu'à 3,9 livres ; 9,5 livres en 1691, de 70 à 73 en 1726 pour les satins unis, de 67 à 71 pour les satins rayés, unis ; 95 livres en 1739, 113 en 1760, 134 en 1768, et 252 pour les satins brochés.

\section{Les Damas}

8 Dans le dictionnaire de Savary, "étoffe faite de soie, dont les façons sont élevées audessus du fond. C'est une espèce de satin moiré ou de moins satinée ; en sorte que ce qui a le grain de satin par-dessus, l'a de moire par dessous. Le véritable endroit du Damas est celui où les fleurs sont relevées et satinées; l'autre côté n'est que l'envers... Damas de la Chine ou des Indes : ils sont de sept, onze et douze aunes de long sur $3 / 8$ et $7 / 16$ de large... Il y en a de ponceau (soit rouge vif, couleur de coquelicot), de noirs, de blancs, de rouges et noirs, de rouge et blanc. ${ }^{3}$ 
Damas, inv. BAD 6752 (GG4), album d'échantillons, 1789, p. 243. Les Arts Décoratifs, Paris

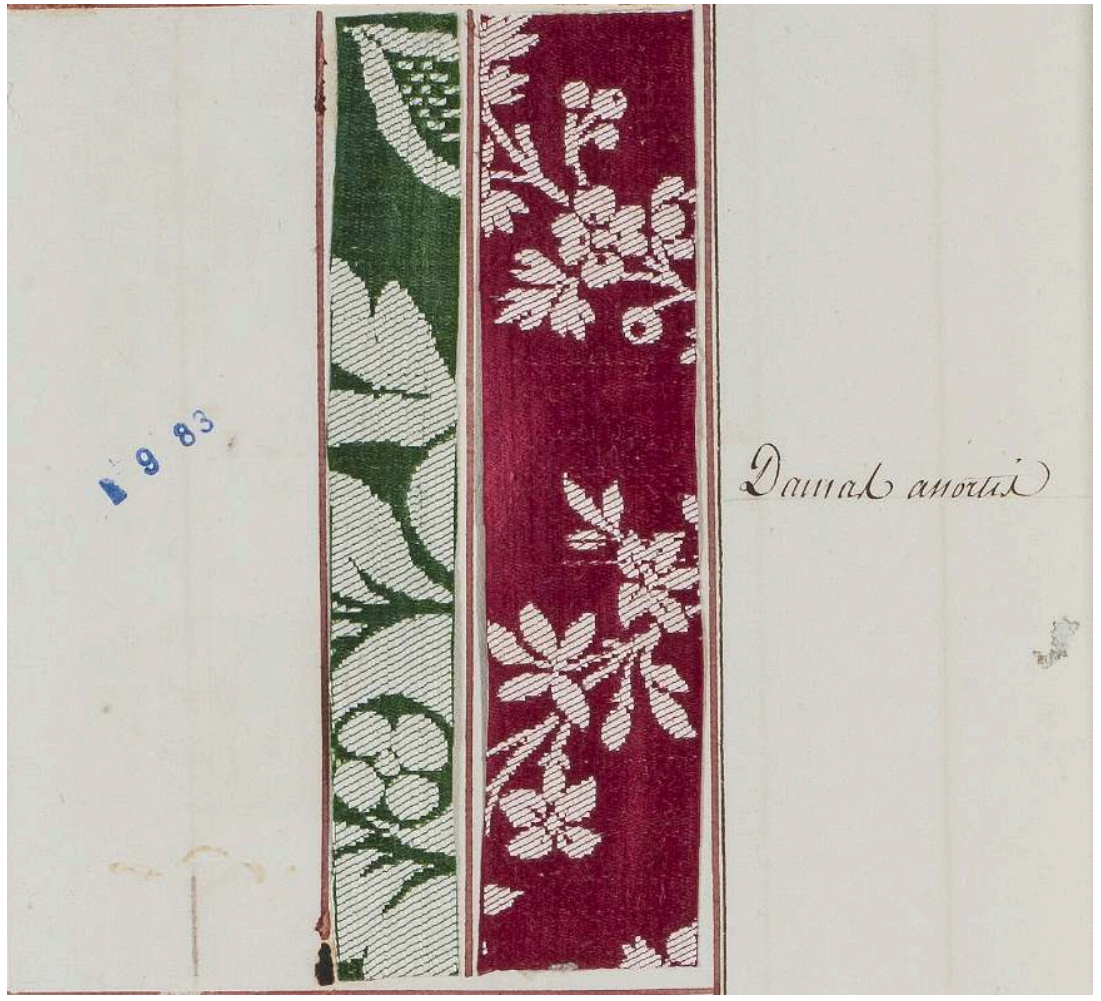

Photo Les Arts Décoratifs, Paris/Jean Tholance (photo soumise à accord préalable, rétrocession photo interdite) 


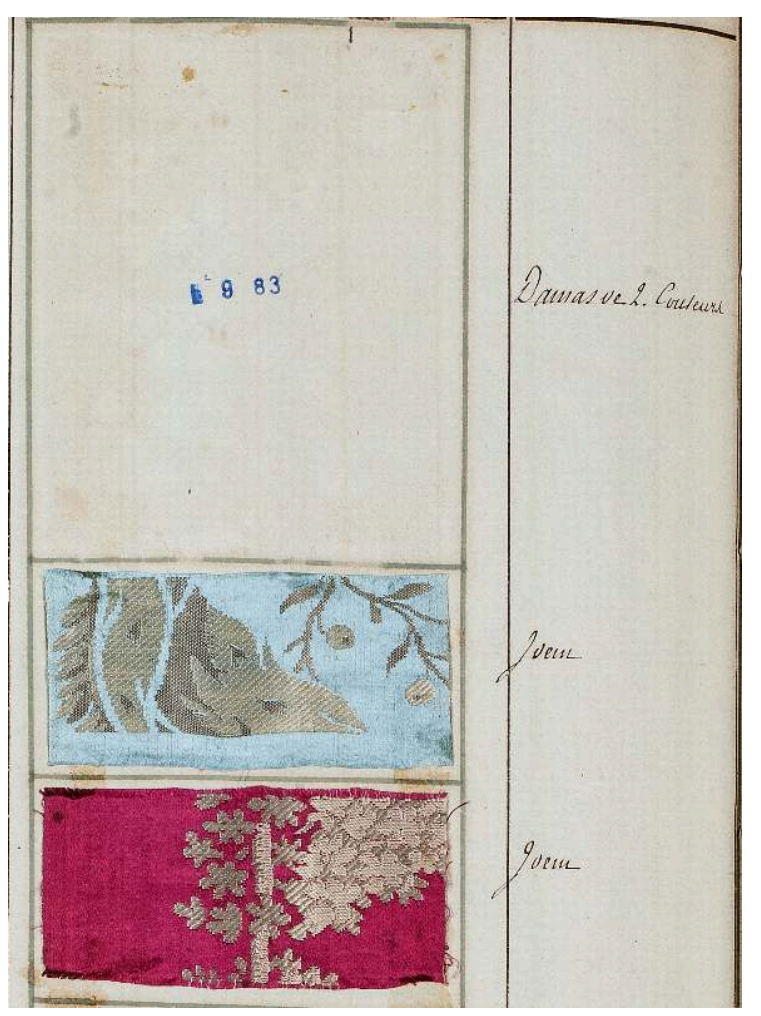

Photo Les Arts Décoratifs, Paris/Jean Tholance (photo soumise à accord préalable, rétrocession photo interdite)

Plusieurs descriptions de ventes permettent une bonne connaissance des multiples variétés de Damas, ayant des tailles différentes, toujours grandes, et atteignant des prix considérables.

En 1723, sont vendus des Damas à fleurs de couleur gros bleu, de 11 aunes et 1/2 à 12 aunes à 160 (les 5), 32 livres la pièce ; des damas sur 5/8, jonquille, jaunes dont un à plusieurs picq (?), blanches, bleu céleste, bleu turquoise, noisette, blanches (l' une à 14 aunes), à treize livres; des damas pour meubler, de $11 \frac{1 / 2}{2}$ à 12 sur $5 / 8$, avec des pièces jonquille, 39 livres; des damas cramoisis de 14 à 15 aunes sur 5/8, à 9 livres, ou de 15 à 16 aunes à dix et demi ; des damas à fleurs de 11 aunes et demi sur $7 / 16$, à fond bleu et blanc ou bleu et olive, à 65 livres.

En 1726 : des damas de 13 aunes $1 / 2$ à 14 , de 61 à 63 livres.

En 1739 : des damas unis 14 aunes à 90 livres, des damas à meubler de même aunage, à 108 livres ; des damas à meubler de 21 à 22 aunes, vendus de 138 à 143 livres.

Le catalogue de 1741, décrit dans le détail les pièces de damas proposés à le vente : 347 unis, (13 aunes $1 \frac{1}{2}$ à 14 sur 7/8, mais aussi de 15 à $15 \frac{11 / 2}{2}$ sur 5/6) : blanc, musc, grenade, paille, bleu, noisette clair ou foncé, gris cendré, gris ardoise, petit gris, gris perle, vert, brun, brun olivâtre, marron, jonquille, brun, café, bleu céleste et bleu turquoise, musc, blanc, grana, rose, rose foncé...; des damas unis à meubler (une vingtaine de pièces, de 20 aunes à $201 / 2$ sur $7 / 8$ à un peu moins), " pièces blanches pots de fleurs"; 179 damas rayés, à peu près des mêmes teintes (aunage $13 \frac{12}{2}$ à 14 sur $7 / 8$ ) : seule la teinte des fonds est donnée, de même nuance que celle des damas unis; une seule fois, le scripteur précise que le damas rayé est blanc et jonquille; des damas à deux couleurs (13 1/2 à 14 
sur $7 / 8$ ou $15 \frac{1}{2}$ à 16 , qui mêle le blanc au bleu céleste, au brun, gris cendré, grana, noisette foncé, noir.

En 1768, des damas rayés ont été vendus à 158 livres, des damas unis à 131, des damas unis étroits, à 197, des damas large à meubler à 340 livres.

\section{Les pékins}

13 «À l'origine, soie chinoise peinte...; par la suite le pékin reste un tissu à rayures dans le sens de la chaîne, constituées par des armures alternées dont l'effet est accentué à la teinture parce que les diverses contextures s'y parent de nuances différentes. $»^{4}$

Cependant, les données distinguent à chaque date des pékins unis et des pékins à rayures, et même des pékins peints.

Citons le catalogue de 1741 : sont vendus 565 pékins unis ( 13 13/2 à 14 sur $7 / 8$ ou 15 à 16$)$ dont les aunages varient un peu mais dont les couleurs se répètent, blanc, vert foncé, bleu céleste, bleu céleste foncé, bleu turquoise, noisette, brun grana, jonquille, vert naissant, petit gris, noir, gris cendré, musc, musc olivâtre ; et 396 rayés ( $15 \frac{1}{2} 2$ à 16 aunes sur 7/8) qui comportent beaucoup de bleu et gris perle, rayé de blanc et jonquille, blanc et gris de lin, bleu et gris perle, blanc et rose pâle ; les rayures sont petites ou larges.

En 1726 , un catalogue de vente évoque des pékins unis de $11 \frac{1 / 2}{2}$ à 12 sur $2 / 3$, à 43 à 45 livres; de $13 \frac{1}{2}$ à 14 sur $2 / 3$ de 52 à 53 livres; et des pékins rayés, de 11 1/2 à 12 sur $2 / 3$, à 48 livres; de $13 \frac{1}{2}$ à 14 sur 2/3, de plus de 50 livres. En 1739, le prix a monté à 66 livres ; en 1760 , à 67 ; et 1768 , à 110 pour des péquins rayés, à 130 pour des pékins unis, et à 192 pour des pékins peints.

\section{Les gourgourans}

17 Aucune description du tissu n'a été trouvée dans Savary. En revanche, l'Encyclopédie de Diderot ${ }^{5}$ décrit ainsi le textile : "étoffe travaillée en gros-de-Tours, mais plus forte en chaîne \& en trame; les soies n'en sont point moulinées, mais elles sont seulement gommées \& préparées par faisceaux de huit brins.... Le gourgouran vient des Indes, où l'on fait employer la soie comme elle se dévide de dessus les cocons. » Ou encore: " tissu de soie à raies armurées ou comportant des dessins ${ }^{6}$. E. Hardouin Fugier : évoque « une riche étoffe de soie des Indes...tissée en fil floche, tantôt unie, tantôt bayadère, souvent brodée. $»^{7}$

Ce sont des pièces de grande taille, et de valeur élevée.

Le catalogue de 1741 détaille ainsi, avec une grande précision, les gourgourans proposés à la vente : 992 gourgourans unis, de 13 et demi à 14 aunes sur 7/8, ou de 15 1/2 à 16 aunes sur 7/8, blanc, gris cendré, petit gris, perle, noir, bleu turquoise, brun, marron, noisette, vert, jonquille, petit gris, bleu céleste, bleu céleste foncé, paille, olivâtre ; et aussi huit pièces à fleurs brochées (de $11 \frac{112}{2}$ à 11 3/4 aunes) sur fonds bleu céleste ou foncé, ou blanc ou vert. »

19 En 1726 : les pièces, de $13 \frac{1}{2}$ à 14 aunes sur 5/7, valent de 75 à 78 livres, et des gourgourans rayés, 80 livres ; 82 en 1739 ; et 119 en 1768 . 


\section{Les Armoisins} armoisins de toutes les couleurs des Indes orientales » Et à Armoisin des Indes : «C'est un taffetas fabriqué aux Indes Orientales, mais plus faible et de moindre qualité que ceux qui se fabriquent en Europe. Les couleurs, surtout le cramoisi et le rouge en sont ordinairement fausses, et ils ont peu de lustre et point du tout de brillant... Il y en a de deux espèces, les arains qui sont des taffetas ou rayés ou carreaux, et les damavars qui sont des taffetas à fleurs. Leurs longueurs sont depuis sept aunes jusqu'à vingt-quatre et leurs largeurs depuis $7 / 8$ jusqu'à cinq sixième. $"^{8}$ Dans l'ordre des documents de ventes, les armoisins sont effectivement suivis par les darins et les jamavars.

21 En 1687 des « armoisins de diverses couleurs » apparaissent dans la vente, à 17,6 livres la pièce ; en 1691, à 17,4 ; en 1716 ou 18, les armoisins de 8 aunes à $81 / 2$ sur $7 / 8$ sont en majorité " assortis de couleurs différentes », et cramoisis, blancs, jaunes. Leur valeur, de 27 à 33,6 livres. De même aunage, des armoisins de Madras aux couleurs plus variées : cramoisi, blanc, jaune, gris, perle, bleu céleste, paille, de 30 à 32,7 livres. En 1725 , l'aunage et la valeur sont indiqués : de 8 aunes à $81 / 2$ sur $7 / 8$ à $11 / 12$. Le prix de 29 à 31 livres; 1726, les pièces sont de même taille, un moins onéreux, de 26,1 à 27,1 livres En 1768, venus du Bengale, les armoisins sont vendus 51,7 livres la pièce.

Le catalogue de 1741 évoque des «armoisins assortis, » de huit aunes sur 7/8 et plus, une majorité de blancs mais aussi des " perle, des jonquille, des citron, des rouge. »

\section{Les Darins}

Ces documents attestent la présence de darins et non pas d'arains (à une exception près). Une hypothèse est proposée : les darins et les arains sont un seul et même tissu, des taffetas rayés. Ce sont des pièces de petite taille (de 8 aunes à 8 1⁄2 sur $7 / 8$ en 1716 ou 18,1725 et 1741) ; des tissus décrits comme "rayés de diverses couleurs » (en 1716 ou 18), et 1741, "assortis de différentes couleurs et rayures, de huit aunes sur $7 / 8$ et plus. »

\section{Les jamavars}

Les jamavars des archives de vente semblent être les damavars cités par Savary, des taffetas à fleurs.

C'est en 1716 que ces tissus sont décrits avec le plus de précision : de 10 1/2 sur 5/8 les deux demi pièces; les rouges à fleurs dominent, accompagnés de pourpre, abricot, jaune, jaune citron, paille, chair, gris perle, bleu, vertes blanches diverses, à 70,5 livres. Dans un autre document de la même date, les rouges à fleurs dominent toujours, à côté des blancs, jaunes, gris, gris souris, izabelle ${ }^{9}$ de 60 à 67 livres.

En 1725 : les pièces sont plus grandes, de 11 et demi à 12 sur $2 / 3$ et la valeur, «à la pièce » de 63,5 à 68 livres.

Le catalogue de 1741 présente les jamavars comme des pièces de 8 aunes sur 7/8, " assortis de différentes couleurs et bouquets. »

Darins ou arains, jamavars, des armoisins soit à rayures, à carreaux, et fleurs brochées ? Sans doute peu différents des taffetas, ou des variétés de taffetas? 


\section{Les taffetas} lustrée $»^{10}$; ils sont également appelés armoisins, calquiere, arains. $»^{11}$ Savary, à «taffetas des indes ", précise ${ }^{12}:$ "Sont d'une fabrique assez faible et peu soyeux... Il y en a de façonnés, de rayés d'or et d'argent, de mouchetés, d'autres à chaînettes, d'autres à fleurs et à carreaux. Les calquiers sont des taffetas à flammes. Les taffetas longuis sont tous à carreaux ; les kemeas (présents en 1687 sous le nom de kencas) sont des taffetas à fleurs de soie...Les longueurs sont de quatre aunes $1 \frac{12}{2}$, de 5 1⁄2, de $71 \frac{12}{2}$, de 8 , de 11 , et de 25 , sur différentes largeurs, de $2 / 3$ à $7 / 8$. »

Roques ${ }^{13}$ écrivait : «On en fait de toutes les couleurs à la réserve des gris et noirs qui ne sont point de leur usage. »

En 1741, au nombre des marchandises prohibées qui seront vendues à condition d'être envoyées à l'étranger, figurent les taffetas rayés de $13 \frac{1 / 2}{2}$ à 14 aunes sur $7 / 8$, à fonds blanc rayés de musc, de jonquille de vert, de rose, de bleu.

En 1687, la vente comprend des taffetas kalquevir, sans doute l'équivalent des calquiers évoqués par Savary, à 26,9 livres la pièce. Trois ans plus tard, en 1691, 1000 pièces de «taffetas à carreaux », ont été vendues 3890 livres, soit un prix beaucoup plus faible, 3,9 livres la pièce. En 1760, des «taffetas foulard» ont été vendus, sans précision de quantité, pour plus de 9000 livres.

\section{Les longuis}

Associés aux taffetas, dans le même document de 1687, figurent les longuis, "à carreaux de pure soie » évoqués dans le Dictionnaire de Savary. Leur prix est de 17,3 livres la pièce. En 1726 sont vendus des longuis, au nombre des marchandises prohibées, de deux aunes et plus, à 5,4 livres, la pièce.

\section{Les kencas}

Des kencas ont une seule fois fait partie des ventes, en 1687. Sous le nom de Kemea, Savary décrit : « taffetas à fleurs de soye qui viennent des Indes. $»^{14}$ E. Hardouin Fugier a repris la même définition; « taffetas à fleurs de soie. $»^{15}$ Dans le dictionnaire ottoman Redhouse, les kancas sont des " étoffe à fleurs or et argent. »"16

Dans Le document de vente de 1687, le scripteur a écrit : "soie à fleurs rayé » et a inscrit la valeur de la pièce, 22 livres, donc un tissu onéreux, à cette date où les prix sont moindres. Pourrait-on traduire brocard?

\section{Les lampas}

Les lampas ne sont cités que deux fois, dans le Catalogue de 1741 et dans la vente de 1768. Sont-ce les lampasses, des «toiles peintes des indes" comme l'exprime Savary ${ }^{17}$ ou les lampas ou lampat que Wellington, citant Wingate, définit comme " un tissu semblable au damas, fait de soie... et de coton, originairement une textile de soie 
peinte $»^{18}$ ? On pencherait pour la deuxième définition car les lampas apparaissent dans les listes des lots vendus en même temps que les soieries, et même à la suite des damas rayés en 1741 ; et en 1768 , les lampas sont cités au milieu des tissus venant de Chine, et à la suite des Damas rayés. Leur valeur aussi, en 1768, suggère que l'hypothèse est bonne.

Damas lampas, inv. BAD 6752 (GG4), album d'échantillons, 1789, p. 239. Les Arts Décoratifs, Paris

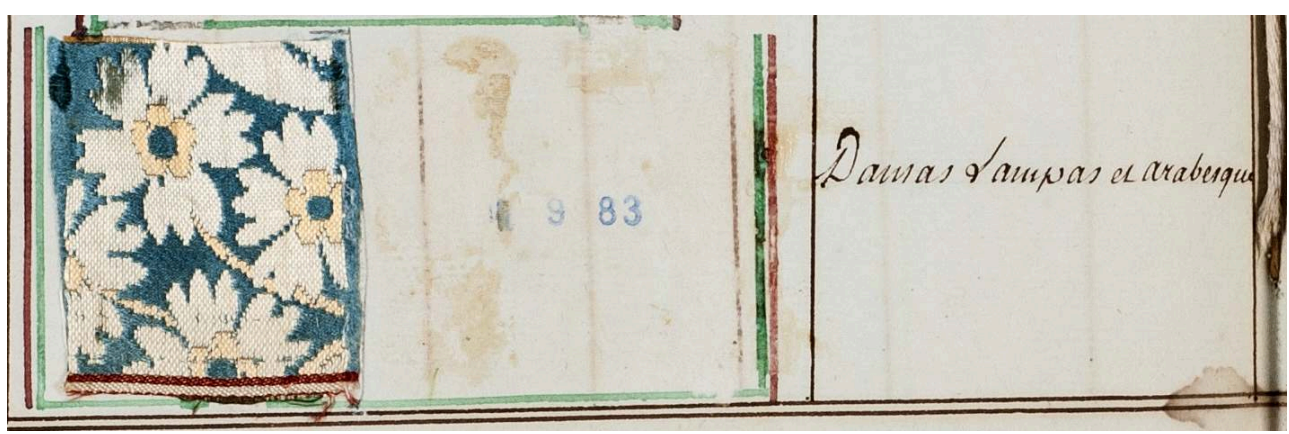

Photo Les Arts Décoratifs, Paris/Jean Tholance (photo soumise à accord préalable, rétrocession photo interdite)

En 1741, le catalogue les présente comme larges ou étroits ; 78 lampas larges $\left(13 \frac{1}{1 / 2}\right.$ à 14 sur 7/8), et 14 lampas étroits ( 11,5 à $113 / 4$ sur $1 / 2)$, «cannelés à ramages brochés », aux teintes déjà énumérées pour d'autres soieries : grana, noisette, vert clair, gris cendré, bleu céleste, bleu turquoise, vert foncé, ou naissant, jonquille, citron, rose.

En 1768, seule date à laquelle apparaisse une valeur, leur prix est très élevé : 262 livres la pièce.

\section{Les mandarines}

Les mandarines sont très rarement citées (en 1741 dans le catalogue, et en 1768 et 69, sans aucune description, ni aucun prix). En 1741, apparaissent quatorze "étoffes à carreaux ou mandarines ", de 13 1⁄2 à 14 aunes sur 7/8), sur fond bleu céleste, citron, jonquille, bleu turquoise, rose et rose vif.

\section{Les patissoyes}

Les patissoyes, «brocard de soie chinoise » selon Wellington, sont plus nombreuses. En 1741, seront vendues six variétés de patissoyes : de 13,1/2 à 14 aunes sur 7/8, ou de 15 ou $15 \frac{1}{2}$ sur 7/8, $15 \frac{1 / 2}{2}$ à 16 sur 7/8, ainsi que des patissoyes étroits unis, de 18 1/2 à 19 sur $1 / 2$, aux mêmes teintes variées, que les autres soieries, noisette, gris cendré, petit gris, gris perle, brun, brun foncé, jonquille, paille, noir, blanc, vert, bleu céleste, bleu turquoise, musc, citron, brun olivâtre.

37 Les pièces sont précieuses : en 1729, le prix de la pièce est de 93 livres ; en 1768, de 157 livres. 


\section{Les gongeras ou gingiras} 1691, dont le nom « bulbul » rappelle le rossignol, nom d'une célèbre mousseline, et le ...chamy peut-être bilad al sham, la Syrie, vendues pour huit livres.

Soierie, Bulbul Chamy, ${ }^{\circ} 585$ sur le site du Victoria and Albert Museum, http://tmoi.org.uk

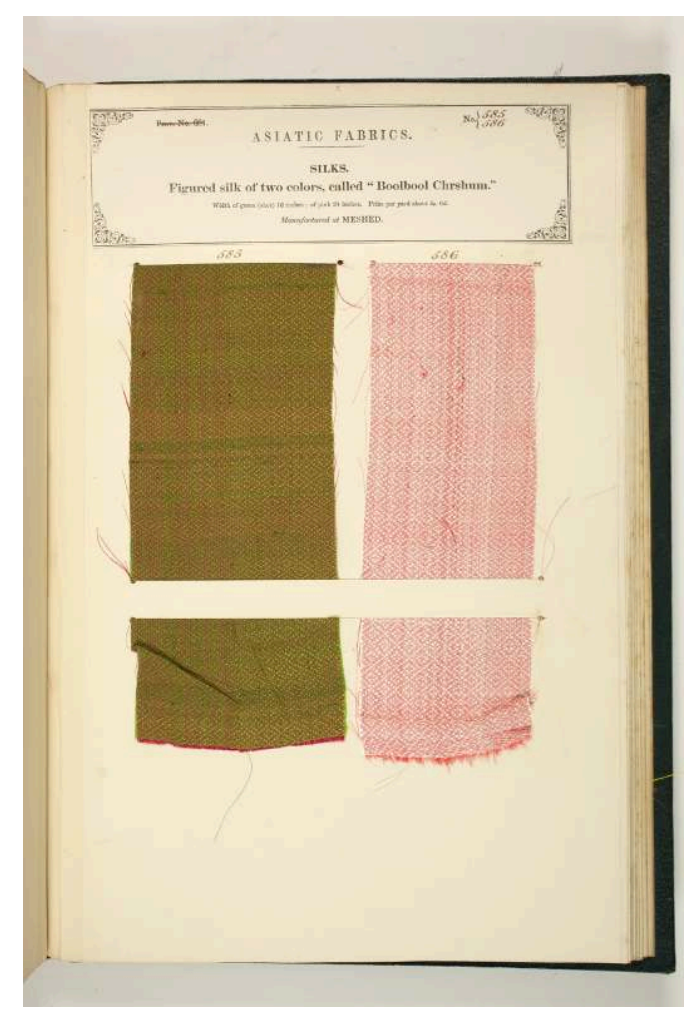

\section{Les velours}

41

En toutes petites quantités, quelques velours, «c'est le plus noble et le plus parfait d'entre toutes les étoffes de soie ", souligne Roques, qui a donc dû en voir fabriquer dans le Gujarat à la fin du XVIIème siècle. 


\section{NOTES}

1. Hardouin-Fugier E., op. cit..

2. Savary, op. cit., II, p. 1488sq.

3. Savary, op. cit., I, p. 1638 sq.

4. Hardouin-Fugier. E, op. cit.

5. Encyclopédie de Diderot, première édition, tome 7, 1757, p. 753.

6. IFTH, Gooogle, article Ameublement.

7. Hardouin-Fugier E., op. cit.

8. Savary, op. cit., I, p. 146.

9. Izabelle : jaune clair, paille, couleur de la robe d'un cheval.

10. Savary, II, p. 1673.

11. Savary II, p. 1646.

12. Savary II, p. 1677.

13. Roques, op. cit., p.95.

14. Savary, op. cit., II, p. 456.

15. Hardouin Fugier E., op. cit.

16. Redhouse, sir James. W. A turkish and english Lexicon, Beirut, Librairie du Liban, 1974.

17. Savary, op. cit., II, p. 484.

18. Wellington Donald, op. cit., glossaire.

19. Savary, II, p. 230.

20. Legoux, op. cit., p. 386 


\section{Les mousselines}

1 L'étymologie du terme a été présentée par Legoux: «masséli... dont a vraisemblablement fait le mot mousseline. »" Fukasawa la définit ainsi : "Mousseline est le nom générique donné à toutes toiles de coton à tissure peu serrée, fines et légères, spécialité exclusive de l'Inde avant la réussite de leur fabrication en Occident. Elles viennent du Coromandel, de Burhanpur en Inde Nord-occidentale" ${ }^{2}$, et surtout du Bengale: "Dans le nombre de diverses productions de l'industrie des Bengalis, la plus importante est l'article des mousselines. $»^{3} \ll$ Les toiles et mousselines [y] sont les plus belles du monde. $»^{4}$

2 Les différentes mousselines, occupent, en nombre, une part voisine du tiers des textiles vendus dans les ports français. Sur la part de leur valeur dans l'ensemble des tissus, nous ne pouvons que proposer des approximations : on ne possède les valeurs que pour peu d'années; de certaines mousselines, peu fréquentes, ou certaines variétés de mousselines, (en particulier les mousselines brodées), aucun prix n'a été enregistré.

3 En gros, d'après les chiffres proposés par Wellington, leur valeur globale représente un peu plus d'un tiers de la valeur des textiles importés (voir tableaux 6 et 7). Heureusement, en suivant les affichettes de vente, et de façon ponctuelle et désordonnée, on peut parfois mettre un prix sur chacune des pièces: il faudra s'y référer.

4 Les mousselines sont nombreuses; en voici les noms, classés par ordre alphabétique : des adatis, des aghabanee, alliballies, bétilles, casses, dissouchaye, doreas, doussoutis, jamdanis, mallemolles, mamobanis, nansouques, organdis, salasoye, serbatis, tangebs, tarnatanes, terindannes et toques.

5 Leur présence dans les ventes est plus ou moins importante. Si l'on écarte des comptes les plus de 8000 pièces de «mousselines " ne portant aucun qualificatif, les casses, les mallemolles et les bétilles occupent près de $2 / 3$ des ventes.

Tableau 8 : Nombre et proportion des différentes pièces de mousselines

\begin{tabular}{|l|l|l|}
\hline Noms des mousselines & Nombre de pièces & Proportion (\%) en nombre \\
\hline Casses & 506576 & 26,7 \\
\hline
\end{tabular}




\begin{tabular}{|c|c|c|}
\hline Mallemolles & 351179 & 18,5 \\
\hline Bétilles & 300127 & 15,8 \\
\hline Dorea & 175853 & 9,3 \\
\hline Tangeb & 131730 & 6,9 \\
\hline Terindanne & 130579 & 6,9 \\
\hline Organdis & 100700 & 5,3 \\
\hline Tarnetanne & 88108 & 4,6 \\
\hline Toque & 50978 & 2,7 \\
\hline Adatis & 23735 & 1,2 \\
\hline Nansouques & 15392 & 0,8 \\
\hline Stinquerke de mousselines & 7962 & 0,4 \\
\hline Serbatis & 6358 & 0,3 \\
\hline Doussoutis & 5599 & 0,3 \\
\hline Jamdanis & 2517 & 0,1 \\
\hline Alliballies & 646 & 0,0 \\
\hline Salasoye & 466 & 0,0 \\
\hline Aghabanee & 450 & 0,0 \\
\hline Mamobobanis & 329 & 0,0 \\
\hline Total & 1899284 & 100,0 \\
\hline
\end{tabular}

6 Et, avec les nuances exprimées plus haut, une fois encore ôtées les simples «mousselines» sans nom précis, les casses, surtout, mais aussi les doréas, les mallemolles, les bétilles et les térindannes ont rapporté $88 \%$ des ventes de mousselines.

Tableau 9 : part occupée par les différentes pièces de mousselines dans la valeur totale des ventes de mousselines

\begin{tabular}{|l|l|}
\hline Noms des moussellines & Pourcentage en valeur (\%) \\
\hline Casses & 38 \\
\hline Dorea & 16 \\
\hline Mallemolles & 14 \\
\hline
\end{tabular}




\begin{tabular}{|l|l|}
\hline Bétilles & 10 \\
\hline Terindanne & 10 \\
\hline Tangeb & 6 \\
\hline Organdis & 4 \\
\hline Nensougues & 2 \\
\hline Toques & 1 \\
\hline mousselines de soie & 0 \\
\hline Jamdanis & 0 \\
\hline Adatis & 0 \\
\hline Dissouchaye & 0 \\
\hline Total & 100 \\
\hline
\end{tabular}

\section{Les casses}

$7 \quad$ Les casses sont les plus fréquentes des mousselines importées. Mousselines ou très fines toiles de coton ? Le mot viendrait peut-être de l'arabe, khâssa, « spécial » ${ }^{5}$, Legoux les décrit comme "une espèce de toilerie qui a toute la finesse, tout le moelleux des plus belles nensouques... La casse a aussi un grain parfaitement uni et un tissage lisse et serré, mais son fil est plat et celui de la nensouque est rond et très tordu. $»^{6}$. Il classe les casses parmi les toiles fortes, sans doute à cause de ce tissage serré. Les pièces, ajoute-til, portent toutes «à peu près huit aunes $1 / 3$ de Paris. Pour Dermigny, les casses sont une " variété de mousseline fine du Bengale, en pièces de 14 ou 16 aunes sur 5/6, 7/8, $11 / 12,13 / 12$ et 15/12 de large. Comme les baffetas, elles portent diverses appellations. Un document de 1750 énumère des variétés de casses, sans en donner ni description, ni explication : casses Bouray, casses Caury, casses Coquemarie, casses Sagrenapour, des noms de lieux?

8 Elles servent à différents usages, explique Legoux ${ }^{7}$, avant tout des chemises. J. Irwin émet l'opinion que les casses exportées en Europe sont des mousselines blanches simples de moyenne qualité, les meilleures étant réservées au Moyen et Proche-Orient. ${ }^{8}$ La variété de ces pièces, en taille et en qualité, explique sans doute de grosses variations de prix : de 30 à plus de 100 livres.

9 À toutes les époques, les casses se présentent sous des tailles différentes : soit 8 1/2à 9 aunes de longueur, sur près de 7/8, ou même $9 \frac{112}{2}$ à 10 sur 11/12à $15 / 16$; soit, le plus souvent, $15 \frac{112}{2}$ à 16 aunes.

10 Certaines casses, en 1716, sont brodées de soie et or. Les mousselines sont particulièrement bien décrites en 1719 : ces casses du Bengale sont de 8 aunes ou plus, ou de 15 1/2 à 16 sur 3/4, de $15 \frac{112}{2}$ à 16 sur $3 / 4$ et sur $7 / 8$ à $11 / 12 ;$ de $15 \frac{1 / 2}{2}$ à 16 sur une 
aune et plus; de $15 \frac{1}{2}$ à 16 sur une aune $1 / 4$ ou sur une aune $3 / 4$; quelques-unes sont à lisières d'or, ou or et argent. Et en 1739 : de $91 \frac{1 / 2}{2}$ à 10 sur 11/12 à 15/16, de 15 aunes sur près de $3 / 4$; ou près $7 / 8$ à $11 / 12$; sur une aune, I aune $1 / 8$. En 1741,14 lots sont de 9 aunes et 358 de 15 à $15 \frac{1}{2}$ aunes. Le Catalogue de 1741 précise que la grande majorité des casses portent des lisières blanches; mais les casses à lisières d'or existent en quantité non négligeable.

11 La taille (surtout la largeur) de la pièce et sa finesse en font la valeur. En 1687, 30 livres. En 1716 ou 18, les casses du Bengale de $8 \frac{11}{4}$ sur près de 7/8, dont certaines rayées de fil écru, sont à 20 livres. De $15 \frac{1 / 2}{2}$ à 16 sur près de $3 / 4$, de 20 à $27 ;$ sur $7 / 8$ de 36 à $48 ;$ sur $7 / 8$ à $11 / 12$ à $15 / 16$, de 49 à 55 ; sur une aune, de 50 à 60 ; sur une aune $1 / 6$, de 60 à 80 ; sur une aune $1 / 4,79$ à 81 . En 1719, les casses du Bengale les plus petites ont été vendues de 26 à 35 ; celles de 15 1⁄2 à 16 aunes de 53 à 67 ; celles à lisières d'or et d'argent, de 82 à 93 . En 1731, 36 livres. En 1738, « les casses depuis les basses sortes jusqu'au plus fines ont été adjugées de 22,10 à 96 livres ». En 1767 et 1768, les prix sont moins élevés (30, 48 et 49 livres), mais on ne sait rien des tailles ni de la finesse des pièces importées. Pour Legoux, le prix d'achat est de 54 livres.

\section{Les mallemolles} ou 15 1/2 et 16 aunes (à deux exceptions près). En revanche, la largeur varie : 5/6, 7/8, 11/12, ou une aune ou plus d'une aune (en 1719, en 1741). Le catalogue de 1741 donne aux mallemolles différents types de lisières : lisière, ou demi (lisière ?), blanche, ou or. atarasoye (de 18 aunes) : ces mallemolles de coton seraient-elles mélangées de fils de soie? Savary, à l'article mallemolle, souligne : «quelques-unes sont rayées d'or et de soye. $»^{14}$ Wellington, dans son tableau 10 , note l'existence, parmi les marchandises vendues, de "mousselines de soie. » Irwin, en revanche, pour une période antérieure, note que la mallemolle est souvent brodée de motifs floraux. ${ }^{15}$ Effectivement, les archives évoquent des mallemolles souvent brodées $(1718,1719,1723,1726,1738)$, «de différents dessins » (1719), à " ramages et colonnes » (1723, et alors de plus petite taille, (4 aunes sur 3/4 à 5/6); ou appelées «assara», "dome» (1738), type de mousselines qu'un document de 1747 classe parmi les mousselines brodées.

La valeur de la mallemolle varie donc beaucoup, avec son degré de finesse, l'existence ou l'absence de broderies, les sallasoye et atarasoye: les mallemolles suivies d'aucun qualificatif se vendent entre 35 et 121 livres, (à l'exception de 1691, 9 livres); les 
mallemolles brodées de 57 à 80 (les dome sont plus chères que les assara), les mallemolles brodées de différents dessin de 110 à 134. Parmi les plus onéreuses sont les salasoyes (93 à 108) et les atarasoyes, (de 18 aunes en 1738), de 108 à 140. Les pièces sont plus ou moins "piquées ", et ce défaut diminue le prix de vente. Pour Legoux ${ }^{16}$, le prix d'achat en serait, à son époque, de 189 francs la pièce, ce qui paraît élevé : soit les prix ont monté à la fin du siècle, soit il s'agit d'une mallemolle particulièrement brodée et fine. Dans How Indian clothed the world ${ }^{17}$, Om Prakash, dans son article estime le prix d'achat de la mallemolle, en Inde et en 1767, à 11 à 24 roupies sicca, soit de 29,7 à 64,8 livres.

Quelques suggestions : «Il y a une autre mallemolle que l'on appelle tarnatane » écrit Savary ${ }^{18}$ Or, l'on trouve bien des tarnatanes parmi les mousselines, mais associées aux bétilles et non aux tarnatanes. Nous traiterons donc des tarnatanes à la suite des bétilles.

19 Faut-il considérer les rares dissouchae, comme les doulebsaies, de Savary « un type de mallemolle, de 16 aunes et demie » ? ${ }^{19}$ En 1739 , les pièces sont de $7 \frac{1 / 2}{\text { sur près de } 3 / 4 \text {, à } 26}$ livres; de 26 à 27 , en 1738.

\section{Les bétilles}

Bétilles et doréas ne sont pas toujours «transparents » : Legoux de Flaix ${ }^{20}$ intitule un de ses sous chapitres, «doréas OU bétilles » et souligne qu'une mousseline de la Côte se nomme doréa, alors qu'en réalité il s'agit d'une bétille, qui ressemble aux doréas du Gange. Se ressemblent-elles? Ses remarques brouillent un peu l'image que l'on peut se faire des deux tissus. Tous les deux des mousselines certes. Mais le Catalogue de 1741 distingue bien les bétilles de la Côte des doréas du Bengale. La différence est d'abord une différence d'origine géographique du tissu : côte de Coromandel et Bengale. Pour Roques, qui voyage une cinquantaine d'années avant 1741, «La bétille est la reine de toutes les toiles. $»^{21}$. Pour Legoux, sous le nom de doréas de la Côte : "mousseline souple, légère, à double raie plate, ou à deux rayures larges au milieu desquelles se trouve une petite raie ...ou deux rayures étroites sur chacun des côtés et une raie large au milieu. $»^{22}$ Savary n'est guère plus clair dans ses définitions : «Bétille : mousseline... de trois sortes : la première appelée simplement bétille est un peu grossière...Sa largeur ordinaire est de $5 / 6$ et la longueur de 16 et de 20 aunes...La deuxième nommée bétille organdi a le grain rond et est très fine...12 aunes et demi de long sur $3 / 4$ et $5 / 6 \ldots$..La troisième qui s'appelle bétille tarnatane est fort claire, $12 \frac{1}{2}$ à13 aunes sur $7 / 8$ de large. $»^{23}$ Pour Irwin, les mousselines, dans le Deccan, portent le nom de «bétilles ». Elles sont souvent teintes en rouge et quelquefois à rayures. $»^{24}$

Dans les affiches de vente, ces trois textiles sont présentés à la suite, comme s'il existait entre eux une ressemblance.

Si l'on suit le détail des archives, c'est la taille de la pièce qui permet de distinguer ces différents types, ou noms, de bétille : les bétilles « ordinaires ou diverses» sont les plus longues, de 15 1/2 à 16 aunes sur des largeurs diverses; les bétilles chavonis ou simplement dénommées chavonis sont de 6 à $6 \frac{1 / 2}{2}$ sur $2 / 3$ sur diverses largeurs; les betilles taranatane, ou simplement tarnatanes, de 12 à $12 \frac{1}{2}$ sur largeurs diverses. Dans le Catalogue de 1741, les tarnatanes ont une mention spéciale et sont bien de 12 aunes, les chavonis, eux aussi traités à part, sont de 6 aunes; les bétilles diverses de 15 1⁄à à 16 
aunes, et même de $19 \frac{1}{2}$ à 20. Il n'est jamais question de bétilles organdis. Parfois, le document signale l'origine, Golconde en 1704.

Quant à l'apparence de ces textiles, peu de renseignements existent : «blanches » en 1687, à côté de « bétilles diverses »; « fines, ou « encore plus fines » ou « moins fines » à plusieurs dates. Sont-elles à rayures parfois, comme le suggèrent Legoux et Irwin, aucune archive ne l'indique. Seule, la couleur blanche est signalée, et pour les bétilles, et pour les chavonis, et pour les tarnatanes.

24 La valeur dépend de la longueur (essentiellement), de la largeur et de la qualité de la pièce. Les bétilles « diverses " sans précision se sont vendues entre 7 et 19 livres à la fin du XVIIème, de 20 à 43 en 1718, de 30 à 56 en 1725, de 30 en 1731, de 30 à 62 en 1739, de 38 en 1768 ; exceptionnellement pour les plus larges et longues et fines (20 aunes de longueur sur plus d'une aune) autour de 60 livres.

Les chavonis, pièces courtes, ont été vendues entre 7 et 10 livres. Les tarnatanes, plus longs, toujours plus onéreuses, de 16 à 27 ; les plus fines et sur plus d'une aune, de 33 à 57 livres en 1726 ; exceptionnellement à 80 livres, de une aune 5/6, en 1739 .

\section{Les doréas}

Les doréas ont une double origine géographique, le Bengale et de la Côte de Coromandel; les affichettes de vente, et toutes les autres sources, attestent donc qu'existe cette double localisation.

« Mousseline, ou toile de coton blanche...venant... particulièrement du Bengale. Il y en a de grosses et fines, de rayées et à carreaux. La longueur de la pièce est ordinairement de 16 aunes sur 7/8 de large. $»^{25}$ Le mot vient de l'hindi, lit-on dans le glossaire de Hobson-Jobson: doriyâ, tissu à rayures ${ }^{26}$. "Mousselines rayées ou quadrillées du Bengale, très variées en genre et en finesse, en pièces de 8 ou de 16 aunes sur 5/6 à 5/4 de large... Doréas Tiranamellé, du Coromandel, en général bien fabriquées, mais moins fines que celles du Bengale, en pièces de 16 aunes sur 5/6. ${ }^{27}$ « Mousseline à rayures ou à carreaux tissée dans l'aire de Malda Kasimbazar ", décrit J. Irwin. ${ }^{28}$ Quant à notre indispensable Legoux : «leur véritable nom est bétille dans l'idiome des Tamouls, car les doréas...se fabriquent dans le Bengale »... et il consacre plusieurs pages, dans la partie de son livre qui concerne la Côte, décrivant le tissu qu'il rapproche, voire confond avec les bétilles. Quand il décrit les exportations du Bengale, il revient aux véritables doréas : "cette doréa est une espèce de jamdani qui participe de la mallemolle du Bengale et de l'organdi de la côte.» On les distingue par leurs rayures : " elles sont fortement battues...Les rayures des doréas de la Côte sont plus serrées. » ${ }^{29}$ 
Dorea, sous le nom de dooreea sur le site tmoi.org.uk, $\mathrm{n}^{\circ} 247$.

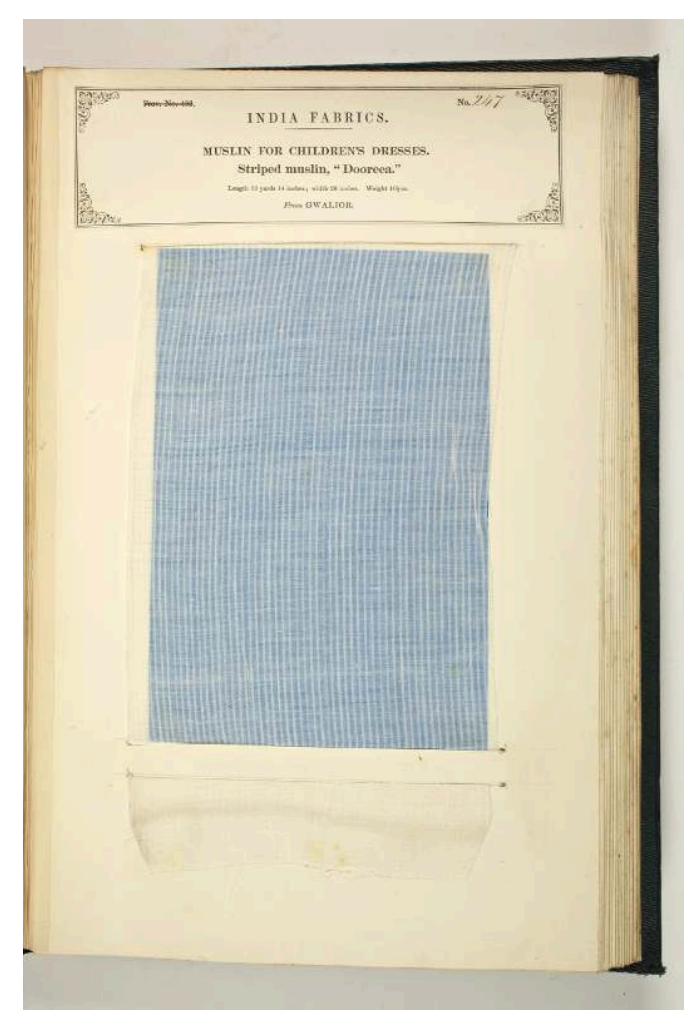

Dorea dit sullah sur le site tmoi.org.uk, $\mathrm{n}^{\circ} 323$.

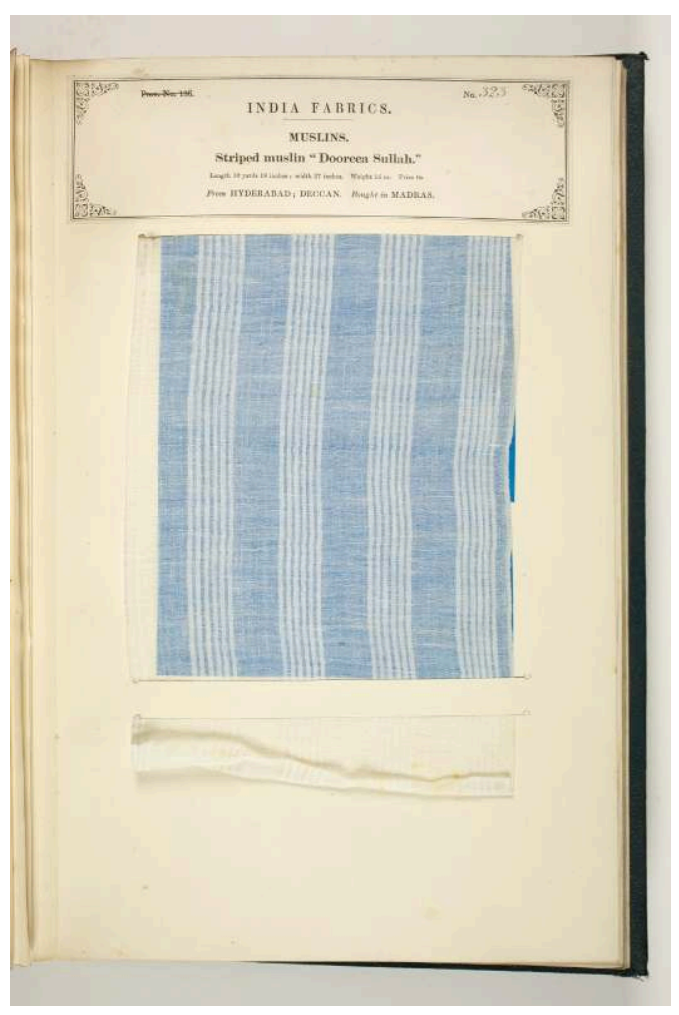


Dorea sous le nom de Charkhana Sullah sur le site tmoi.org.uk, $n^{\circ} 327$.

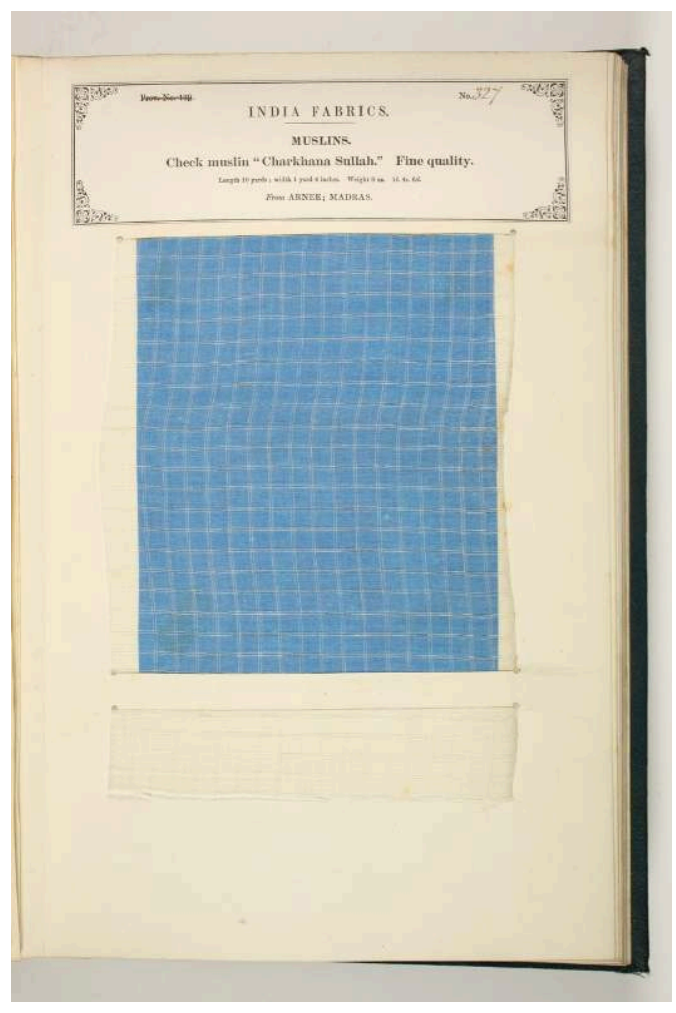

Doreas sur le site tmoi.org.uk $n^{\circ} 247,248,249,281,283$, et 323 . Ci-dessous $n^{\circ} 281$

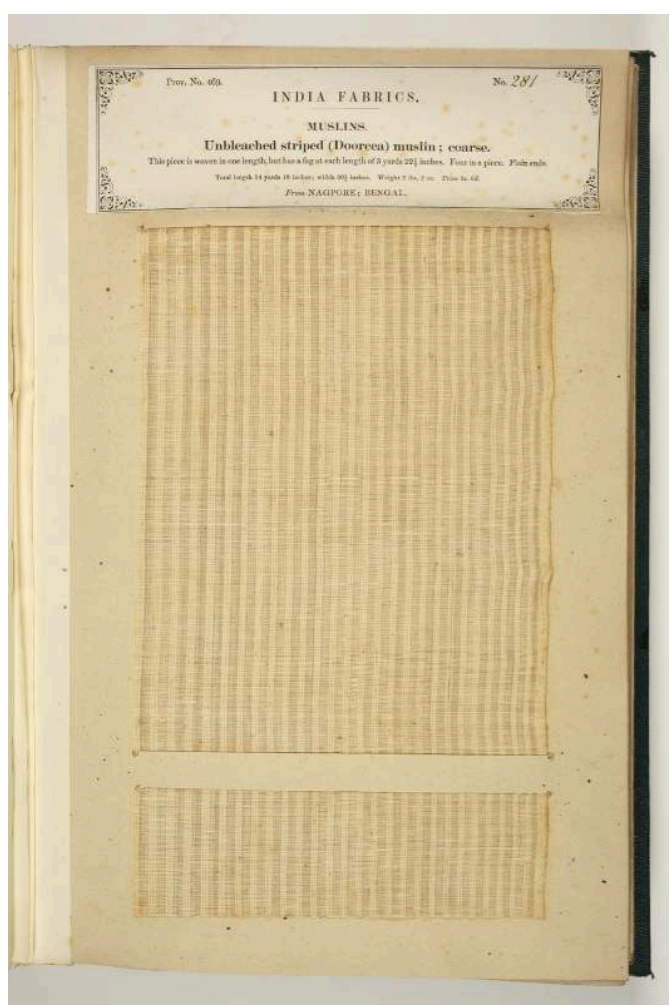

À travers un document de 1716 ou 18, l'image de la pièce s'éclaire : les doréas sont des mousselines à rayures, dont la taille peut être petite, moyenne ou grosse et parfois 
rayées de fil écru; en 1716, peu de carreaux; au moins certains sont bordés d'une lisière d'or. Elles ont été vendues entre 62 et 82 livres. Le Catalogue de 1741 aussi consacre 21 pages à une description minutieuse et variée de chacune des pièces de cette mousseline, de 15 ำ à 16 aunes : blanches ou rousses, la plupart sont bordées de lisières, d'or, la plupart à carreaux de taille différente.

Dans les ventes se trouvent aussi des doréas «Cachioura » $(1741,1750)$ adjectif accolé au nom de certaines mousselines brodées (mallemolle Cachioura), ou même de jamdani et des doréas Chandercona, lieu que Dermigny ${ }^{30}$, place dans district situé à l'ouest de Chandernagor.

Les pièces de doréas de la côte de Coromandel mesurent 12 à 12 1/2 aunes sur 5/6, rarement 15 1/2 à 16 sur 5/6 (1725) tandis que les doréas du Bengale sont plus longs, 16 aunes sur $3 / 4$ à 5 à $5 / 6$ ou $7 / 8$ à 11/12).

31 Les doréas de la Côte semblent moins estimés que ceux du Bengale, à cette date du moins, 1725 : de 40 à 53 livres, de 53 à 100 pour les doréas du Bengale. En 1760 les doreas de la côte ont été vendus 64 livres, les doréas du Bengale, à 76. Legoux ${ }^{31}$ donne aux doréas de la Côte qu'il nomme bétilles, un prix d'achat de 336 francs la courge, près de 17 livres la pièce ; pour les doréas du Bengale, un prix achat de 43,2 livres pour les doréas du Bengale.

La valeur des pièces varie donc beaucoup ; le prix moyen se situe entre 55 et 75 livres exceptionnellement plus de 100 livres.

La largeur de la pièce influe sur sa valeur : en 1726 , les doréas de 12 à 12 1/2 sur 3/4 à 5/6 valent 45,5 livres; de 16 aunes sur près de $7 / 8$, de 58 à 65 ; de 16 aunes sur $3 / 4$ à $5 / 6$, de 70 à 73 ; sur $7 / 8$ à $11 / 12$, de 79 à 90 livres; la finesse également: en 1738, les doréas communs (de 16) ont été vendus de 39 à 44 livres, de sortes supérieurs, de 58 à 73 ; les plus fines, de 92 à 120 ; les superfines de 129 à 152. Om Prakash, dans How India clothed the world en estime le prix d'achat, en 1767, de 12 à 16 roupies sicca, soit de 32,4 à 43,2 livres.

Il existe également des doréas brodés, parfois groupés dans un chapitre spécial, «broderies diverses »: doréas brodés à 100 livres en 1731 ; doréas assara, en 1750 ; et doréas Cachioura ou Chandercona. Leur valeur en est importante : en 1719, 110 livres ; 1731, 60, (plus du double d'un doréa simple); en $1738: 267 ; 1739,280$ à 293 livres.

\section{Les nansouques}

Nainsukh, une belle mousseline «Plaisir des yeux $»^{32}$. Legoux affirme «qu'elles forment le principal assortiment de nos cargaisons. »Cependant, les données, dont le Catalogue de 1741, infirment la remarque : les nansouques ne comptent que pour moins de $1 \%$ dans le nombre de pièces de mousselines importées. Quant à Savary, il ne mentionne pas même le nom de nansouques, ni dans le Dictionnaire, ni dans son article général sur les mousselines. ${ }^{33}$ Legoux lui consacre de nombreuses pages ${ }^{34}:$ "la plus belle des mousselines ", "toile de coton dont le tissu se fait avec un fil d'une finesse extrême. Son réseau doit être très serré sur la chaîne et sur la trame, quoique simple et très uni, sans inégalité et sans rayures dans la pièce... 16 aunes sur $5 / 4$ de large »... Puis il insiste sur la finesse plus ou moins grande qui s'explique par le nombre de fils utilisés, de 3000, 3500 et 4000 fils, « les plus belles fabriques à Dacca... Se distingue par l'égalité, l'uni et le reflet très blanc de ses fils et leur rondeur parfaite... Large tête en fil d'or et une petite 
barre d'une ligne et demie de ce même fil qui termine la pièce ; celle-ci est en outre liserée d'un cordonnet de cinq à six brins de soie verte; on voit sur le milieu de la largeur de la tête une petite pyramide brodée en coton rouge. »

Nansouque, sous le nom de nyansook, sur le site tmoi.org.uk n 245

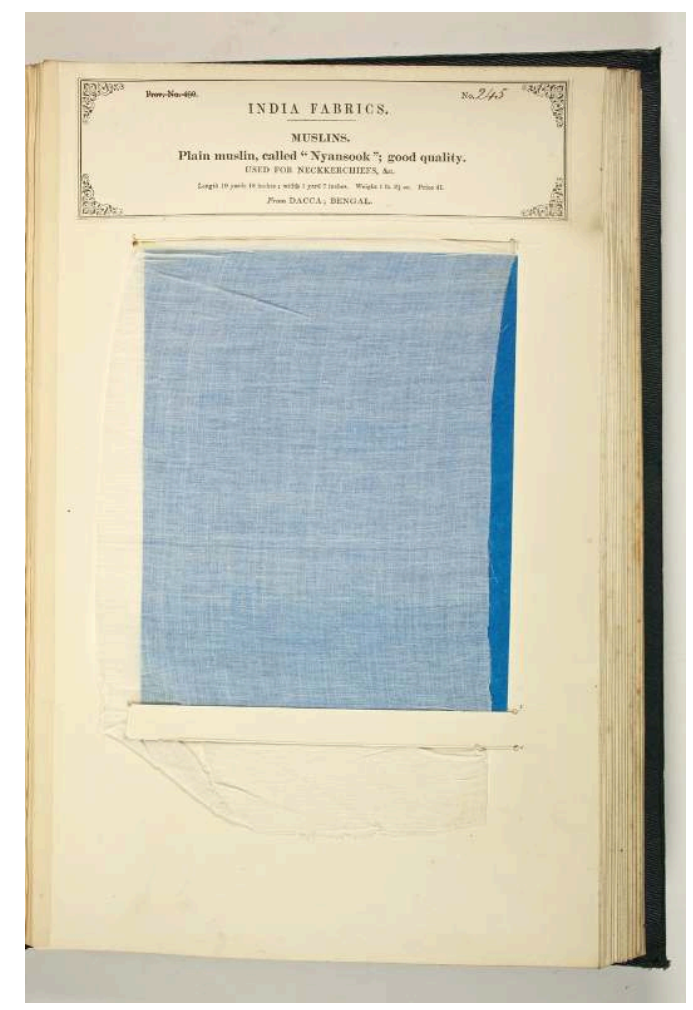

"Autre mousseline dans le genre des mallemolles ", constate simplement Blancard. ${ }^{35}$ Pour Dermigny : «mousseline dans le genre des mallemolles en pièce de 8 et 16 aunes sur $5 / 6$ et une aune. $»^{36}$

Les longueurs attestées sont bien de $15 \frac{1}{2}$ à 16 aunes sur des largeurs qui varient : 3/4 ou $7 / 8,5 / 8$ ou 11/12. Seules les pièces dites "nensouques Assara " sont d'une demilongueur, huit aunes. Une seule fois, en 1719, la nansouque est dite «rayée de fils écrus. »

Les nansouques sont souvent brodées, peut-être d'un point de chainette: «ces broderies sont bien exécutées sans doute...Dans l'Indoustan, on ne connaît que la broderie point de chaînette. ${ }^{37}$ Ces nansouques brodées sont dites assara, dome, japonis, maramat, sans que l'on connaisse la signification de ces adjectifs : noms de lieux ? Types de broderies ${ }^{38}$ ?

39 La valeur des nansouques est très élevée, entre 60 et 85 livres suivant la taille, et suivant la finesse de la pièce. Les nansouques brodées sont chères. En 1731, la nansouque s'est négociée à 60 livres, la nansouque assara à 70. En 1738 et 39, existent des nansouques japonis, assara de huit aunes, dome de 15 1/2 à 16 : les japonis et les assara se sont vendues entre 124 et 146 livres, les dome, plus grandes, entre 240 et 280 livres.

Legoux donne un prix d'achat: les plus fines des nansouques, achetées 216 livres la pièce ; 164 pour les moyennes ; 112 pour les plus ordinaires, prix qui paraissent élevés. 
41 Mallemolles, nansouques et doréas apparaissent souvent sous forme de demi-pièces dont le prix d'achat est plus élevé que celui des pièces entières, remarque Legoux. ${ }^{39}$

\section{Les organdis}

42 "Sorte de bétille ou toile de coton » définit Savary ${ }^{40}$, qui renvoie d'ailleurs à l'article "mousseline». A l'article bétille, Savary note que la « bétille organdi a le grain rond et est très fine. La pièce contient 12 aunes $1 / 2$ de long sur $3 / 4$ et $5 / 6$. $»^{41}$

« Il est peu d'articles des exportations de la Côte de Coromandel...dont le nom soit plus connu que celui de cette espèce de marchandise...L'organdi est une espèce de mousseline...[dont les caractères sont les suivants]: «Elasticité et raideur du fil,... arrangement des brins de coton dans la chaîne et la trame...,tous les fils espacés à une égale distance... la tête des pièce porte un liseré de fil d'or "; Legoux ${ }^{42}$ consacre cinq pages exaltées à la fabrication de ce tissu. «Tissu très clair mais fil très fort » remarque Blancard ${ }^{43}$; tissu vendu entre 47 à 70 livres. " Tissu très clair et fil très fort » reprend Dermigny. ${ }^{44}$

44 Les données ne contiennent pas de meilleure description du tissu. En revanche, l'aunage de la pièce semble beaucoup plus varié que ne l'indique Savary : si, à toutes les dates, la taille de 12 à $12 \frac{1}{2}$ a été notée, sur des largeurs variées, $(7 / 8,9 / 16,5 / 6,3 / 4$, une aune et plus), il existe aussi dès 1718 , des pièces beaucoup plus longues $\left(15 \frac{1}{2}\right.$ à $16,19 \frac{1}{2}$ à 20) sur des largeurs aussi variées que pour les pièces de $12 \frac{1}{2}$.

45 Les prix dépendent de la longueur et surtout de la largeur, et de la date de vente : autour de 25 livres pour les petites pièces de $12 \frac{1}{2}$ sur $9 / 16$, de 50 pour les plus longues sur une aune et plus, plus chères à mesure que les années passent : de 35 à 40 pour les plus courtes et les plus étroites, pour monter jusqu'à 70,75 livres pour les autres.

\section{Térindannes et térindins (ou terindains)}

Térindannes et térindins (ou terindains) : on ignore si ces noms différents expriment des variétés de qualité.

"Une mousseline, en général de qualité supérieure, souvent tissée dans le district de Dacca $»^{45}$; une mousseline blanche, rajoute Chaudhuri ${ }^{46}$. «Unie que l'on peut classer entre le tangeb et la nansouque $»^{47}$; "mousseline unie du Bengale, intermédiaires entres les tanjebs et les nansouques, en pièces de 16 aunes sur $7 / 8$ ou $11 / 12 .^{48}$ HobsonJobson ${ }^{49}$ propose un sens donné par les tisserands : « une sorte de tissu pour le corps ", de : «tarh, une sorte de, en arabe, et andâm, le corps en persan; et la définit comme mousseline aussi.

Les données attestent de la grande variété des térindannes et térindins, de finesse, de longueur, de valeur. La finesse compte beaucoup dans l'appréciation du tissu : en 1726, quatre variétés de mousseline sont distinguées : les pièces de 15 1⁄2 à 16 sur $7 / 8$ à 11 de ont été vendues de 47 à 50 livres; les mêmes, plus fines, de 55 à 60 ; encore plus fines de70 à 81 ; très fines 96 à 104 ; sur une aune et plus, jusqu'à 102 livres.

Dans un document de 1750, qui énumère seulement les noms des tissus présents dans un navire, le Brillant, sont mentionnés des noms d'origine, accolés à terindannes, Chandercona, Santipour. Dermigny, dans l'appendice VII de son ouvrage, « Mémoire 
sur le commerce du Bengale", indique que Santipour se trouve dans le Bengale occidental, près de Chandernagor, et que Chandercona est situé dans un district à l'ouest de Chandernagor ${ }^{50}$.

\section{Chunderkhana muslin, sur le site tmoi.org.uk n459}

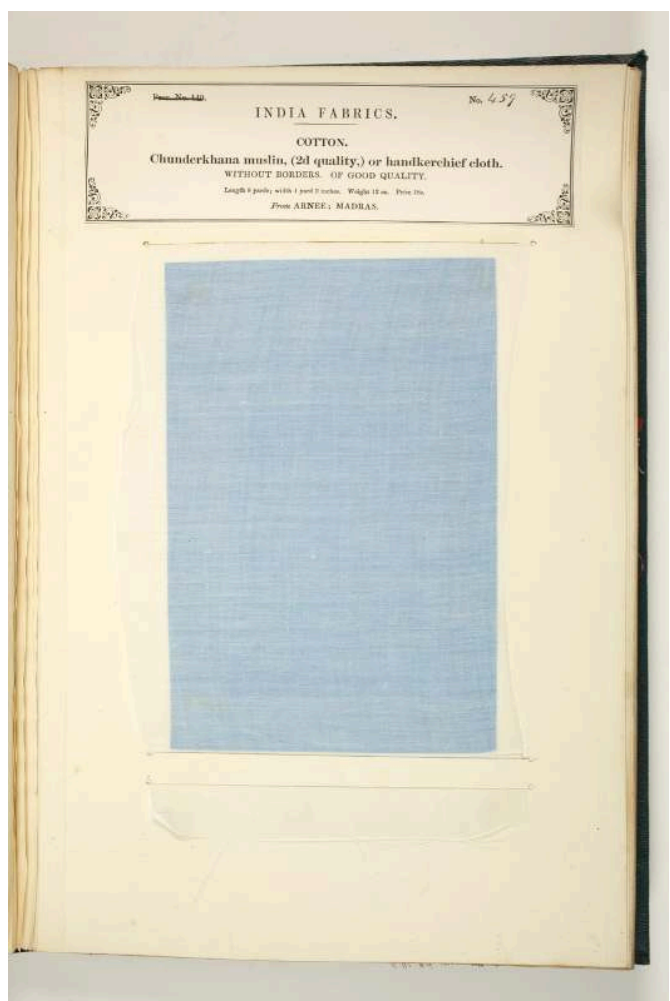

Certaines sont dites "avec lisière d'or (1716). Souvent, ces mousselines sont brodées. Certaines terindannes " rayés et brodés de différents dessins » (1716); d'autres sont dits "à ramage " (1718), ou "à bouquets de desseins, à colonne, à ramage " (1726).» Dès 1731, elles portent le qualificatif de assara, ou dome, ou japonis, ou maramat (1731, 1738, 1739, 1741, 1750), comme d'autres mousselines sans que l'on sache le type de broderie que recouvrent ces termes...et encore moins l'illustrer.

Brodées, elles souvent de petit aunage ( 7 aunes 3/4, ou de 8 sur $7 / 8$ à $11 / 12$, ou de $73 / 4$ à 8 aunes sur 7/8), mais il existe également (peu) des pièces brodées longues comme ces terindannes de 16 sur 3/4 à 5/6 « à bouquets de dessins. »

Les térindanes brodées sont chères. En 1731, les japonis ont été vendues 100 livres, les assaras 65 , les dome, 72, les maramat, 70. En 1738 , les terindannes assara de 8 aunes entre 125 à 133 livres, les terindannes maramat, 148,1; les japonis de140 à 147 livres. En 1767, une mousseline térindanne poranchouque est vendue à 70 livres la pièce.

\section{Les tanjebs}

Les tanjebs, du mot persan «body adorning», ornement du corps, pour HobsonJobson. ${ }^{51}$

Pour Savary, « certaines mousselines ou toiles de coton doubles, cependant un peu claires... Les unes sont bordées de fils de coton et les autres unies. Les brodées ont 16 
aunes à la pièce trois quarts de large, et les unies 16 aunes de long sur $7 / 8$ de large.. ${ }^{52}$; une description peu différente de celle de Blancard: «sorte de mousseline double qui est cependant dans la classe des claires, unie, ou rayée. ${ }^{53}$ Et Dermigny reprend: " sorte de mousselines doubles et cependant assez claires, 14 et 16 aunes sur 5/6 et 11/12. Il y en a de nombreuses espèces : unies, rayées, brodées, etc. $»^{54}$

La taille de la pièce, en largeur, est beaucoup plus variée que ne l'indique ces scripteurs : en 1716 par exemple, de 15 1/2 à 16 sur $7 / 8$ à 11/12, 3/4, 15/16, sur une aune et demie, sur $3 / 4$; en 1741 , de 15 1/2 à 16 sur $3 / 4$ et sur $11 / 12$ à $15 / 16$; en 1739,15 1/2 à 16 sur $3 / 4$ et plus; sur $11 / 12$ à $15 / 16$; sur une aune et plus; en longueur, la taille est de $15 \frac{11 / 2}{\text { à }} 16$ aunes, à l'exception de 1723 , tangebs brodés de 16 ou de 17 aunes sur $3 / 4$.

Certains tanjebs sont sans doute unis, comme ceux de 1741, de 15 1/2 à 16 sur plusieurs largeurs, «à lisière blanche. " D'autres sont brodés. En 1716, de 15 1/2 à 16 sur $7 / 8$ à 11/12, " brodés de différents dessins »; en 1723, tangebs brodés de 16 sur $3 / 4$ ou de 17 sur $11 / 12$, «à lisière d'or »; en 1726, tangebs " brodés à fleurs de différents dessins »; en 1731 , tangebs dome et maramat; des maramat en 1738 et 39 ; en 1741 , des tangebs dome encore, $15 \frac{1}{1 / 2}$ sur $3 / 4$ et des tangebs Mogarat (maramat ?).

Tangeb, sous le nom tunzab, sur site tmoi.org.uk n 244

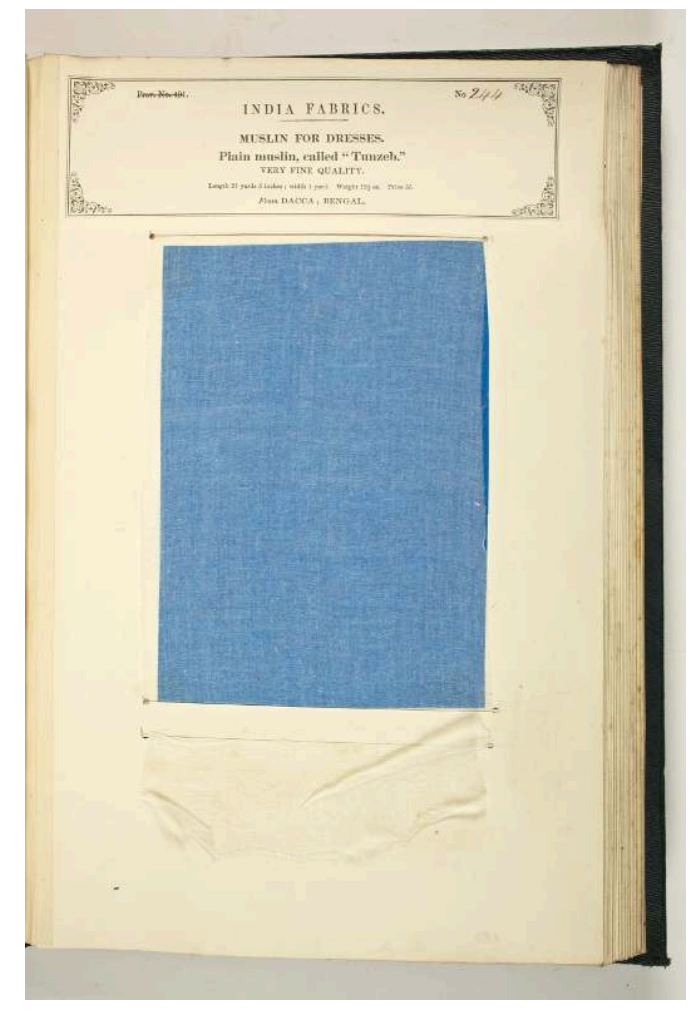

La valeur est fonction de la finesse, de la taille et de la présence ou non de la broderie. En 1687 et 1691, les prix sont peu élevés, 34, et 11 livres. En 1716, de 40,5 à 66 livres suivant la largeur, tandis que les tangebs brodés ont été estimés à 103 ; en 1719, de 47 à 65, quelques pièces rayées de fil écru, de 73 à 91 ; à lisière d'or, de 87 à 91 ; les tangebs brodés de 130 à 175 . En 1731, les tangebs simples à 40, les maramat à 69, les dome à 70 . Les années suivantes, les tangebs unis se sont vendus entre 35 et 50 livres, tandis que les tangebs brodés de différentes sortes entre 90 et 145 livres. 


\section{Mousselines brodées}

58 Ces mousselines brodées éveillent l'intérêt esthétique. Nous reproduisons deux illustrations de mousselines brodées.

Mousselines brodées dites Chikan sur le site tmoi.org.uk n 255 et 256, et aussi 257, 258, 259. Cidessous $n^{\circ} 255$

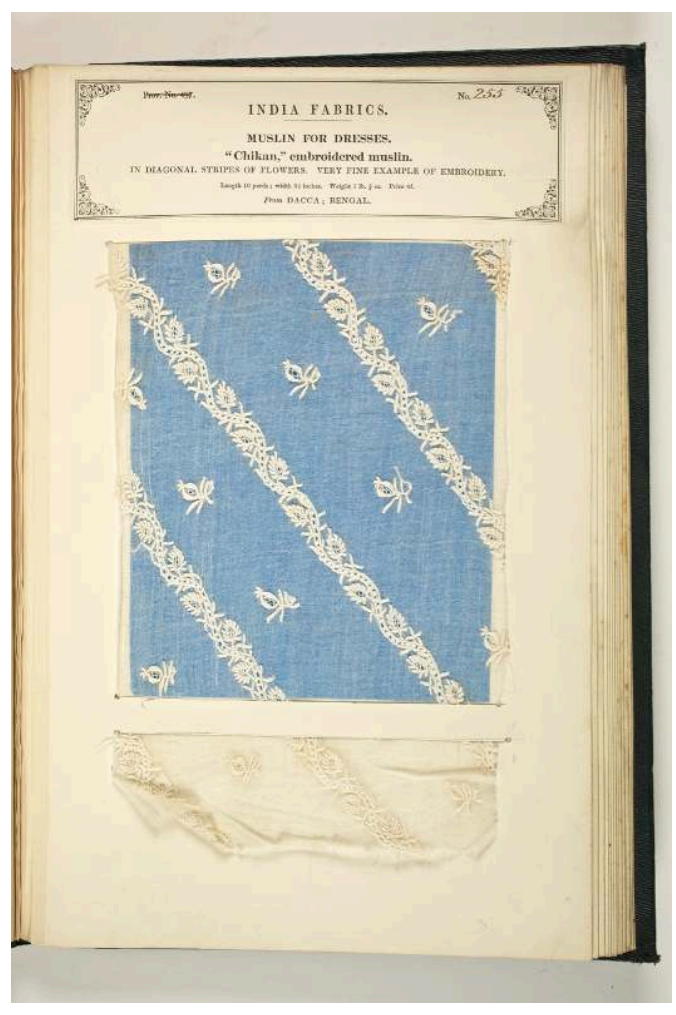


Mousselines brodées dites Chikan sur le site tmoi.org.uk n²56

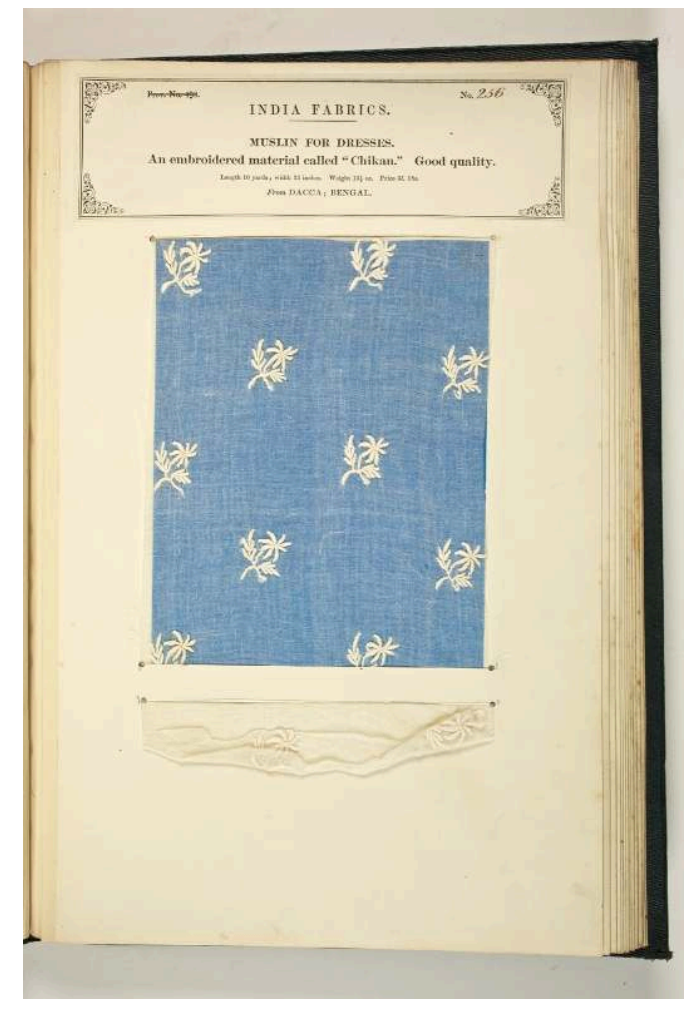

\section{Les jamdani}

59 « Une espèce d'organdi broché, à fleurs de couleurs ou blanches ; cette étoffe est jolie, légère...Les fleurs isolées ou les bouquets qui y sont brochés semblent être découpés et rattachés après coup sur la pièce.» ${ }^{55}$ "Mousseline brocardée de soie de couleurs, en général avec des fleurs...quelquefois tissée coton soie à la manière des doréas, la production la plus chère des métiers de Dacca. $\aleph^{56}$ Mousseline donc brochée et non brodée $^{57}$. Cependant certains jamdani sont qualifiés, comme les nansouques et terindins, d'un adjectif indiquant que le tissu est brodé, « dome » et « maramat. »

La pièce est toujours de petit aunage : en 1726, 1738 et 1741, de 7 aunes $3 / 4$ à huit sur $7 / 8$ à 11/12. La pièce connaît des prix variés : des jamdanis sans qualificatif de 40 à 56 livres, 98 en 1767 ; en 1738, un jamdani dome, 147 livres. 
Jamdani sous le nom Jamdanee, sur le site tmoi.org.uk $n^{\circ} 253$

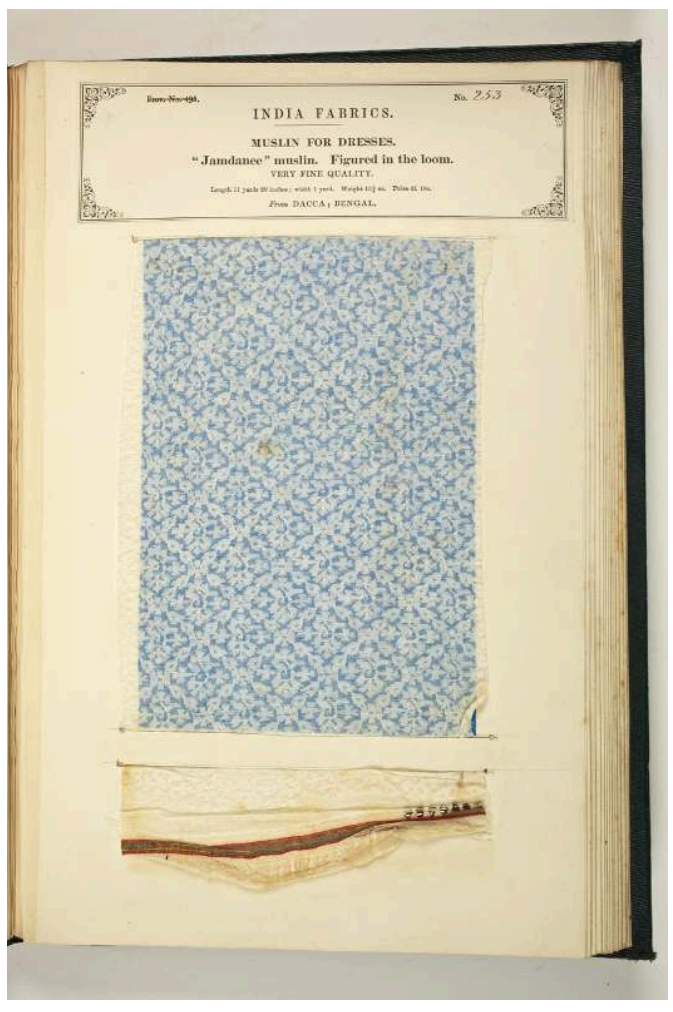

Jamdani sous le nom Jamdanee, sur le site tmoi.org.uk $n^{\circ} 254$

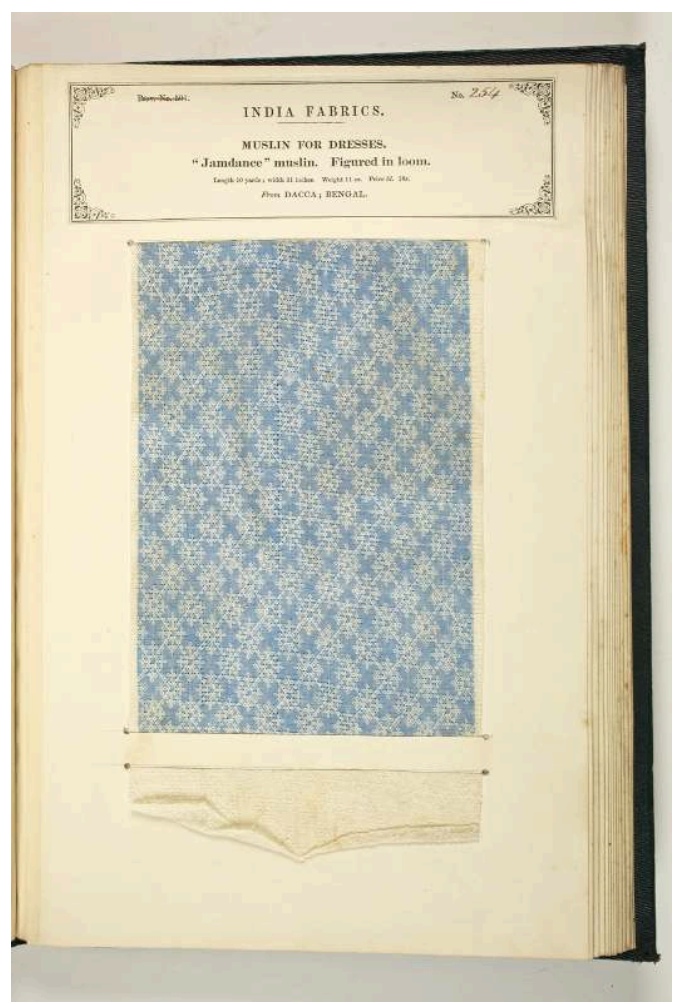




\section{Les Tocques}

61 Les Tocques, «mousseline ou toile de coton fine...La pièce a 16 aunes sur 7/16 et demi aune de large. $\|^{58}$ La longueur de la pièce est confirmée à chacune des dates de nos sources, de $15 \frac{1}{2}$ à 16 ; les largeurs sont plus variables : 7/12 à 5/8 ou 9/16 en 1716 ; en 1726, 9/16, une aune et plus ; $3 / 4$ en 1739 .

Le catalogue de 1741 donne quelques précisions sur l'apparence de la pièce : à « lisière blanche » et à » lisière d'or ». Il existe plusieurs sortes de toques : «à fil de bétille » dont la largeur est toujours d'une demi aune, et la longueur de $15 \frac{1}{1} 2$ à 16 ; et des toques à fil d'organdi, en 1739, de 12 aunes seulement sur 9/16 à 7/12.

63 La valeur dépend toujours de la finesse ; ainsi, en 1726, de 21 livres à 72 pour les très fines; et de la qualité du fil : pour les toques fil de bétille, de 16 à 20 livres, pour les toques fil d'organdi, plus prisées, de 27 à 30.

\section{Adatais}

Fine toile de coton ou mousseline? Savary évoque une mousseline, surtout fabriqué au Bengale, de dix aunes sur $3 / 4 .{ }^{59}$ Pour Irwin, ce sont des « mousselines souvent de bonne qualité tissées surtout dans le district de Dacca ${ }^{60}$; "mousseline de fabrication serrée $»^{61}$ pour Dermigny , tissus très fins, et très clairs en pièces de $8 \frac{1}{2}$ sur $5 / 6$ à 11/12. L'emplacement, dans les affichettes des ventes entre baffetas, garas, sanas et hamans (des toiles) laisse cependant le doute. E. Hardouin Fugier considère que l'adati, est une " toile de coton très fine et claire, sorte de mousseline légère. " $^{62}$

La longueur de la pièce n'est jamais de dix aunes, mais de $7 \frac{1 / 2}{2}$ à 8 aunes sur $7 / 8$ ou 11/12 (ce qui laisserait entendre que les indications étymologiques du glossaire Hobson-Johnson sont bonnes : le mot hindi, âdhâ signifie moitié.

La valeur n'est jamais élevée, de 3 à livres en 1687, entre 20 et 30 aux autres périodes, plus souvent 20 que 30 .

\section{Les serbatis}

67 Ignorées de Savary. Sous le nom de seerbands, ou sirband, pour Hobson-Jobson, « un nom pour turbans ${ }^{63}$ Irwin les qualifie de « fines mousselines tissées dans la région de Dakka. $»^{64}$ Dans l'empire ottoman, effectivement, nombre des mousselines étaient utilisées pour les turbans, ou les ceintures. Pour Dermigny, ce sont des «mousselines ordinaires du Bengale ", peut-être une variété inférieure de mallemolle. ${ }^{65}$ Chaudhuri en fait « une belle mousseline blanche, de Dacca. $»^{66}$

68 En 1716 et 1718 , des pièces de $15 \frac{1}{2}$ à 16 aunes sur 3/4 et plus, rayées de fil écru, sont vendues entre 50 et 54 livres la pièce; en 1719, les pièces de même aunage, encore rayées de fil écru, entre 62 et 82 livres ; en 1726, la pièce, de même aunage encore sur $3 / 4$ à 5/6, 55 livres, 50 livres en 1731 ; un peu moins prisées en 1738 : entre 40 et 48 livres.

69 Comme nombre de mousselines, ces serbatis, rayées de fil écru ont été brodés: leur valeur s'élève alors à 75 livres. 


\section{Les sirisafs}

Les sirisafs ne sont cités que dans le Catalogue de 1741, et n'existent dans les glossaires que sous des formes orthographiques différentes. Pour Irwin, sous le nom de serribaff, ce sont des « mousselines blanches de bonne qualité " ${ }^{67} ;$ « mousseline blanche de belle à excellente qualité destinée en partie à l'exportation "pour Chaudhuri. ${ }^{68}$ Sous le nom de sirsaja ou sirsaye, Dermigny parle de "mousselines à larges ou petites raies. ${ }^{69}$ Aucune description n'atteste la présence de ces raies. On ose à peine évoquer un autre sens, celui de drap (Charchaf en arabe).

71 Le Catalogue de 1741 présente plusieurs types de sirisafs : des sirisafs brodés de 6 aunes à $6 \frac{1 / 2}{2}$ sur $7 / 8$ et plus, des sirisafs de doréas, des sirisafs Moga (de 8 aunes $1 / 2$ à $8 \frac{3 / 4}{4}$ sur près de $3 / 4$ ). Moga signifie soie : ces sirisafs sont-ils brodés de soie ?

Les aghabanies et les aliballies (sont-ce les mêmes ?), mousselines très présentes dans le monde ottoman, sont rares dans les ventes. Nos données n'apportent sur elles aucune indication. Hobson-Johnson définit ainsi les « alibballies » : " d'après la traduction des tisserands, mousseline de belle texture ", dont l'étymologie serait peut-être 'alâ, en

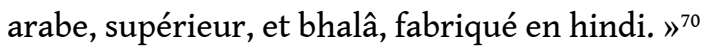

\section{NOTES}

1. Legoux. p. 345.

2. Katsumi Fukasawa, Toilerie et commerce du levant d'Alep à Marseille, Editions du CNRS, 1987, p. 41.

3. Legoux, p. 328.

4. Blancard P., p. 291.

5. Hobson-Jobson, p. 707.

6. Legoux, p. 344.

7. Legoux, p. 346.

8. Irwin John, op. cit., III, p. 68.

9. Savary, op. cit., II, p. 620.

10. Hobson-Jobson, op. cit., p. 595.

11. Legoux op. cit., p. 340.

12. Blancard Pierre op. cit., p. 291.

13. Dermigny, op. cit., p. 440.

14. Savary, op. cit., II, p. 620.

15. Irwin John, III 70.

16. Legoux, op. cit., p. 343.

17. How India clothed the world, The World of South Asian Textiles,1500-1850, , ed. by G. Riello, Titrhankar Roy, Brill, Leiden Boston, 2009, p. 242.

18. Savary, op. cit., II, p. 612.

19. Savary, op. cit., I, p. 1730.

20. Legoux, op. cit., I, p. 105.

21. Roques, op. cit., p. 120.

22. Legoux, op. cit., p. 106 sq. 
23. Savary, I, p. 322.

24. Irwin, III, 40.

25. Savary, op. cit., I p. 1711.

26. Hobson-Jobson, op. cit., p. 707.

27. Dermigny Louis, op. cit., p. 439.

28. Irwin John, op. cit., III, p. 68.

29. Legoux, op. cit., p. 362 sq.

30. Dermigny Louis, op. cit., p. 422.

31. Legoux, op. cit., p. 111 et 365 .

32. Hobson- Jobson, op. cit., p. 708.

33. Savary, op. cit., II, p. 826.

34. Legoux, op. cit., p. 329 sq.

35. Blancard, op. cit., p. 293.

36. Dermigny, op. cit., p. 441.

37. Legoux, op. cit., p. 339.

38. Crill R., dans Indian Embroidey, présente beaucoup de ces broderies faites au point de chaînette ; mais il existe d'autres points.

39. Legoux, op. cit., p. 366.

40. Savary, op. cit., II, p. 929.

41. Savary, op. cit., I, p. 322.

42. Legoux, op. cit., p. 111.

43. Blancard Pierre, op. cit., p. 235.

44. Dermigny Louis, op. cit., p. 441.

45. Irwin, op. cit., III, p.72.

46. Chaudhuri, op. cit., p. 505.

47. Blancard Pierre, op. cit., p. 294.

48. Dermigny Louis, op. cit., p. 448.

49. Hobson-Jobson, op. cit., p. 709.

50. Dermigny Louis, op. cit., p. 421, 422.

51. Hobson-Jobson, op. cit., p. 708.

52. Savary, op. cit., II, p. 1692.

53. Blancard Pierre, op. cit., p. 293.

54. Dermigny Louis, op. cit., p. 443.

55. Legoux, op. cit., p. 116.

56. Hobson-Jobson, op. cit., p. 707 et Irwin op. cit., III, p 70.

57. Au Musée Galliéra, on nous a expliqué que ce tissu était toujours broché avec motif dans le fil de trame.

58. Savary, op. cit., II, p.1821.

59. Savary, op. cit., I, p. 22.

60. Irwin, op. cit., I, p.66.

61. Dermigny Louis, op. cit., p. 437.

62. Hardouin Fugier E., op. cit.

63. Hobson-Johnson, op. cit., p. 707.

64. Irwin John, op. cit., III, p. 71.

65. Dermigny Louis, op. cit., p. 442.

66. Chaudhuri, op. cit., p. 505.

67. Irwin John, op. cit., I, p. 30.

68. Chaudhuri, op. cit., p. 505.

69. Dermigny Louis, op. cit., p. 442.

70. Hobson-Johnson, op. cit., p. 706. 


\section{Mouchoirs et stinkerques}

\section{Les mouchoirs}

1 Les mouchoirs, dans leur énorme majorité, sont faits de toile de coton. Près de 650000 pièces, pendant ces trente-neuf années, ont été importées auxquelles s'ajoutent les stinkerques, genre de mouchoirs sur pièces de mousseline.

2 La soie, cependant, constitue un exceptionnel matériau, un peu plus de $1 \%$ de l'ensemble des mouchoirs, « soie », sans qualification, ou « taffetas », ou " armoisin », et encore plus rare, neuf mouchoirs de "sousi", tissu coton soie. Savary ${ }^{1}$, à l'article "mouchoirs» évoque ces mouchoirs d' " étoffes de coton mêlé de soie » qui sont propres à faire des mouchoirs à tabac. Quelques rares chaparouma sont considérés comme des mouchoirs de taffetas de soie.

3 Apparaissent également quelques mouchoirs de toile peinte, moins de $1 \%$, au nombre des marchandises prohibées. En 1741, 1200 mouchoirs sont décrits dans le Catalogue : " peints fonds blanc de différentes bouquets et bordures "; sans doute se rapprochentils des mouchoirs évoqués par Legoux ${ }^{2}$ : « espèce de toile peinte et qui se fabrique dans les mêmes manufactures que les chittes...; deux sortes de mouchoirs dits "à vignette ", [soit] grands carrés peints sur de la percale, [soit] petits carrés sur des salampouris...le salampouri est plus souple, plus moelleux convient davantage à l'usage que l'on se propose de faire de cette espèce de mouchoirs qui ne sert assez ordinairement qu'aux dames ou aux hommes qui ne prennent pas de tabac. ${ }^{3}$ Blancard les désigne aussi comme mouchoirs à vignette "d'une toile très fine pareille à celle des belles percales ; ils ont une bordure peinte en diverses couleurs et divers goûts. $»^{4}$ Malheureusement, le prix de ces petites toiles peintes n'est pas connu.

$4 \quad$ Les mouchoirs de coton sont de loin les plus fréquents.

5 Sont proposées aux marchands des pièces destinées aux mouchoirs, qui seront divisées en carrés plus ou moins nombreux suivant les catégories. Dans une pièce se font de 8 (rare) à 15 (sur 9/16 à 7/12) à 20 mouchoirs (sur 2/3). Blancard ${ }^{5}$ reprend l'affirmation de Legoux sur les huit mouchoirs à la pièce et précise : « ils sont teints en gros bleu; ils ont une bordure de différente largeur formée par des fils moins foncés. Il y en a de plusieurs qualités et de plusieurs prix.» 
6 L'on ne saura jamais rien sur 361000 "mouchoirs", sans autre indication de lieu d'origine, ni de description, soit plus de la moitié. A mesure que les années passent, les scripteurs indiquent plus volontiers l'origine des mouchoirs, que résume le tableau cidessous :

Tableau 10 : origine géographique des mouchoirs, en pourcentage.

\begin{tabular}{|l|c|}
\hline Mouchoirs du Bengale & 56,5 \\
\hline Mouchoirs du Masulipatam et Sacergatis & 20,5 \\
\hline Mouchoirs de Pondichery & 11,1 \\
\hline Mouchoirs de Trinquebar & 3,3 \\
\hline Mouchoirs de Paliacate & 3,2 \\
\hline Mouchoirs de soie & 3,2 \\
\hline Mouchoirs peints & 1,5 \\
\hline Mouchoirs autres & 0,7 \\
\hline Total & 99,9 \\
\hline
\end{tabular}

\section{Les mouchoirs du Bengale}

7 Les mouchoirs du Bengale l'emportent en nombre sur tous les autres mouchoirs, (exceptionnellement de huit à la pièce, ou de dix, plus fréquemment de 15, ou 20 à la pièce), constituant le quart des mouchoirs vendus. À l'article " mouchoirs ", Savary ${ }^{6}$ signale que « les mouchoirs proviennent...particulièrement du Bengale. » Legoux ${ }^{7}$ les nomme «mouchoirs de Burgos " «Cet article, dit-il, ne paraît dans nos exportations que depuis environ 70 à 80 années...des mouchoirs bleus à l'imitation des mouchoirs rouges qui se font à Paliacate...Les mouchoirs de Burgos sont un article important de nos exportations, soit pour l'Europe, soit pour les différentes régions d'Asie, soit enfin pour les diverses échelles des côtes d'Afrique.. »

Dans les documents d'archives, ils sont dits «bleu et rouge » en 1716 et 1726 ; « bleu et blanc » en 1738 et 39 . Et plus ou moins fins : en 1726, les mouchoirs du Bengale de 15 à la pièce sur $7 / 12$ à $5 / 6$ sont vendus de 12 à 17 livres; bleus et rouges de 20 à la pièce, de 27 à 29 livres et, plus fins, de 34 à 40 . Les prix resteront à peu près les mêmes jusqu'en 1767 ; ou un peu plus bas pour les mouchoirs sur 9/16 à 7/12, moins de 15 livres.

9 Le Catalogue de 1741 décrit longuement les mouchoirs du Bengale. La plupart sont qualifiés d'un bref « sortes ordinaires ", de 15 à la pièce sur 9/16 à 7/12, ou 20 à la pièce sur près de $2 / 3$. Certains d'entre eux (peu) sont qualifiés d' " écru » (de 20 à la pièce), ou de bleu et blanc ( 8 et 10 à la pièce), ou à raies rouges ( 8 à la pièce). 240 pièces sont qualifiées « à petits carreaux ». Moins nombreux, les « sortes anglaises » : ou bleus, ou à 
raies rouges (15 à la pièce), ou bleus et blancs (de 10 à la pièce). Enfin, les "sortes hollandaises » sont rares, de 15 à la pièce sur près de $2 / 3$.

\section{Les mouchoirs du Mazulipatnam}

Les mouchoirs du Mazulipatnam, ou Masulipatan arrivent en deuxième position (environ $20 \%$ des mouchoirs « qualifiés »). Legoux ${ }^{8}$ constate : «Après les trois articles de toileries blanches de la côte, le plus important est celui des mouchoirs de Mazulipatnam...On n'emploie le mot de sorte pour les mouchoirs dits de Mazulipatnam que lorsqu'on parle de lieux particuliers...des cantons où on les fait fabriquer. On en connaît deux dans la province de Condavir, celui de Vétépaléom et celui de Sacergaon, que les Européens prononcent Sasserganti.» ... «On reconnaît les mouchoirs du Mazulipatnam à la teinture du coton, à la qualité de leur fil, à la préparation qu'on leur donne et à l'odeur de cette marchandise ", (qui est l'odeur de l'huile dans laquelle on fait imbiber les fils.) Le rouge...tire sur la couleur pourpre ; le coton est rond et le fil très tordu. $»^{9}$

11 "Les pièces de coton appelées Masulipatam... sont de 32 mouchoirs à la pièce, chaque mouchoir a demi aune en carré.» explique Savary. ${ }^{10}$ Mais les données des ventes infirment ces constatations : ces mouchoirs sont taillés à 8 à la pièce (ou de 10 à la pièce en 1726 ) sur près de $2 / 3$, ou $9 / 16$ à $7 / 12$, ou $3 / 4$. Les prix sont compris entre 15 et 20 livres pour les largeurs de $9 / 16$ à $7 / 12$, entre 22 et 35 livres pour les mouchoirs à $2 / 3$. Et s'élèvent sans doute en fonction de la finesse du tissu: Legoux ${ }^{11}$ précise que les « mouchoirs, tous de 12 à la pièce, sont de 26 conjons, de 30 et de $36 .$. et échelonne leur valeur, à l'achat, entre 315 et 630 livres la courge, soit entre 16 et 31 francs la pièce.

12 En 1741, le scripteur décrit, dans le catalogue, ces mouchoirs du Masulipatam qui, (cette année-là ?) sont toujours de 8 à la pièce sur près de $2 / 3$. Les couleurs sont, dans quelques cas, évoquées : « fonds de Masulipatam à cornière rouge ; ou fonds à carreaux bleus et blancs, bordure de sacergatis ; ou fonds à carreaux rouge et blanc, ou à carreaux rouges et blancs, rayés de bleu, ou de blanc; les carreaux sont grands ou petits; ou fonds à carreaux rouges et bleus, bordures à carreaux rouges et blancs à raies blanches; ou fonds de Paliacate, bordures à carreaux bleus, cornières rouges; ou enfin rouge foncé.» A en croire Legoux, le rouge domine dans ce type de mouchoirs...un rouge qui tire sur le pourpre. ${ }^{12}$

\section{Les mouchoirs de Sacergati}

13 Legoux les inclut dans les mouchoirs du Masulipatam, «de deux sortes, dit-il, dans les provinces de Condavir : celui de Vétépaléom et celui de Saccergaon que les Européens prononcent Sassergati... C'est le fil qui les distingue : «Le fil de ces mouchoirs est rond (de Vétépaléom), celui de Sassergati n'est que demi-rond... Ils sont teints par les mêmes procédés ", et Legoux évoque une "riche et belle couleur rouge » dont la beauté tient aux procédés de la teinture. ${ }^{13}$ Blancard regroupe les mouchoirs du Masulipatam et de Vintepaleom dans un même groupe de "mouchoirs à fond rouge ou à carreaux...Leur couleur dans les belles qualités se conserve autant que le mouchoir...Leur qualité se distingue par le nombre de conjons. $»^{14}$

Les sacergatis sont taillés à huit $(1739,1741)$ ou à 16 à la pièce $(1738,1741)$; sur des largeurs qui vont de $9 / 16(1739,1741)$ à $2 / 3$ ou $5 / 6$ (en 1741). Leur prix est plus élevé 
que celui des mouchoirs dits du Masulipatam : en 1738, les mouchoirs taillés 16 à la pièce se sont vendus entre 47 et 50 livres la pièce ; ceux de 8 sur $5 / 8$, de 25 à 26 ; sur $2 / 3$ de 28 à $29 ;$ sur $3 / 4$, de 28 à 31 . En 1739, de 8 à la pièce, sur $9 / 16$, de 48 à 51 . En 1760, de 39 livres.

Les Sassergati, d'après J. Irwin ${ }^{15}$, porteraient la marque d'une technique particulière : «type de coton, affirme-t-il dont les fils de chaine et les fils de trame sont teints avant le tissage », technique dite du tie-dyed.

\section{Les mouchoirs de Pondichery}

Les mouchoirs de Pondichery sont moins présents (11\%). Et moins onéreux. Toujours taillés, dans nos documents, en 16 à la pièce sur $2 / 3$; bleu et rouge, ou bleu et blanc (en 1741), bleu et rouge fin ou bleu et blanc fin (en 1725). Ces mouchoirs se vendent peu cher : de 16 à 20 livres, un exceptionnel maximum de 35 livres, en1725, et un prix en baisse dans les années 1767-68, inférieur à 15 livres.

\section{Les mouchoirs de Paliacate}

Les mouchoirs de Paliacate (huit lieues au nord de Madras) sont longuement décrits par Legoux. ${ }^{16}$ "Leur finesse, la beauté de leurs tissus, le brillant des couleurs, leur variété et leur solidité, le moelleux de la toile rendent cette espèce de marchandise précieuse aux consommateurs...Beaucoup plus variée que les mouchoirs du Masulipatam...pour leur finesse...pour leurs couleurs qui sont multipliées à l'infini... Couleurs légères et brillantes, bon teint mais le rouge est beaucoup plus rosé que celles de...Masulipatam. Les teinturiers réussissent supérieurement dans les couleurs vertes et jaunes, c'est dans les teintures bleu et puce qu'ils excellent...Solidité et brillant du rouge... ». Les moins fins, écrit Legoux " conviennent mieux pour le commerce et les échanges qui se font sur les différentes côtes d'Afrique ». Comment reconnaître les mouchoirs de Paliacate des autres? « En les repliant sur lui-même en triangle, ceux de Paliacate forment un carré parfait...Les carreaux du dessin de Paliacate sont en général de seize lignes, pied du roi ; ceux des autres manufactures sont ou plus petits ou plus grands. »

Le catalogue de 1741 ignore ces variétés de teintes et présente des mouchoirs qui sont seulement « à petits ou grands carreaux rouges et blancs, rouges et bleus. »

La valeur? Legoux ${ }^{17}$ échelonne les prix d'achat entre 294 francs la courge, soit 14,7 livres la pièce, et 630 francs (soit 20 livres la pièce), à l'exception de ceux qui sont d'une exceptionnelle qualité, « 200 pagodes la courge soit 1680 francs les 20 pièces, soit 84 la pièce. »

Dans les ventes, les prix sont, en 1738 (12 à la pièce), de 47 livres à 60,1 la pièce, suivant l'une des trois qualités mentionnées; en 1739 (12 à la pièce sur 2/3) et suivant la qualité, de 44,6 livres à 68,1; en 1761, (14 mouchoirs à la pièce), de 23,1 la pièce ; en 1767, de 86 livres la pièce, et de 75 en 1768. 


\section{Les mouchoirs de Trinquebar}

Les mouchoirs de Trinquebar sont de 10 à la pièce sur 2/3. Le catalogue de 1741 les présente avec « de moyens carreaux, surtout, mais également petits, ou grands, façon de Paliacate ou façon du Masulipatam ». Legoux les décrit comme inférieurs à ceux de Paliacate. Ils seront vendus d'ailleurs à des prix inférieurs, de 19 livres en 1768 et 1739, à 23, 24 en 1738 .

\section{Chandernagor, Karikal, Madrapac}

Chandernagor, Karikal, Madrapac (1740) apportent également quelques centaines de ces pièces.

\section{Les stinquerques}

Inconnus dans les importations avant le XVIIIème siècle, les stinquerques connaissent le maximum de popularité lors du deuxième quart du siècle. Legoux ${ }^{18}$ les définit ainsi : « les steinkerques sont des mouchoirs qui tiennent de la mallemolle par leur souplesse, et de la doréas par la qualité du coton dont on se sert pour leur tissage...La trame est en fil de mallemolle, la chaîne se fait avec le coton de cette autre espèce de mousseline, ... d'où leur force et leur souplesse...Le réseau de cette espèce de mousseline imite le tissu des linons batiste. » Dermigny ${ }^{19}$ précise la définition et l'origine du mot, sous le nom de "mouchoirs stinquerques, de 20 à la pièce sur 3/4, plus communs que les organdis; la mode européenne, qui en fait des cravates et des fichus, leur a donné leur nom en souvenir de la bataille de Steinkerque (1692). » Ce sont donc des mouchoirs brodés sur mousselines fines et non pas sur de vulgaires toiles de coton.

Les affichettes de vente et les catalogues les décrivent souvent comme brodés sur différents types de mousselines »: en 1716/18, les stinquerques sont brodés sur mallemolle, de $3 / 4$ à $5 / 7$ en carré ; ou brodés sur mallemolles, en ovales; ou sur casses, de $3 / 4$ à $5 / 6$ en carré; ou sur tangebs de $2 / 3$ à $5 / 6,5$; ou enfin sur dorea, de 20 à la pièce, sur 3/4 dont 10 à " petites rayes d'or et d'argent. » En 1716, les stinquerques sont sur "mousselines rayées à fleurs ». Les mêmes noms de mousselines apparaissant en 1719, 1741 ; s'ajoute l'organdi en 1768. En 1723, les «stinquerques sur mallemolles, de une aune et quart de long, sont brodées de soye de différentes couleurs, rose, bleu, blanc, mogue, cramoisi, gros vert, violette, pistache, jaune, gros vert, vert celadon, vert de pré, et autres couleurs non définies. » En 1726, les stinquerques sont sur mallemolles brodées d'or et d'argent. En 1767, venant de Pondichery, sont vendus des stinquerques «fil d'organdi à barre de couleurs ",

Les prix ne sont que rarement indiqués: en 1716/18, de 5 à 6 livres pour des stinquerques dont on ne connaît pas le nombre à la pièce, de 60 lorsqu'ils sont de vingt à la pièce sur doréa. En 1723, les stinquerques sur mallemolles brodées de soye ont été vendus 30 livres. Sans indication de nombre à la pièce, en 1738, de 10 à 12 livres, et en 1760 de 37, de 46 en 1767, de 18 à 37 sur fil d'organdi, en 1767 et 1768. Legoux en donne le prix d'achat; de 8 à 16 roupies sicca la pièce de dix mouchoirs (de 21 à 43 livres). 


\section{NOTES}

1. Savary, op. cit., II, p. 809.

2. Legoux, op. cit., p. 95-96.

3. Blancard Pierre, op. cit., p. 237.

4. Blancard Pierre, op. cit., p. 237.

5. Blancard Pierre, op. cit., p. 237.

6. Savary, op. cit., I, p. 809.

7. Legoux, op. cit., p. 370-372.

8. Legoux, op. cit., p. $39 \mathrm{sq}$

9. Legoux, op. cit., p. 6061.

10. Savary, op. cit., II, p. 810.

11. Legoux, op. cit., p. 41-42.

12. Legoux, op. cit., p. 63.

13. Legoux, op. cit., p. 43.

14. Blancard, Pierre, p. 238.

15. Irwin John, op. cit., II, 42.

16. Legoux, op. cit., p. 62 sq.

17. Legoux, op. cit., p. 76.

18. Legoux, op. cit., p. 372 sq.

19. Dermigny Louis, op. cit., p. 441. 


\section{Les toiles de coton}

1 En nombre, les quelques près 3400000 toiles de coton variées, blanches et de couleurs, teintes, rayées, importées des Indes pendant toutes ces années, utilisées en France ou exportées à l'étranger, ont constitué plus de la moitié des cargaisons indiennes. B. Nicolas ${ }^{1}$ remarque : «Les toiles blanches pouvaient subir un processus de coloration, soit par immersion dans un bain de couleur unique, soit par impression de différentes couleurs...Il ne faut pas omettre les toiles à motif de carreaux ou de rayures qui, vers le milieu du XVIIIème se virent attribuer la dénomination de guinées et de guingans et composèrent majoritairement la part textile de la cargaison de traite... »

2 Nous utiliserons les récits des voyageurs, les dictionnaires divers, les données d'archives pour tenter la meilleure description possible de chacune de ces toiles. Commençons par en énumérer les noms, par ordre alphabétique. Une deuxième étape établira la part très variée qu'occupe chacune de ces toiles dans les caragaisons textiles indiennes.

En vrac, et par ordre alphabétique : des ambertees, annabas, baftas, bajupataux, beram, basin-kermichis, berams, chanders, chazelas, chilas, chukerees, coutelines, coupis bolsas boclan, deribands, doutis, fottamouras, fottes, garas, guinées, guingans, hamans, katequis, korottes, limaces, mamoudis, mauris, nankins, neganepaux, nekanias, percales, platilles, salempore, sanas-salgasis, sauvaguzee, socrotes; auxquelles il faut rajouter des toiles diverses blanches et de couleurs seulement répertoriées sous le nom de «toiles. »

4 Citons, sans comprendre leur présence dans les cargaisons, quelques «platilles» qualifiées par Savary ${ }^{2}$ de "toiles de lin très blanches ", et quelques 320 pièces d'anabas « « toiles de fil de coton bleu et blanc » ", vendues à Nantes en 1756. Ces toiles feraientelles partie des toiles de traite? Elles sont effectivement citées dans les cargaisons négrières ${ }^{3}$. Elles semblent avoir été fabriquées non pas en Inde, mais dans le royaume et les pays d'Europe. Gageons qu'un scripteur, soit en Inde, sur les lieux d'exportation, ou à Lorient, a appelé de ce nom des toiles qui ressemblaient à des platilles ou autres, et dont l'appellation indienne était ignorée

Les cotonnades ont été très inégalement présentes dans les arrivées et les ventes.

6 Reprenons dans le tableau suivant les seules cotonnades dont la quantité, par rapport aux importations totales, représente plus de $1 \%$ de l'ensemble des cotonnades 
importées, et, dans un premier temps, sans distinguer les toiles blanches des toiles de couleur ou rayées.

7 Nous ne ferons que citer, chemin faisant, le nombre de pièces des étoffes très peu représentées.

Tableau 11 : principales toiles de coton, en nombre et en pourcentage

\begin{tabular}{|l|l|l|}
\hline Noms des toiles & Nombre & Proportion \\
\hline Guinées & 850945 & 25,1 \\
\hline Salempores & 688566 & 20,3 \\
\hline Garas & 547563 & 16,1 \\
\hline Baftas & 306738 & 9,0 \\
\hline Guingans & 179579 & 5,3 \\
\hline Sana Salgazis & 146991 & 4,3 \\
\hline Hamans Amans & 108102 & 3,2 \\
\hline Doutis & 93759 & 2,8 \\
\hline Basin kermichis & 84670 & 2,5 \\
\hline Percale & 48101 & 1,4 \\
\hline Coupis Boclan & 33822 & 1,0 \\
\hline
\end{tabular}

8 Les seules guinées, salempores, garas et baftas, toiles grosses et toiles fines, toiles blanches et bleues, arrivent de loin en tête des importations de toiles, 70,5\%. Beaucoup moins présentes, les guingans, les sanas, les hamans, les doutis, les basins ; percales et coupis. Plus de 20000 pièces de limaces ou limaneas, chazelas, socrotes, fottes et korottes. Plus de 10000 pièces de nekanias, katéguis, bajupataux, neganepaux, coutelines, mauris, savaguzee, chilas et nankins. Plus de 5000 pièces pour les deribands et ambertees ; plus de 1000, pour les beram, fottamoura, mamoudis. Moins de 500 pour les annabas, camelots, platilles, baramete, chuckeree et chanders.

9 En valeur, si l'on se fie aux données du tableau 10 de Wellington, qui concernent un nombre peut-être trop faible d'années pour être entièrement fiable, et englobe des " toiles diverses ", non qualifiées, la proportion est à peu près identique.

La valeur totale des toiles vendues s'élève à 15519489 livres. On ne saura rien de précis sur la valeur propre de certaines toiles de coton, seulement qualifiées de "diverses » (un montant élevé : 1841070 livres, soit 11,9\% -beaucoup- de la valeur totale des toiles), des « autres » ou « abîmées ». Enlevons-les avec regret du calcul total.

11 Les guinées, les garas, les salempores et les baftas ont occupé de loin la première place dans la valeur des toiles vendues pendant ce presque un siècle : 
Tableau 12 : valeur des pièces, en chiffres absolus et en proportion (y compris les tissus qui représentent moins de $1 \%$ de la valeur des cargaisons)

\begin{tabular}{|c|c|c|}
\hline & Valeur en livres & Pourcentage \\
\hline Guinées & 4326557 & 31,9 \\
\hline Garas & 2437138 & 18,0 \\
\hline Salempores & 2124600 & 15,7 \\
\hline Baftas & 1905740 & 14,1 \\
\hline Doutis & 529485 & 3,9 \\
\hline Hamans ou Amans & 510378 & 3,8 \\
\hline Sanas & 326522 & 2,4 \\
\hline Basins ou Kermichi & 313461 & 2,3 \\
\hline Guingans & 273623 & 2,0 \\
\hline Nekanias & 177424 & 1,3 \\
\hline Percales & 135295 & 1,0 \\
\hline Nankin & 95216 & 0,7 \\
\hline Chazelas & 82685 & 0,6 \\
\hline Contelines & 63646 & 0,5 \\
\hline Bajutapaux & 61986 & 0,5 \\
\hline Korottes & 41098 & 0,3 \\
\hline Neganepaux & 40023 & 0,3 \\
\hline Coupis, Boclan, Bolsas ou Rasta & 38622 & 0,3 \\
\hline Socrotes & 29703 & 0,2 \\
\hline Limaces & 29586 & 0,2 \\
\hline Fottes & 8497 & 0,1 \\
\hline Challis & 8036 & 0,1 \\
\hline Kateguis & 485 & 0,0 \\
\hline Total & 13559806 & 100,0 \\
\hline
\end{tabular}


Les proportions de ces diverses cotonnades varient un peu, en nombre et en valeur. On peut cependant constater que les guinées, salempores, garas, baffetas, ont été de loin les toiles les plus demandées. Dans la classification effectuée en 1716 par le scripteur d'une affiche de vente, ces toiles ont plutôt été qualifiées de " toiles grosses de coton ", à l'exception des sanas et des chanders, « toiles fines »; devant les guinées, les percales, les socrotes, le scripteur avait inscrit : « toiles grosses et fines».

Nous les présenterons ces toiles par ordre d'importance dans les importations, sans nous soucier de la couleur des pièces, ni de leur caractère de toiles licitement importées pour être vendues, ou dites prohibées, importées pour être vendues hors du royaume.

\section{Les Guinées}

14 "Une toile de coton blanche, plus fine que grosse... La pièce est de 29 aunes $1 / 2$ à trente aunes sur $7 / 8$ » décrit Savary 4 , Pour Dermigny ${ }^{5}$, les guinées blanches sont des " pièces de 27 à 28 aunes sur 5/6 et 7/8 qui forment la partie la plus importante des cargaisons $\mathrm{du}$ Coromandel, car l'Europe en consomme beaucoup pour l'impression. Elles sont en général de bonne qualité, mais leur finesse varie énormément. » Legoux ${ }^{6}$ constate : «On connaît à la côte de Coromandel des guinées du nord et des guinées du sud ou de Seilon....Les guinées du nord forment à peu près la majeure partie des cargaisons de la Côte...Dans les idiomes des Indous, dit-il, on prononce kindé, ce qui signifie pièce longue...La guinée est de toutes les espèces de toiles celle qui porte le plus grand aunage. "...Legoux insiste aussi sur la variété des pièces «liée à leur plus ou moins grande finesse»: "On connaît six espèces de guinées du nord. Elles reçoivent toutes leurs dénominations du nombre de conjons dont elles se composent...La plus commune, celle de 19 conjons, ne porte que 2280 fils. La plus fine, celle de 50 en porte 6000 . Legoux conclue : « toutes les espèces de cette toilerie se reconnaissent par la qualité des fils qui sont tors, par leur égalité en finesse et leur arrangement de tissage, qui fait voir un grain uni, une trame frappée également dans toute la longueur de la pièce." le voyageur commerçant explique le devenir de la toile : «La guinée est une très bonne espèce pour l'usage. On en fait de beaux linges de corps, de table...Les chittes...les toiles peintes...se peignent ou s'impriment sur des guinées de vingt-trois et de vingt-six conjons. »

Le nom de guinée recouvre plusieurs types de toiles. Plusieurs épithètes, dans les sources, qualifient la cotonnade, dont certains sont géographiques : guinées (tout court, sans doute blanches), guinées blanches, guinées blanches « sorte hollandaise ", guinées de Masulipatam, de Pondichery, de la Côte ; et guinées bleues.

La principale distinction doit être faite entre "guinées blanches » et " guinées bleues ». La couleur, l'aunage et la destination du produit les différencient. Legoux remarque : "Les guinées de 23 et de 19 conjons...sont teintes en bleu. On les exporte à la côte d'Afrique, où elles sont avantageusement vendues, de même que dans les Antilles. Les guinées bleues, sont toutes coupées en demi-pièces ...ce sont les sortes les plus communes des guinées. »

Que disent nos affichettes? Les guinées bleues ne se distinguent pas uniquement par la couleur, mais aussi par l'aunage et la valeur, moindre, conséquence de la mauvaise qualité constatée par Legoux. En 1716/18, les guinées bleues sont présentées comme des «demi pièces »; en 1739, elles sont de 14 aunes; en 1741, de13 1/2 à 14 aunes sur 
près de $7 / 8$ à 1⁄2. En 1712, une affichette qualifie ainsi une guinée : « guinées ou pagnes pour turbans. »

18 Les guinées blanches, toujours en longues pièces de 29 aunes et plus, sont d'origine diverse. Guinées de la Côte, guinées du Masulipatam, guinées de Pondichery; de qualités, (ou sortes), et forcément de prix très différents.

Legoux de Flaix, pour 1786, donnent des prix, qui doivent être les prix d'achat en Inde : de 28,8 à 31,3 la pièce ${ }^{7}$, et de $20 \%$ moins élevés dans les années antérieures. Les prix de vente, dans nos archives, sont évidemment plus élevés : est-il arbitraire de considérer que le prix de vente dans le royaume est de deux à trois fois plus élevé que le prix d'achat suggéré par Legoux ? En 1719, les guinées blanches de 29 à 30 aunes sur $7 / 8$ se vendent de 49 à 56 livres; de 30 sur $7 / 8$, de 60 à 65 ; de 30 à 31 sur $7 / 8,107$, et exceptionnellement 120. En 1726, de 29 à 30 aunes sur $7 / 8$, de 32 à 33,7 livres; de la première sorte, de 35,5 à 37,1 ; de la deuxième sorte, de 30 aunes sur $7 / 8$, de 40 à 53 ; de la troisième sorte de 31 aunes sur $7 / 8$ de 64 à 75 ; de la quatrième sorte, de 80 à 92 . En 1739, les guinées du Masulipatam communes se sont vendues de 33,4 à 40,4 livres; un peu plus fines, de 40,14 à 41,19; encore plus fines, de première sorte de 71, à 77,7.

La même année, en 1739, les guinées bleues de 14 aunes se sont négociées de 16,1 à 17,13 livres, soit moins de la moitié du prix des guinées blanches; en 1687, elles valaient 11,6 livres au moment où les blanches étaient estimées 29,1. En 1767, les guinées blanches venant de Pondichery, se vendaient 42 livres, les guinées bleues, 26,9: en gros, moitié prix.

\section{Les salempores ou salempouris}

21 Savary, ${ }^{8}$ à l'article salampouris, propose : « toile que l'on fait dans plusieurs endroits de la côte de Coromandel. Il y en a de blanches et de bleues. Les blanches font 72 cobres de long sur 2 et un quart de large. Le bleues n'ont que 32 cobres de longueur sur la largeur des blanches. »

Faut-il considérer comme "guinées » les salempouris blancs? A suivre Legoux, on hésite : a-t-il considéré les salempores comme des guinées fabriquées dans le pays de Seilon, « des guinées de Seilon $»^{9}$; « on prononce en tamoul seilampari, ce qui signifie toile de Seilon.» Il consacre cependant quelques pages de description aux seuls salempores : «Une toile légère, fine, et jolie, souple, molle, et dont le grain quoiqu'uni ne l'est cependant pas autant que celui de la percale...Le fil des salempouris est régulièrement filé, demi-tordu et fin... le coton produit par leurs contrées, dans le Maléalame et de Carnate, utilisé pour la trame du salempouris, le coton de Madrepac et de Canjivarom pour la chaîne", "aspect approchant de celui des casses du Bengale...quarante gadges de long, ce qui fait 16 aunes, la largeur, une gadge $3 / 4$, soit $7 / 10$ d'aune... On en fait du linge de corps, des serviettes...et particulièrement des mouchoirs à vignettes » (c'est à dire des mouchoirs peints).

Les affichettes de vente distinguent toujours les toiles bleues par leur couleur, tandis que l'expression salampores, sans adjectif, s'applique sans doute aux seules toiles blanches. Les salempores bleus constituent $15 \%$ des salempores importés. Marchandises prohibées, elles sont destinées à l'exportation, comme les semi-guinées bleues et beaucoup d'autres textiles. 

sur 7/8. Mais il existe des pièces plus longues : en 1718 et 1719 , à côté des pièces de 12 aunes, ont été vendues des pièces de 29 à 30 aunes et demi sur 7/8; en 1718, des salempores bleus portent aussi le même grand aunage. Très rarement, la largeur varie : $7 / 8$, sauf en $1725,5 / 6$, et en $1719,12 \frac{1}{2}$ à 13 . pièce a valu 4 livres. En 1718, les pièces de 12 sur $7 / 8$ ont été vendues de 20 à 22 livres ; de 12 à $12 \frac{1}{2}$ sur $7 / 8$, de 21 à $23 ;$ de $12 \frac{1}{2}$ à 13 sur $7 / 8$, de 30 à $31 ;$ de 29 à 30 aunes sur $7 / 8$ de 40 à 46 ; de 30 sur $7 / 8$ de 57 à 71 . En 1719, les valeurs sont à peu près les mêmes valeurs, mais les grandes pièces sont plus onéreuses (de 30 à 31 aunes sur 7/8 de 76 à 120 livres).

La qualité est également un facteur de variation: en 1719, 1725, 1726, 1738, quatre « sortes » de salempores ont été présentées, à des prix qui vont de 14 à 45, 50 livres. Les salempores bleus atteignent les prix de la plus basse sorte du salempore blanc. Apparaissent quelquefois dans la description des salempores un adjectif «sorte hollandaise » (de 11 aunes 3/4 sur 5/6), estimé à 10 à 11 livres (1725), alors que, dans le même temps, le salempore de Pondichery vaut entre 17 et 43 livres suivant la sorte. Le même adjectif « sorte hollandaise » s'applique (rarement, en 1725) aux guinées.

\section{Les garas ou garats}

Savary, Irwin, Chaudhuri, s'accordent sur le caractère médiocre de la toile. Pour Savary ${ }^{10}$ : c'est une "grosse toile de coton blanche", de 9 aunes $2 / 3$ ou $14 \frac{1}{1 / 2}$. Legoux ${ }^{11}$ constate : «c'est la plus commune et la plus médiocre de toutes les espèces de toile du Bengale... Les Indiens n'emploient cette qualité de toile qu'à faire les premières enveloppes des balles de leurs belles marchandises... ou quelques culottes, quelques pagnes..., des torchons, des garde pieds. » [mais]... les garats furent recherchés pour alimenter les manufactures d'indiennes qui s'établissaient en France, dans la Grande Bretagne ». Pour Hobson-Jobson, ${ }^{12}$ à l'article gurrahs : « probablement de l'hindi, gârhâ, « un tissu brut, non blanchi. »

À l'heure actuelle, dans le Tamil Nadu, une toile blanche de mauvaise qualité, dénommée "gada ", sert à envelopper les paquets que l'on expédie. Faisons l'hypothèse qu'il s'agit du même type de mauvaise toile d'emballage, fonction qu'évoquait pour d'anciens temps Hobson-Jobson: "ces toiles sont utilisées, entre autres choses, pour emballer, pour envelopper les morts. »

En 1741, ces médiocres des toiles arrivent au premier rang, en nombre, des toiles importées. Savary en fait une toile du Gujarat ; mais, nos affichettes en font des toiles du Bengale, Dacca, Jougdia. 
Garas, inv. BAD 6752 (GG4), album d'échantillons, 1789, p. 79. Les Arts Décoratifs, Paris

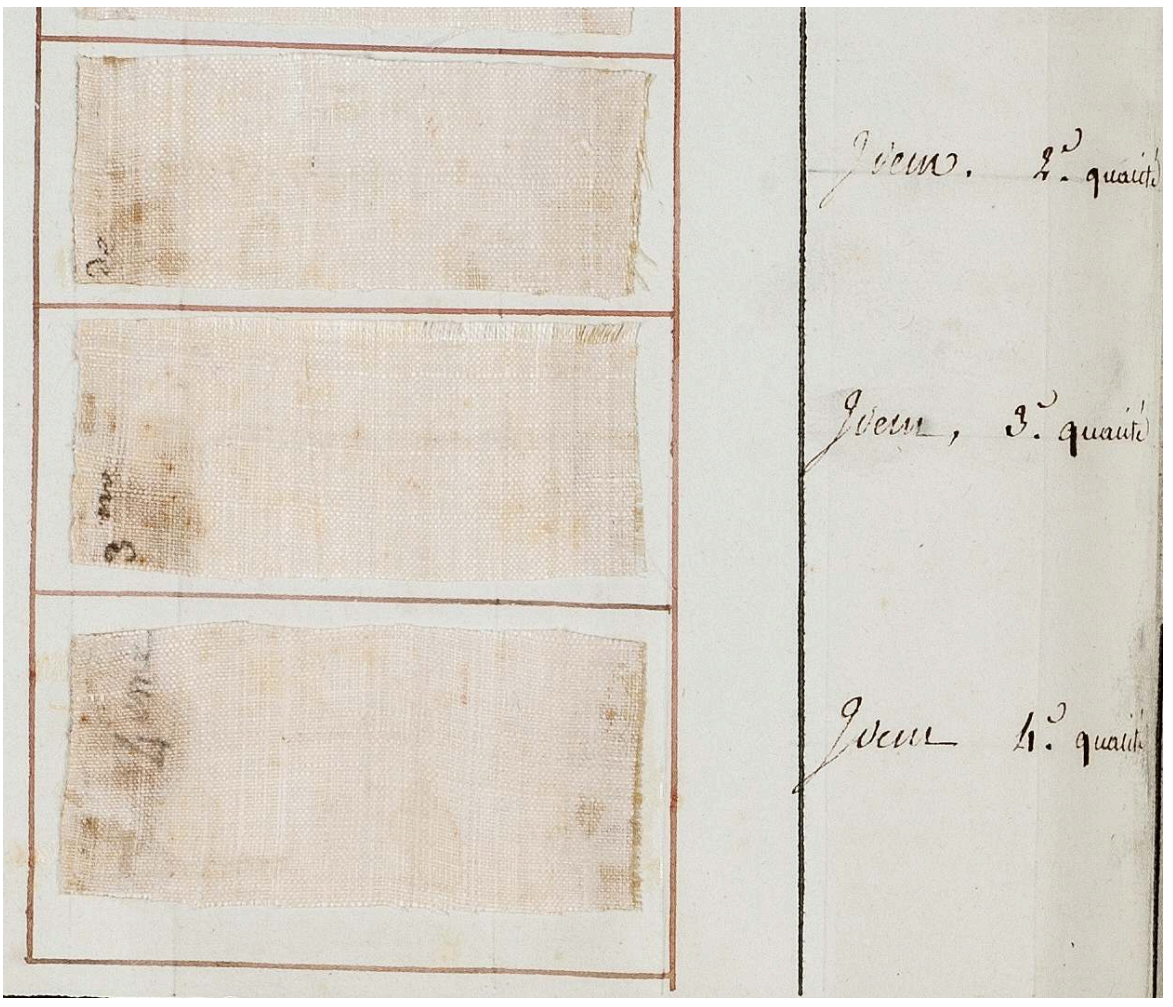

Photo Les Arts Décoratifs, Paris/Jean Tholance (photo soumise à accord préalable, rétrocession photo interdite)

Garas, inv. BAD 6752 (GG4), album d'échantillons, 1789, p. 75. Les Arts Décoratifs, Paris

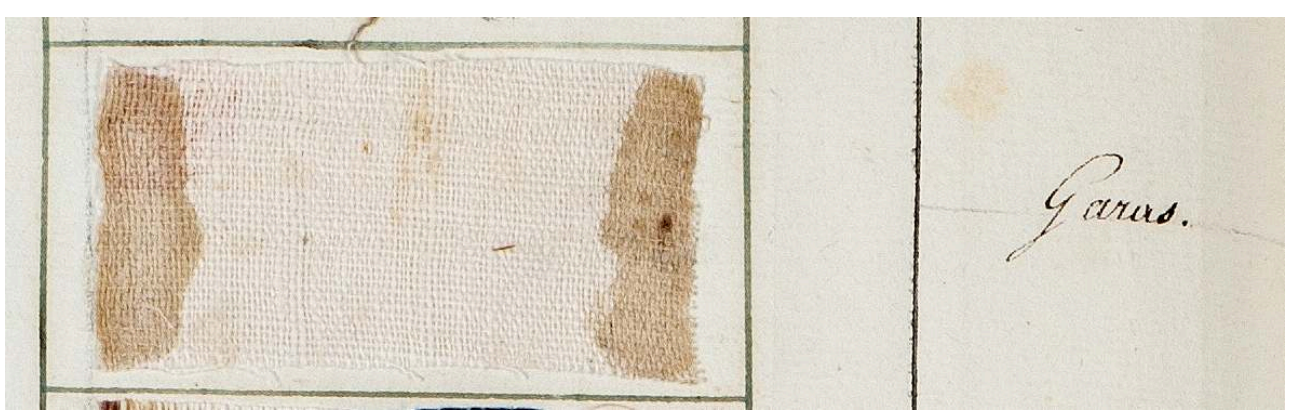

Photo Les Arts Décoratifs, Paris/Jean Tholance (photo soumise à accord préalable, rétrocession photo interdite) 
Garas, sous le nom de Gurrah, sur le site tmoi.org.uk. II existe plusieurs autres photos de garas $n^{\circ} 297,300,303,306$. Ci-dessous photo ${ }^{\circ} 297$

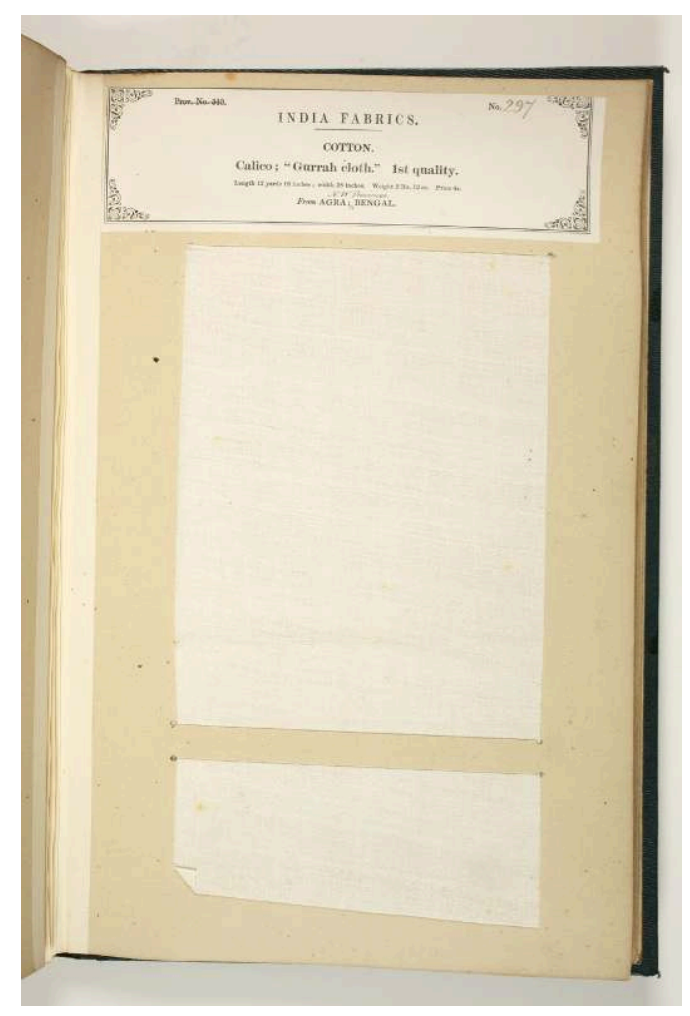

La plupart des garas affichent un aunage qui oscille entre 11 1/2 et $131 / 2$ à 14 aunes sur près de $7 / 8$; très rarement des pièces plus longues, de 29 aunes $1 / 2$ sur près de $7 / 8$, en 1738 et 1741 . Sont également vendus quelques garas bleus.

La valeur, de 2,2 livres, en 1691, varie avec la taille des pièces : de 9,1 à 10,7 pour les 12 aunes sur 7/8, de 11,3 à 13,8 pour les 14 aunes; ou de 12 sur $7 / 8$, de 22,1 à 23,16 ou de 23,3 à 26 pour les 29 aunes. Il n'est jamais fait mention de «sortes» ou de qualités différentes. Pendant l'ensemble de la période, les garas ont été vendus de 15 à 25 livres. Quant aux quelques garas bleus, ils ont atteint le prix de 14,7 livre en 1738, le prix des plus petites pièces de garas. Legoux ${ }^{13}$ affirme que les plus chers des garas se vendent 3,5 roupies sicca $(* 2,7)$, soit 9,45 livres.

Une contradiction: en nombre, les garats, occupent la troisième place ${ }^{14}$. Les tissus importés, alors qu'en valeur, ils sont au deuxième rang, bien que le tissu soit de mauvaise qualité et peu cher. Cette contradiction s'explique sans doute: ont été ôtées des calculs plus de $11 \%$ des cotonnades, sans nom, ou abîmées, peut-être des guinées, ou des salempores, ou autres toiles, ce qui fausse la proportion relative de la valeur de chacune des étoffes.

\section{Les baffetas}

Les baffetas : « du persan bâfta, tissé $»^{15}$ pour Hobson-Jobson. « «Toile toute de fil de coton blanc, très grosse...13 aune $3 / 4$ à 14 de longueur $7 / 8$ de large. Il y en a aussi qui n'ont que $5 / 6$ de large et même une demie aune. $\aleph^{16}$ Roques $^{17}$ remarquait, pour les années 1676 1691, et dans le Gujarat, que "la qualité des baffetas est la meilleure de toutes les toiles qui se font aux Indes et d'un bon service...Les baffetas sont souvent 
destinés, au moins dans cette région, à être peints (ou imprimés) en chit. » Après la famine de 1630 dans le Gujarat, les baffetas ont été imités dans d'autres parties de

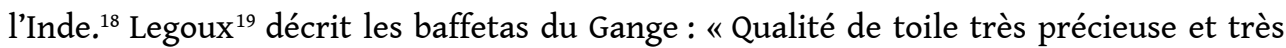
utile pour tous les usages de la vie...Mais c'est principalement pour l'impression et l'usage des manufactures d'indiennes qu'elle est utilement utilisée en Europe. » "Les qualités varient infiniment, on en fait de très fins et d'autres aussi grossiers que des garats. " "Autre toile de la classe des communes, mais supérieure aux garras, pour Blancard. ${ }^{20}$ Dermigny évoque ces "toiles communes du Bengale et de Surate, d'une qualité supérieure à celle de garats, $9 \frac{1}{2}$ à 10 aunes et 11 à11 1/2 et en deux largeurs, 3/4 et $5 / 6 \ldots$... Différentes appellations, d'après le nom des districts où on les fabrique: Eliabad, Joindpour, Jougdia, Lockipour $»^{21}$, etc.

La taille des pièces est variée, plus que ne le suggèrent Savary, et Dermigny. La plupart des pièces, certes, sont de 10 1/2 à 11 aunes sur 3/4, ou sur 5/6 en 1726 ; mais aussi de 8 ou 9 en 1738, et de 14 en 1739 et 41. En 1741, par exemple, le catalogue cite des baffetas blancs de 14 sur de 7/8, et des baffetas d'Ajanabad de 10 1/2 sur illisible. Les aunages varient de $81 / 2$ à 9 aunes sur près de 14 aunes. Sept cent pièces sont qualifiées de baffetas d'Ajanabad. Parmi elles, 64 pièces sont dites « à petites lisière d'or. "

La valeur de la pièce est, comme d'habitude, fonction de sa taille, de sa finesse...et de la date. En 1687, les baffetas blancs ont été vendus 6,7 livres. En 1691, des baffetas de Nefsary, 4: des baffetas blancs, 4,19. En 1739, par exemple, la valeur de la pièce a dépendu de sa plus ou moins grande finesse, mais aussi de ses différents aunages : de 8 aunes sur près de $3 / 4$, de 14 à 17 livres ; sorte plus fine 18,1 à 20,$1 ;$ de $91 / 2$ sur près de $3 / 4$ de 22 à 23,1 ; ceux de $101 / 2$ sur près de $7 / 8$ de 27,1 à 30,7 ; baffetas de Patna de $10 \frac{1 / 2}{\text { sur }}$ $1 / 2$, de 13,0 à 14,4 ; de 14 sur $9 / 1616,1$; de 15 sur $7 / 12$, 20 ; de 14 sur peut être 1 de d'Ajanabad, 27,1 à 28,12. Legoux ${ }^{22}$, en estimait le prix d'achat, de 9,5 à 18 livres.

Sur l'image de la pièce, nos sources ne sont pas tout à fait muettes : les baffetas peuvent être blancs ou bleus; en 1728, 1570 pièces de baffetas bleus sont vendues. En 1738, des baffetas de couleur bleue ont été vendus entre 10 à 10,6 livres, la même année, les blancs de petite taille se sont vendus au même prix, tandis que les plus fins et les plus grands valaient de 21 à 24 ; en 1717 ont été présentés des baffetas rayés de fil écru, à 24,6 livres. En 1767 et 68, les prix montent un peu : 22 et 33 livres.

Les localités évoquées à propos des baffetas, sont d'abord le Bengale, plus particulièrement Jougdia, Ajanabad et Nefsary.

En résumé, les quatre toiles de coton les plus vendues ne sont pas de belles cotonnades. Chacune d'entre elles (à l'exception des garats, de mauvaise qualité), peut être qualifiée de grosse, ou de fine. La valeur n'est pas forcément un indice de qualité, de finesse, car l'aunage a aussi son importance. Ces toiles ne sont pas toutes blanches: chacune d'entre elles présente deux variétés, les toiles blanches, les toiles bleues.

\section{Les guingans}

Pour Savary ${ }^{23}$ : «Toile de fil de coton quelquefois mêlé de fil d'écorce d'arbre qui n'est ni fine ni grosse; il y en a de bleues et de blanches, dont la pièce comprend pour l'ordinaire huit aunes de long sur $3 / 4$ à $5 / 6$ de large ». Pour Legoux ${ }^{24}$ : «La majeure partie de ces guingans sont tissés en toiles à quatre fils...Le guingan est une toile rayée à barres étroites ou plus ou moins larges et de couleur rouge, ou rouge et bleu mélangé. 
Ces rayures sont des fils qui entrent dans la chaîne de la pièce, et qui ne se trouvent jamais dans les fils de trame... Excellence des teintures et du coton qui sert à faire les raies ou barres du guingan et le tissage de cette étoffe. " Dermigny ${ }^{25}$ en fait une description à peu près identique : «toiles du Coromandel à petites raies rouges de 6 aunes et demi sur $5 / 8$; elles sont à quatre fils c'est à dire que la trame est à deux fils et qu'en les tissant on prend deux fils de chaîne. Le principal centre de fabrication est à Karikal. » On trouve plusieurs origines fantaisistes dans Hobson-Jobson, dont la plus probable, pour les auteurs, est un mot javanais, ginggang, une toile rayé ou à carreaux. 26

Les lieux de fabrication sont nombreux : guingan de la Côte, de Karikal, de Pondichery, du Masulipatam, de Madras, de Paliacate, toutes places situées sur la côte de Coromandel.

Donc, une toile de coton, mais sans doute mêlée parfois de soie : Savary parle d' »écorce d'arbre » (de la soie); nos affichettes signalent la vente de guingans d'herbe en 1725 et 26 , et une seule fois de guingan « armoisin » en 1768.

Guingans divers, inv. BAD 6752 (GG4), album d'échantillons, 1789, p. 341. Les Arts Décoratifs, Paris

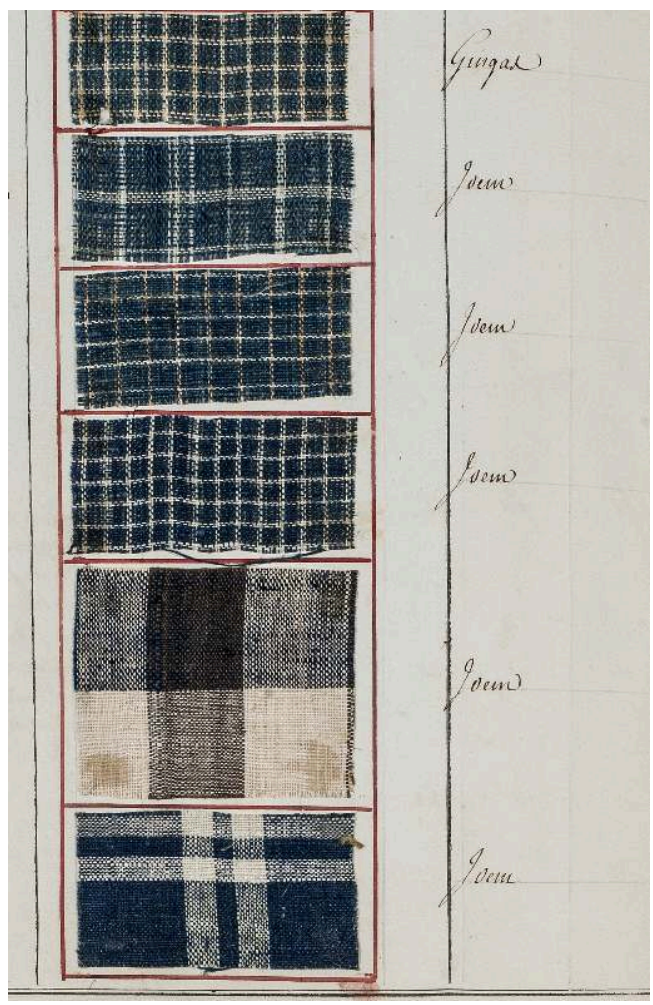

Photo Les Arts Décoratifs, Paris/Jean Tholance (photo soumise à accord préalable, rétrocession photo interdite) 
Guingans divers, inv. BAD 6752 (GG4), album d'échantillons, 1789, p. 87. Les Arts Décoratifs, Paris

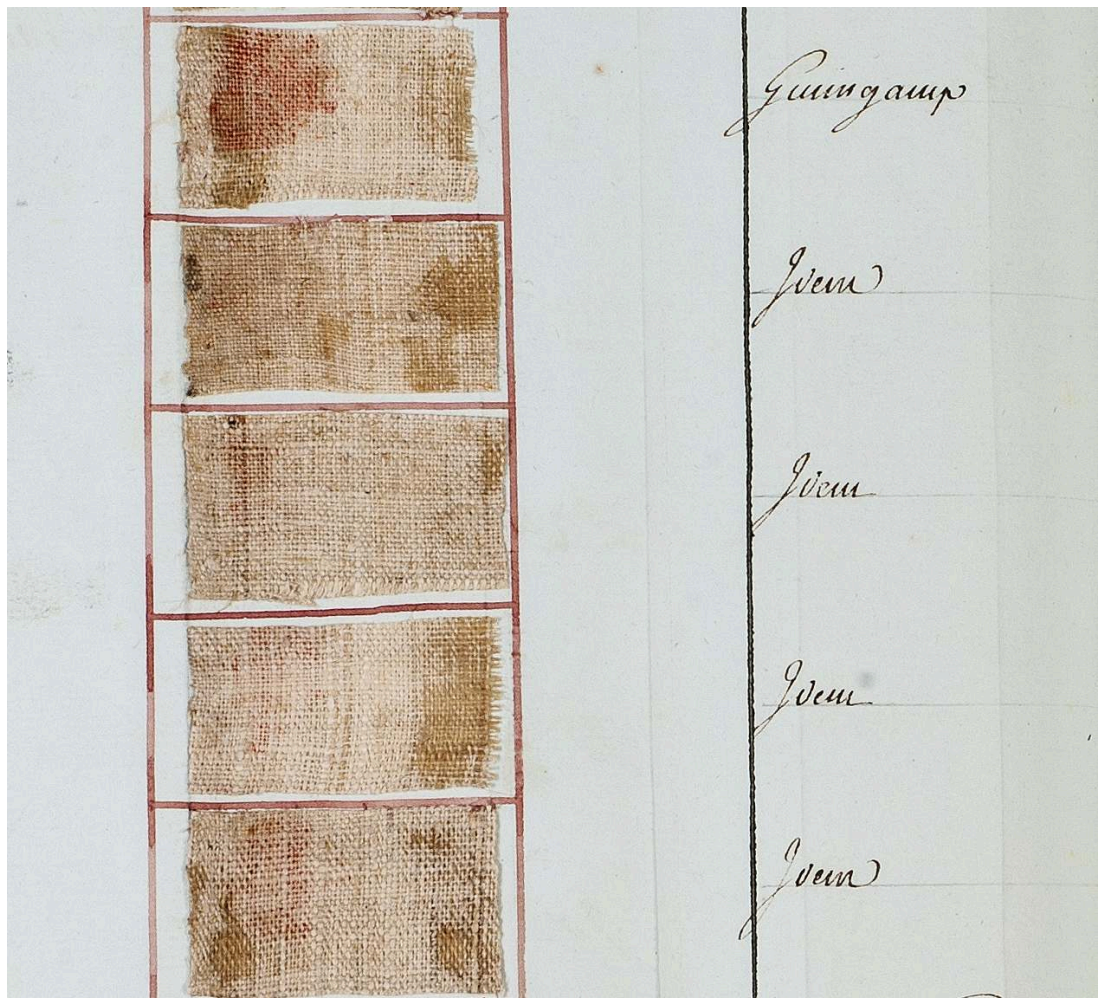

Photo Les Arts Décoratifs, Paris/Jean Tholance (photo soumise à accord préalable, rétrocession photo interdite)

Guingans divers, inv. BAD 6752 (GG4), album d'échantillons, 1789, p. 73. Les Arts Décoratifs, Paris

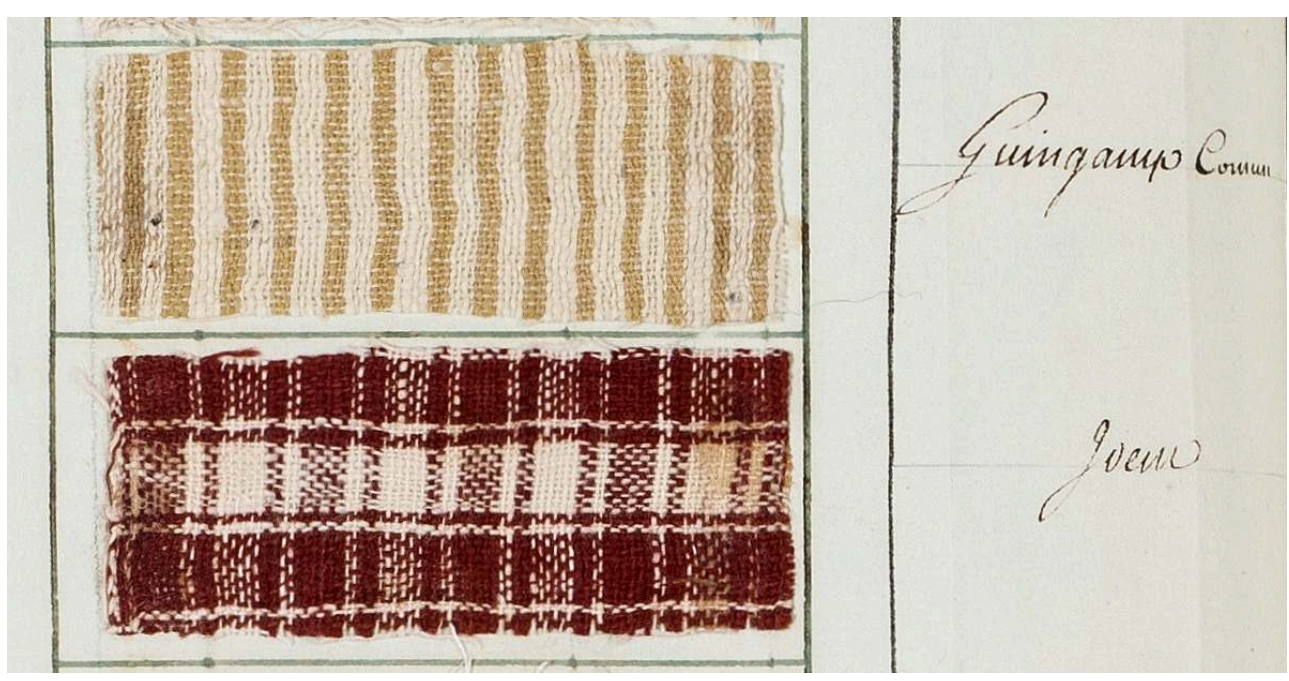

Photo Les Arts Décoratifs, Paris/Jean Tholance (photo soumise à accord préalable, rétrocession photo interdite) 
Guingan commun sur le site tmoi.org.uk, $n^{\circ} 417$

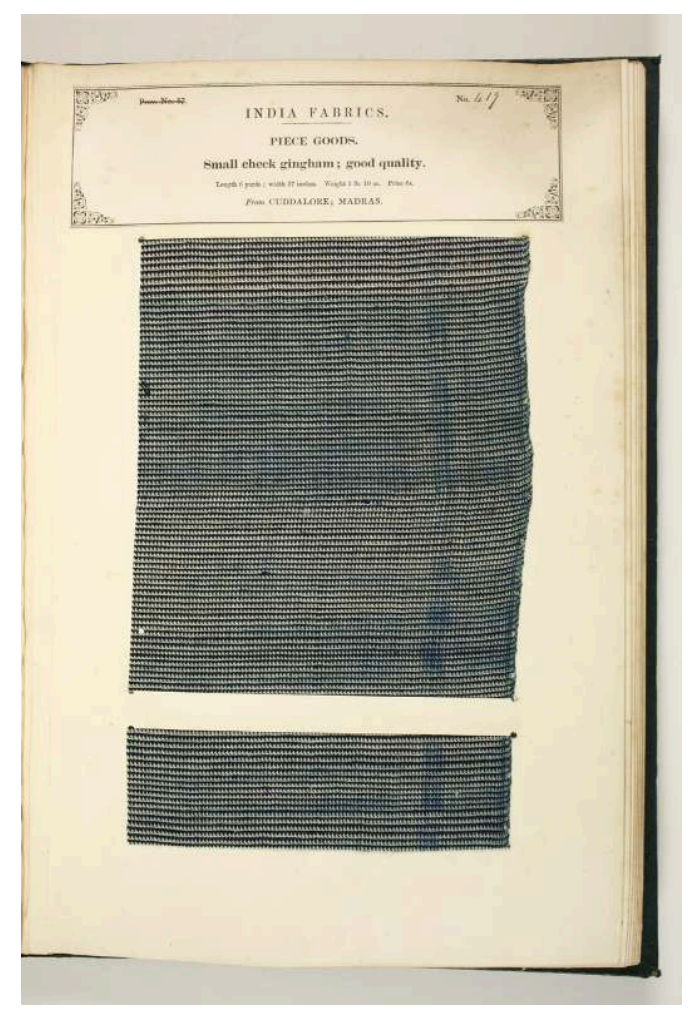

Guingan à petits carreaux sur le site tmoi.org.uk, $n^{\circ} 416$

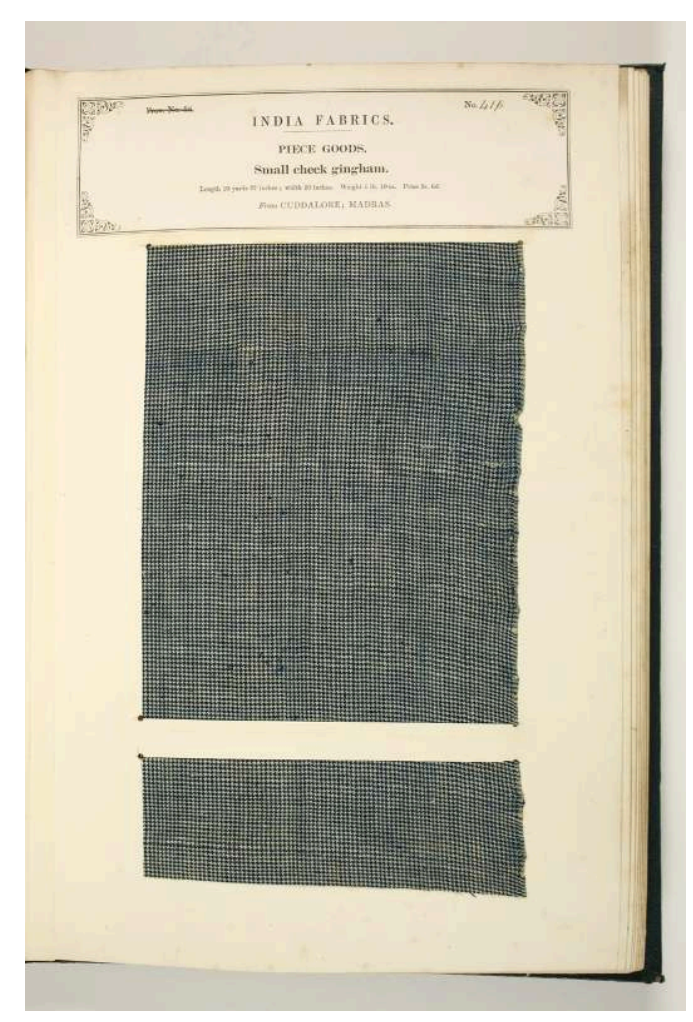




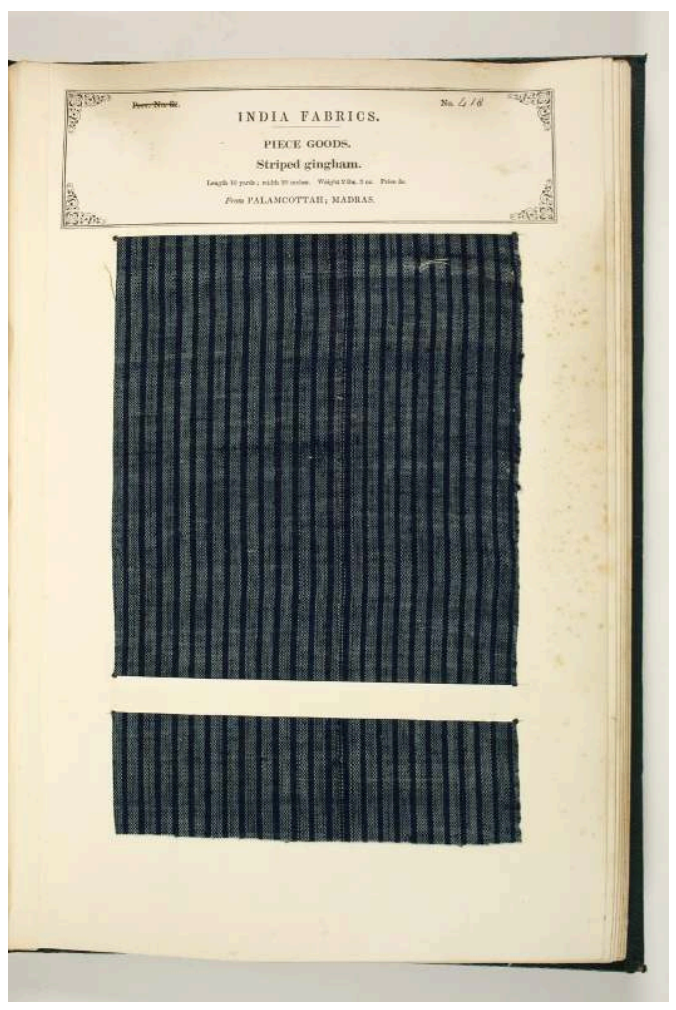

42 Ces pièces de couleur (en 1687, la vente parle de " guingan de couleur ») sont de petits aunages, petite longueur et petite largeur, de 5 aunes $3 / 4$ à 6 aunes et demie, sur 5/6, 7/8. 9/16, 9/19. Dans la vente de 1712, les guingans sont «bleus et blancs, rayés ». Legoux propose des longueurs de 12 aunes, sur différentes largeurs; seules les plus larges sont exportées, dit-il. Legoux et Blancard constatent que ces guingans sont des pièces très demandées pour le Iles Philipines, se font à Karikal et de là passent à Pondichéry. " ${ }^{27}$ Les guingans sont des pièces prohibées.

Leur valeur, à une exception près (1767) varie avec la « sorte » et la largeur : entre 9 et 16 livres. Un guingan, particulièrement large et même un peu plus long que d'usage, en 1726, a été vendu 30 livres; de même qu'en 1767 et 68, des guingans du Masulipatam autour de 30 livres.

Dans l'affichette de 1768 figurent les quantités de pièces, leur prix d'achat, leur origine, leur prix de vente : les guingans de Pondichery sont à 6 livres; les guingans de Madras à 12 ; ceux du Masulipatam, à 82 livres. Donc il y a guingan et guingan: «il n'y a pas de marchandise dont le prix soit plus varié, constatait Legoux p. 131, de 1 à 34 francs la pièce, à l'achat.

45 Les quelques balacor signalés sont-ils des guingans? Un document de 1729 inscrit en effet "guingan balassor » En 1716, ces pièces sont de petites pièces de quatre aunes à quatre $\frac{1}{2}$. Le lot comprend quatre pièces de balassor et quatre pièces de pinasses, à 15 livres, soit moins de 2 livres la pièce, en moyenne. 


\section{Les sanas}

46 "Toiles de coton blanches ou bleues, qui ne sont ni fines ni grosses...du Bengale. Les blanches ont à la pièce 9 aunes $1 / 3$ sur $3 / 4$ à $5 / 6$ et les bleues $11 \frac{11 / 4}{\text { à }} 12$ sur $7 / 8$. $»^{28}$ Dermigny $^{29}$ atteste aussi de l'existence de sanas bleus. En 1691, les sanas sont dénommées : sanas ou amans, à 19 livres

En 1739 et 1741, les ventes mentionnent des sanas de 11 aunes $1 / 2$ sur $3 / 4$ à $7 / 8$ et de 11 3/4 à 12 aunes, sur $7 / 8$ et plus. Les autres années $(1716,1718$ et 1725), c'est la longueur indiquée par Savary qui prévaut: 9 à 9 aunes $1 / 4$ sur 3/4,5/6, 7/8. Quelquefois le lieu d'origine a été mentionné : en 1750, sanas de Jougdia et de Monnepour, et, en 1767, du Bengale.

48 L'apparence de la pièce n'est pas souvent précisée : la couleur bleue n'est pas évoquée, pour cette toile qui semble être une toile "fine"; en 1716, se trouvent des sanas "brodés de mogue à ramage. »

La valeur, toujours liée à la largeur de la pièce, varie entre 12 et 35 livres.

Un mystère : en 1691, l'extrait de la vente signale l'existence de 37 balles de sanas OU amans, à 5,9 livres la pièce. En 1687, pourtant les deux tissus, comme par la suite, ont bien été distingués : à 10,3 pour les amans et à 18,9 pour les sanas. Cette confusion, et le fait que, dans les ventes sanas et hamams ou amans soient toujours proches suggèrent qu'il existe une ressemblance entre les deux toiles, que la largeur de la pièce semble différencier.

\section{Hamans ou amans}

51 «Toile de coton blanches, très fines et fort serrées, dont la fabrique approche assez celle des toiles de Hollande...Les meilleures sont les Bengaloises...Portent ordinairement 9 aunes $1 / 2$ de long sur une aune $1 / 6$ de large. $»^{30}$ Même définition chez Blancard. ${ }^{31}$ Legoux les nomme âmames et explique l'étymologie par "hammam ", baignoire chez les Indous «qui en font les linges qui leur servent à s'envelopper en sortant de se baigner ou de faire leurs ablutions ... Cette qualité de toile, par sa finesse, le grain de son tissu lisse et serré, par son immense largeur, enfin par sa force la fait autant rechercher par les Européens que par les peuples qui habitent les autres parties du monde. $»^{32} \mathrm{Il}$ ne faut pas les confondre, dit-il, avec les percales, le réseau de la percale est plus serré, moins souple. $\|^{33}$

Une seule indication précise de lieu : Jougdia. elle est de 9 à $9 \frac{1 / 4}{4}$ sur une aune $1 / 8,1 / 6$. Seul le catalogue de 1741 donne quelques indications sur son apparence : de nombreuses pièces portent une lisière blanche, et moins souvent lisière d'or.

La valeur est liée à la largeur de la pièce (de une aune $1 / 8$ à une aune $1 / 6$ ), et à la finesse de la toile : de 20-25 à 45-50 livres. En 1726, par exemple, les pièces de 1 aune 1/6 ont été vendues de 26 à 28 livres ; plus fines, 31 à 39 ; encore plus fine, 42 à 47.

Sana et amans se ressemblent-ils au point d'être confondus en 1691 ? Peut-être, mais les hamans sont de plus grande largeur et sont plus onéreuses. 


\section{Doutis}

Doutis, sous le nom Dhotee, sur le site sur le site tmoi.org.uk, $n^{\circ} 123$

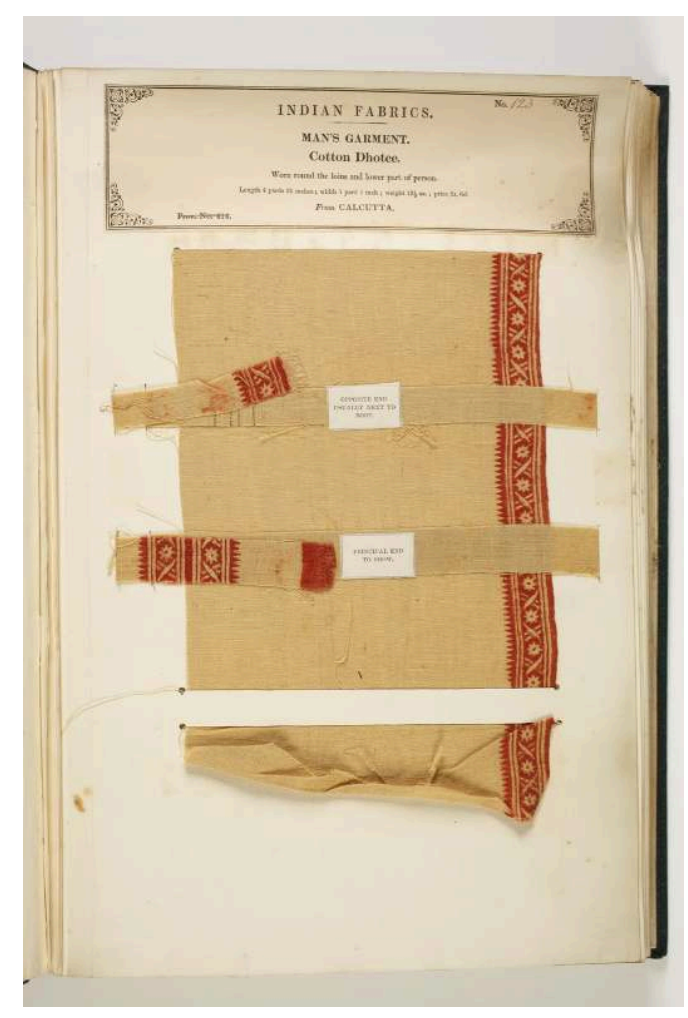

Doutis, sous le nom Dhotee, sur le site sur le site tmoi.org.uk, $n^{\circ} 124$

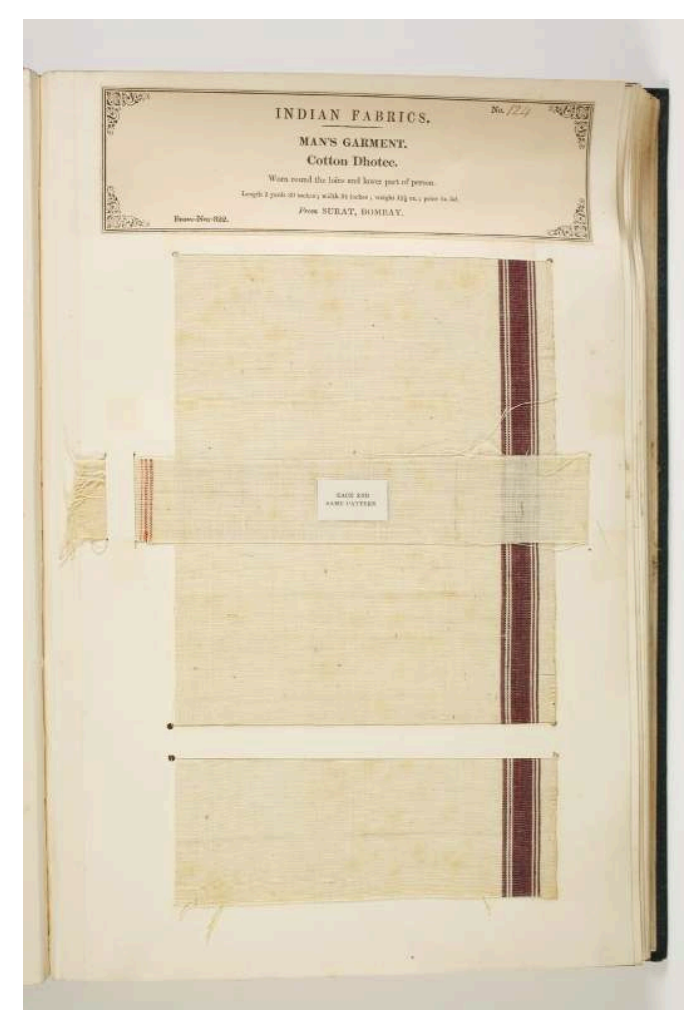




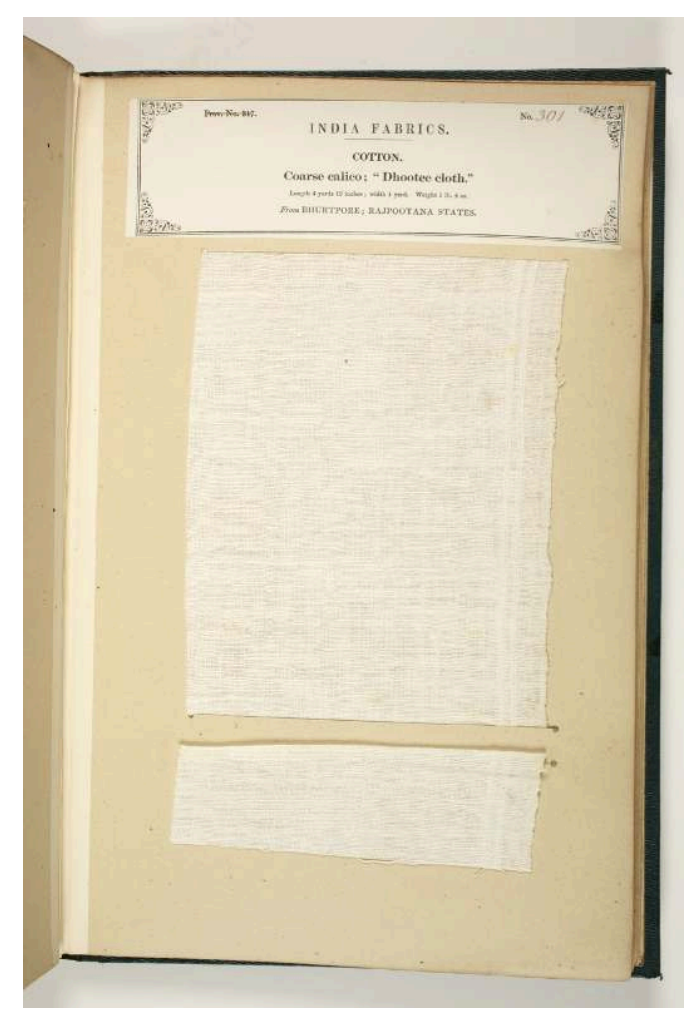

Savary en fait «des toiles blanches de coton, assez grossières...particulièrement de Surate. La longueur est de 14 aunes ou environ et la largeur depuis 5/6 d'aune, jusqu'à une aune et 5/6...Les doutis étaient autrefois en France du nombre des toiles qu'on y imprimait avant que le commerce des toiles peintes eût été défendu. $»^{34}$ Pour Irwin « un calicot fort de mauvaise qualité. $»^{35}$

La pièce semble assez longue : en 1739, les doutis dorgagis sont de 13 aunes ; en 1741, de $13 \frac{1}{2}$ à 14 aunes sur $2 / 3$, ou $3 / 4$ ou une aune et plus.

En 1687, les «toiles doutis blanches de différentes qualités », ont été vendues 6,5 livres la pièce. En 1691, les doutis font partie de balles associant berams et baftas : à 3,5 pièce ; doutis et dorgagis, à 4 livres la pièce. En 1739, des doutis dorgagis, de 13 aunes, de 16 livres 1/2 à 35,1. En 1767, 17 livres; et en 1768, 14 livres. Doutis et dorgagis sont donc associés, soit qu'ils apparaissent comme deux tissus différents, soit que le mot dorgagis soit un qualificatif de doutis. Roques ${ }^{36}$, qui n'évoque jamais le douti, parle souvent des dorgagis du Gujarat, "grosse toile...de plus ou moins bonne qualité. » Gageons qu'en 1691, on distingue encore les deux toiles ; mais qu'après le déclin du Gujarat, les deux mots sont devenus synonymes.

Les dotis font encore partie des vêtements indiens masculins, portés dans les campagnes du sud surtout, plus que dans les villes : ce sont de grandes pièces de deux mètre environ, en coton, de couleur blanche ou autre, et de qualité différente. 


\section{Les basins}

Les basins sont souvent qualifiés du nom de l'aire de fabrication, le Bengale ; en réalité, ils se font dans le Bengale, à Pondichery et sur la Côte.

Dans un long article sur les basins européens, des toiles fréquemment rencontrées en Europe, Savary consacre quelques lignes aux basins de Indes « blancs et sans poil...Les uns croisés ou serge et les autres à carreaux ou ouvrés. Les meilleurs sont ceux qui se fabriquent au Bengale, à Pondichery, et à Ballasor. Ces derniers sont les plus estimés. ${ }^{37}$ Ils apparaissent dans les descriptions de Legoux comme des marchandises de la Côte de Coromandel : «Après les guinées, les percales et les mouchoirs, une des plus importantes importations de la Côte pour l'Europe. Ces basins se fabriquent avec un double fil, tant dans la chaîne sur la trame [...], d'où la force, le moelleux, l'uni, des basins du Coromandel. ${ }^{38}$ Dermigny ajoute que : « les plus beaux sont des goudelours ». (de l'actuelle Cuddalore, à quelques kilomètres de Pondichery).

On n'a guère de renseignement sur cette toile banalement blanche. Le catalogue de 1741 distingue cependant sous le nom de basins du Bengale des toiles de 7 à aunes à $71 / 2$, sur $3 / 4$ à $5 / 6$, ou de plus d'une aune, qui sont le plus fréquemment unis, mais aussi à « œil de perdrix $»$.

3 L'aunage n'est pas de 9 aunes (et même de 10 à 16 pour Legoux), mais de 7 aunes $1 / 2$ à $3 / 4$ sur différentes largeurs, de 5/6 à plus d'une aune; la valeur, suivant la largeur de la pièce, varie de 32 à 45 livres. En 1739, par exemple, les basins de 7 aunes 3/4 sur 5/6 ont été vendus de 42,1 à 43,6 livres ; ceux de $7 / 8$ à 11/12, à 42 livres ; sur une aune et plus, de 44,1 à 45,7 livres. Legoux estime le prix d'achat des pièces à une quarantaine livres.

Basins, inv. BAD 6752 (GG4), album d'échantillons, 1789, p. 103. Les Arts Décoratifs, Paris

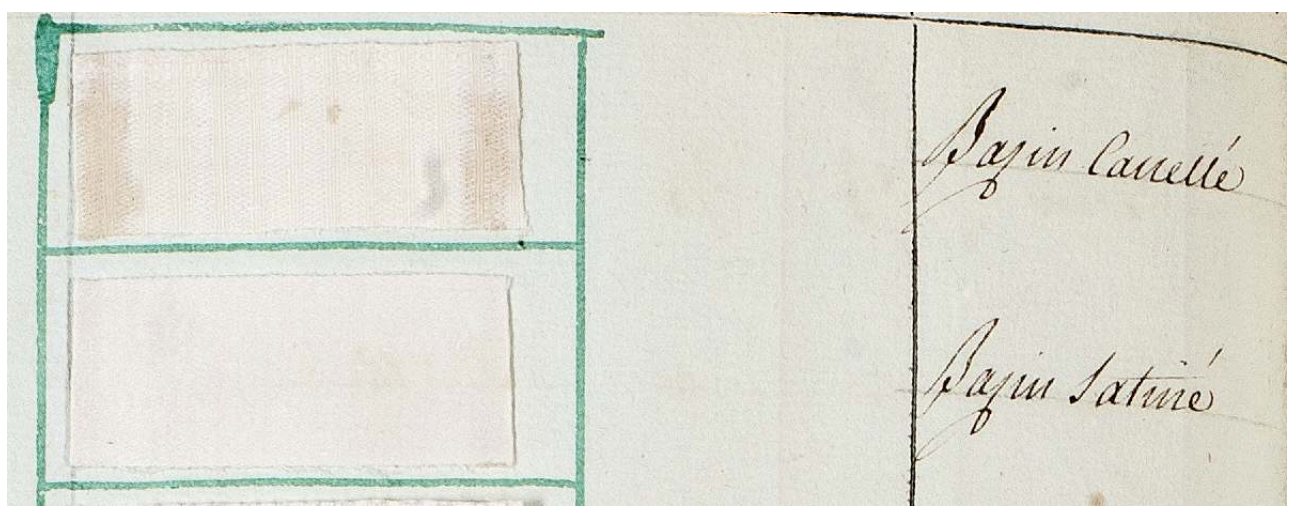

Photo Les Arts Décoratifs, Paris/Jean Tholance (photo soumise à accord préalable, rétrocession photo interdite) 


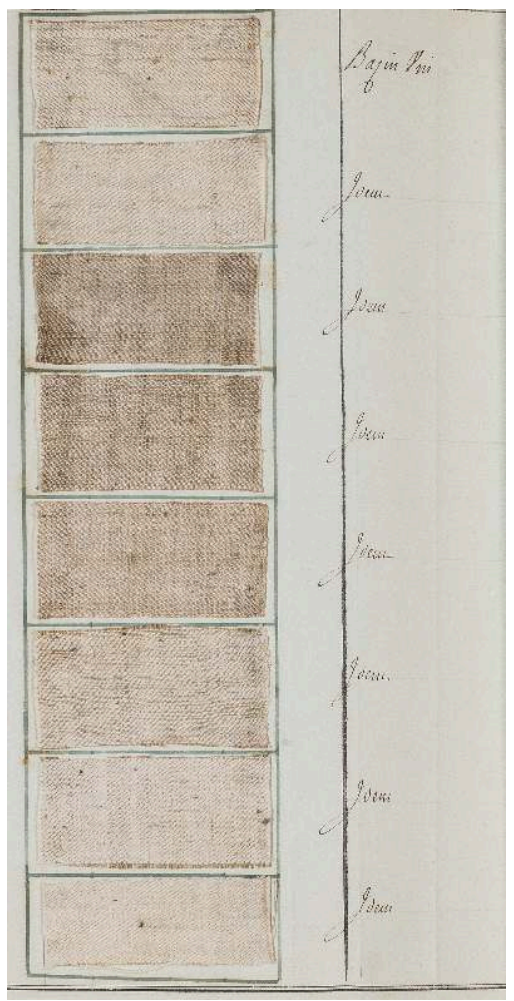

Photo Les Arts Décoratifs, Paris/Jean Tholance (photo soumise à accord préalable, rétrocession photo interdite)

\section{Percales}

De Parkâlâ, " étincelle, morceau de verre ", dans le glossaire de Hobson Jobson. ${ }^{39}$

Sous le nom de percales-mauris, (même nom dans un document de 1720), Savary désigne des «toiles de coton blanches, plus fines que grosses qui viennent des Indes orientales, particulièrement de Pondichery... Portent sept aunes et un quart de longueur sur une aune et $1 / 8$ de large. $»^{40}$ Pour Dermigny, "toile du Coromandel de qualité supérieure quoiqu'il y en ait de différentes finesses et de différents prix; en pièces 7 33/4 à 8 aunes sur 15/16. Elles sont connues dans l'Inde sous le nom de chittes. C'est avec ces belles toiles que l'on fait ces indiennes connues en Europe sous le nom de perses. $»^{41}$ Legoux rapproche les percales des amames : "Quelque rapprochement qui puisse se trouver entre la tissure de l'amame et celle de la percale, ces deux qualités de toile... présentent des caractères différents. Le réseau de la perkale est plus serré, moins souple et moins moelleux que le tissu de l'amame... Tissu très serré, fil demi rond... le fil est à deux brins filés ensemble... surface parcheminée... On ne connaît dans l'Inde que des perkales de 32, 38 et 46 conjons... neuf aunes $3 / 5 . »^{42} \mathrm{En} 1777$, les percales sont qualifiées de fines. Pour Irwin, et Chaudhuri: "une toile de bonne qualité, renommée pour la finesse et la régularité de son tissage et pour sa solidité, tissée autour de Madras et de Golconde, le calicot le plus adapté à la fabrication de chintz. Autour de 8 yards sur un ${ }^{43}$ " C'est pour cette raison que la toile est par excellence pour la peinture des chittes... Toutes les chittes fines ne se font que sur cette espèce de toile... Elle est la seule... qui soit propre à redevoir les couleurs. $»^{44}$ 
Jusqu'en 1738, l'aunage de la toile est bien de sept aunes à sept et demi, sur une largeur qui dépasse l'aune : de 7 aunes sur $7 / 8$ à $11 / 12$ sur près d'une aune ou une aune $1 / 8$ jusqu'à cette date. Après 1738, la longueur augmente, de 12 à 16 aunes, la largeur diminue, $7 / 8$ ou $15 / 16$ d'aune.

67 Le prix, faible pour la fin du XVIIème siècle, de 7 à 11 livres, varie dans les années qui suivent suivant les largeurs, de 20 à 33 livres; pour des pièces plus grandes, de 48 à 63 livres dès 1738. Legoux en estimait le prix, à l'achat, à 80 pagodes d'or la courge, ce qui fait 660 francs de France, soit 33 livres la pièce. Une origine apparaît en 1720 et 1777, sous le nom "percales de Madrapac», "les manufactures les plus renommées sont celles des districts de Madrepac et de Cajivarom... peu éloignés des comptoirs de Pondichery et de Madras. $»^{45}$ La toile doit être rangée parmi les « toiles fines. »

\section{Les mauris... ou mouris... ou percales}

68 Citons leur nom, mais associons-les aux percales.

"Qu'on nomme autrement percales, sorte de toile blanche de coton » ${ }^{46}$; et sous le nom de mouris ${ }^{47}$ " toiles de coton, fines, grossières, larges, ou étroites, des blanches et des rouges... 12 aunes de long sur différentes largeurs une aune $3 / 4$, une aune $1 / 4 . »$ Moorees, "des toiles bleues» pour Hobson-Jobson ${ }^{48}$. En 1687, ces "mauris», sont cités, sans aunage et au prix de 11,3 à 19 livres, onéreux par rapport aux autres toiles de la même époque. En 1712, 1720, à côté des percales madrapac figurent des percales mauris.

\section{Les Boclans ou boleans, ou bolkas ou bolcas coutils et coupis et rasta}

"Ces pièces, coutis ou bolcas ou boclans sont des «espèces de coutil fait de fil de coton...Il y en a de tout blancs et d'autres rayés de jaune dont les raies se font avec du fil de coton. ${ }^{49}$ Même description chez Dermigny, "tout blancs ou rayés de jaune pâle ». On suppose que ce nom de coutil, présent dans les affichettes, n'était pas un nom de tissus indien, mais un mot rajouté par le scripteur qui connaissait l'existence en France de ce tissu. E. Hardouin-Fugier décrit les coutils européens : ce sont des toiles serrées, épaisses, destinées surtout à la literie et à l'ameublement ; mais « le coutil pour chemises est discrètement rayé. » 
Coutils divers, inv. BAD 6752 (GG4), album d'échantillons, 1789, p. 261. Les Arts Décoratifs, Paris

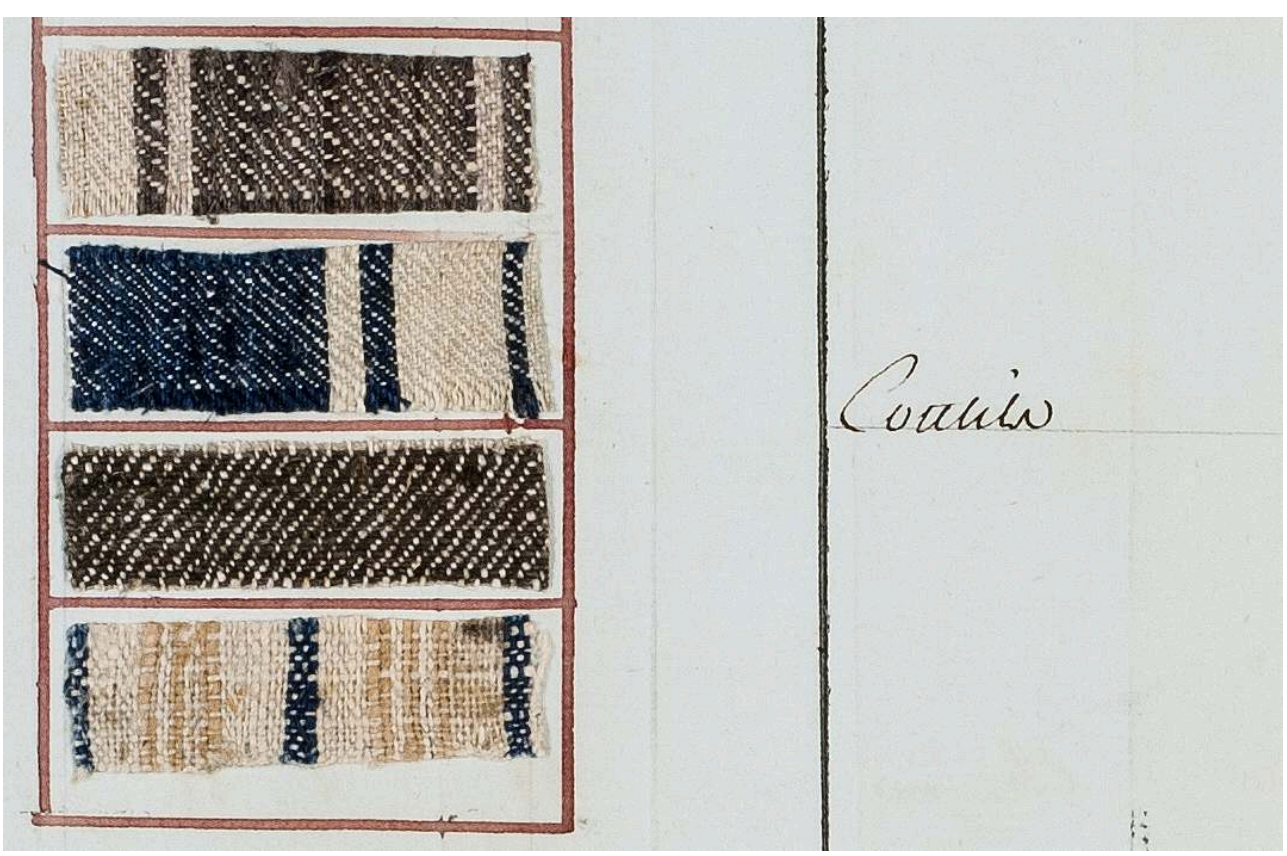

Photo Les Arts Décoratifs, Paris/Jean Tholance (photo soumise à accord préalable, rétrocession photo interdite)

Coutils divers, inv. BAD 6752 (GG4), album d'échantillons, 1789, p. 307. Les Arts Décoratifs, Paris

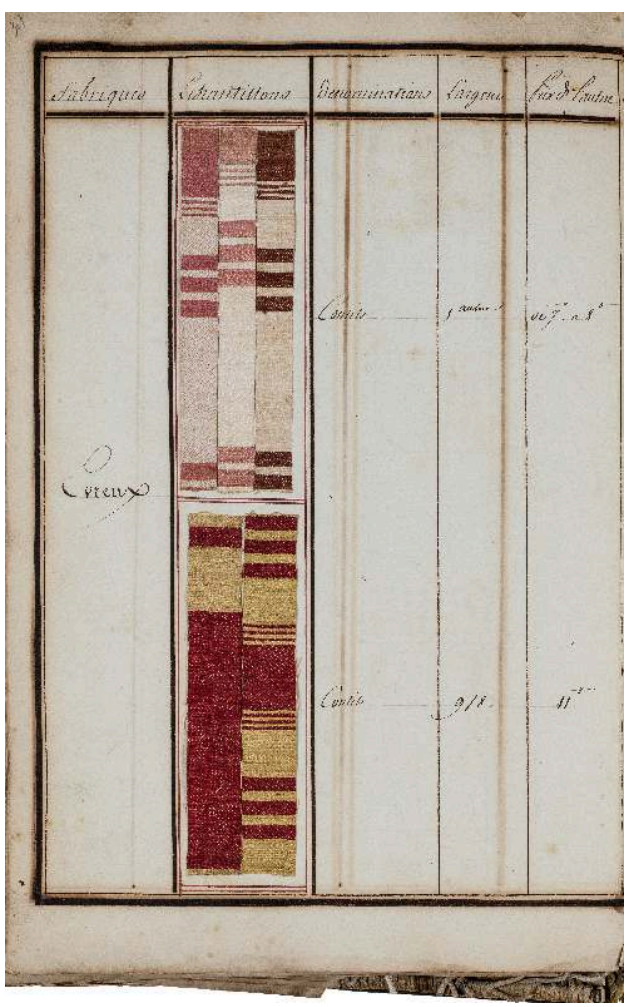

Photo Les Arts Décoratifs, Paris/Jean Tholance (photo soumise à accord préalable, rétrocession photo interdite) 
Coutils bon teint, inv. BAD 6752 (GG4), album d'échantillons, 1789, p. 77. Les Arts Décoratifs, Paris

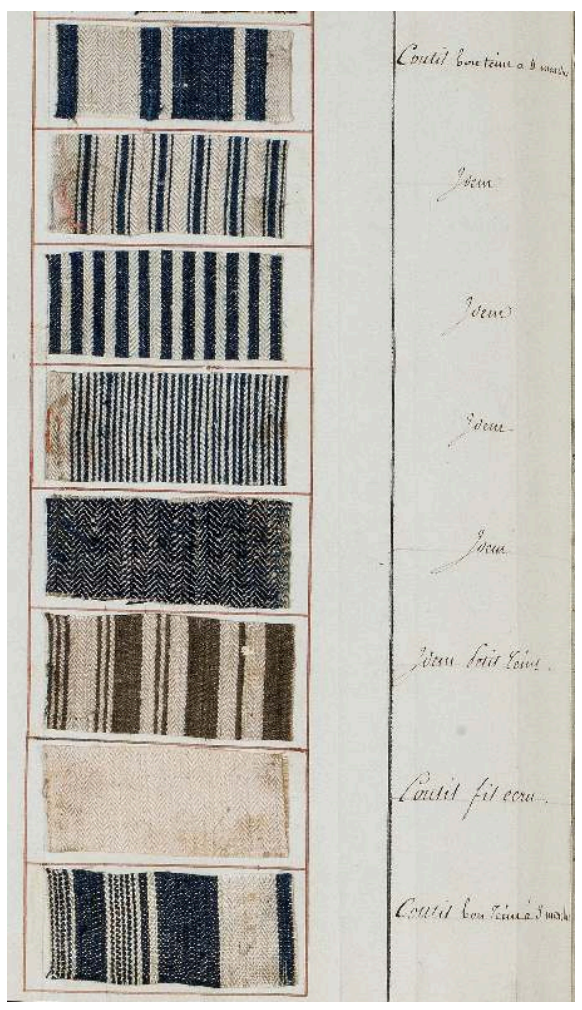

Photo Les Arts Décoratifs, Paris/Jean Tholance (photo soumise à accord préalable, rétrocession photo interdite)

70 Ces pièces sont toutes de 8 aunes sur près de $7 / 8$; les valeurs oscillent entre 14 et 17 livres.

71 Les coupis ont été transformés en coutils ou bolcas par Wellington. Mais, dans le catalogue de 1738 et 1741 , les deux termes apparaissent, distincts. Ces coupis sont aussi bien distingués par Savary ${ }^{50}$ : « des toiles très fortes, très solides, et serrées, blanches ou à rayures, ou à carreaux, spécialement apportées du Bengale, selon Savary, de 8 aunes (ici de sept aunes et demi à sept aunes $3 / 4$ ).

Coupis, inv. BAD 6752 (GG4), album d'échantillons, 1789, p. 75. Les Arts Décoratifs, Paris

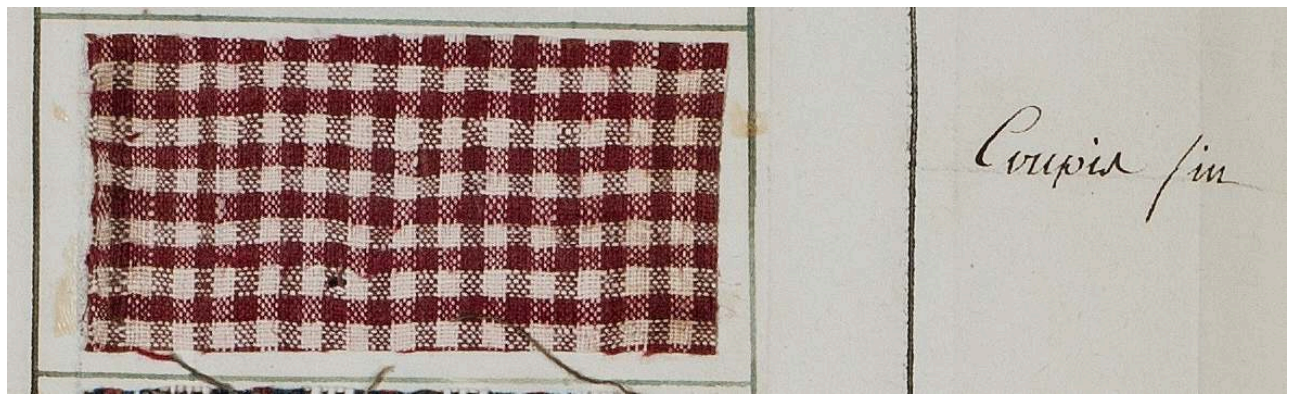

Photo Les Arts Décoratifs, Paris/Jean Tholance (photo soumise à accord préalable, rétrocession photo interdite) 
Coupis, inv. BAD 6752 (GG4), album d'échantillons, 1789, p. 305. Les Arts Décoratifs, Paris

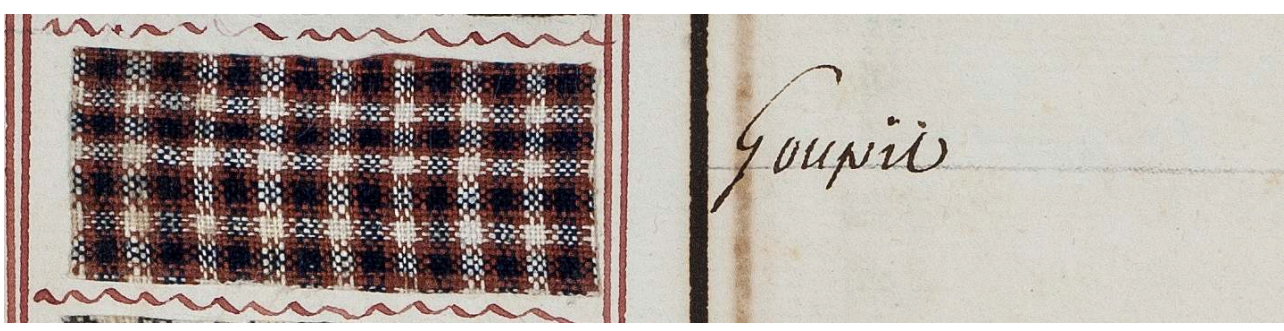

Photo Les Arts Décoratifs, Paris/Jean Tholance (photo soumise à accord préalable, rétrocession photo interdite)

Coupis, inv. BAD 6752 (GG4), album d'échantillons, 1789, p. 377. Les Arts Décoratifs, Paris

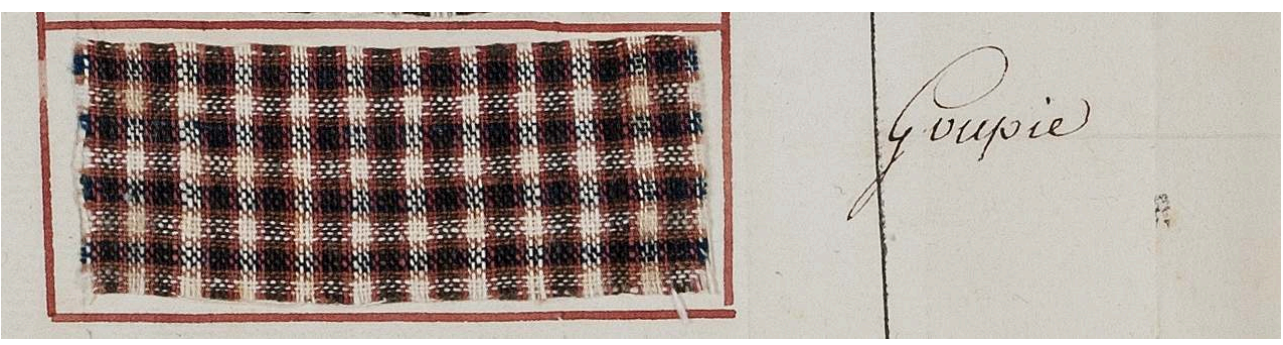

Photo Les Arts Décoratifs, Paris/Jean Tholance (photo soumise à accord préalable, rétrocession photo interdite)

Les coupis se sont vendues de 16 à 20 livres.

Plusieurs documents $(1725,1760)$ font des quelques rastas des ventes un synonyme de coupis : rasta ou coupis. (1704, « rattas de diverses couleurs)». La seule différence en semble la taille : en 1726, les coupis, distingués des rasta, sont de 7 aunes et ont été vendus de 16 à 17 livres, tandis que les rasta sont de 5 aunes et demi à 3/4 sur 3/4. Et se sont vendus plus cher, 19 livres. Les rasta seraient-ils des coupis de plus petite longueur?

Bref, l'hésitation l'emporte : coupi, coutils, boclan, rasta? Peut-être des étoffes un peu différentes, mais de toute façon prohibées, à rayures ou à carreaux.

Un doute: comme, dans les listes, ces toiles suivent les guingans, les caladaris, les tapchilas, parfois tissus de coton soie, les rayures seraient-elles de soie?

\section{Les limancais ou limaces}

Les limancais ou limaces sont des cotonnades rayées aussi, de meilleure qualité ${ }^{51}$, si on les rapproche des lemanee décrites par Chaudhuri. De 12 aunes sur 7/8 en 1741, et de petit prix, de 4, 9 à et 13 livres (en 1768, 1761, 1767).

\section{Les chazelas}

77 Sont-ils à rapprocher des chellas ? Ou chelloes « étoffes de coton bon marché avec des raies rouges, bleues ou noires...peut-être destinées à la traite des esclaves. $»^{52}$ 


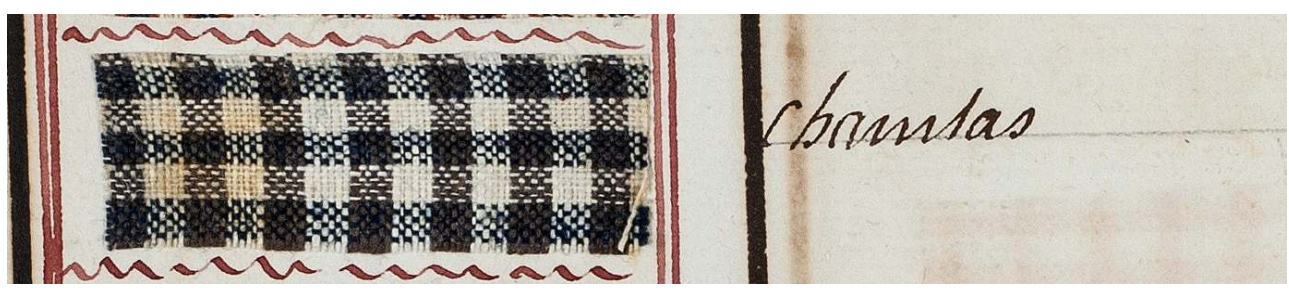

Photo Les Arts Décoratifs, Paris/Jean Tholance (photo soumise à accord préalable, rétrocession photo interdite)

Chazelas, inv. BAD 6752 (GG4), album d'échantillons, 1789, p. 306. Les Arts Décoratifs, Paris

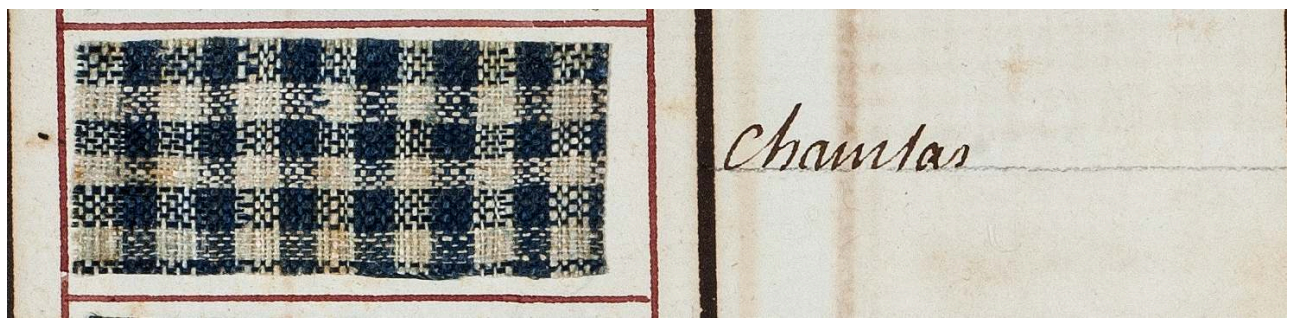

Photo Les Arts Décoratifs, Paris/Jean Tholance (photo soumise à accord préalable, rétrocession photo interdite)

Les données en font des pièces de 14 aunes sur $3 / 4$, seulement décrits en 1741 : rouges et blancs ou bleus et blancs, ou rouges et bleus, vendues entre 11 et 26 livres.

\section{Les socretons ou socrotes}

Des pièces assez mystérieuses, ignorées de Savary, d'Irwin, simplement qualifiées de «toile du Coromandel» pour Dermigny ${ }^{53}$, «toile de coton blanche importée de Pondichery " pour E. Hardouin, qui a la tentation de rapprocher le nom de seersucker et sirsakas ; « calicot » pour Wellington, sous le nom de « socrote, sorcrote, socquette. »

Qu'indiquent nos données? Ce sont de longues et larges pièces, à toutes les dates envisagées : en 1716, 16 aunes sur 7/8, ou une aune ou une aune $1 / 2$; même longueur en $1723,1726,1739$; en 1741 , de $15 \frac{1 / 2}{2}$ à 16 aunes sur $3 / 4$ et plus ou sur près de $7 / 8$; ou de 15 $1 / 2$ à 16 sur $11 / 12$; ou de «trois fils » en $15 \frac{1 / 2}{2}$ à 16 sur $11 / 12$. Les sirsakas, mélange coton soie, ne font que $9 \frac{1}{2}$ à 11 aunes.

81 Les socretons sont bien des toiles de coton, d'assez belle qualité. Leur valeur dépasse les 41 livres, et est fonction de la taille de la pièce, de 41 à 66 livres.

\section{Les Fottes, ou foutes}

Pour Savary, ce sont des «toiles de coton à carreaux qui sont apportées des Indes Orientales particulièrement du Bengale dont la pièce a une aune et demie de long sur sept huit de large. Quatre fottes font une pièce. $»^{54} \mathrm{~J}$. Irwin décrit : vient du persan «a kind of loin-band »... des toiles de coton de couleur exportées de l'Est et de l'Ouest de l'Inde. ${ }^{55}$ Dans l'Empire ottoman, la fûta est une « serviette dont on se couvre le milieu du corps, comme d'un pagne, au hammâm. ${ }^{56}$ 
Photte, inv. BAD 6752 (GG4), album d'échantillons, 1789, p. 379. Les Arts Décoratifs, Paris

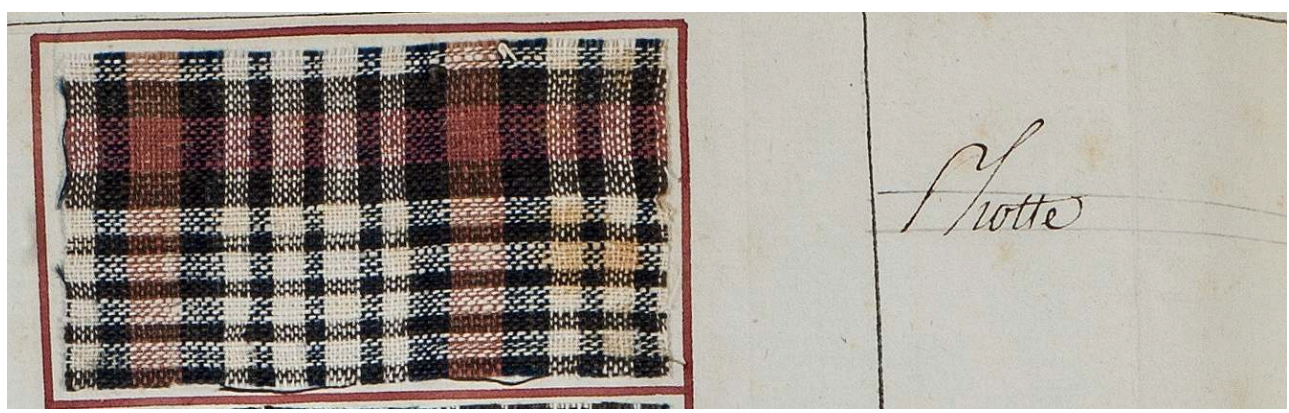

Photo Les Arts Décoratifs, Paris/Jean Tholance (photo soumise à accord préalable, rétrocession photo interdite)

Photte, inv. BAD 6752 (GG4), album d'échantillons, 1789, p. 306. Les Arts Décoratifs, Paris

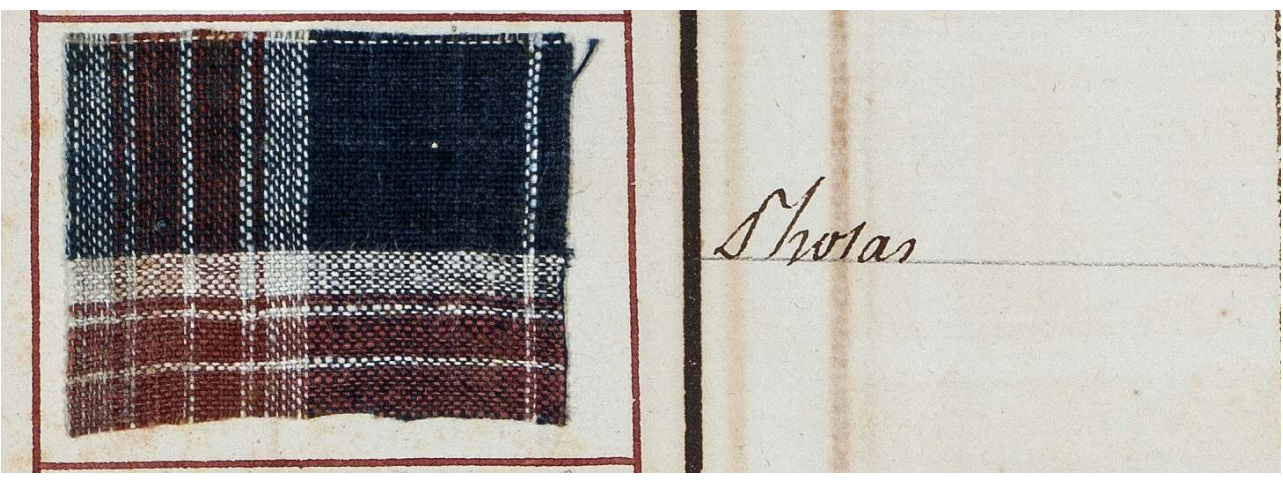

Photo Les Arts Décoratifs, Paris/Jean Tholance (photo soumise à accord préalable, rétrocession photo interdite)

Photte, inv. BAD 6752 (GG4), album d'échantillons, 1789, p. 71. Les Arts Décoratifs, Paris

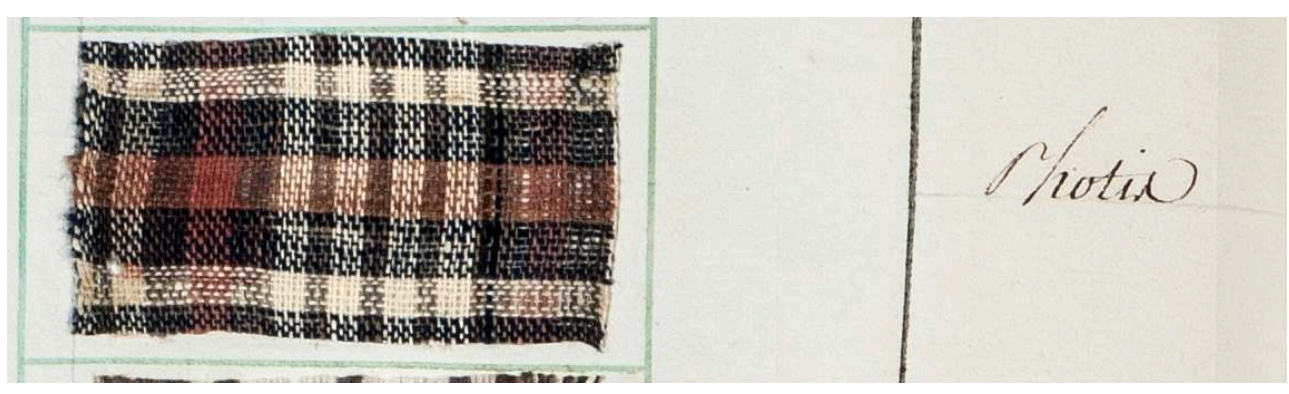

Photo Les Arts Décoratifs, Paris/Jean Tholance (photo soumise à accord préalable, rétrocession photo interdite)

Peu de renseignements par nos archives, sauf la confirmation (en 1737) qu'une pièce renferme quatre fottes.

\section{Les korottes}

Aucune description dans nos données. Faut-il rapprocher ces korottes des korathes ou toques de Cambaye de Savary, de "grosses toiles de coton, petites pièces de trois 
aunes » (Savary, II, p. 458) ? Pour Wingate, cité par Wellington, la korotte est une « vulgaire toile de coton.»

Les korottes font partie des tissus prohibés, soit de couleurs, soit rayés. En 1760, ils voisinent, dans les listes des ventes, les limancais, les guingans.

Corote, inv. BAD 6752 (GG4), album d'échantillons, 1789, p. 306. Les Arts Décoratifs, Paris

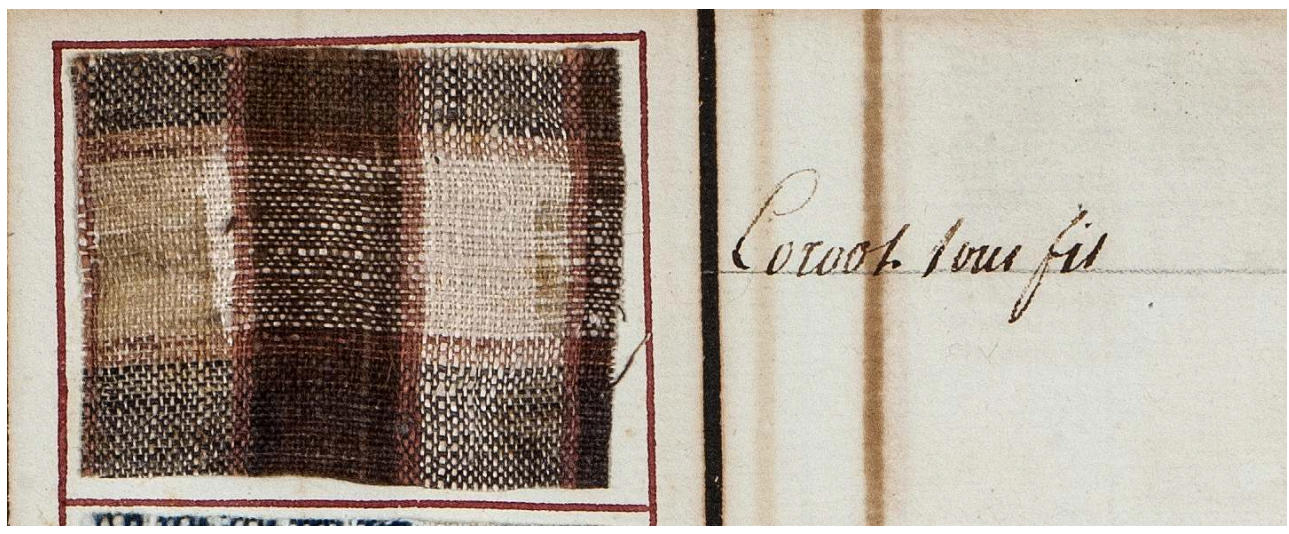

Photo Les Arts Décoratifs, Paris/Jean Tholance (photo soumise à accord préalable, rétrocession photo interdite)

Corote pour les « nègres », inv. BAD 6752 (GG4), album d'échantillons, 1789, p. 305. Les Arts Décoratifs, Paris

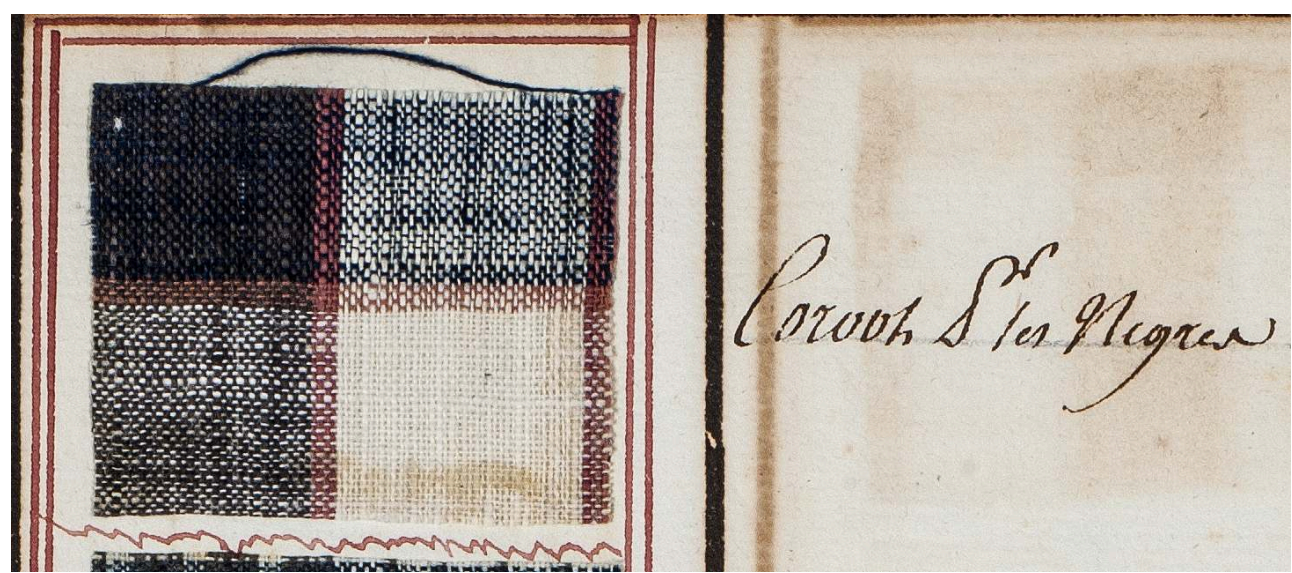

Photo Les Arts Décoratifs, Paris/Jean Tholance (photo soumise à accord préalable, rétrocession photo interdite)

Corote, inv. BAD 6752 (GG4), album d'échantillons, 1789, p. 379. Les Arts Décoratifs, Paris

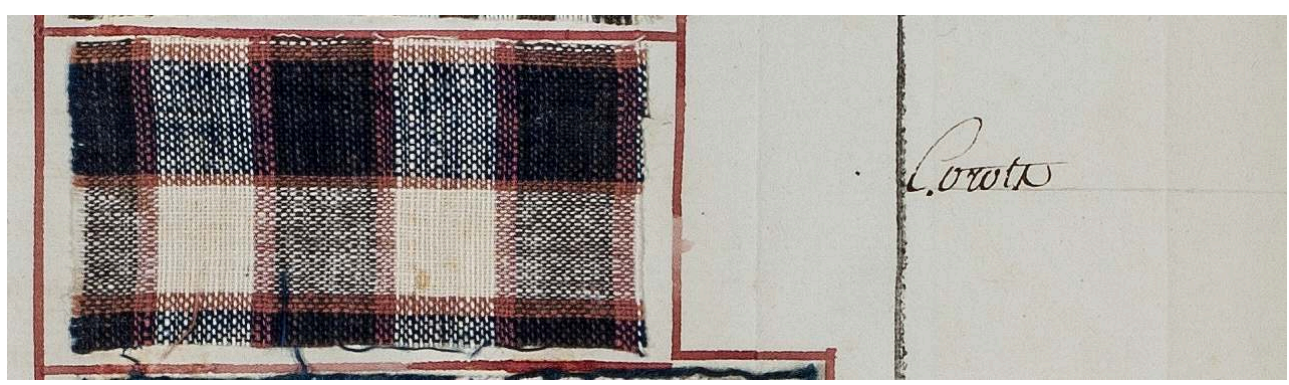

Photo Les Arts Décoratifs, Paris/Jean Tholance (photo soumise à accord préalable, rétrocession photo interdite) 
Les prix, du moins en 1767 et 68 , sont très faibles, de cinq à six livres.

\section{Les nekania}

Les nekania n'apparaissent que dans les ventes de 1767, 68. Sous le nom de necanée, E. Hardouin décrit : "toile rayée de bleu et de blanc ", et Dermigny ${ }^{57}$ : " toiles communes du Coromandel, rayées de bleu et de blanc, les nécanées brouard (larges) de 11 aunes de long sur $3 / 4$, les nécanées narou (étroites) de 10 aunes sur 2/3. Aucune indication d'aunage dans nos listes, mais une valeur : 17 à 19 livres.

Nikanias, inv. BAD 6752 (GG4), album d'échantillons, 1789, p. 305. Les Arts Décoratifs, Paris

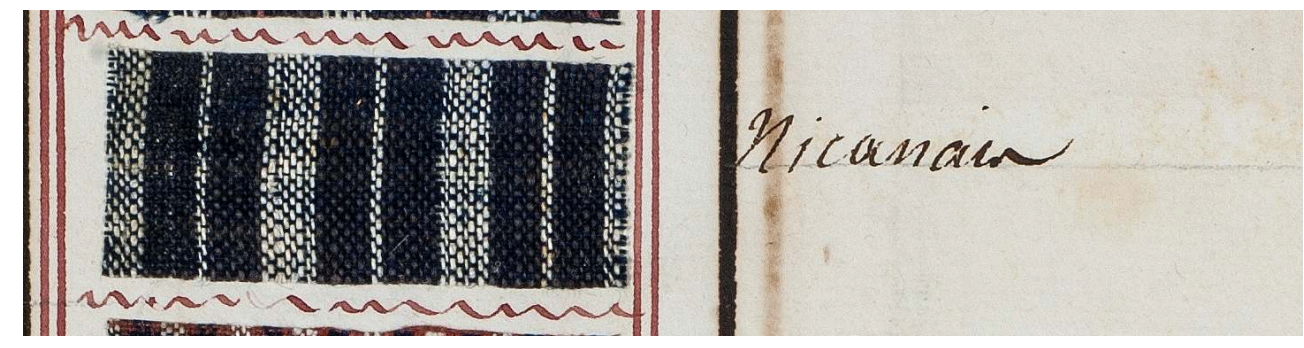

Photo Les Arts Décoratifs, Paris/Jean Tholance (photo soumise à accord préalable, rétrocession photo interdite)

Nikanias, inv. BAD 6752 (GG4), album d'échantillons, 1789, p. 306. Les Arts Décoratifs, Paris

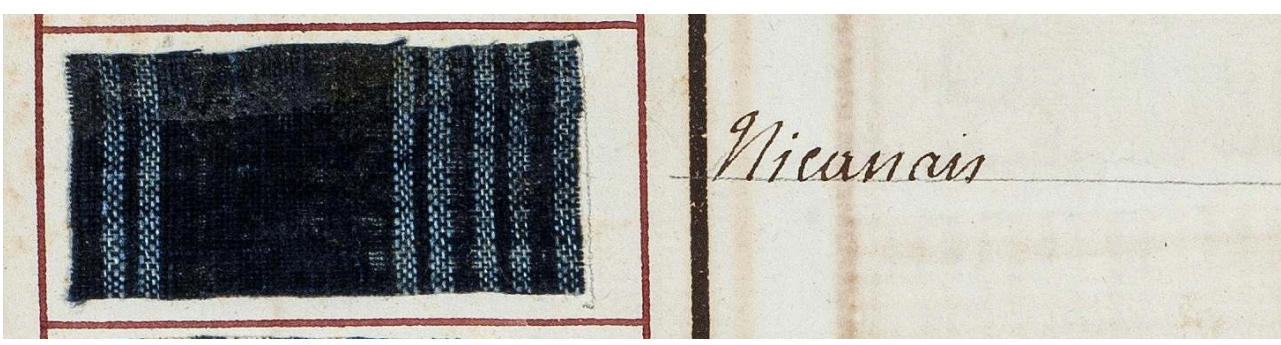

Photo Les Arts Décoratifs, Paris/Jean Tholance (photo soumise à accord préalable, rétrocession photo interdite)

Grands nikanias, inv. BAD 6752 (GG4), album d'échantillons, 1789, p. 379. Les Arts Décoratifs, Paris

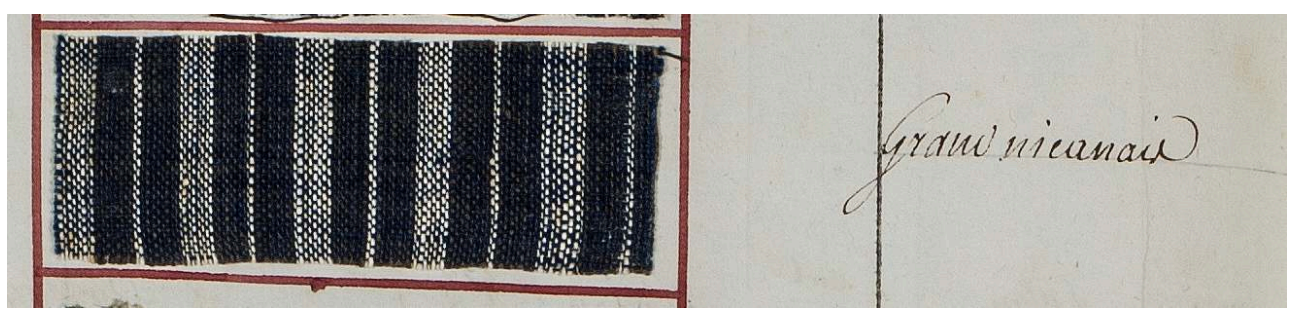

Photo Les Arts Décoratifs, Paris/Jean Tholance (photo soumise à accord préalable, rétrocession photo interdite) 


\section{Les Katequi}

Les Katequi : "Toile de coton bleu qu'on tire des Indes orientales, particulièrement de Sourate. Les pièces de kattequi n'ont que deux aunes cinq huit de long, sur cinq six de large. ${ }^{158}$ Dans les inventaires après décès damascains, les kantkî, ou kandakî, sont toujours de couleur rouge. Et la traduction de kandakî, dans le dictionnaire de Barthélémy est "rouge foncé..$^{59}$ "Une affichette de 1724 traduit: «katequis ou pagnes »; 1729, 1731 katequis ou pagnes à carreaux. »

Le tissu n'est signalé dans les ventes qu'en 1767 : il a été vendu 7,9 livres.

\section{Les bajupataux}

Savary ignore la toile, de même que Chaudhuri et Irwin. Dermigny ${ }^{60}$ en donne une description: "il s'en trouve de deux qualités. La première est une toile à grands quadrilles formés de bandes bleues et blanches, la seconde est une toile égale, mais les cadrilles formés de filets rouges et bleus, tirant moins et plus étroits. Et elle vaut $10 \%$ de moins. " Hobson-Jobson en donne une étymologie possible: dl'hindi, be-jûla, «without join » et pât « a piece. " ${ }^{61}$

Bajupataux, inv. BAD 6752 (GG4), album d'échantillons, 1789, p. 305. Les Arts Décoratifs, Paris

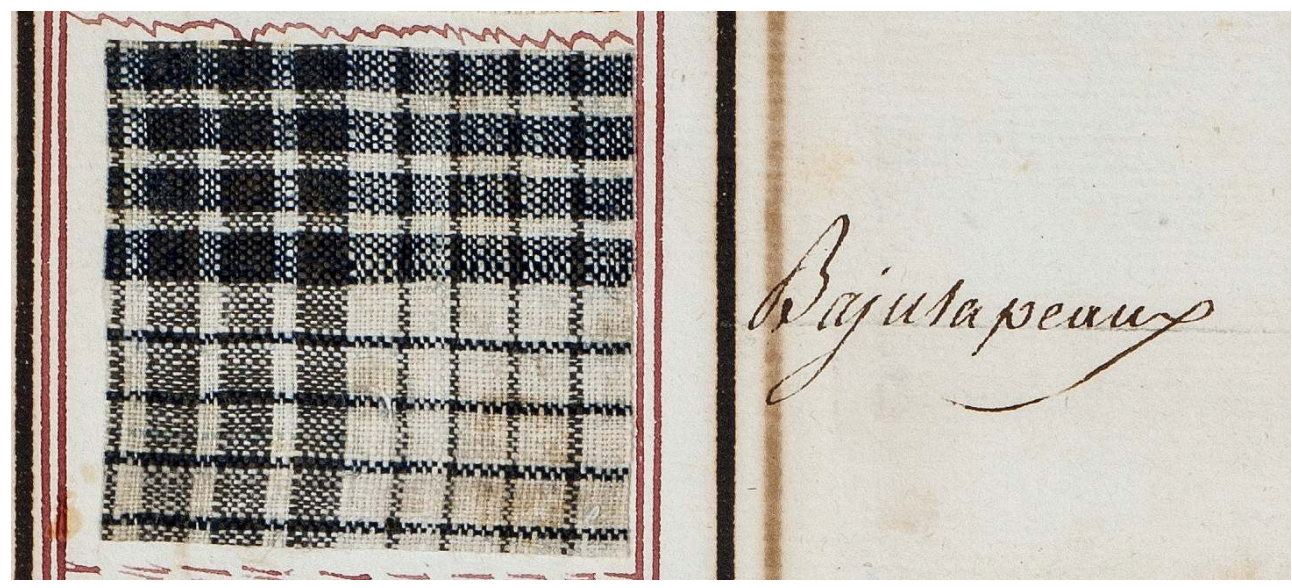

Photo Les Arts Décoratifs, Paris/Jean Tholance (photo soumise à accord préalable, rétrocession photo interdite) 
Bajupataux, inv. BAD 6752 (GG4), album d'échantillons, 1789, p. 306. Les Arts Décoratifs, Paris

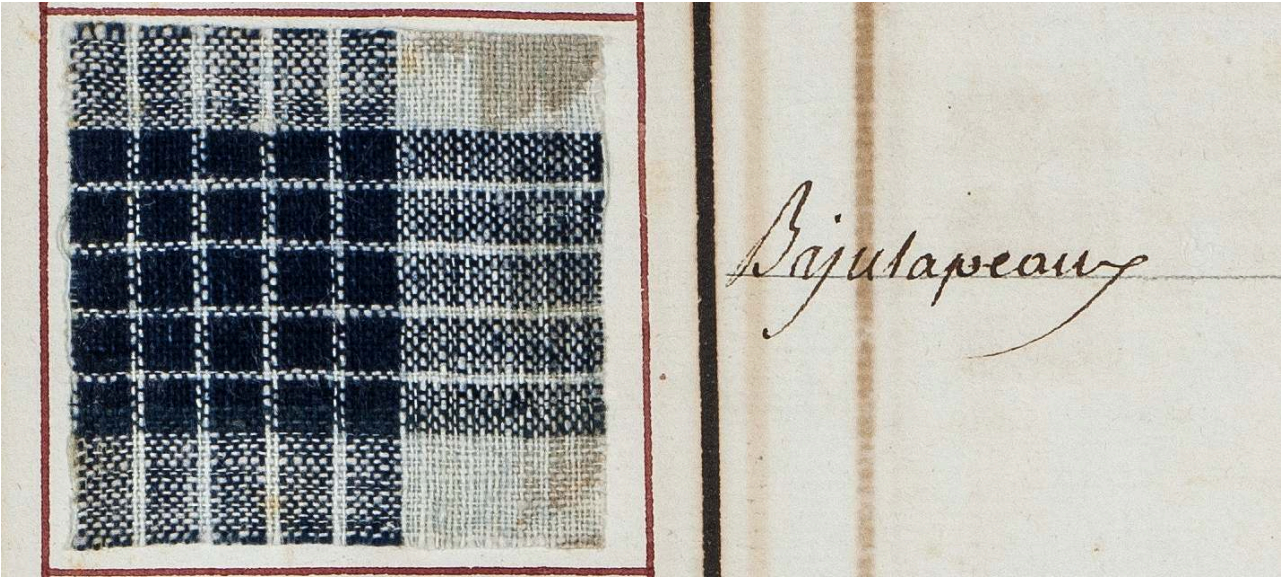

Photo Les Arts Décoratifs, Paris/Jean Tholance (photo soumise à accord préalable, rétrocession photo interdite)

Bajupataux, inv. BAD 6752 (GG4), album d'échantillons, 1789, p. 377. Les Arts Décoratifs, Paris

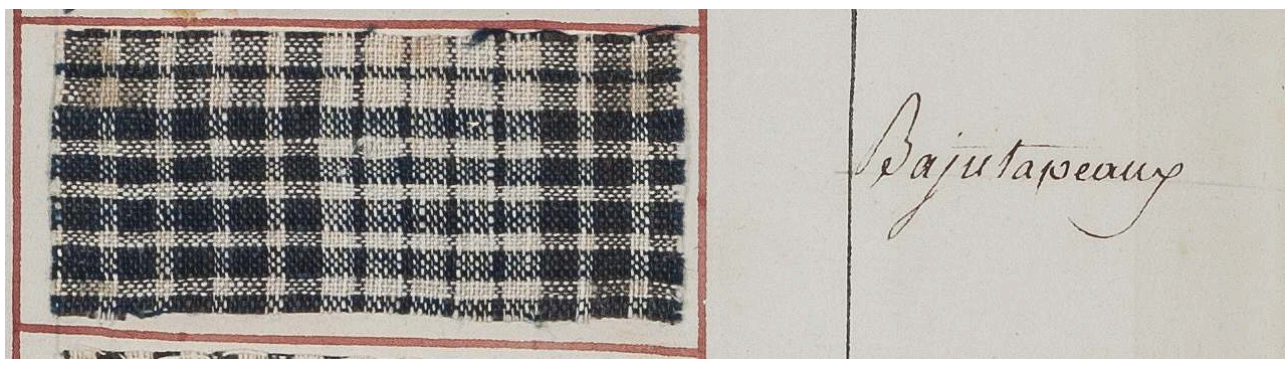

Photo Les Arts Décoratifs, Paris/Jean Tholance (photo soumise à accord préalable, rétrocession photo interdite)

91 En 1739 et 41, les aunages correspondent aux indications de Dermigny : 13 aunes $1 / 2$ à 14 aunes sur $3 / 4$ à 5/6. Seul le catalogue de 1741 donne la couleur des bajupataux, bleu et blanc.

92 Les valeurs s'échelonnent entre à 28 livres.

\section{Les neganepaux}

Il s'agit de «toiles communes » explique Blancard ${ }^{62}$, « celles qui se font sur la côte de Coromandel sont préférées à celles de Surate et de Cambaye tant à cause de la qualité de leur toile que par la bonté de leur teint...Ces diverses toiles sont un objet assez important dans les retours pour l'Europe ; elles y sont employées, ainsi que les demi et quart de guinées bleues, pour l'assortiment des cargaisons de navires qui vont faire la traite des nègres à la Côte de Guinée. »

Ces toiles sont de nouveau ignorées de Savary, de Chaudhuri et de Irwin, à moins que son Neckanees soit notre neganepaux, « un calicot rayé bon marché63. Pour HardouinFugier, sous le même nom de necanée, ils sont rayés de bleu et blanc; mais pour Dermigny ${ }^{64}$, ils "sont quadrillés de rouge et de filets jaunes... de 10 à 13 livres. Et « rouge et bleu », dans le catalogue de 1741 (et sur l'échantillon des Arts décoratifs) 

précédente, de 18 à 24 livres.

Néganépaux, inv. BAD 6752 (GG4), album d'échantillons, 1789, p. 377. Les Arts Décoratifs, Paris

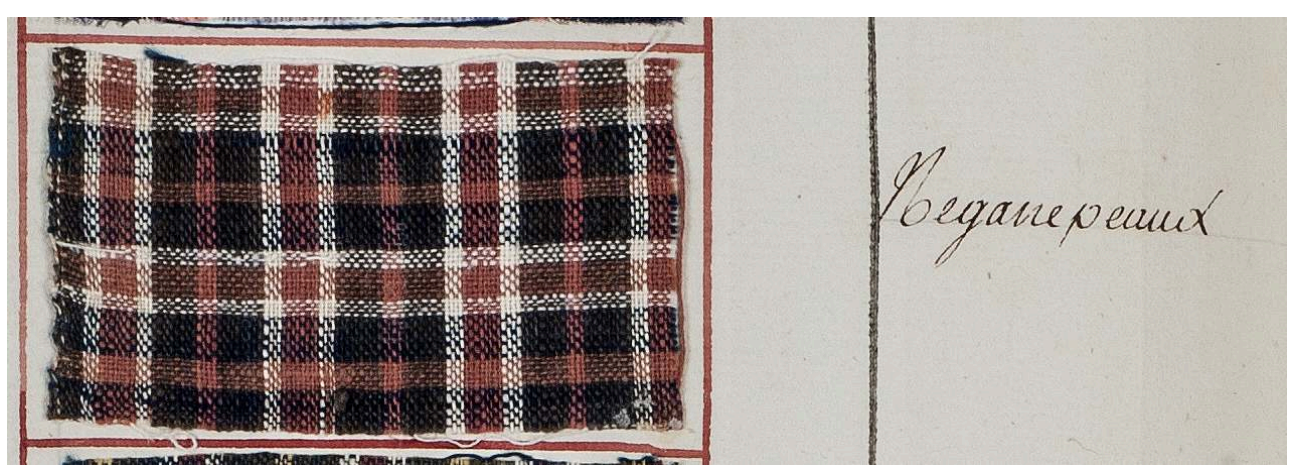

Photo Les Arts Décoratifs, Paris/Jean Tholance (photo soumise à accord préalable, rétrocession photo interdite)

\section{Les coutelines}

Les coutelines, "grosse toile de coton blanche, ou bleue» (ou jaune rajoute E. Hardouin-Fugier), de Surat, 14 aunes de long sur $3 / 4$ et 5/6 de large. $»^{65}$

Un seul document en 1691, évoque ce tissu, et le scripteur a indiqué, pour nous, « coutelines ou toiles teintes en bleu. » La valeur des toutes les pièces contenues dans des balles (qui renferment également des baftas blancs), est, en moyenne, de 4,19 livres la pièce.

\section{Les Chilae, ou chelas ou cheiloes ou chelles ou chillas}

Évoquées dès 1687, ces chelas, qualifiées de «toiles rouges de Séronge.» En face du nom, une croix a été mise par le scripteur, comme devant les chittes, toiles peintes, des tours de lit de chittes fines, des couvertures de toiles peintes piquées, suggérant que ces chelas faisaient partie des toiles peintes.

Mais toutes les définitions privilégient la "toile de couleur» et non la toile peinte. A l'article chillas, Savary ${ }^{66}$ note : " toile de coton à carreaux, du Bengale, 8 aunes de long sur 3/4 à 5/6. Et à l'article chelles « toiles de coton à carreaux de différentes couleurs...de Surat particulièrement, 13 ou 14 aunes sur 3/4. Pour Hobson-Jobson, le mot dériverait peut-être de sâlû, un textile rouge. E. Hardouin rajoute que ces toiles servent de« pagne pour les femmes esclaves en Inde. » Enfin, à l'article Chelloes, Irwin ${ }^{67}$ écrit : « un coton bon marché, avec des raies rouges bleues ou noires, pas mentionné avant la fin du XVIIème, peut-être requis pour le trafic d'esclaves. » ; l'indication est donnée aussi par Chaudhuri ${ }^{8}$ : cheiloes, "coton, rayé, mauvaise qualité, Gujarat, pour le trafic d'esclaves. » 
Chilas, inv. BAD 6752 (GG4), album d'échantillons, 1789, p. 75. Les Arts Décoratifs, Paris

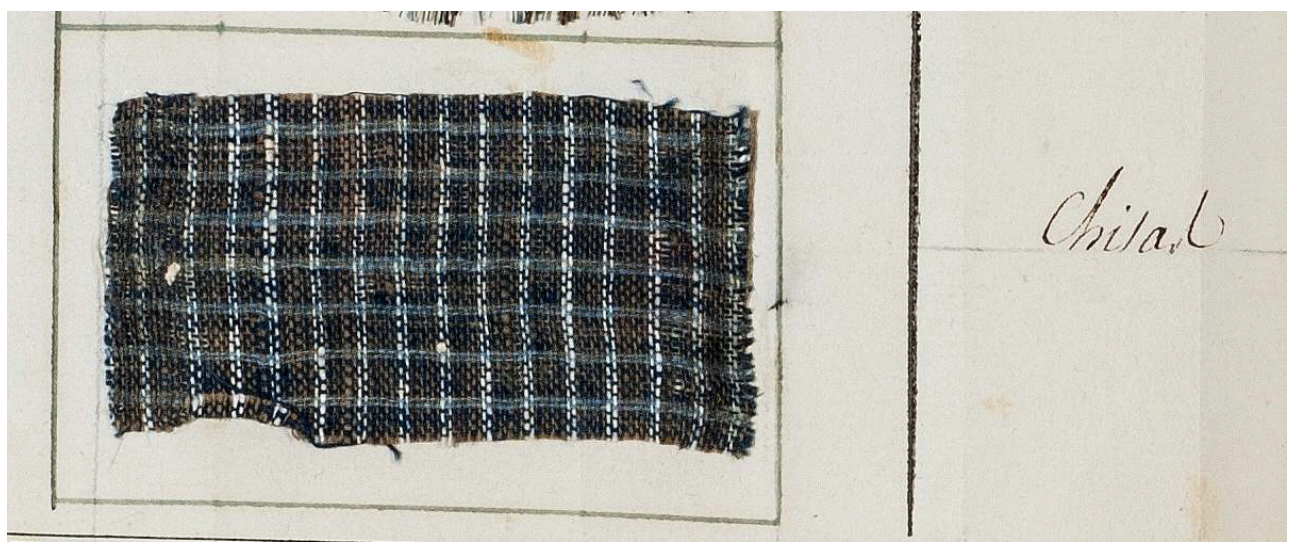

Photo Les Arts Décoratifs, Paris/Jean Tholance (photo soumise à accord préalable, rétrocession photo interdite)

Un aunage de 7 aunes $3 / 4$ à 8 sur 3/4, apparaît dans la vente de en 1726 .

Dans les catalogues de vente, à l'exception de 1687, ces tissus voisinent les elatchas, les rastas ou coupis, les chazelas, les nekanias, tous prohibés, et souvent à rayures. Leur prix : 3,4 livres en 1687 ; de 15 à 18 en 1726.

L'ensemble des photos témoigne de la ressemblance de toutes ces cotonnades de couleurs, à carreaux, à rayures.

\section{Les Nankins}

Leur nom fait allusion à la ville chinoise Nankin dans laquelle ces nankins ont été autrefois fabriqués. Legoux de Flaix en donnerait-il une explication ? Les nankins se font «avec le coton à laine roussâtre " ${ }^{69}$; il signale, comme étant fabriqué dans le Gujarat, un nankin fait avec du coton qui a «le duvet roux », et " convient pour nos importations à la Chine où on la métamorphose en nankin que les Chinois nous revendent ensuite. " ${ }^{70}$ Pour Dermigny, ces « toiles de coton à tissu serré et fort » ont été imitées dans l'Inde et dans l'Europe. ${ }^{71}$ "Lisse, serré, solide », ajoute E. Hardouin. Ils n'apparaissent dans les ventes qu'à la toute fin du XVIIIème siècle, les années 1767, 68, et 69. Mais dans le document de 1768, qui indique la région d'arrivage des étoffes, le nankin vient de Chine !!

4 En 1768, des pièces de nankins verts et bleus ont été vendus, à 6 livres et demie la pièce, jaune en 1769. Seul renseignement que nous aient livré les archives.

\section{Les deriabadis ou deribands}

Savary, sous le nom de deriband, définit des “ toiles blanches de coton qui viennent des Indes Orientales. Il y en a d'étroites et de larges, plus de la première sorte que de l'autre. La longueur des pièces de deribands étroits est de neuf aunes et leur largeur de cinq huit. ${ }^{72}$ Roques rapproche les deraibadis des chauderas ou chuters ou chianters "bonnes pour mettre en blanc car elles ont assez de corps. " ${ }^{73}$ Irwin note : " D'après Deyrabad, ...une bonne qualité de calicot simple et blanc. $»^{74}$ Le tissu provient de la partie occidentale de l'Inde. Deyrabad est situé à l'est de Delhi. 
Roques souligne que le tissu n'est pas mentionné après 1650. Cependant, les données signalent que des deriabad d'Agra (pour Roques, "Les meilleures viennent d'Agra ») font partie des ventes en 1691 pour l'année 1744. Et quelques centaines de pièces sont vendues en 1741. Le tissu est peut-être repris après le déclin de la région de Surate, pour être fabriqué ailleurs, de moins bonne qualité. («de qualité moyenne, voire médiocre, d'usage domestique " pour Chaudhuri). ${ }^{75}$

L'aunage inscrit dans le catalogue de 1741 correspond aux descriptions de Savary : de 8 aunes $1 / 2$ à 9 sur $1 / 2$.

108 En 1691, 1600 pièces de deriabadis d'Agra ont été vendues à 2,2 roupies la pièce, un faible prix, même en cette fin de XVIIème siècle, où les prix sont bas. On ne possède pas d'autres prix de vente.

\section{Les ambertees}

Nous mentionnerons rapidement quelques pièces peu nombreuses d'ambertees, ou amerty.

110 Pour Irwin ${ }^{76}$ les ambertees sont des « tissus blancs de qualité supérieure, tissés dans la région de Patna». Ce tissu semble avoir été exporté, vers le marché londonien en particulier, surtout au début du XVIIème, "de façon occasionnelle après 1650." Chaudhuri sous le nom d'Emerty, estime le tissu « de qualité » moyenne..$^{77}$ Le glossaire de Hobson-Jobson en donne une étymologie possible : «emmertie, de l'hindi amraratî, imratî, doux comme du nectar. $»^{78}$

111 Ce textile n'a pas disparu plus tard puisqu'on le trouve à plusieurs reprises dans nos archives. En 1739, les amerty de 10 aunes sur $3 / 4$ ont été vendus 16,5 livres; ceux de 11 aune $1 / 2$ sur 3/4, 21 livres, 6 . Sous le nom d'amerty d'Ajanabar, la toile figure dans le catalogue de 1741 , de 10 aunes $3 / 4$ sur $2 / 3$. On en retrouve aussi le nom en 1750 .

112 Irwin $^{79}$ considère que Les luckhowries ou laycowries sont synonyme des ambertees. En 1741 , sont vendues quelques 250 pièces de Lokory de Mogara, de 9 aunes $1 / 2$ à 9 aunes $3 / 4$.

\section{Les mamoudîs, mousselines ou toiles?}

On hésite. Les descriptions sont rares et contradictoires. Savary l'ignore. La plus complète description en est trouvée chez Roques ${ }^{80}$, donc pour une période antérieure : « Des toiles fines avec du corps de 16 cobes de long et d'une de large, de 20 roupies à cinquante roupies la courge » (soit de 9 aunes environ, la pièce valant 43 livres [...] Ils sont assez fins et ont assez de corps pour soutenir la peinture...Ils peuvent être mis en chittes » [...] Les plus onéreuses, vous pouvez les mettre en blanc qui réussiront fort bien au blanchissage [...] On les fabrique à Chamely, à deux journées de Séronge (dans le Gujarat) et ils y mettent au bout de la pièces trois ou quatre trames de fils d'or pour faire connaître leur fabrique.» Legoux, Irwin, également. Dermigny évoque plusieurs possibilités : « variété de toile peinte des Indes ; une sorte de toile blanche qui se vend à Smyrne mais vient du golfe persique et de l'Inde. ${ }^{81}$ "Terme général pour calicot " annonce sèchement Wellington ${ }^{82}$ » Toile encore pour Legoux. ${ }^{83}$ Toile très fine ? Ou mousseline ? Parfois la distinction devait être difficile. Dans l'article «Piece Goods » de Hobson-Jobson ${ }^{84}$, les mamoodies ou Mahmûdî sont de «belles et estimées mousselines, 
ou des tissus de coton de bas prix »! George Birwood ${ }^{85}$ compte le mamudi comme une des dizaines de cotonnades de la région de Oudh.

114 Dans le Catalogue de 1741, les mamoudis se nomment de mamoudis unis d'Ajanabar, et mamoudis Baroguery, portant parfois de petites lisières d'or ; ou des Mamoudis brodés, tous d'un peu plus de dix aunes sur $1 \frac{1}{2}$ et plus. Nous n'en avons trouvé aucune valeur. La vente de 1769 comprend des mamoudis dome, donc brodés, comme d'autres mousselines.

115 On aurait penché vers la "mousseline », puisque les mamoudis peuvent être brodés, et être bordés de lisière d'or ; mais trop de sources font allusion à leur possible utilisation en chittes, peintes sur des tissus qui ont un certain corps. "Ces mamodis servent aux femmes pour tabliers, cornettes, colet, besoins de nuit et plus au menu peuple qu'aux personnes de qualité qui aimeront mieux se servir d'une bétille grossière pour se distinguer d'un mamodi fin. ${ }^{86} \mathrm{Ce}$ tissu se rapproche du chander ou chawter.

\section{Les chukerees}

116 Les pièces sont peu nombreuses. Irwin ${ }^{87}$ les qualifie de «calicot rayé bon marché, considérés comme des marchandises type guinées, et destinées surtout au trafic des esclaves. »

\section{Les chander ou chawter}

117 «Calicot simple et blanc, en général de bonne qualité, tissé dans de nombreuses régions de l'ouest des Indes. $»^{88}$ Dans les inventaires après décès damascains, ce tissu est qualifié effectivement de «blanc » et rapproché du mamoudi.

\section{Divers... et pour le plaisir des yeux}

118 Mentionnons, sans plus, les quelques exceptionnels articles «finis " s'ajoutant aux étoffes qui apparaissent dans les ventes. En 1716, 289 manchettes, 150 jarretières de soie, des « juppes » brodées de soie, des fichus brodés d'or et d'argent, 513 ceintures et des ceintures à houppes d'or et d'argent ; des turbans de mallemolle; des bas de soie. 


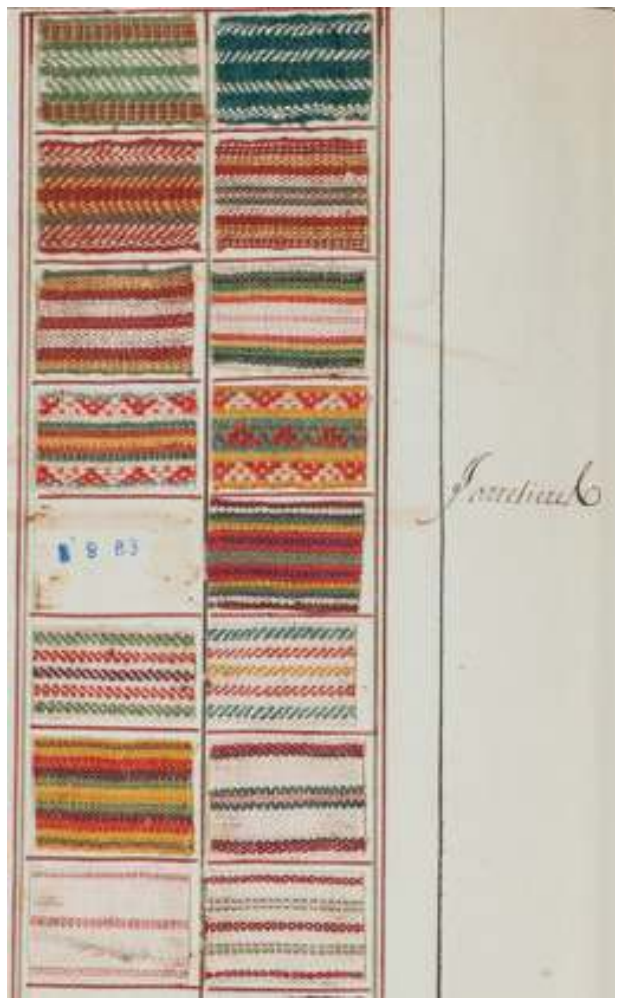

Photo Les Arts Décoratifs, Paris/Jean Tholance (photo soumise à accord préalable, rétrocession photo interdite)

119 En 1723, dans un document ${ }^{89}$ qui énumère les marchandises prohibées, figure une longue liste d'objets, habits et parures ; 25 garnitures de boutons de soie ; un lot de six ceintures de prêtres en soie noire, de deux aunes $3 / 4$ de longueur, deux ceintures de soie, une ceinture d'épée, 22 jarretières de soie, cinq cordons de soie, six douzaines de lacets, le tout a été vendu 212 livres; six gilets de entiers et piqués de soie, 17 livres ; une toilette brodée de soie sur satin de chine; deux turbans de soie, 58 bonnets brodés de soie moque, 61 livres ; 47 bonnets brodés de soie de couleur, de Daka, 12 livres ; 9 vestes complètes et culottes brodés, 39 livres ; 50 corsets brodés de soie de couleur de Daka sur sanas et basins, 22 livres ; ...et un habit chinois complet.

Et surtout, dans les premières années, près de 75000 cravates, comme on l'a signalé, les cravates ont leur part dans les cargaisons : plus de $1 / \%$ de tous les tissus en nombre, $0,2 \%$ en valeur. "Brodées ", sans mention de tissu, en 1691 ; une balle est vendue 1878 livres; ou toutes faites de mousselines diverses, doréa, bétille, organdi, tarnatane, ou rayées d'or, venant de Dakka et du Bengale, lorsque l'origine en est signalée. Les cravates sont importées dès 1691, mais n'apparaissent plus dans les ventes à partir de 1734. En 1726, 12 cravates composant une pièce de tarnatane de une aune $1 / 4$ sur $1 / 2$ valent 20 livres; faites en fil de bétille, 16 ; les cravates du Bengale, de 10 à la pièce de une aune $1 / 3$ sur $1 / 2$ à $9 / 16$ à $7 / 12$, de 19 à 36 livres.

Les yeux sont un peu dépités. On imaginait dans ces salles de vente de Lorient un défilé de ces toiles peintes qui font la gloire des musées et le bonheur des collectionneurs, toucher des yeux des soieries chatoyantes et multicolores. Seules les fines mousselines n'ont pas déçu : elles sont présentes et nombreuses et variées. Mais, en fait, les toiles de coton, blanches ou de couleurs, unies, à raies ou à carreaux, licites ou prohibées, et de 
valeur souvent moyenne, constituent la part de loin la plus importante des cargaisons de textiles provenant des Indes et de Chine.

On ne peut que conclure avec Brigitte Nicolas que ce commerce... n'est que rarement un commerce de luxe. $»^{90}$

\section{NOTES}

1. Nicolas B. 2006, Lorient, la Bretagne et la traite, (XVIIe-XIXe siècle), Musée de la Compagnie des Indes, Cahier de la Compagnie des Indes, $\mathrm{n}^{\circ}$ 9/10, 2006, p. 99.

2. Savary, op. cit., II, p. 1117

3. Aka Kouamé, Cargaisons négrières, Thèse Université de Nantes, p. 28.

4. Savary, op. cit., II, p. 299.

5. Dermigny Louis, p. 440.

6. Legoux, op. cit., p. 2 à 15.

7. Legoux, op. cit., p. 10.

8. Savary, op. cit., II, p. 1466.

9. Legoux, op. cit., p. 2 à 33.

10. Savary, op. cit., II, p. 214.

11. Legoux, op. cit., p. 359-360.

12. Hobson-Jobson, p. 707.

13. Legoux, op.cit., p. 362.

14. Legoux, op.cit., p. 362.

15. Hobson-Jobson, op. cit., p. 46.

16. Savay op. cit., I, p. 207.

17. Roques, op. cit., p. 79.

18. Irwin John, op. cit., I, 25.

19. Legoux, op. cit., p. 355, à 357.

20. Blancard Pierre, op. cit., p. 292.

21. Dermigny Louis, op. cit., p. 437.

22. Legoux, op. cit., p. 857.

23. Savary, op. cit., II, p. 299.

24. Legoux, op. cit., p. 127 sq.

25. Dermigny Louis, op. cit., p. 440.

26. Hobson-Jobson, op. cit., p. 375.

27. Blancard Pierre op. cit., p. 240.

28. Savary op. cit., II, p. 1476.

29. Dermigny Louis, op. cit., p. 442.

30. Savary, op. cit., II, p. 313.

31. Blancard Pierre, op. cit., p. 292.

32. Legoux, op. cit., p.351.

33. Legoux. Op. cit., p. 352.

34. Savary, op. cit., I, p. 1730.

35. Irwin John, I, p. 28.

36. Roques, op. cit., p. 65. 
37. Savary, op. cit., I, p. 289.

38. Legoux, op. cit., p. 120-121.

39. Hobson-Jobson, op. cit., p. 708.

40. Savary, op. cit., II, p. 1047.

41. Dermigny Louis, op. cit., p. 442.

42. Legoux, op. cit., p. 25 sq.

43. Irwin John, II, p. 42.

44. Legoux, op. cit., p. 26.

45. Legoux, op. cit., p. 24, 25, 29.

46. Savary, op. cit., I, p. 698.

47. Savary, op. cit., II, p. 826.

48. Hobson-Jobson, op. cit., p. 707.

49. Savary, op. cit., I, p. 396.

50. Savary, op. cit., I, p. 1543.

51. Chaudhuri, op. cit., p. 501.

52. Irwin John, op. cit., I, 27.

53. Dermigny Louis, op. cit., p. 447.

54. Savary, op. cit., II, 144.

55. Irwin John, op. cit., I, 29.

56. Barthélémy A. op. cit.

57. Dermigny Louis, op. cit., p. 441.

58. Savary, op. cit., II, p. 455.

59. Barthélémy, op. cit., 1969.

60. Dermigny Louis, op. cit., p. 352.

61. Hobson-johnson, op. cit., p. 706.

62. Blancard Pierre, op. cit., p. 239-240.

63. Irwin John, op. cit., I, 29.

64. Dermigny, Louis, op. cit., p. 352.

65. Savary, op. cit., I, p. 1085 et I, p. 699.

66. Savary, op. cit., I, p. 749.

67. Irwin John, op. cit., I, p. 27.

68. Chaudhuri, op. cit., p. 501.

69. Legoux, op. cit., p. 16.

70. Legoux, op. cit., p. 280.

71. Dermigny Louis, op. cit., p. 441.

72. Savary, op. cit., I, p. 1674.

73. Roques, op. cit., p. 117.

74. Irwin John, op. cit., I, 27.

75. Chaudhuri, op. cit., p. 501.

76. Irwin, op. cit., III, p. 67.

77. Chauduri, op. cit., p. 504.

78. Hobson-Jobson, op. cit., p. 707.

79. Irwin, op. cit., III, 67.

80. Roques, op. cit., p. 119.

81. Dermigny Louis, op. cit., p. 440.

82. Wellington Donald, op. cit., p. 223.

83. Legoux, op. cit., p. 35.

84. Hobson-Jobson, op. cit., p. 707.

85. Birdwood G., op. cit., p. 81.

86. Roques, op. cit., p. 110. 
87. Irwin John, op. cit., I, p. 27.

88. Irwin, John, op. cit., I, p. 27.

89. HH223 et $223 / 12$.

90. Nicolas B. Le goût de l'Inde, op cit., p. 23. 


\section{Conclusion}

1 Différents types de sources autorisent l'observation des cargaisons indiennes acheminées dans les ports du royaume pendant plus d'un siècle: les textiles ont constitué l'essentiel du commerce des Compagnies des Indes.

2 Affiches de vente, bulletin d'adjudication, récits de voyageurs commerçants, dictionnaires consacrés à la description des marchandises indiennes permettent d'observer un à un chacun des textiles qui chargent les cargaisons : sa composition, sa taille, son prix, sa couleur, ses rayures, ses fleurs, ses lisières, etc.

3 Ces descriptions, et quelques échantillons de textiles trouvés au Victoria and Albert Museum à Londres, d'autres au Musée des Arts décoratifs à Paris, ont souvent autorisé à définir de façon concrète les quelques centaines de tissus différents vendus en France : qu'est-ce qu'un tangeb, une casse, une mallemolle, un canadari, un alibani, un baffetas, un jamawar, un salampore, un néganépaux un, bajupataux, un korotte? Sur chacun de ces noms, on a tenté de mettre une image, de reproduire une texture. Les conservateurs de musées, les propriétaires de collections touchent souvent des textiles dont le nom leur est inconnu. Espérons que nos indications les aideront dans leur travail d'identification.

4 Ne négligeons pas la beauté des tissus peints, des étoffes chatoyantes, à rayures, à carreaux, à fleurs, la légèreté des mousselines, souvent brodées : mais, dans ce voyage est-ouest, les banales toiles de coton, blanches et colorées, les humbles mouchoirs, ont occupé la part fondamentale des importations.

5 Le voyage ne s'arrête pas aux ports du royaume: d'autres vaisseaux se chargent d'exporter vers l'Afrique une bonne partie (on en a tenté la quantification) de ces étoffes dont le lot le plus important est constitué d'étoffes " prohibées ». Là-bas, elles seront échangées contre des noirs qui continueront de force le circuit vers des contrées occidentales encore plus lointaines, les Antilles, l'Amérique. Ce commerce se poursuit avec la traversée du retour : les navires chargés de denrées « exotiques » reviennent à leur lieu de départ. La boucle s'est fermée. Espérons que les échanges auront été fructueux, sinon équitables. C'est l'histoire, une autre histoire. 


\section{Bibliographie}

Aka Kouamé, Les cargaisons de traite nantaise au XVIIIème siècle, une contribution à l'étude de la traite négrière française, Thèse de doctorat d'histoire, Nantes, Université de Nantes, 2005.

Barthélémy, Adrien, Dictionnaire Arabe-Français, Dialectes de Syrie: Alep, Damas, Liban, Jérusalem, 2 vol., Paris, Librairie orientaliste Paul Geuthner, 1969.

Birdwood, George C.M., The industrial Arts of India with map and woodcuts, 2 vol., South Kensington Museum Art Handbooks, Londres, Chapman and Hall, 1880.

Blancard, Pierre, Manuel du Commerce des Indes orientales et de la Chine, Paris, Bordeaux, 1806 ; dans sa version reprint, Nabu Public Domain Reprints, 4 novembre 2011.

Boilat, P.-David, Abbé, Esquisses sénégalaises, Paris, P. Bertrand, 1853.

Bosman, W. Voyage de Guinée, Utrecht, 1705.

Recueil des échantillons des toiles et des toileries Généralités de Normandie, Rouen, daté de 1789, collection des Arts décoratifs.

Chaudhuri Kirti N., The trading world of India and the English East India Company, 1660-1760, Londres, Cambridge University Press,1978, version digitalisée, 2006.

Coquery-Vidrovitch, Catherine, La découverte de l'Afrique, Paris, l'Harmattan, 2003.

Crété, Liliane, La traite des nègres sous l'ancien régime, Paris, Perrin, 1989.

Crill, Rosemary, Indian Ikat Textiles, Londres, Victoria and Albert Museum Publications, 1998.

Crill, Rosemary, "Textiles in Kutch », dans Chistopher W. London ed., The arts of Kutch, Bombay, Marg Publications, 2000.

D’Allemagne, Henry-René (D'), La toile imprimée et les indiennes de traite, Paris, Gründ, 2 tomes, 1942.

Daget, Serge, La traite négrière, Rennes, Ouest-France, 1990.

De Wismes, Armel, Nantes et le temps des négriers, Paris, France-Empire, 1992.

Dermigny, Louis, 1959-1960, Cargaisons indiennes. Solier et Cie 1781-1793, 2 vol., Paris, SEVPEN, 1959.

Dozy, Reinhart, Supplément aux dictionnaires arabes, 2 vol., reproduction de l'édition originale de 1881, Beyrouth, Librairie du Liban, 1968.

Ducousso, Gaston, L'industrie de la soie en Syrie et au Liban, Beyrouth-Paris, A. Challemel, 1913.

Hardouin-Fugier, Elizabeth, Berthod, Bernard, Chavent-Fusaro, Les étoffes : dictionnaire historique, Paris, Les éditions de l'armateur, 1994. 
Encyclopédie ou Dictionnaire raisonné des sciences, des arts, et des métiers, éditée de 1751 à 1772 sous la direction de Diderot et D'Alembert. Tome 7

Establet, Colette et Pascual, Jean-Paul, Ultime voyage pour la Mecque, les inventaires après décès de pèlerins morts à Damas vers 1700, Damas, Institut français de Damas, 1998.

Fukasawa Katsumi, Toilerie et commerce du levant d'Alep à Marseille, Paris, Editions du CNRS, 1987.

Flachat, Jean-Claude, Observations sur le Commerce et sur les Arts d'une partie de l'Europe, de l'Asie, de l'Afrique et même des Indes Orientales, Lyon, Jacquenot, 1766.

Haudrère, Philippe, La Compagnie française des Indes au XVIIIe siècle, 2 tomes, Paris, Les Indes savantes, 2005.

Haudrère Philippe, Le Bouedec, Gérard, Les Compagnies des Indes, Rennes, Edition Ouest-France, 1999.

Hauser, Henri, Recherche et documents sur l'histoire des prix en France de 1500 à 1800, Paris, Les Presses modernes, 1936.

Hobson-Jobson, A glossary of colloquial anglo-indian words and phrases, New Delhi, Munshiran Manoharlal Publishers Pvt Ltd, v. Yule, Henry et Burnell, A.C, 1994.

How India clothed the world, The World of South Asian Textiles,1500-1850, Brill, Leiden, Boston, ed. by G. Riello, Tirthankar Roy, 2009.

Irwin, John, "Indian textile trade in the seventeenth century, Journal of Indian textile History, Ahmedabad, India, Calico Museum of Textiles, 2ème édition, 1996.

Labat, Jean-Baptiste (Père), Le voyage du chevalier des Marchais en Guinée en en 1725-1727, 2 tomes, Paris, 1730.

Legoux de Flaix, Alexandre, Essai historique, géographique et politique sur Indoustan : avec le tableau de son commerce : ce dernier pris dans une année moyenne, depuis 1702 jusqu'en 1770, époque de la suppression du privilège de l'ancienne Compagnie des Indes Orientales, deux volumes, Paris, Pougin, 1807. Version reprint "from the collection of the University of Michigan Library ", M. Library. Avril 2009.

Les Compagnies des Indes, Édition publiée sous la direction de René Estienne, Paris, Coédition Gallimard / Ministère de la Défense - DMPA, 2013.

Lolanda Guevara et Carles Puig, Les mesures du monde Calendriers, longueurs et mathématiques, Paris, dans Le monde est mathématique coll. dirigée par Cédric Villani, 2010.

Lodjou Gayibor, Nicolas, Africains et Européens dans le golfe de Guinée

Margoline-Plot, Eugénie, La Bretagne et la culture asiatique au XVIIIème siècle, Lorient, Université de Bretagne sud (Lorient), 10 janvier 2014.

Margoline-Plot, Eugénie, Les Pacotilles d'indiennes, la Boutique et la mer, thèse soutenue à l'université de Bretagne-Sud, sous le sceau de l'Université européenne de Bretagne Sud, 2014.

Mehdi Zmuda, "Saint Malo port négrier? "XVIIème-XVIIIème siècle, Villiers-sur-Marne Phenix editions, 2004.

Nicolas, Brigitte, Lorient, la Bretagne et la traite, (XVIIème-XIXème siècle), Lorient, Musée de la Compagnie des Indes, Cahier de la Compagnie des Indes, $\mathrm{n}^{\circ}$ 9/10, 2006.

Nicolas, Brigitte, Le goût de l'Inde, actes du colloque organisé le 4 et 5 juin 2007 par le Musée de la Compagnie des Indes et l'université de Bretagne-Sud, Rennes, Presses Universitaires de Rennes, et Musée de la Compagnie des Indes, 2008.

Nicolas, Brigitte, «La compagnie française des Indes et le textile indien » in Le goût de l'Inde, Presses universitaires de Rennes, 2008, p.20 à 31 . 
Pluchon, Pierre, Paris, La route des esclaves, négriers et bois d'ébène au XVII e siècle, Paris, Hachette, 1980.

Redhouse, Sir James W., A turkish and english Lexicon, Beirut, Librairie du Liban, 1974.

Römer L.F, Le Golfe de guinée, 1700-1750, Traduction, introduction et notes par Mette Dige Hess, Paris, l'Harmattan, 1989.

Roques, Georges, La manière de négocier aux Indes 1676-1691, texte présenté et annoté par Valérie Bérinstain, Paris, Ecole Française d'Extrême-Orient, Maisonneuve et Larose, 1996.

Savary des Brulons, Jacques, 1723, Dictionnaire universel de commerce, Ouvrage posthume du Sr Jacques Savary des Bruslons (ed 1726-1732) 2 vol., Paris, Jacques Estienne, dans l'édition reprint BNF, Hachette Livre, 2011.

Tarrade, Jean, «Le commerce colonial de la France à la fin de l'ancien régime », Paris, PUF, 2 tomes, 1972.

Villiers P. Duteil, J.P, l'Europe, la mer et les colonies, XVII XVIII siècles, Paris, Hachette, 1997.

Watson, J. Forbes, Textile Manufactures and the Costumes of the People of India, London, India Office, 1866.

Wellington, Donald C., French East India Companies, a historical account and record of trade, Oxford, Hamilton Books, 2006. 


\section{Liste des tableaux}

1 Tableau 1 : Évolution générale des importations des Compagnies des Indes (en valeur)

Tableau 2 : Valeur et proportion des différents produits importés

Tableau 3: Part de chaque groupe d'étoffes (en nombre et en proportion) dans l'ensemble des importations

Tableau 4 : Valeur en chiffres absolus et en proportion de tous les groupes de tissus

Tableau 5 : Valeur en chiffres absolus et en proportion de tous les groupes de tissus, sans les inclassables

Tableau 6 : Nombre des tissus prohibés dans les cargaisons

Tableau 7 : Valeur des tissus prohibés dans les cargaisons

Tableau 8 : Nombre et proportion des différentes pièces de mousselines

Tableau 9 : Part occupée par les différentes pièces de mousselines dans la valeur totale des ventes de mousselines

Tableau 10 : Origine géographique des mouchoirs

Tableau 11 : Principales toiles de coton, en nombre et en proportion

Tableau 12 : Valeur des pièces, en chiffres absolus et en proportion

\section{Liste des graphes}

2 Graphe 1 : Nombre de textiles importés suivant les années

Graphe 2 : Valeur des textiles importés suivant les années 